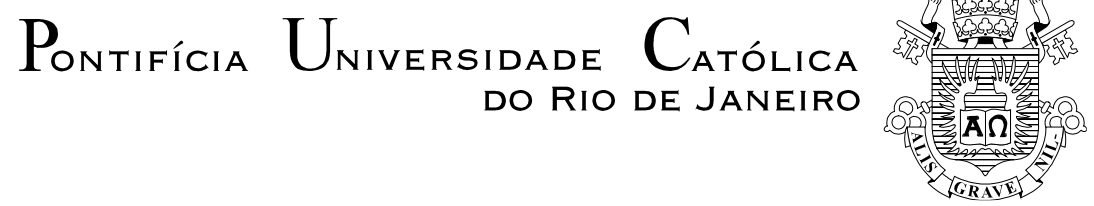

Jose Eduardo Ruiz Rosero

Caracterização Óptica e Morfológica de Pontos Quânticos de InAs

Dissertação de Mestrado

Dissertação apresentada ao Programa de Pósgraduação em Engenharia Elétrica da PUC-Rio como requisito parcial para obtenção do título de Mestre em Engenharia Elétrica.

Orientadora: Profa. Patrícia Lustoza de Souza Coorientador: Prof. Mauricio Pamplona Pires

Rio de Janeiro Abril de 2015 


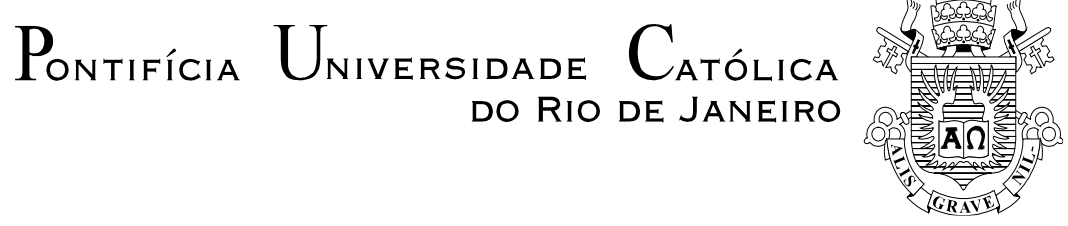

Jose Eduardo Ruiz Rosero

\title{
Caracterização Óptica e Morfológica de Pontos Quânticos de InAs
}

Dissertação apresentada como requisito parcial para obtenção do grau de Mestre pelo Programa de PósGraduação em Engenharia Elétrica do Departamento de Engenharia Elétrica do Centro Técnico Científico da PUCRio. Aprovada pela Comissão Examinadora abaixo assinada.

\author{
Profa. Patrícia Lustoza de Souza \\ Orientador \\ Departamento de Engenharia Elétrica - PUC-Rio
}

Prof. Mauricio Pamplona Pires

Coorientador

UFRJ

Prof. Sidnei Paciornik

Departamento de Engenharia Química e de Materiais

Prof. Bruno Araujo Cautiero Horta
UFRJ

Prof. José Eugenio Leal

Coordenador Setorial do Centro

Técnico Científico - PUC-Rio

Rio de Janeiro, 27 de abril de 2015 
Todos os direitos reservados. É proibida a reprodução total ou parcial do trabalho sem autorização da universidade, do autor e do orientador.

\section{Jose Eduardo Ruiz Rosero}

Graduou-se em Engenharia Eletrônica pela Universidad de Nariño-San Juan de Pasto - Colombia 2013.

Ficha Catalográfica

Ruiz Rosero, Jose Eduardo

Caracterização óptica e morfológica de pontos quânticos de InAs / Jose Eduardo Ruiz Rosero ; orientadora: Patrícia Lustoza de Souza ; co-orientador: Mauricio Pamplona Pires. - 2015.

112 f. : il. (color.) ; $30 \mathrm{~cm}$

Dissertação (mestrado)-Pontifícia Universidade Católica do Rio de Janeiro, Departamento de Engenharia Elétrica, 2015.

Inclui bibliografia

1. Engenharia elétrica - Teses. 2. Pontos quânticos. 3. Fotoluminescência (PL). 4. Microscopia de força atômica (AFM). I. Souza, Patrícia Lustoza de. II. Pires, Mauricio Pamplona. III. Pontifícia Universidade Católica do Rio de Janeiro. Departamento de Engenharia Elétrica. IV. Título.

CDD: 621.3 


\section{Agradecimentos}

A Capes e à PUC-Rio, pelos auxílios concedidos, sem os quais este trabalho não poderia ter sido realizado.

A todos os professores e funcionários do Departamento pelos ensinamentos e pela ajuda.

À minha orientadora Professora Patrícia, pelo apoio e parceria para a realização deste trabalho.

A meu coorientador o professor Mauricio Pamplona Pires, por sua ajuda em todas as etapas da investigação.

A minha mãe Mireya Rosero e Javier Delgado pela educação, atenção e amor incondicional.

A todos meus colegas do LabSem que me brindaram sua ajuda, apoio e amizade.

A todos os amigos da PUC-Rio.

A todos os amigos e familiares que de uma forma ou de outra me estimularam e me ajudaram.

Aos professores que participaram da Comissão examinadora. 


\section{Resumo}

Ruiz Rosero, Jose Eduardo; Souza, Patrícia Lustoza de. Caracterização óptica e morfológica de pontos quânticos de InAs. Rio de Janeiro, 2015. 112p. Dissertação de Mestrado - Departamento de Engenharia Elétrica, Pontifícia Universidade Católica do Rio de Janeiro.

Se faz um estudo detalhado da produção de pontos quânticos de InAs crescidos sobre ligas de InGaAlAs que, por sua vez, são depositadas em substratos de InP de forma casada. Através da caracterização óptica e morfológica dos pontos quânticos obtém-se a dependência tanto da altura quanto da densidade dos pontos produzidos em função das condições de crescimento. Os pontos quânticos são produzidos em condições de crescimento variadas. A temperatura, o tempo de crescimento e a taxa de deposição são os parâmetros alterados de uma amostra para a outra. São utilizadas técnicas de microscopia de força atômica (AFM) e fotoluminescência (PL) para avaliar o efeito dos parâmetros de crescimento epitaxial sobre a qualidade óptica das estruturas obtidas, as alturas dos pontos quânticos nucleados, a homogeneidade e a densidade da distribuição resultante. É desenvolvida a otimização no processamento digital das imagens de AFM para obter melhores resultados em suas análises. São correlacionados e analisados os resultados obtidos em AFM como a altura e a densidade dos pontos quânticos e seus respectivos picos de emissão de PL. Finalmente foram feitas simulações dos níveis de energia dos pontos quânticos para correlacioná-las com os valores dos picos dos sinais de PL e as alturas dos pontos quânticos.

\section{Palavras-chave}

Pontos quânticos; fotoluminescência; microscopia de força atômica (AFM). 


\section{Abstract}

Ruiz Rosero, Jose Eduardo; Souza, Patrícia Lustoza de (Advisor). Optical and morphological characterization of InAs quantum dots. Rio de Janeiro, 2015. 112p. MSc. Dissertation-Departamento de Engenharia Elétrica, Pontifícia Universidade Católica do Rio de Janeiro.

A detailed study is performed of the production of InAs quantum dots grown on InGaAlAs lattice matched to InP. Performing the optical and morphological characterization of the quantum dots the dependence of the height and density of the quantum dots with the growth conditions is obtained. The quantum dots were produced under different growth conditions. Temperature, growth time and growth rate were changed from one sample to another. We use atomic force microscopy (AFM) and photoluminescence (PL) techniques to evaluate the effect of the growth conditions on the optical quality of the obtained structures, as well as the quantum dots heights, their homogeneity and density distribution. Image processing of AFM images was optimized to allow better accuracy in the analysis of quantum dot height. The AFM results, such as quantum dots height and density, were related and analyzed with their respective PL emission. Finally, simulations of the quantum dots' energy levels were performed to correlate them with the quantum dots height and PL signal.

\section{Keywords}

Quantum dots; photoluminescence; atomic force microscopy (AFM). 


\section{Sumário}

1. Introdução.

2. Conceitos envolvidos no desenvolvimento da dissertação. 23

2.1. Fabricação das amostras investigadas. 28

2.1.1. Substratos. 29

2.1.2. Epitaxia por metal-orgânicos em fase vapor (MOVPE). 29

2.2. Processo de caracterização das amostras investigadas. 32

2.2.1. Fotoluminescência. 32

2.2.1.1 Montagem Experimental. 33

2.2.2. Microscopia de Força Atômica. 35

3. Metodologia de análise dos resultados. 39

3.1. Estrutura das amostras. 39

3.2. Metodologia de análise de fotoluminescência. 41

3.3. Metodologia de análisede microscopia de força atômica (AFM). 43

3.3.1. Processamento convencional dasimagensde AFM. 45

3.3.2. Otimizaçãono processamento dasimagensde AFM. 49

3.3.3. Comparação entre os métodos convencional e otimizado para o processamento das imagens do AFM. 57

4. Discussão dos resultados. $\quad 60$

4.1. Influência do tempo de crescimento sobre os pontos quânticos. $\quad 60$

4.2. Influência do fluxo de TMIn sobre os pontos quânticos. 63

4.3. Influência da temperatura de crescimento sobre os pontos quânticos. 
4.4. Correlação dos resultados de altura e densidade.

4.5. Análise da fotoluminescência. 68

4.6. Simulação de níveis de energia de pontos quânticos.

4.7. Análise das tensões do InAs. 81

5. Conclusões e Trabalhos Futuros. 83

5.1. Conclusões. 83

5.2. Trabalhos Futuros. $\quad 84$

Referências Bibliográficas. $\quad 86$

Apêndice A. $\quad 90$

Apêndice B. $\quad 97$

Apêndice C. 105 


\section{Lista de Figuras}

Figura1. Relação entre o planeta terra, uma bola de futebol e uma molécula de carbono 60. A terra é aproximadamente cem milhões de vezes maior que uma bola de futebol, que é aproximadamente cem milhões de vezes maior que uma molécula de carbono 60 (fulereno), (tomada de http://nanotech.ica.ele.puc-rio.br/).

Figura 2. Escala de comprimento de $1 \mathrm{~m}$ até $0,1 \mathrm{~nm}$, o intervalo entre $1 \mathrm{e}$ $100 \mathrm{~nm}$ está amplificado no lado esquerdo, (tomada de http://nanotech.ica.ele.puc-rio.br/).

Figura 3. Representação de dos elementos com parâmetros de rede diferentes, (a) dois elementos separados com parâmetros de rede diferente, (b) crescimento das primeiras camadas tensionadas, (c) relaxamento e formação de pontos quânticos.

Figura 4. Formação de pontos quânticos no processo Stranski-Krastanov. (a) Diagrama da energia do sistema em função do tempo. (b) Formação de uma camada bidimensional estável (energia $E_{e}$ ). (c) Formação da camada metaestável (energia $E_{c}$ ), a espessura crítica foi atingida. (d) Relaxamento da camada metaestável e início da nucleação. (e) Pontos quânticos formados.

Figura 5. Substrato à direita e sua representação à esquerda.

Figura 6. Diagrama das principais reações químicas no sistema MOVPE. As ligações químicas nas moléculas dos gases precursores são quebradas pela alta temperatura dentro do reator. À direita vemos a formação de uma camada epitaxial de InP sobre o substrato. As moléculas precursoras são a fosfina ( $\mathrm{PH}_{3}$, fonte de fósforo), e o trimetil-índio (TMIn, fonte de índio). 30

Figura 7. Equipamento de MOVPE modelo AIX200.

Figura 8. Representação de amostra. A camada buffer sempre é crescida primeiro sobre o substrato. 
Figura 9. Processo de fotoluminescência quando o material é irradiado com fótons de energia $\hbar w$. (a) Em semicondutores maciços. (b) Em uma estrutura do tipo ponto quântico.

Figura 10. Montagem do experimento de fotoluminescência.

Figura 11. Ilustração do princípio de funcionamento do AFM.

Figura 12. Energia potencial da interação entre dois objetos em função da distância.

Figura 13. Estrutura das amostras.

Figura 14. Estrutura da amostra NR0319.

Figura 15. Medida de fotoluminescência com diferentes potências do feixe de laser incidente sobre a amostra NR0307 realizadas a $15 \mathrm{~K}$.

Figura 16. Ajuste da medida de fotoluminescência $(300 \mathrm{mw})$ da amostra NR0307 realizada a $15 \mathrm{~K}$.

Figura 17. Medida de fotoluminescência com diferentes potências do feixe de laser incidente sobre a amostra NR0319, medidas feitas a $15 \mathrm{~K}$.

Figura 18. Amostras de pontos quânticos com alturas homogêneas (região superior) e heterogêneas (região inferior). Em (a) temos a topografia e em (b) os histogramas correspondentes. Neste caso, a amostra heterogênea apresenta uma distribuição log-normal.

Figura 19. Esquema de uma amostra, os pontos quânticos são representados por círculos. Como pode ser observado, a densidade em (a) é maior que em (b).

Figura 20. Imagem gerada por o AFM. (a) Vista superior. (b - parte superior) vista em 3D. (b - parte inferior) vista transversal.

Figura 21. Imagem gerada por o AFM depois do processo de nivelamento do plano. (a) Vista superior. (b - parte superior) vista em 3D. (b - parte inferior) vista transversal.

Figura 22. Imagem gerada por o AFM depois dos processos de nivelamento do plano e demais correções necessárias. (a) Vista superior. (b - parte superior) vista em 3D. (b - parte inferior) vista transversal.

Figura 23. Processo de contagem de pontos e alturas. (a) Vista transversal de uma imagem pronta para a análise. (b) Threshold estabelecido para encontrar pontos (regiões azuis). (c) Vista transversal das alturas máximas de cada ponto. 
Figura 24. (a) Imagem da superfície de uma amostra. (b) Projeção da linha ressaltada na parte (a).

Figura 25. Representação de uma amostra de pontos quânticos com diferentes alturas de threshold. (a) Altura de threshold baixa. (b) Altura de threshold média. (c) Altura de threshold alta. (d) Altura de threshold por regiões.

Figura 26. Imagem da superfície de uma amostra. (a) Imagem pronta para ser processada. (b) Resultados dos nove métodos de Auto Local Threshold com os parâmetros default.

Figura 27. (a) Imagem da superfície de uma amostra. (b) Projeção da linha ressaltada na parte (a).

Figura 28. Representação do crescimento de pontos coalescendo. (a) Pontos crescendo. (b) Pontos coalescidos. (c) Pontos coalescidos divididos pelo método Watershed.

Figura 29. Exemplo do processamento de uma parte da superfície da amostra. (a) Imagem pronta para ser processada. (b) Zonas reconhecidas pelo Auto Local Threshold. (c) Separação de pontos coalescidos mediante Watershed. (d) Pontos escolhidos para a análise final.

Figura 30. Histograma e ajuste por distribuição log-normal das alturas dos pontos quânticos da amostra NR0244 mediante o método comum.

Figura 31. Histograma e ajuste por distribuição log-normal das alturas dos pontos quânticos da amostra NR0244 mediante o método otimizado.

Figura 32. Resultados de Threshold para uma das imagens de pontos quânticos da superfície da amostra NR0244. (a) Imagem pronta para ser processada. (b) Resultado de Threshold global (método convencional). (c) Resultado de Auto Local Threshold (método otimizado) e separação dos pontos coalescidos.

Figura 33. Resultados de Threshold e os pontos selecionados para a análise final de uma das imagens de pontos quânticos da superfície da amostra NR0244. (a) Pontos detectados com o método sem otimização. (b) Pontos detectados pelo método otimizado. (c) Pontos selecionados com o método sem otimização para a análise, vistos na imagem pronta para ser processada. (d) Pontos selecionados com o método otimizado para a análise, vistos na imagem pronta para ser processada. 
Figura 34. Relação entre a densidade de pontos quânticos e a quantidade de material crescido sobre a amostra (unidades em Mono Camadas "Mono Layers"), os números se referem à identificação das amostras.

Figura 35. Relação entre a altura dos pontos quânticos e a quantidade de material crescido sobre a amostra (unidades em Mono Camadas "Mono Layers"), os números se referem à identificação das amostras. A barra de erro corresponde ao desvio padrão da distribuição Log-normal.

Figura 36. Representação do crescimento de pontos quânticos para altas quantidades de material depositado sobre a amostra, (a) pontos começam seu crescimento, (b) pontos começando a coalescer, (c) pontos crescendo e coalescendo sobre os outros.

Figura 37. Relação entre a densidade dos pontos quânticos e o fluxo de TMIn.

Figura 38. Relação entre a altura dos pontos quânticos e o fluxo de TMIn. A barra de erro corresponde ao desvio padrão da distribuição Log-normal.

Figura 39. Relação entre densidade de QD e a temperatura de crescimento.

Figura 40. Relação entre a altura dos QD e a temperatura de crescimento. A barra de erro corresponde ao desvio padrão da distribuição Log-normal.

Figura 41. Relação entre a altura dos pontos quânticos e a densidade da amostra para a família de amostras com tempo de crescimento de 4,8 segundos. A barra de erro corresponde ao desvio padrão da distribuição Log-normal.

Figura 42. Relação entre o pico de estado fundamental de fotoluminescência e a altura dos pontos quânticos de todas as amostras crescidas. A barra de erro corresponde ao desvio padrão da distribuição Log-normal.

Figura 43. Esquema da estrutura de pontos quânticos de InAs com gap parcialmente tensionado de $471 \mathrm{meV}$, sobre material quaternário de InGaAlAs com gap de $1020 \mathrm{meV}$.

Figura 44. Gap em função da altura de pontos quânticos; Círculos: InGaAs/GaAs; Quadrados: InAs/GaAs a partir da referência (Narvaez, 2005).

Figura 45. Comparação dos valores simulados em outros trabalhos (Narvaez, 2005) e os obtidos neste trabalho (Energias de transição de pontos 
quânticos, com gap de InAs = $784 \mathrm{meV}$ ). N: Valores do trabalho (Narvaez, 2005); T: Valores obtidos neste trabalho.

Figura 46. Energia dos elétrons em função do volume do ponto quântico a partir da referência (Ngo, 2006).

Figura 47. Energia dos buracos em função do volume do ponto quântico a partir da referência (Ngo, 2006).

Figura 48. Comparação do gap de pontos quânticos em função da altura entre as simulações feitas neste trabalho e as simulações obtidas no trabalho (Ngo, 2006).

Figura 49. Energias de transição de pontos quânticos em função da altura, com gap de InAs $=784 \mathrm{meV}$.

Figura 50. Energias de transição de pontos quânticos em função da altura, com gap de InAs $=471 \mathrm{meV}$.

Figura 51. Energias de transição de pontos quânticos em função da altura, com gap de InAs $=565 \mathrm{meV}$.

Figura 52. Histograma e ajuste por distribuição log-normal das alturas dos pontos quânticos da amostra NR0305.Xc representa o valor da média da distribuição.

Figura 53. Transições dos dois primeiros níveis de energia para pontos quânticos de $5.3 \mathrm{~nm}$ em função da tensão do material. São marcadas em azul, os pontos correspondentes para uma energia de gap de InAs tensionado de $571 \mathrm{meV}$.

Figura 54. Ajuste da medida de fotoluminescência $(300 \mathrm{~mW})$ da amostra NR0305.

Figura 55. Relação entre a altura dos pontos quânticos e a energia do gap do InAs.

Figura 56. Histograma e ajuste por distribuição log-normal das alturas dos pontos quânticos da amostra NR0221.Xc representa o valor da média da distribuição.

Figura 57. Histograma e ajuste por distribuição log-normal das alturas dos pontos quânticos da amostra NR0227.Xc representa o valor da média da distribuição. 
Figura 58. Histograma e ajuste por distribuição log-normal das alturas dos pontos quânticos da amostra NR0228.Xc representa o valor da média da distribuição.

Figura 59. Histograma e ajuste por distribuição log-normal das alturas dos pontos quânticos da amostra NR0237.Xc representa o valor da média da distribuição.

Figura 60. Histograma e ajuste por distribuição log-normal das alturas dos pontos quânticos da amostra NR0243.Xc representa o valor da média da distribuição.

Figura 61. Histograma e ajuste por distribuição log-normal das alturas dos pontos quânticos da amostra NR0244.Xc representa o valor da média da distribuição.

Figura 62. Histograma e ajuste por distribuição log-normal das alturas dos pontos quânticos da amostra NR0302.Xc representa o valor da média da distribuição.

Figura 63. Histograma e ajuste por distribuição log-normal das alturas dos pontos quânticos da amostra NR0303.Xc representa o valor da média da distribuição.

Figura 64. Histograma e ajuste por distribuição log-normal das alturas dos pontos quânticos da amostra NR0304.Xc representa o valor da média da distribuição.

Figura 65. Histograma e ajuste por distribuição log-normal das alturas dos pontos quânticos da amostra NR0305.Xc representa o valor da média da distribuição.

Figura 66. Histograma e ajuste por distribuição log-normal das alturas dos pontos quânticos da amostra NR0306.Xc representa o valor da média da distribuição.

Figura 67. Histograma e ajuste por distribuição log-normal das alturas dos pontos quânticos da amostra NR0307.Xc representa o valor da média da distribuição.

Figura 68. Histograma e ajuste por distribuição log-normal das alturas dos pontos quânticos da amostra NR0308.Xc representa o valor da média da distribuição. 
Figura 69. Medida de fotoluminescência com diferentes potências do feixe de laser incidente sobre a amostra NR0221.

Figura 70. Medida de fotoluminescência com diferentes potências do feixe de laser incidente sobre a amostra NR0227.

Figura 71. Medida de fotoluminescência com diferentes potências do feixe de laser incidente sobre a amostra NR0228.

Figura 72. Medida de fotoluminescência com diferentes potências do feixe de laser incidente sobre a amostra NR0237.

Figura 73. Medida de fotoluminescência com diferentes potências do feixe de laser incidente sobre a amostra NR0243.

Figura 74. Medida de fotoluminescência com diferentes potências do feixe de laser incidente sobre a amostra NR0244.

Figura 75. Medida de fotoluminescência com diferentes potências do feixe de laser incidente sobre a amostra NR0302.

Figura 76. Medida de fotoluminescência com diferentes potências do feixe de laser incidente sobre a amostra NR0303.

Figura 77. Medida de fotoluminescência com diferentes potências do feixe de laser incidente sobre a amostra NR0304.

Figura 78. Medida de fotoluminescência com diferentes potências do feixe de laser incidente sobre a amostra NR0305.

Figura 79. Medida de fotoluminescência com diferentes potências do feixe de laser incidente sobre a amostra NR0306.

Figura 80. Medida de fotoluminescência com diferentes potências do feixe de laser incidente sobre a amostra NR0307.

Figura 81. Medida de fotoluminescência com diferentes potências do feixe de laser incidente sobre a amostra NR0308.

Figura 82. Medida de fotoluminescência com diferentes potências do feixe de laser incidente sobre a amostra NR0319.

Figura 83. Ajuste da medida de fotoluminescência (300mw) da amostra NR0221 realizada a $15 \mathrm{~K}$.

Figura 84. Ajuste da medida de fotoluminescência (300mw) da amostra NR0227 realizada a $15 \mathrm{~K}$.

Figura 85. Ajuste da medida de fotoluminescência $(300 \mathrm{mw})$ da amostra NR0228 realizada a $15 \mathrm{~K}$. 
Figura 86. Ajuste da medida de fotoluminescência $(300 \mathrm{mw})$ da amostra NR0237 realizada a $15 \mathrm{~K}$.

Figura 87. Ajuste da medida de fotoluminescência $(300 \mathrm{mw})$ da amostra NR0243 realizada a $15 \mathrm{~K}$.

Figura 88. Ajuste da medida de fotoluminescência $(300 \mathrm{mw})$ da amostra NR0244 realizada a $15 \mathrm{~K}$.

Figura 89. Ajuste da medida de fotoluminescência $(300 \mathrm{mw})$ da amostra NR0302 realizada a $15 \mathrm{~K}$.

Figura 90. Ajuste da medida de fotoluminescência (300mw) da amostra NR0303 realizada a $15 \mathrm{~K}$.

Figura 91. Ajuste da medida de fotoluminescência (300mw) da amostra NR0304 realizada a $15 \mathrm{~K}$.

Figura 92. Ajuste da medida de fotoluminescência (300mw) da amostra NR0305 realizada a $15 \mathrm{~K}$.

Figura 93. Ajuste da medida de fotoluminescência (300mw) da amostra NR0306 realizada a $15 \mathrm{~K}$.

Figura 94. Ajuste da medida de fotoluminescência (300mw) da amostra NR0307 realizada a $15 \mathrm{~K}$.

Figura 95. Ajuste da medida de fotoluminescência $(300 \mathrm{mw})$ da amostra NR0308 realizada a $15 \mathrm{~K}$.

Figura 96. Ajuste da medida de fotoluminescência (300mw) da amostra NR0319 realizada a $15 \mathrm{~K}$. 


\section{Lista de Tabelas}

Tabela 1. Condições de crescimento dos pontos quânticos.

Tabela 2.Condições de crescimento da camada de pontos quânticos e seus resultados das análises, variando o tempo de crescimento (quantidade de material) e mantendo fixos os outros parâmetros.

Tabela 3.Condições de crescimento da camada de pontos quânticos e seus resultados das análises, variando o fluxo de índio e mantendo fixos os outros parâmetros.

Tabela 4.Condições de crescimento da camada de pontos quânticos e seus resultados das análises, variando a temperatura de crescimento e mantendo fixos os outros parâmetros.

Tabela 5. Comparação dos valores simulados em outro trabalho (Narvaez, 2005) e os obtidos neste trabalho (Energias de transição de pontos quânticos, com gap de InAs tensionado = $784 \mathrm{meV}$ ).

Tabela 6. Comparação de valores deste trabalho com as simulações de outro trabalho (Ngo, 2006).

Tabela 7.Condições de crescimento da camada de pontos quânticos e os resultados da análise de suas propriedades ópticas e morfológicas. 


\section{Introdução}

A tecnologia é o conjunto de conhecimentos técnicos, cientificamente ordenados, que permitem desenhar e desenvolver produtos e serviços que facilitam a adaptação ao meio ambiente e a satisfazer as necessidades essenciais e os desejos da humanidade.

$\mathrm{O}$ mundo moderno demanda constantemente novas tecnologias e dispositivos mais eficientes e complexos para satisfazer suas necessidades e melhorar suas condições de vida. Para ter dispositivos mais eficientes e de menor tamanho se precisa de componentes pequenos e que consumam menores quantidades de energia, processadores que trabalhem de forma mais rápida, transmissões de informação de alta velocidade, entre outras. Uma forma de conseguir isto é mediante a miniaturização.

A miniaturização é o processo tecnológico mediante o qual se tenta reduzir o tamanho dos dispositivos eletrônicos (Grundmann, 2010). A miniaturização dos dispositivos eletrônicos tem sido um bom parâmetro para medir o avanço e o desenvolvimento do setor da informática. Quanto menores são os dispositivos que são usados, maior é o número de dispositivos que cabem num mesmo espaço, melhorando a potência e a eficiência de nossos computadores. O fenômeno da miniaturização foi descrito com grande precisão em 1965 por Gordan Moore, fundador de Intel Corporation, com a formulação da lei de Moore que estabelece que o tamanho de um transistor se reduza em $50 \%$ cada ano e meio (Moore, 1965).

Um grande avanço na tecnologia foi a aparição da nanotecnologia. O prefixo "nano" vem do grego e significa "anão". Um nanômetro equivale à bilionésima parte de um metro. Para ter uma ideia, um cabelo humano tem entre 80.000 e $150.000 \mathrm{~nm}$ de largura. Mais uma comparação é que se uma partícula se desloca com uma velocidade de $1 \mathrm{~nm}$ por segundo, ela demoraria mais de 30 anos em percorrer uma distância de um metro. Outra comparação que dá uma ideia da escala nanométrica é a relação entre o planeta terra, uma bola de futebol e uma 
molécula de carbono 60 mostradas na figura 1. A terra é aproximadamente cem milhões de vezes maior que uma bola de futebol, e uma bola de futebol é aproximadamente cem milhões de vezes maior que uma molécula de carbono 60 (fulereno).

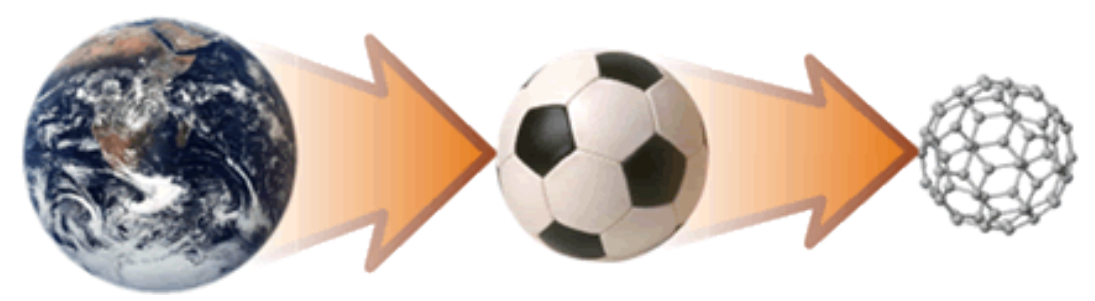

Figura1. Relação entre o planeta terra, uma bola de futebol e uma molécula de carbono 60. A terra é aproximadamente cem milhões de vezes maior que uma bola de futebol, que é aproximadamente cem milhões de vezes maior que uma molécula de carbono 60 (fulereno), (tomada de http://nanotech.ica.ele.puc-rio.br/).

Pode-se observar na figura 2 a escala de comprimento de $1 \mathrm{~m}$ até $0,1 \mathrm{~nm}, 1$ nm equivale a 10 angstrons $(\AA)$. O intervalo entre 1 e 100 nm está amplificado no lado esquerdo da figura. O "mundo nanométrico" tem interesse na escala de 100 $\mathrm{nm}$ até a escala atômica, aproximadamente $0,2 \mathrm{~nm}$.

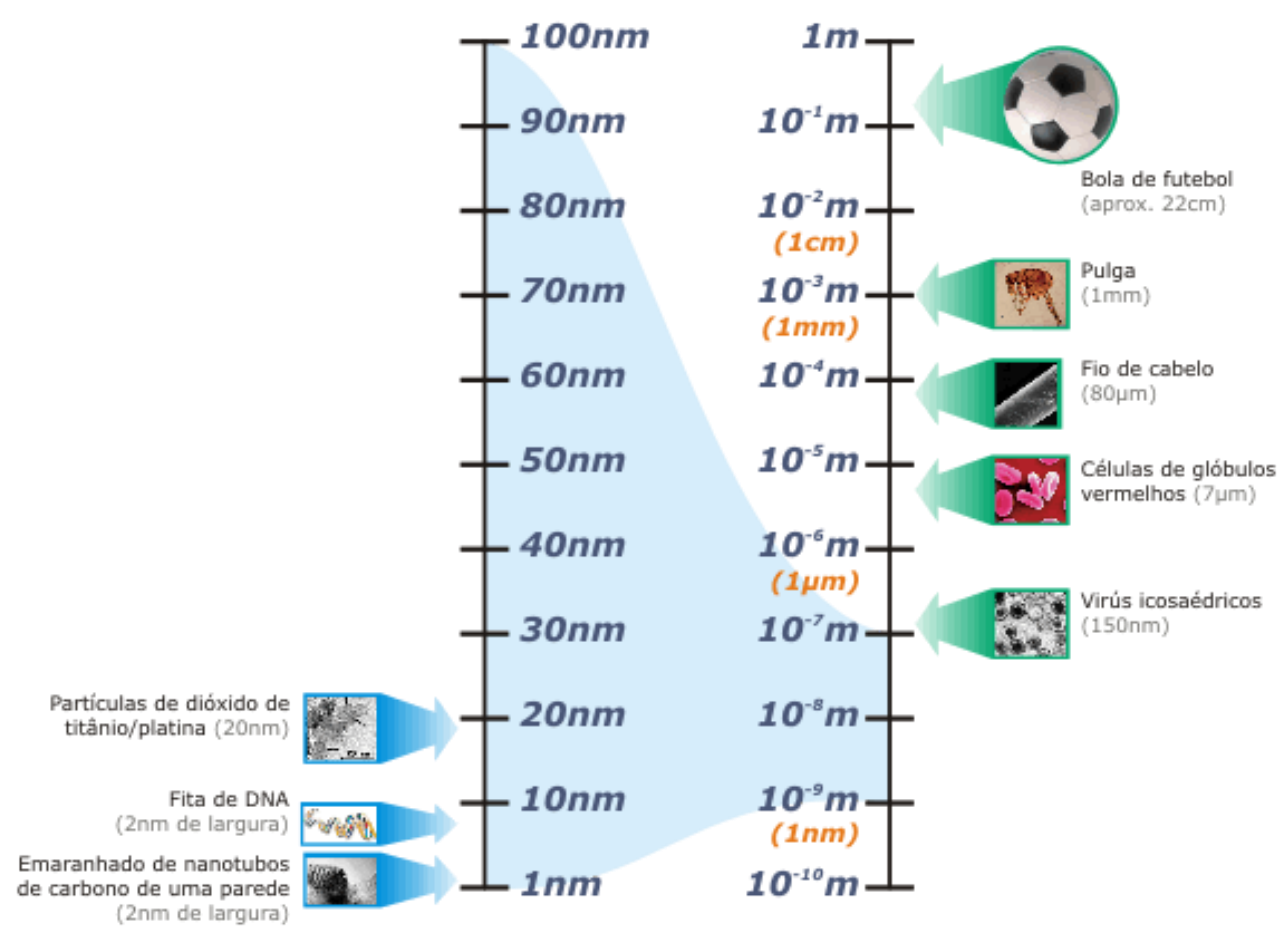

Figura 2. Escala de comprimento de $1 \mathrm{~m}$ até $0,1 \mathrm{~nm}$, o intervalo entre 1 e $100 \mathrm{~nm}$ está amplificado no lado esquerdo, (tomada de http://nanotech.ica.ele.puc-rio.br/). 
A nanotecnologia é a manipulação da matéria na escala atômica, molecular e supramolecular (Dowling, 2004). Uma das mais antigas descrições de nanotecnologia faz referência ao objetivo tecnológico particular de manipular de forma precisa os átomos e moléculas para fabricação de produtos na macroescala (Drexler, 1986,1992), conhecida na atualidade como nanotecnologia molecular. A nanotecnologia compreende o estudo, criação, síntese, manipulação e aplicação de materiais, aparelhos e sistemas funcionais mediante o controle da matéria na nanoescala. Quando se manipula a matéria numa escala tão pequena, fenômenos e propriedades totalmente novas se apresentam como o confinamento de partículas e a quantização da energia. Portanto, os cientistas utilizam a nanotecnologia para criar materiais, aparelhos e sistemas inovadores e mais baratos com propriedades únicas.

Fatores que causam diferenças nos nano-materiais em comparação com outras estruturas são o aumento da área da superfície e a aparição de efeitos quânticos. O aumento da área da superfície é que quanto menor seja um dispositivo, maior será a proporção de átomos na superfície, o que pode criar materiais muito mais reativos que os comuns, já que mais átomos da sua estrutura ficam na superfície sendo expostos aos outros compostos. Os efeitos quânticos aparecem quando as dimensões das estruturas são muito pequenas, da ordem de alguns nanômetros, já que estas pequenas dimensões confinam partículas dentro dos dispositivos ao limitar o deslocamento das partículas em 1, 2 ou 3 dimensões.

A optoeletrônica é uma das muitas áreas que se pode melhorar com a aplicação de nanotecnologia (Capasso, 2000). Na optoeletrônica se encontra um grande interesse em estudar dispositivos fotodetectores por suas diversas aplicações (Towe, 2000; Silva, 2008; Souza, 2007) como em: detectores de gases; câmaras térmicas usando sensores de infravermelho que podem ser aplicadas em sistemas de segurança de processos industriais, já que detectam a temperatura dos diferentes componentes o que permite ter um controle global das temperaturas do sistema; sistemas de comunicações que não dependem de fios nem cabos enterrados no solo, pois as comunicações poderiam ser feitas através do ar; entre outras.

Componentes nanométricos são aqueles que têm pelo menos uma de suas dimensões abaixo de $100 \mathrm{~nm}$, por exemplo, componentes que têm uma dimensão menor a $100 \mathrm{~nm}$ como os filmes finos ou poços quânticos que confinam partículas 
em uma dimensão; componentes que têm duas dimensões menores a 100 nm como os fios quânticos ou nanotubos que confinam partículas em duas dimensões; e componentes que têm as três dimensões menores que $100 \mathrm{~nm}$, como os pontos quânticos, que confinam partículas nas três dimensões, estes componentes são chamados muitas vezes de componentes 0-D (de zero dimensões).

Para aproveitar certas características como o confinamento de partículas e a quantização dos níveis de energia se precisa ter estruturas de tamanho reduzido como são os filmes finos, nanotubos, poços, fios e pontos quânticos, sendo os pontos quânticos as estruturas de interesse deste trabalho.

Os pontos quânticos são estruturas que por suas características podem melhorar o desempenho e as propriedades dos dispositivos, por exemplo, nas células solares e outros dispositivos optoeletrônicos podem gerar diferentes níveis de energia eletrônicos para operar em energias específicas. Estas melhoras são possíveis se os pontos quânticos têm boa qualidade óptica e morfológica. Para se poder controlar a forma, a altura e a densidade, é necessário conhecer as condições de fabricação e identificar a influência destas condições sobre o resultado final dos pontos quânticos. Estes são motivos pelos quais é necessário ter uma caracterização das amostras fabricadas com diferentes parâmetros de crescimento (Bimberg, 1999).

Uma caracterização das condições de crescimento com as informações do efeito gerado sobre as amostras é útil para fazer uma calibração precisa e obter pontos quânticos com características controladas.

Em função do exposto anteriormente, este trabalho teve como objetivo realizar uma caracterização das propriedades ópticas e morfológicas das amostras com pontos quânticos em função da temperatura de crescimento, da quantidade de material depositado e do fluxo do TMIn, a fim de se ter um controle de crescimento dos pontos quânticos de InAs sobre camadas do material quaternário de InGaAlAs.

Os objetivos secundários são:

- Aperfeiçoar o processamento da análise das imagens do AFM com o fim de ter medidas mais exatas das alturas dos pontos quânticos.

- Compreender as propriedades dos pontos quânticos em função das condições de crescimento. 
- Correlacionar as propriedades ópticas com as morfológicas dos pontos quânticos.

No capítulo 2 se faz um pequeno resumo de alguns conceitos necessários para este trabalho. Descreve-se o que são os pontos quânticos e algumas propriedades deles, explica-se a forma de serem fabricados, o equipamento necessário e a técnica utilizada para o crescimento das amostras de pontos quânticos.

No capítulo 3 se encontra a estrutura das amostras e suas diferenças nas condições de crescimento dos pontos quânticos; a metodologia de análise das amostras, detalhando os processos de análise de fotoluminescência e de microscopia de força atômica. Explica-se o método convencional de fazer a análise das imagens de AFM e se descreve o método otimizado proposto para fazer a análise das imagens.

No capítulo 4 são discutidos os resultados do estudo como a influência do tempo de crescimento, o fluxo de TMIn e a temperatura de crescimento. Correlaciona-se os resultados das alturas e densidades dos pontos quânticos, se faz a análise da fotoluminescência das amostras, uma simulação de níveis de energia de pontos quânticos e a análise do gap do InAs tensionado em relação às alturas dos pontos quânticos.

No capítulo 5 se encontram as conclusões dos estudos feitos nesta dissertação e as recomendações para realizar trabalhos futuros baseados nesta pesquisa.

Na parte final da dissertação se encontra o apêndice A onde estão as figuras dos resultados de caracterização morfológica representada em histogramas e ajuste por distribuição log-normal das alturas dos pontos quânticos, o apêndice B com os sinais de fotoluminescência emitidos pelas amostras para diferentes potências do feixe de laser, e o apêndice C com os ajustes dos sinais de fotoluminescência com gaussianas para os sinais de $300 \mathrm{~mW}$. 


\section{2 Conceitos envolvidos no desenvolvimento da dissertação}

A física de estado sólido é a área na qual se descreve a estrutura eletrônica de um material como uma estrutura de bandas eletrônicas, ou simplesmente uma estrutura de bandas de energia. A estrutura eletrônica se baseia no fato que numa molécula os orbitais de um átomo se sobrepõem produzindo um número discreto de orbitais moleculares. Quando uma grande quantidade de átomos se junta, como nas estruturas sólidas, o número de orbitais de valência (os níveis de energia mais altos) é tão grande, e a diferença de energia entre os estados de mais baixa e mais alta energia permanece inalterada, que se pode considerar que os níveis de energia formam bandas contendo um contínuo de energias. Porém, devido que alguns intervalos de energia não contêm orbitais, independentemente do número de átomos agregados, se criam certas lacunas energéticas entre as diferentes bandas denominadas de gap.

A banda de valência está ocupada pelos elétrons de valência dos átomos, quer dizer, aqueles elétrons que se encontram na última capa ou nível energético do átomo. Os elétrons de valência são os que formam os enlaces entre os átomos, mas não intervêm na condução elétrica se for isolante.

A banda de condução está ocupada pelos elétrons livres, quer dizer, aqueles elétrons que se desligaram dos seus átomos e podem se mover facilmente. Estes elétrons são os responsáveis por conduzir a corrente elétrica.

A banda proibida ou gap de energia do inglês band gap, é a diferença de energia entre a parte superior da banda de valência e a parte inferior da banda de condução. Ela está presente em isolantes e semicondutores. A condutividade elétrica de um semicondutor intrínseco depende em grande medida da largura do gap. Os portadores úteis para conduzir são os elétrons que têm energia suficiente para poder saltar a banda proibida e os buracos deixados na banda de valência. Em consequência, para que um material seja bom condutor de corrente elétrica deve ter pouca ou nenhuma separação entre as bandas de valência e condução (que se podem chegar a sobrepor), de forma que os elétrons possam saltar entre as bandas. 
Quando a separação entre as bandas é maior, o material se comporta como um isolante. Em ocasiões, a separação entre bandas permite a excitação de elétrons entre as mesmas de apenas alguns elétrons. Nestes casos, o material se comporta como um semicondutor.

Existem estruturas com uma, duas ou três dimensões da ordem nanométrica como os poços quânticos, fios quânticos e pontos quânticos que conseguem confinar partículas em uma, duas ou três dimensões.

Poço quântico quantum well, é a denominação recebida por um poço de potencial que confina, em uma dimensão, partículas que originalmente tinham liberdade para se mover nas três dimensões, forçando-as a ocupar uma zona determinada.

A estrutura que confina partículas em duas dimensões é chamada fio quântico quantum wire, confinando os elétrons de condução na direção transversal do fio.

Os pontos quânticos são estruturas nanométricas geralmente formadas de materiais semicondutores, as quais conseguem confinar nas três dimensões partículas como os elétrons da banda de condução, os buracos da banda de valência e os pares formados por eles. Os pontos quânticos confinam partículas em três dimensões porque estão imersos em um material de gap maior. Os elétrons têm energia quantizada em valores discretos devido ao confinamento, por isso são chamados por vezes como átomos artificiais, estes valores de energia pode-se controlar mudando as propriedades físicas dos pontos quânticos como o tamanho ou a forma.

Quanto aos métodos e as técnicas de fabricação destas estruturas (nanofabricação) elas consistem em simplesmente transformar as matérias primas em produtos com as características e as funcionalidades desejadas (Wolfgang, 2004).

A nanofabricação tem como objetivo obter estruturas, componentes, dispositivos, maquinaria e sistemas com as características de nanoescala em uma, duas ou três dimensões. Para tal se faz uso de métodos especiais para realizar a estruturação nanotecnológica de componentes. Devido que a nanotecnologia implica na fabricação de partículas de escala muito pequena, são vários os métodos atuais que permitem fabricar este tipo de componentes de escala nano. Os métodos top-down e bottom-up, que sendo métodos opostos em termos de sua 
filosofia de operação, convergem em sua finalidade, estes métodos são muito utilizados e cada um deles tem por sua vez, uma série de técnicas específicas.

Os métodos top-down começam o processo de fabricação de nanoestruturas a partir de matérias grandes, que se vão reduzindo para formar dispositivos de tamanhos na escala nanométrica. Este tipo de nanotecnologia é muito utilizado até agora, especificamente na área da eletrônica onde predominam processos de miniaturização. A técnica mais utilizada neste método é a nanolitografia que consiste em usar raios de elétrons para produzir desenhos em químicos fotossensíveis, os quais são depois suprimidos para expor a nova superfície. Esta técnica é uma das principais na fabricação de circuitos integrados (Wolfgang, 2004).

Na fabricação mediante os métodos bottom-up se começa com uma estrutura nanométrica como uma molécula e mediante um processo de montagem ou autoorganização, se cria um dispositivo maior que a estrutura inicial. Este método permite que a matéria possa ser controlada de forma extremamente precisa. Desta forma o nível de miniaturização que se consegue mediante este método, é superior ao conseguido pelo método top-down, sendo superadas as limitações da miniaturização presentes no campo da eletrônica (Wolfgang, 2004). A grande variedade de técnicas destes últimos métodos (bottom-up), pode-se dividir em três grandes categorias.

A síntese química, que envolve a produção de matérias primas, como moléculas ou partículas, que se pode usar diretamente em produtos em forma desordenada, formando blocos ou níveis mais avançados de ordenamento. O tipo de nanomaterial mais conhecido, empregando esta técnica, são as nanopartículas.

A montagem posicional, esta é a única técnica capaz de manipular e posicionar átomos e moléculas, um a um. Embora, contamos com instrumentação capaz de realizar estes processos, a ordenação de átomos feito um a um é muito laboriosa, e atualmente não é apropriada para se levar a escala industrial.

$\mathrm{Na}$ auto-organização espontânea os átomos ou moléculas são posicionados por si mesmos em nanoestruturas ordenadas mediante interações químicas ou físicas entre as subunidades. Estes fenômenos têm ocorrido na natureza há milhares de anos (cristais de sal, flocos de neve), no entanto, ao nível industrial é relativamente novo. A utilização desta técnica em um nível industrial é uma grande revolução já que muitas estruturas como os pontos quânticos são 
fabricadas ao mesmo tempo em uma mesma camada e não é necessária a intervenção de máquinas para fazer o posicionamento de cada átomo, reduzindo grandemente os custos. O crescimento epitaxial é um exemplo da técnica de autoorganização espontânea.

Para o desenvolvimento de estruturas bidimensionais (poços quânticos), o crescimento epitaxial foi amplamente utilizado durante muito tempo. Atualmente há um interesse enorme na produção de estruturas com um número menor de dimensões como fios quânticos e pontos quânticos. Para tal, são requeridas ao menos uma das dimensões espaciais limitadas a cerca de 10nm, porém, esse é o limite de resolução na fabricação com técnicas tradicionais do tipo top-down como a litografia e processos de corrosão (Zhang, 2003). Além disso, estas técnicas não permitem que o crescimento seja realizado em uma única etapa.

Para a fabricação destas estruturas são preferíveis processos de crescimento bottom-up, capazes de produzir estruturas com dimensões espaciais da ordem de nanômetros com um custo mais baixo, e se pode produzir todos os pontos quânticos de uma mesma camada simultaneamente para algumas técnicas. Uma técnica delas é auto-organização espontânea (Seifert, 1997). Este processo de auto-organização ocorre mediante as transições morfológicas induzidas por tensão na interface de dois semicondutores com parâmetros de redes diferentes (InAs/InGaAlAs). Este modelo de crescimento é conhecido como StranskiKrastanov (Baskaran, 2012). Na figura 3 (a) se mostra a representação de dois elementos com parâmetros de rede diferentes, na parte (b) o crescimento das primeiras camadas tensionadas, na parte (c) se observa o relaxamento e formação de pontos quânticos. 

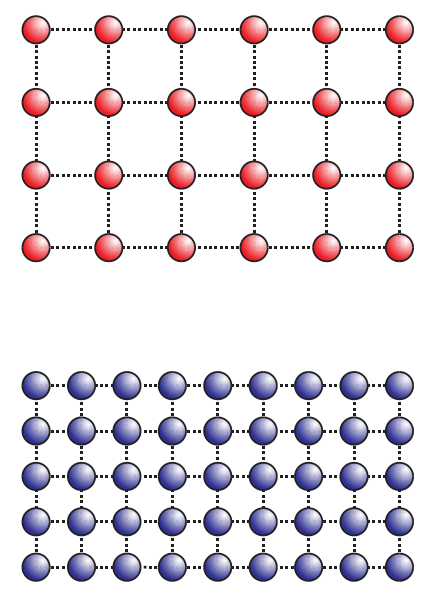

(a)

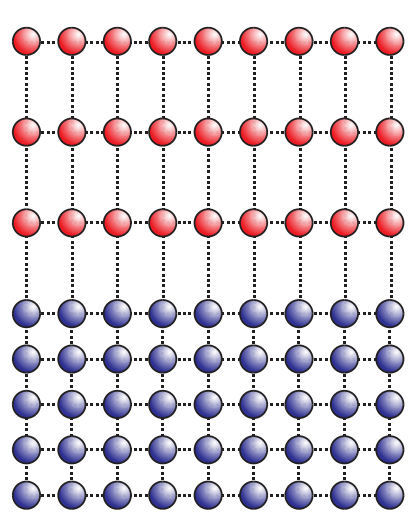

(b)

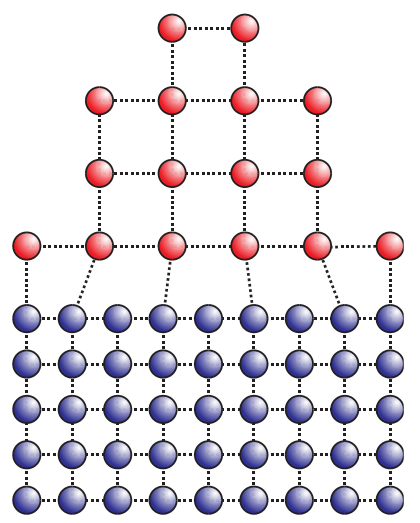

(c)

Figura 3. Representação de dos elementos com parâmetros de rede diferentes, (a) dois elementos separados com parâmetros de rede diferente, (b) crescimento das primeiras camadas tensionadas, (c) relaxamento e formação de pontos quânticos

Na figura 4 (a) se mostra o diagrama da energia do sistema em função do tempo. À medida que o tempo de deposição e a espessura de material aumenta, a energia elástica do sistema cresce. O sistema se mantém estável até certa espessura, na qual a energia é $E_{e}$, como se mostra na figura 4 (b). Após esta etapa, se continua com a formação de uma camada metaestável. A espessura máxima dessa camada é limitada pela energia critica $E_{c}$, como se mostra na figura 4(c). Quando se atinge a energia crítica, há relaxamento local e a energia diminui, atraindo outros átomos, figura 4(d). Nessa etapa ocorre um relaxamento da camada metaestável, sendo consumida parte da tensão na formação de estruturas tridimensionais. No começo da transição morfológica, quando a energia do sistema é muito maior que $E_{e}$, o relaxamento é rápido. Após certo tempo, quando boa parte da tensão já foi relaxada na transição morfológica, o material em excesso do equilíbrio forma os pontos quânticos figura 4(e). A estrutura é constituída de uma fina camada bidimensional estável (Wetting Layer) sobre a qual existem os pontos quânticos. 


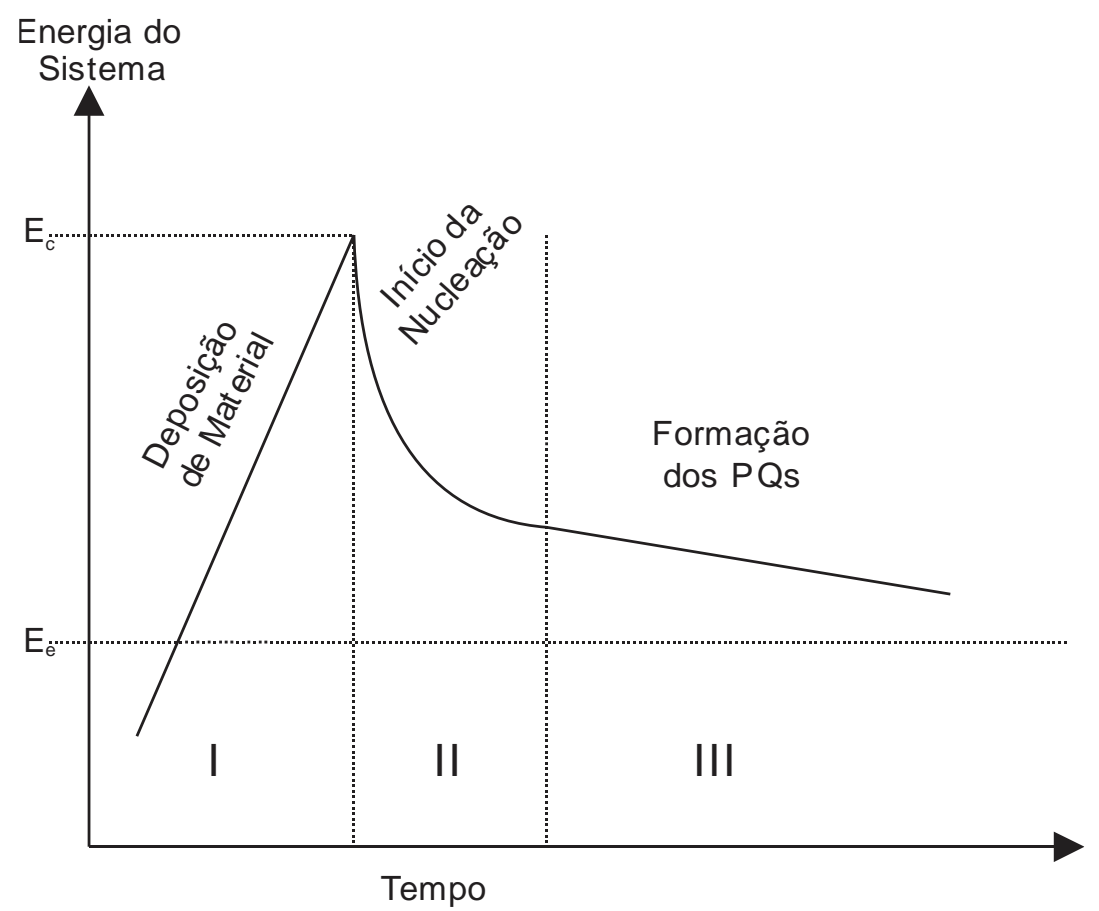

(a)

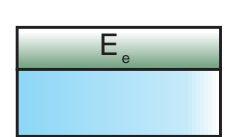

(b)

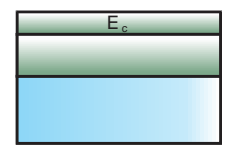

(c)

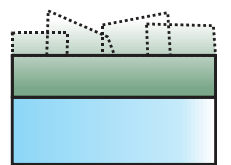

(d)

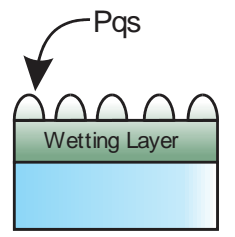

(e)

Figura 4. Formação de pontos quânticos no processo Stranski-Krastanov. (a) Diagrama da energia do sistema em função do tempo. (b) Formação de uma camada bidimensional estável (energia $E_{e}$ ). (c) Formação da camada metaestável (energia $E_{c}$ ), a espessura crítica foi atingida. (d) Relaxamento da camada metaestável e início da nucleação. (e) Pontos quânticos formados.

\section{1}

\section{Fabricação das amostras investigadas}

O processo de fabricação dos pontos quânticos foi feito por epitaxia, a qual consiste em crescer um filme de material sobre um substrato, através da deposição de camadas atômicas sucessivamente. São conhecidas diferentes técnicas de epitaxia, entre elas: MBE (Molecular Beam Epitaxy) (Cho, Arthur, 1975; Herman, 1996), LPE (Liquid Phase Epitaxy) (Dawson, 1972; Capper, 2007) e MOVPE (Metal-Organic Vapor Phase Epitaxy) (Stringfellow, 1989). Nesta dissertação foram feitas todas as amostras com a técnica MOVPE, que será discutida na seção 2.1.2. 


\subsection{1}

\section{Substratos}

A base da amostra e do crescimento no processo de epitaxia é o substrato. O substrato é uma pastilha (wafer) de um material semicondutor no qual são crescidas as camadas da amostra. $\mathrm{O}$ substrato tem forma circular, com diâmetro entre 2" e 6" (Figura 5). Geralmente os substratos são semicondutores de um material só como o germânio ou silício, ou por materiais binários como o arseneto de gálio e o fosfeto de índio, que podem ser dopados intencionalmente com impurezas ou não.
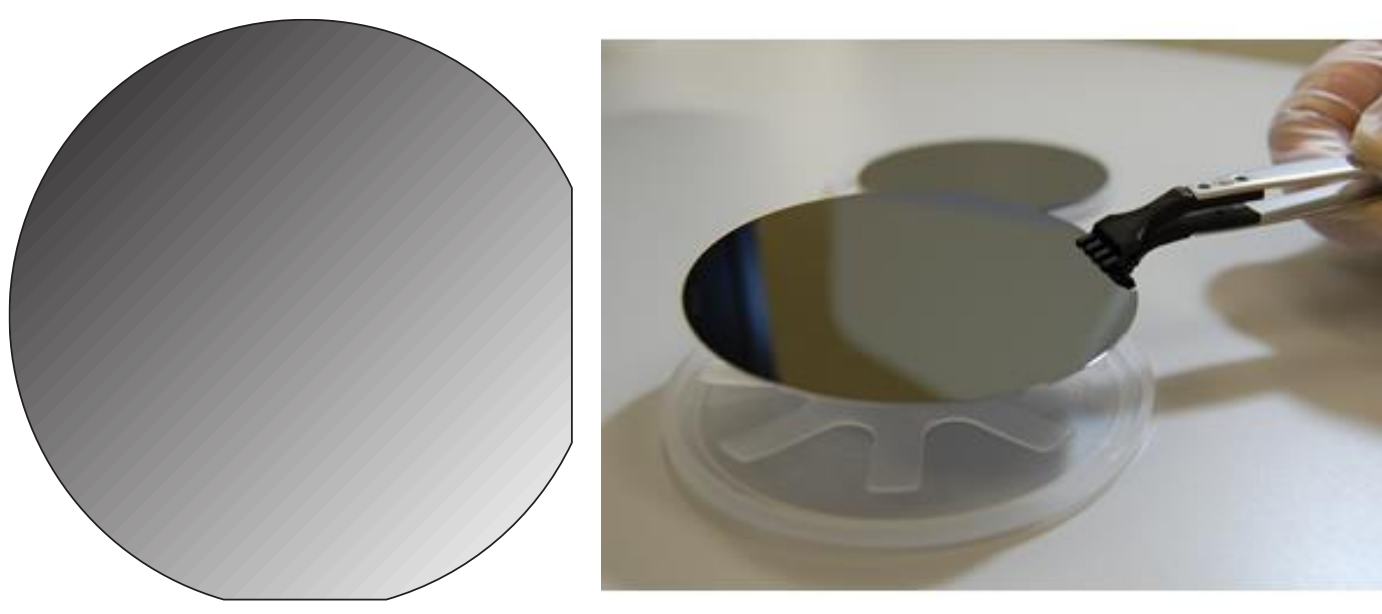

Figura 5. Substrato à direita e sua representação à esquerda.

\subsection{2 \\ Epitaxia por metal-orgânicos em fase vapor (MOVPE)}

A técnica de epitaxia por Metal-Orgânicos em Fase de Vapor (do inglês Metal-Organic Vapor Phase Epitaxy; MOVPE) foi desenvolvida por Manasevit em 1968/1969.Ele é um dos principais métodos para a fabricação de dispositivos optoeletrônicos.

O equipamento de MOVPE utilizado é um modelo AIX200 da empresa alemã AIXTRON (Figura 7).

O crescimento ocorre dentro de um reator a altas temperaturas com atmosfera controlada (temperaturas na faixa $450^{\circ}-750^{\circ} \mathrm{C}$ e pressões da ordem de 100 mbar). Os gases precursores e o gás de arraste (hidrogênio) são misturados e injetados dentro do reator sobre o substrato aquecido (Mourão, 2013; Micha, 2015). As moléculas precursoras são descompostas pela ação das altas 
temperaturas, liberando diversos subprodutos. Esses subprodutos reagem entre si ocorrendo assim o crescimento epitaxial através da deposição de material (algumas partículas dos subprodutos), em camadas, sobre o substrato. Algumas das reações podem ser esquematizadas conforme a figura 6 .

A fórmula química da reação e:

$$
\left(\mathrm{CH}_{3}\right)_{3} \mathrm{In}+\mathrm{PH}_{3} \rightarrow \mathrm{InP}+3 \mathrm{CH}_{4}
$$
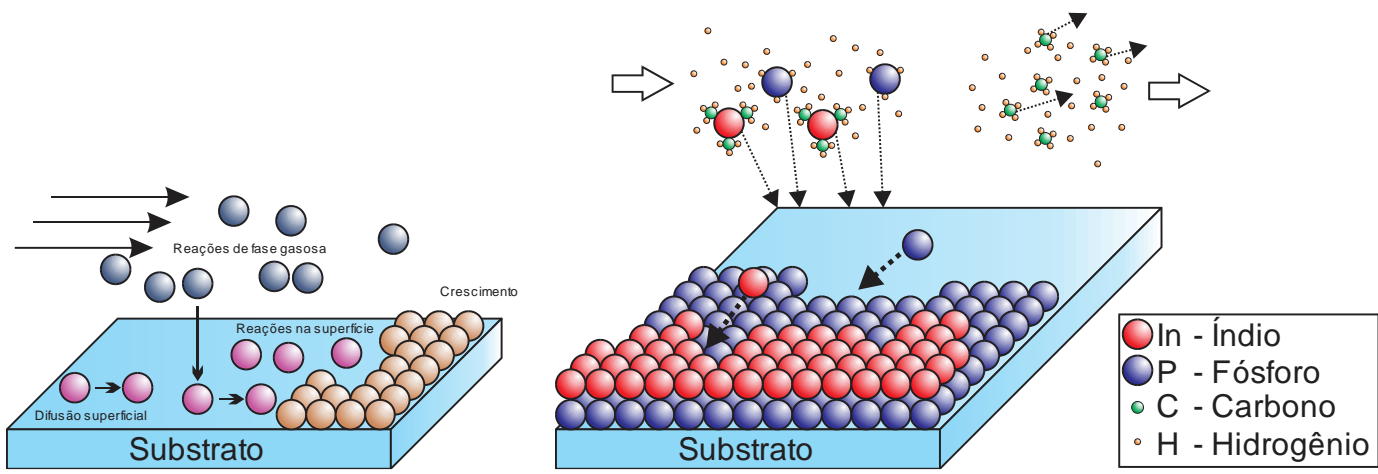

Figura 6. Diagrama das principais reações químicas no sistema MOVPE. As

ligações químicas nas moléculas dos gases precursores são quebradas pela alta temperatura dentro do reator. À direita vemos a formação de uma camada epitaxial de InP sobre o substrato. As moléculas precursoras são a fosfina ( $\mathrm{PH}_{3}$, fonte de fósforo), e o trimetil-índio (TMIn, fonte de índio).

O crescimento de uma camada precisa da disponibilidade de seus gases precursores para a ocorrência das reações químicas e sua deposição. Por exemplo, precisa átomos de gálio e de arsênio para o crescimento de uma camada de GaAs. Se algum deles não estiver presente não há formação da camada epitaxial. A proporção entre eles é de muita importância porque pode afetar as taxas de crescimento. 


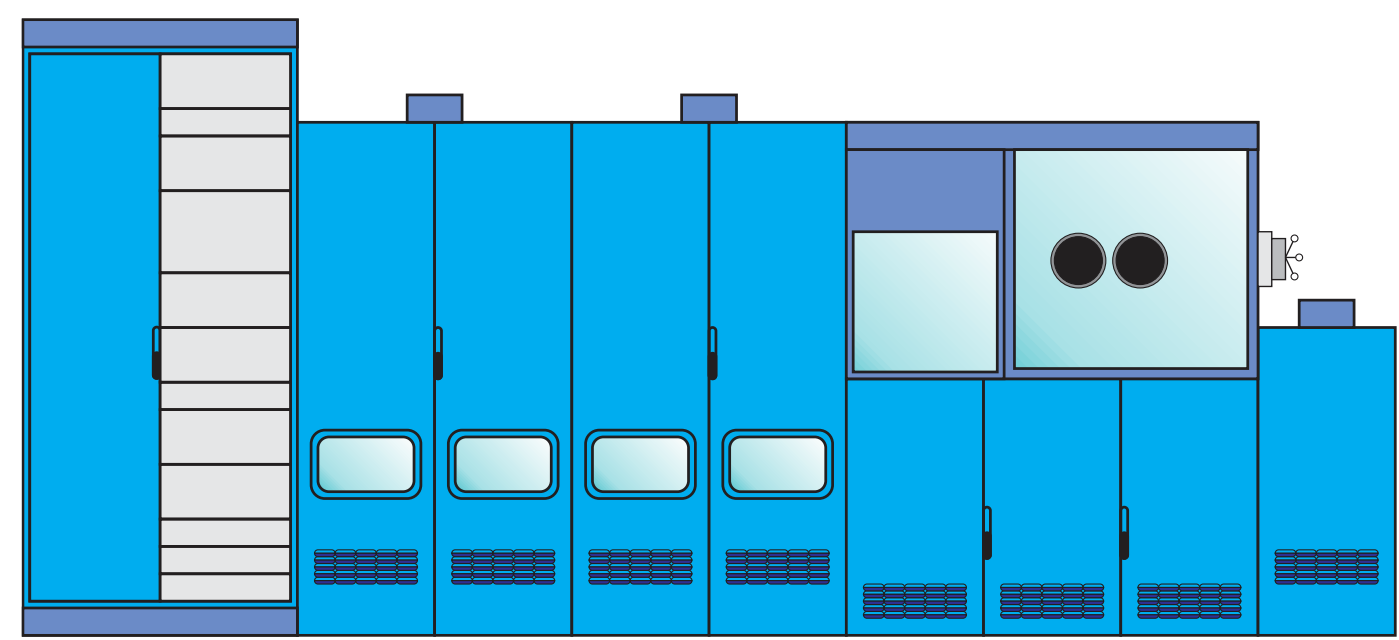

Figura 7. Equipamento de MOVPE modelo AIX200.

Quando são produzidos os substratos, a técnica não forma estruturas cristalinas com uma boa qualidade como são crescidas em MOVPE. Por isso deve ser feita uma deposição de uma camada buffer acima do substrato, garantindo a cristalinidade na superfície sobre a qual será crescida uma camada epitaxial.

Na figura 8 se pode ver a representação do substrato com a presença de uma camada buffer acima dele e na parte superior uma camada epitaxial simples, ou seja, uma única camada diferente do material do substrato (a camada buffer é do mesmo material do substrato).
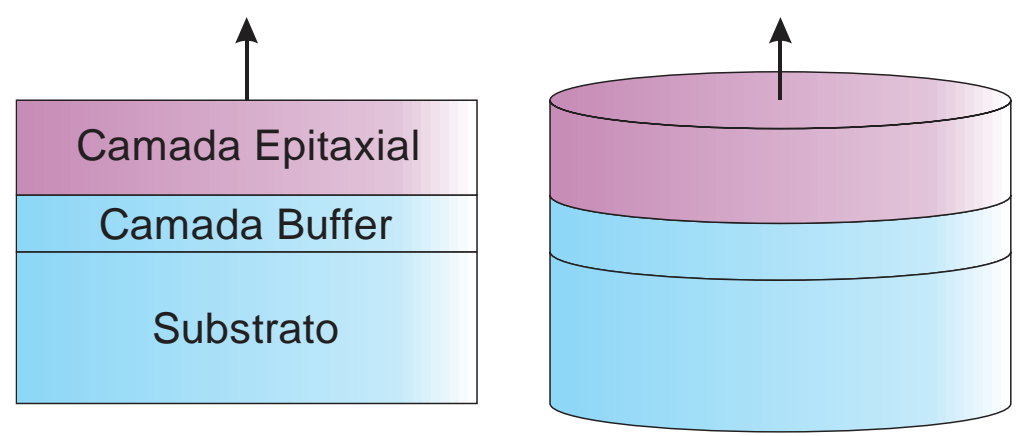

Figura 8. Representação de amostra. A camada buffer sempre é crescida primeiro sobre o substrato.

Normalmente as amostras finais são mais complexas, têm mais camadas de diferentes características e materiais. É necessário calibrar cada camada para sua fabricação. 


\section{2 Processo de caracterização das amostras investigadas}

Para ter um controle das calibrações feitas no reator e os resultados das variações nos parâmetros, foram feitas caracterizações de tipo ópticas e morfológicas. Para obter uma caracterização óptica das amostras, foi necessário fazer um estudo da fotoluminescência (descrita em 2.2.1) de cada amostra, e um estudo da superfície da amostra (onde estão localizados os pontos quânticos) com técnicas de microscopia de força atômica, descrita em 2.2.2.

\subsection{1 Fotoluminescência}

A fotoluminescência é um processo físico no qual um material absorve radiação luminosa, e posteriormente emite fótons com um comprimento de onda que pode ser diferente da radiação incidente. $\mathrm{O}$ fóton absorvido geralmente tem uma energia maior que a energia do gap do semicondutor, assim os portadores são excitados a uma energia maior que a da banda proibida, e tendem a entrar em equilíbrio energético com a rede cristalina (termalização) até que os elétrons atinjam a energia mínima do gap e aí ocorre a recombinação, resultando assim na emissão de fótons menos energéticos (comprimento de onda maior).

Em semicondutores maciços a energia da radiação reemitida (preferencialmente a temperatura ambiente) equivale exatamente à diferença de energia entre o fundo da banda de condução e o topo da banda de valência, ou seja, o gap do material (Figura 9 (a)), porém, a temperaturas mais baixas, pode-se observar emissões a energias menores devido à presença de impurezas no material. Quando existem estruturas mais complexas capazes de confinar os elétrons, por exemplo, em um ponto quântico, aparece a quantização dos níveis de energia em função do confinamento. Nesse caso a fotoluminescência gerada corresponde a energias de transições eletrônicas mais energéticas que as presentes no sistema sem pontos quânticos (Figura 9 (b)). 


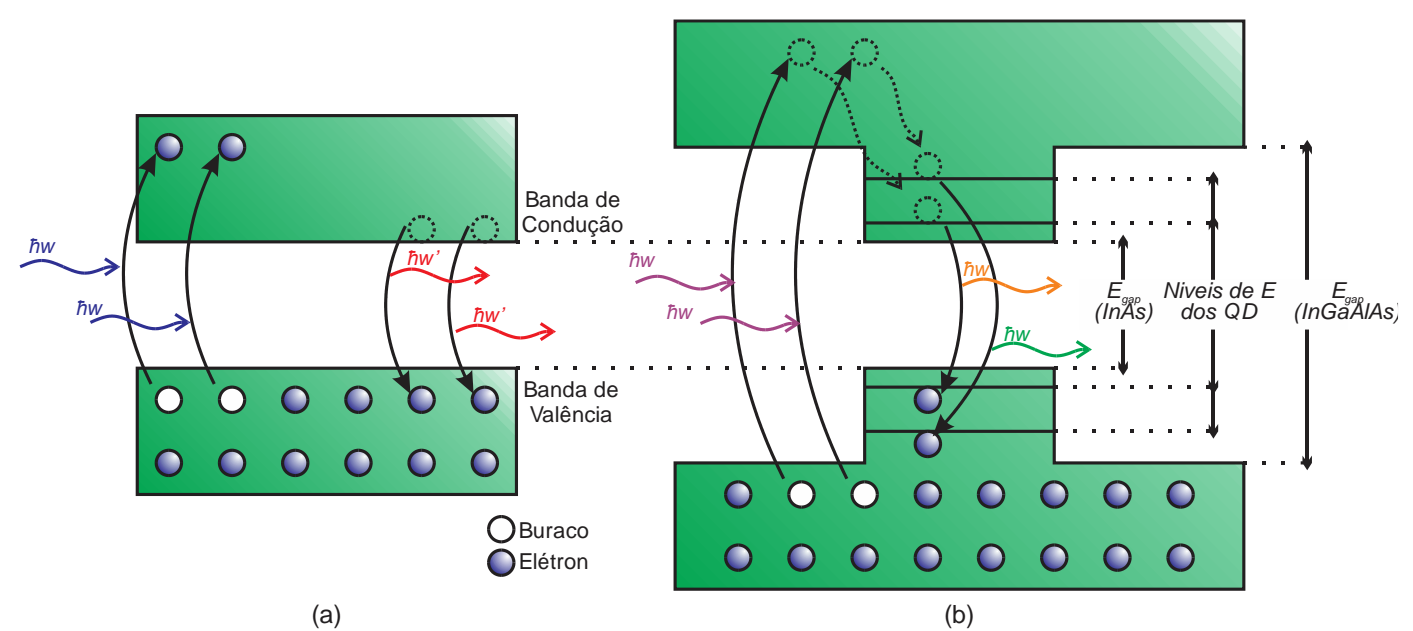

Figura 9. Processo de fotoluminescência quando o material é irradiado com fótons de energia $\hbar w$. (a) Em semicondutores maciços. (b) Em uma estrutura do tipo ponto quântico.

Para um fóton ser absorvido, deve possuir uma energia maior do que o gap do material. Se essa condição é satisfeita, com a mínima energia o fóton é capaz de promover um elétron à banda de condução, o que deixa um buraco na banda de valência, que junto com o elétron excitado se conhece como par elétron-buraco. $\mathrm{O}$ sistema, que agora se encontra num estado excitado, deve voltar ao estado fundamental pelo processo inverso, pois não há estados intermediários. O par elétron-buraco é desfeito pela liberação de energia através da emissão de um fóton com a mesma energia inicial. Mas não existe (dentro de certos limites) uma energia máxima para ser absorvida. Nesse caso o elétron pode ser excitado a um nível de energia superior ao mínimo (banda de condução). Acima da banda de condução existe um contínuo de estados disponíveis, permitindo que o elétron perca parte da sua energia por meio de processos térmicos (Pankove, 1971). Quando o elétron atinge o mínimo de energia possível (fundo da banda de condução), ele se recombina com o buraco da banda de valência, gerando um fóton com energia menor do que aquele que foi absorvido no início.

\subsubsection{1}

\section{Montagem Experimental}

$\mathrm{Na}$ figura 10 é mostrada a montagem experimental de uma medida de fotoluminescência. A fonte luminosa é um laser de argônio de comprimento de 
onda igual $514.5 \mathrm{~nm}$, cujo feixe tem sua amplitude modulada através da passagem por um chopper mecânicoo qual consiste de uma hélice que interrompe o feixe por intervalos periódicos (foi trabalhado com uma frequência de modulação próxima de $160 \mathrm{~Hz})$.

Um conjunto de espelhos direciona o feixe até à amostra. Um dos espelhos é dicróico, ou seja, tem refletividade seletiva a um determinado comprimento de onda (nesta montagem, o espelho dicróico selecionado tem refletividade para o comprimento de onda do laser). Próximo da amostra é localizada uma lente convergente que focaliza o feixe sobre a amostra, que está situada dentro de um criostato com vácuo próximo a $3 \times 10^{-6} \mathrm{mbar}$ e temperatura de $15 \mathrm{~K}$. Parte dos fótons no feixe são absorvidos pela amostra os quais geram pares elétron-buraco e outra é refletida. A radiação observada é composta por fótons do laser que foram refletidos pelas lentes e a janela do criostato, e por fótons da luminescência gerada pela amostra. A radiação volta a passar pela lente anterior e pelo espelho dicróico. O espelho dicróico remove a radiação do laser presente neste feixe, mas transmite a luminescência da amostra.

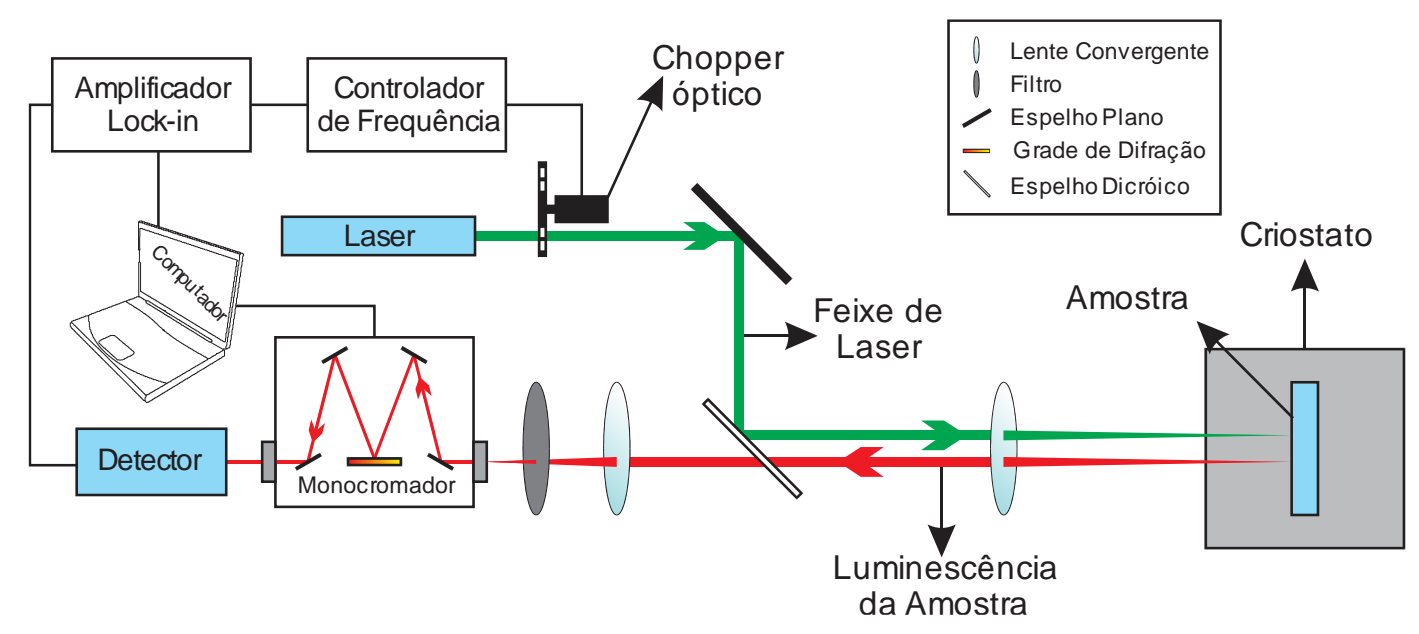

Figura 10. Montagem do experimento de fotoluminescência.

A radiação da luminescência é focalizada sobre a fenda de um monocromador através de outra lente convergente. Após passar pelo monocromador, o feixe é analisado por um detector de InGaAs. O comprimento de onda que chega de fato ao detector é controlado pelo ângulo que a grade de difração do monocromador faz com o feixe incidente. Ela roda com alta precisão por um motor de passo controlado por um computador o que permite que o 
comprimento de onda na saída seja bem definido. A leitura do detector passa para um amplificador lock-in, que através de um sinal de referência (sinal do chopper), remove sinais com frequências diferentes da modulação e faz a análise comum nível mínimo de ruído (ruídos somente na frequência de modulação). Os dados são então enviados a um computador.

\subsection{2}

\section{Microscopia de Força Atômica}

O microscópio de força atômica pode ser o mais versátil membro da família dos microscópios conhecidos como "Scanning Probe Microscopes" (SPM), os quais geram imagens pelo "sentir" ao invés do "olhar".

Os instrumentos ópticos tem limitação de resolução em objetos de 200 a 300 $\mathrm{nm}$, quase a metade do comprimento de onda da luz visível. O AFM opera pela detecção das forças intermoleculares que aparecem no sistema microscópico formado por uma ponteira e uma amostra varrida por ela. Os SPMs são basicamente compostos por uma ponteira ou agulha, materiais piezo elétricos, circuitos de realimentação e um computador com software especializado. O sensor é o componente mais importante, pode medir com resoluções da ordem de angstroms. O AFM forma imagens que são um mapa de distribuição superficial de forças (entre a ponta e a amostra) e altura, além de conseguir resoluções verticais de até 0.5 angstrom. Um aspecto importante é que a amostra pode não ser afetada fisicamente pelo AFM durante as varreduras, permitindo a repetição das medições. Trata-se de uma técnica não destrutiva.

A técnica de microscopia de força atômica (Atomic Force Microscope, AFM) criada em 1986 (Binnig, Quate, 1986), é utilizada para fazer medições com muita precisão nas superfícies dos materiais, entre elas a topografia da superfície, as forças envolvidas e suas propriedades, numa escala nanométrica. 


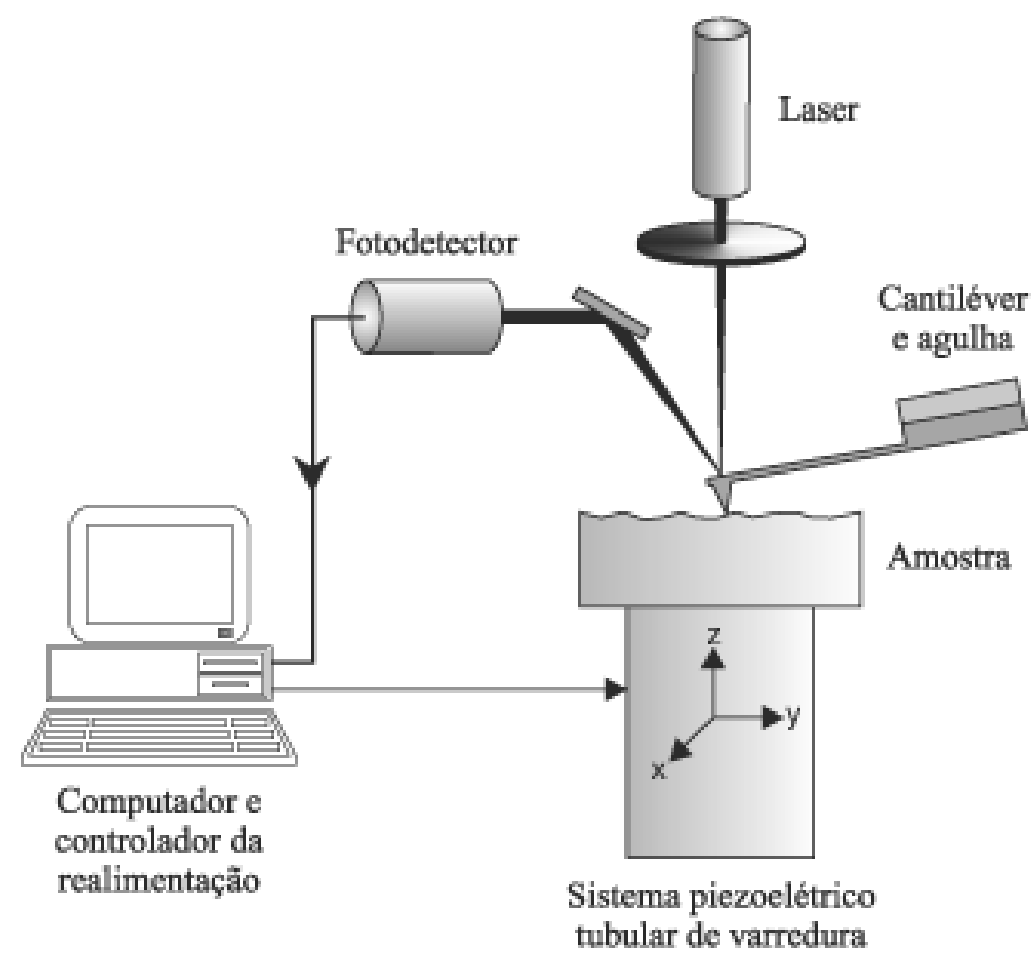

Figura 11. Ilustração do princípio de funcionamento do AFM.

O AFM tem diversos modos de operação (Zanette, 2010), mas o princípio de funcionamento para todos os tipos de operação é o mesmo: a medição de um braço (cantiléver), no qual em sua extremidade é fixada uma ponteira ou agulha; é feita a medição da deflexão do cantiléver, que é lida por um fotosensor por meio de um feixe de laser focalizado na extremidade do braço e refletido sobre o fotosensor. Essa deflexão é gerada por forças de atração ou repulsão entre a ponta e a superfície enquanto a ponteira se move pela amostra. A varredura na superfície é feita nas duas dimensões ( $\mathrm{x}$ e y). As informações de todas as medições são enviadas para um computador, o qual forma a imagem mediante um software específico.

Existem diversos modos de operação, contato, não contato e o modo intermitente "tapping".

No modo contato, a ponta faz a varredura sobre a superfície da amostra, aplicando uma força constante e sem elevar a ponta da superfície. A força aplicada está relacionada com a deflexão que experimenta a ponta mediante a constante de força do cantiléver. Portanto, trabalhar em uma determinada deflexão constante é trabalhar a uma força constante, pois são proporcionais. Assim se fixa uma deflexão de trabalho e na medida em que se faz a varredura, o cantiléver sobe 
e desce (em Z) para manter uma deflexão constante. O movimento vertical do cantiléver permite obter uma imagem topográfica da amostra que geralmente é chamada como Imagem das alturas.

No modo de contato intermitente se aplica um sinal senoidal, fazendo oscilar a ponta na sua frequência de ressonância. As varreduras se efetuam numa amplitude de oscilação constante, denominada amplitude de trabalho. O cantiléver sobe e desce (em Z) para manter essa amplitude constante em todo instante. O movimento vertical do cantiléver proporciona a imagem das alturas.

No modo de não contato também se aplica uma onda senoidal fazendo oscilar a ponta muito perto da superfície, mas sem chegar a fazer contato com a amostra. Quando a ponta oscilante passa por diferentes alturas, isso acaba gerando uma variação na frequência de oscilação. Essa variação pode ser monitorada de duas maneiras: amplitude ou fase constante, subindo ou descendo a ponta oscilante para manter um dos parâmetros constantes; e a frequência constante.

Dos diversos modos de operação do AFM, o modo utilizado para as medidas desta dissertação foi o modo de contato intermitente (tapping). Nesse modo de operação, o braço oscila numa frequência bem próxima à sua frequência de ressonância. Deste jeito, a ponta só entra em contato com a amostra por pouco tempo, motivo pelo qual não ocorre um dano na superfície da amostra. O sistema de realimentação mantém a oscilação constante do sistema (Sánchez, 2003).

$\mathrm{Na}$ figura 12 se mostra a função de força entre a ponteira e a amostra em função da distância de separação entre elas. Pode-se observar que quando a distância entre a ponteira e a amostra é muito pequena, existe uma força de repulsão entre elas. Esta força de repulsão vai diminuindo conforme se vão separando a ponteira e a amostra, até chegar à linha de força nula. Se aumenta a separação, a ponteira e a amostra experimentam uma força atrativa entre elas que aumenta conforme se vão separando, até alcançar o valor máximo de atração. Se continua aumentando a separação, a força atrativa começa a diminuir com uma tendência de atingir a linha de força nula. 


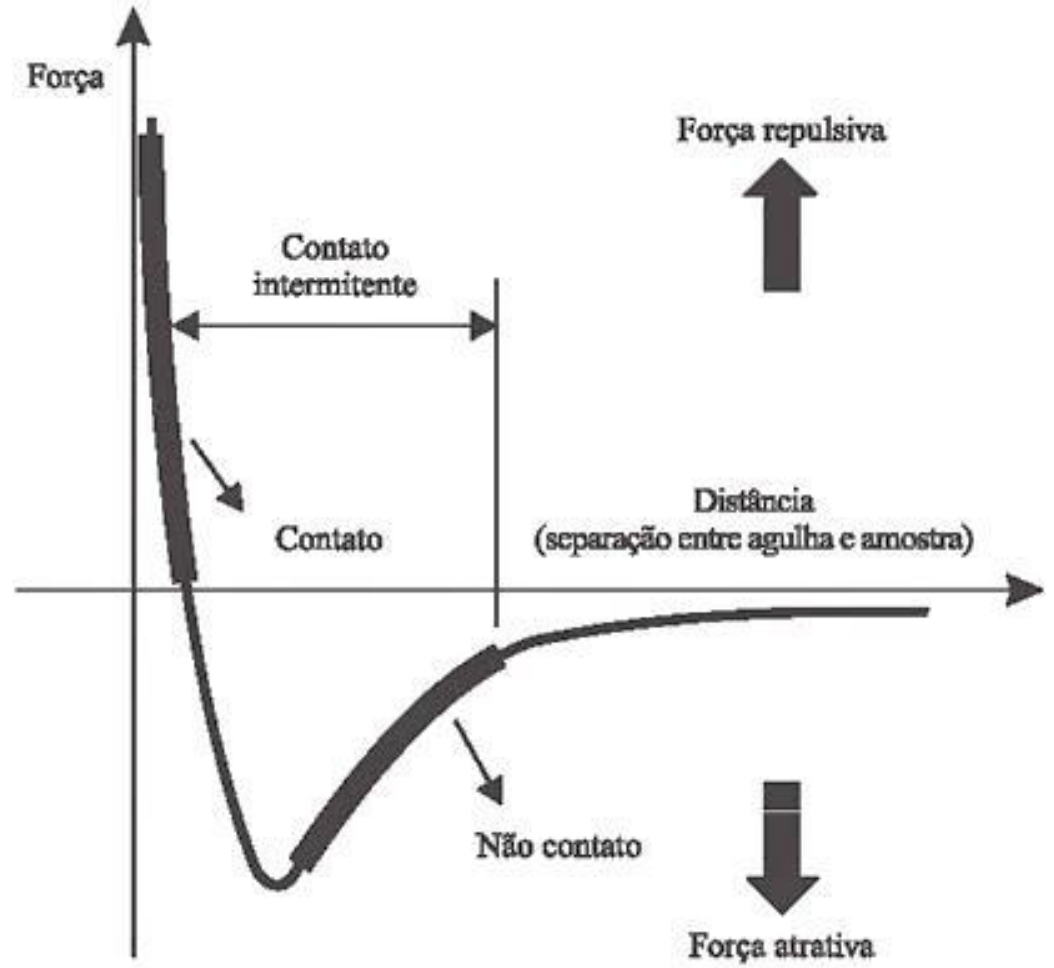

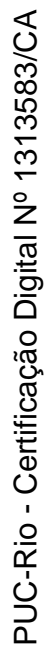

Figura 12. Energia potencial da interação entre dois objetos em função da distância. 


\section{3 Metodologia de análise dos resultados}

\section{1}

\section{Estrutura das amostras}

Todas as amostras que foram estudadas têm a mesma configuração: um substrato de InP, sobre o qual é crescido o buffer, e depositado sobre ele o material quaternário (InGaAlAs) sobre o qual os pontos quânticos são crescidos. Esta estrutura (sem o substrato) se repete, figura 13.

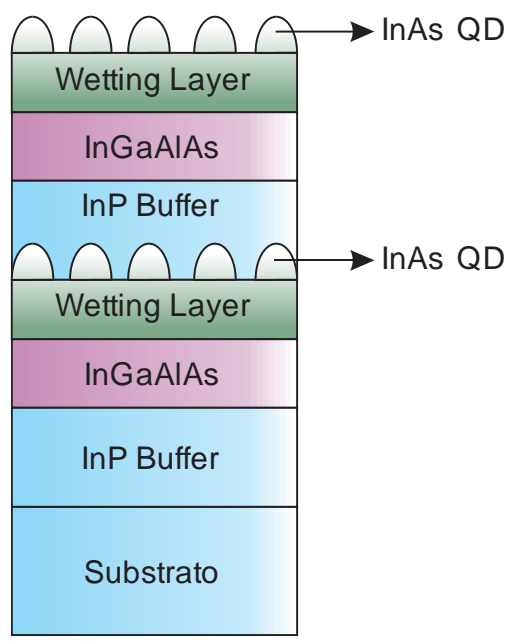

Figura 13. Estrutura das amostras.

Na tabela 1 se observa as amostras e a calibração das condições de crescimento para os pontos quânticos. Nela são apresentadas somente as camadas dos pontos quânticos, sobre as quais versará este estudo.

As condições de crescimento usadas no reator vão além das mostradas na tabela 1. Contudo, apenas para aquelas que são de interesse para o resultado, e com base em seu comportamento, são feitas as análises e, portanto, elencadas na tabela 1 . 


\begin{tabular}{|l|r|r|r|r|}
\hline \multirow{2}{*}{ Amostra } & TMIn & TC & QM & TemC \\
\cline { 2 - 5 } & (sccm) & (seg) & (ML) & ( ${ }^{\mathbf{C}}$ ) \\
\hline NR0221 & 78 & 4,8 & 2,36 & 520 \\
\hline NR0227 & 78 & 5,5 & 2,70 & 520 \\
\hline NR0228 & 78 & 6,2 & 3,05 & 520 \\
\hline NR0237 & 78 & 5,5 & 3,05 & 530 \\
\hline NR0243 & 78 & 4,8 & 2,52 & 525 \\
\hline NR0244 & 78 & 4,8 & 2,18 & 515 \\
\hline NR0302 & 78 & 4,8 & 1,98 & 510 \\
\hline NR0303 & 78 & 4,8 & 2,79 & 535 \\
\hline NR0304 & 78 & 4,1 & 2,01 & 520 \\
\hline NR0305 & 78 & 6,9 & 3,39 & 520 \\
\hline NR0306 & 100 & 4,8 & 3,02 & 520 \\
\hline NR0307 & 120 & 4,8 & 3,63 & 520 \\
\hline NR0308 & 60 & 4,8 & 1,82 & 520 \\
\hline
\end{tabular}

Tabela 1. Condições de crescimento dos pontos quânticos. TMIn: TMIn Q source; TC:

Tempo de crescimento; QM: Quantidade de material; TemC: Temperatura de

\section{Crescimento}

As amostras são de duas famílias diferentes, a família de amostras NR02XX e a família de amostras NR03XX, estas famílias de amostras foram crescidas em épocas diferentes (diferença de 4 meses), pois se fizeram estudos de altura e densidade de pontos quânticos para as primeiras amostras (NR02XX) e com os resultados foi proposta uma série nova de amostras (NR03XX) para complementar os estudos feitos e ter uma análise de outros valores de parâmetros de crescimento.

A amostra adicional (NR0319) foi crescida, da qual foram excluídas as camadas de pontos quânticos, trata-se de uma amostra de referência. Isto foi feito com a intenção de caracterizar a fotoluminescência do material quaternário (InGaAlAs), o modelo da amostra é mostrado na figura 14.

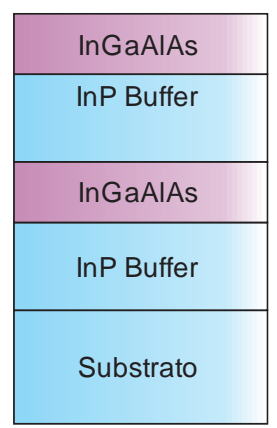

Figura 14. Estrutura da amostra NR0319. 


\section{2 \\ Metodologia de análise de fotoluminescência}

Foram feitas as medidas de fotoluminescência para cada amostra, tentando manter as mesmas condições de caracterização para todas. As medições se fizeram com quatro diferentes potências do feixe de laser incidente sobre a amostra $(50 \mathrm{~mW}, 150 \mathrm{~mW}, 300 \mathrm{~mW}$ e $500 \mathrm{~mW})$, entre uma faixa de energia de 1.2 até $0.57 \mathrm{eV}(1033$ até $2175 \mathrm{~nm})$. No criostato as condições são bem controladas, temperatura de $15 \mathrm{~K}$ e vácuo perto de $3 \times 10^{-6}$ mbar. As fendas no monocromador sempre são as mesmas: as condições de luminosidade na sala ótica (sala onde fica a montagem da fotoluminescência) são mantidas sempre iguais.

Para os sinais de fotoluminescência obtidos para cada amostra, é realizado um ajuste das curvas para se identificar as diferentes emissões de radiação. $\mathrm{Na}$ figura 15 se mostra o sinal emitido pela amostra NR0307 para diferentes potências do laser.

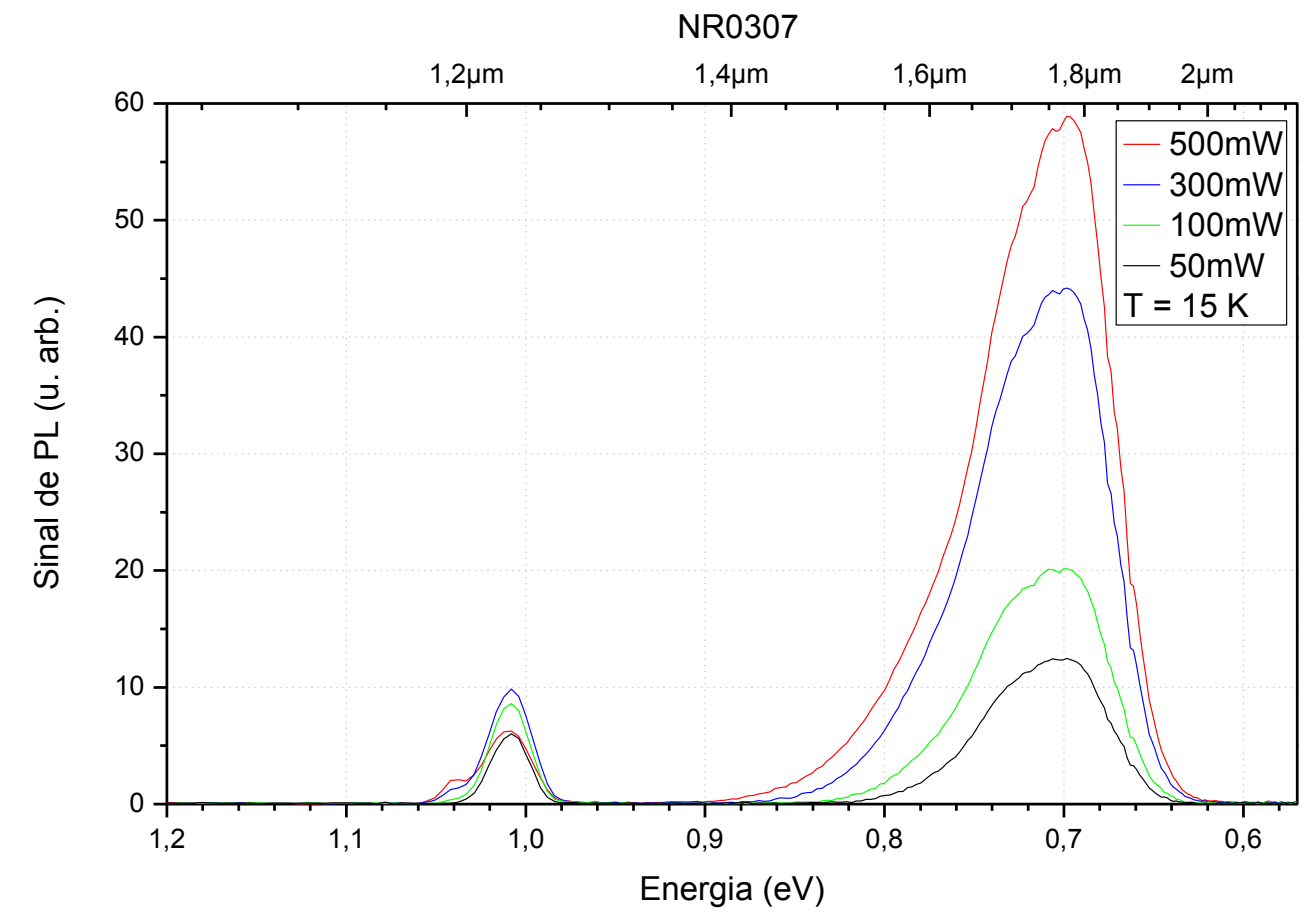

Figura 15. Medida de fotoluminescência com diferentes potências do feixe de laser incidente sobre a amostra NR0307 realizadas a $15 \mathrm{~K}$.

$\mathrm{Na}$ figura 16 se mostra o ajuste estabelecido para o sinal da amostra NR0307 para uma potência do laser de $300 \mathrm{~mW}$. O ajuste é feito para a parte da 
fotoluminescência do material quaternário para emissões de energias em torno de 1 a $1,1 \mathrm{eV}$ com base na amostra de referência NR0319. O sinal de energias mais baixas de $0,9 \mathrm{eV}$ vem dos pontos quânticos. $\mathrm{O}$ ajuste realizado para o sinal de fotoluminescência gerado pelos pontos quânticos é feito com gaussianas de tal forma que sua soma delas seja o mais semelhante à curva total de fotoluminescência. A escolha de duas ou mais gaussianas é determinada pela simetria que se observa na curva, estas gaussianas correspondem ao nível fundamental de energia e primeiro excitado dos pontos quânticos como será mostrado mais adiante.

Os resultados dos ajustes para os sinais de fotoluminescência de todas as amostras estão no apêndice $\mathrm{C}$ com a intenção de não saturar o documento com muitos gráficos.

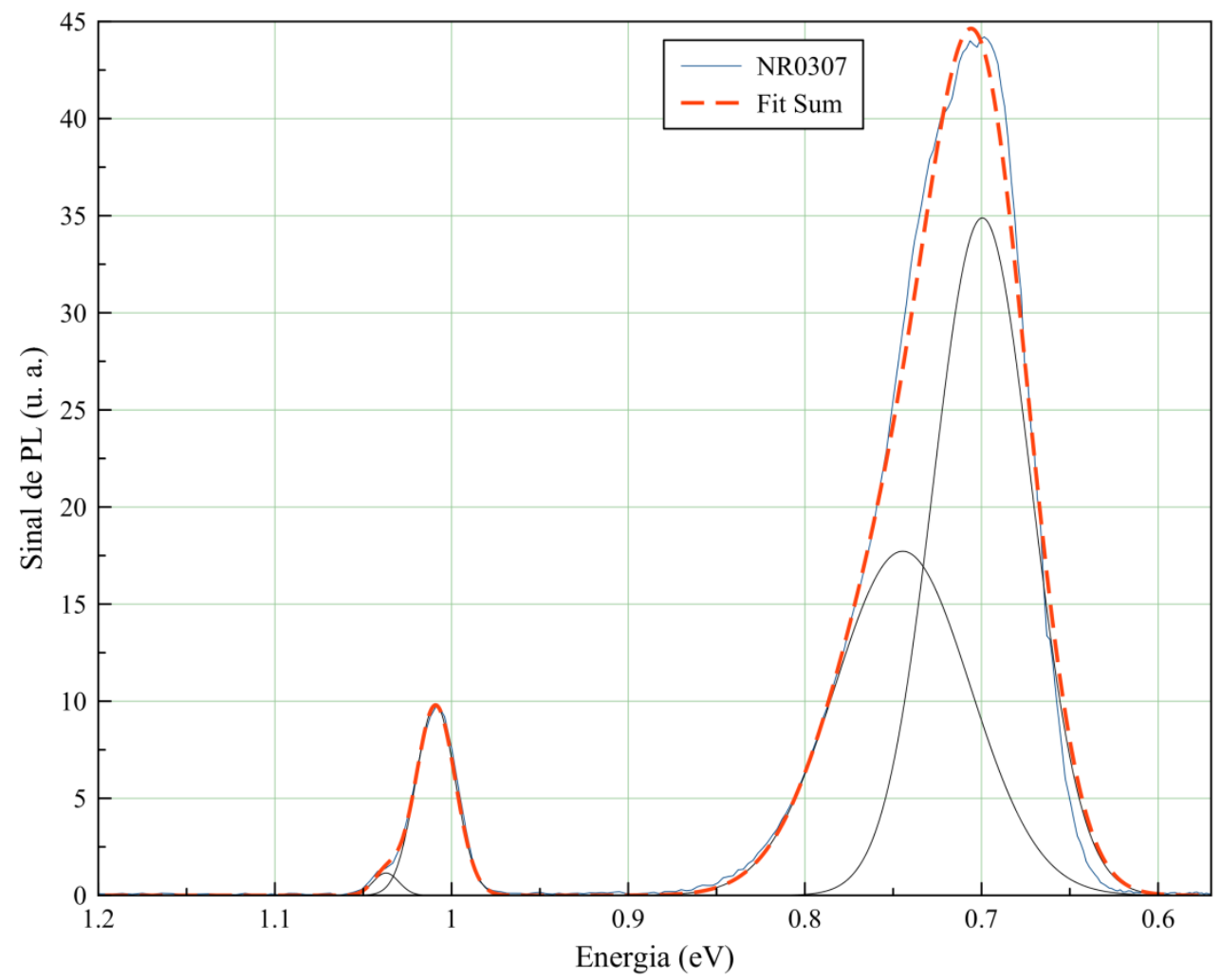

Figura 16. Ajuste da medida de fotoluminescência (300mw) da amostra NR0307 realizada a $15 \mathrm{~K}$.

A fotoluminescência da amostra NR0319 está representada na figura 17. Esta medida foi feita com objetivo de conhecer a fotoluminescência do material 
quaternário e, assim, poder identificá-la nas medidas de fotoluminescência das outras amostras.

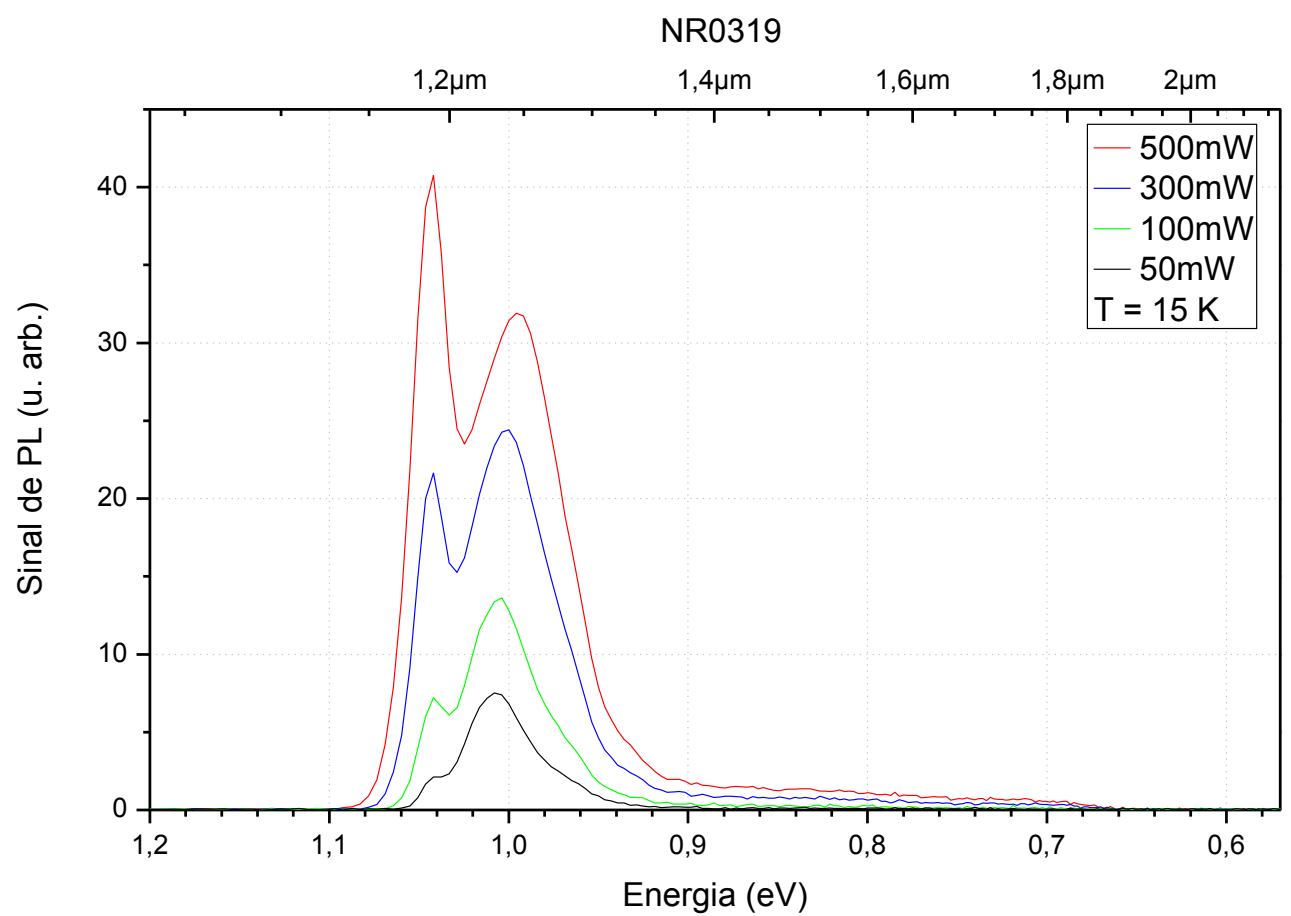

Figura 17. Medida de fotoluminescência com diferentes potências do feixe de laser incidente sobre a amostra NR0319, medidas feitas a $15 \mathrm{~K}$.

\section{3 \\ Metodologia de análise de microscopia de força atômica (AFM)}

A caracterização das propriedades morfológicas das amostras consta da informação das alturas e densidade dos pontos quânticos. Esses dados são obtidos mediante técnicas de AFM.

Para cada amostra se mede as alturas dos pontos quânticos e se faz um histograma da sua distribuição, idealmente os pontos teriam a mesma altura como na figura 18 (a) (região superior), mas na realidade isto não acontece em função da natureza aleatória do processo de auto-organização. As amostras apresentam pontos quânticos de diferentes alturas, tendo maior presença de determinadas alturas como se vê na figura 18 (a) (região inferior). Neste caso, as amostras heterogêneas serão ajustadas com uma distribuição log-normal (Bergmann, 2008) sendo a altura característica de cada amostra o valor da média da distribuição e o erro o desvio padrão, esta distribuição é uma das mais frequentemente observadas 
na natureza e descreve um grande número de fenômenos físicos, biológicos e inclusive sociológicos. Esta distribuição é constantemente observada como resultado de vários processos de cristalização (Bergmann, 1997), especialmente em processos aleatórios de nucleação e crescimento Random Nucleation and Growth (RNG) que usualmente resultam em distribuições log-normal para sua classificação pela altura dos pontos quânticos crescidos (Bergmann, 1998).
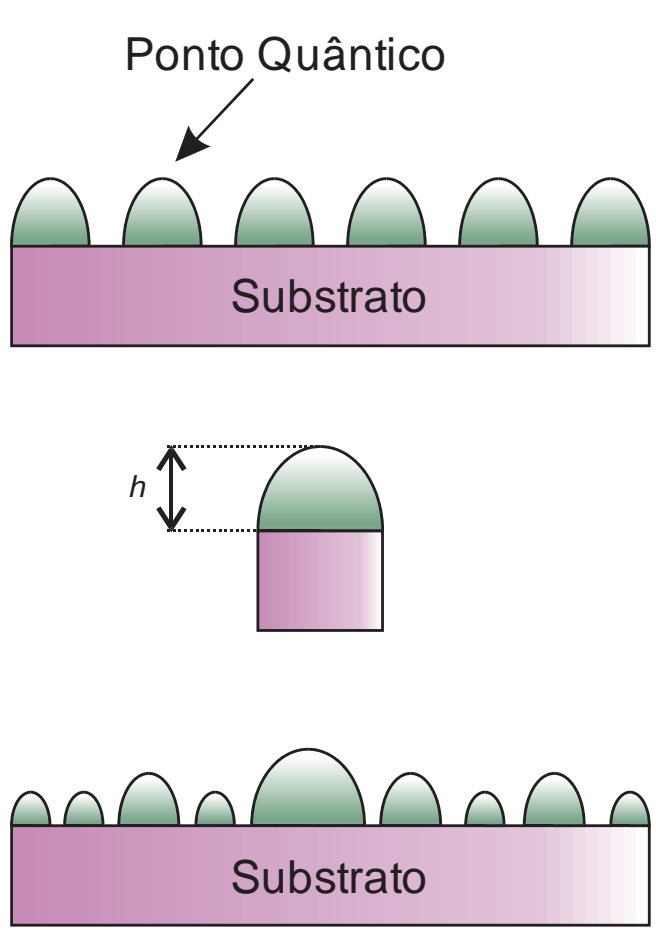

(a)
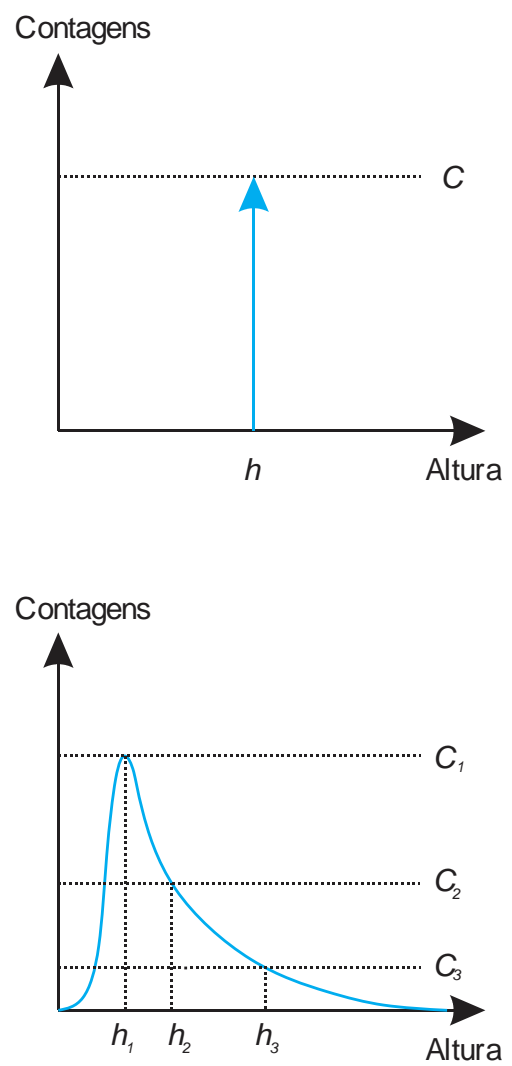

(b)

Figura 18. Amostras de pontos quânticos com alturas homogêneas (região superior) e heterogêneas (região inferior). Em (a) temos a topografia e em (b) os histogramas correspondentes. Neste caso, a amostra heterogênea apresenta uma distribuição lognormal.

O valor da densidade é facilmente calculado. Tendo os dados das alturas dos pontos quânticos registrados (número de pontos quânticos) e conhecendo a área medida, pode-se calcular a quantidade de pontos quânticos presentes numa área determinada. O processo de caracterização é feito em diferentes regiões de cada amostra para garantir a representatividade da medida. 
Na figura 19 pode-se observar o esquema de duas amostras, uma com alta densidade de pontos quânticos (a) e a outra com baixa densidade (b).

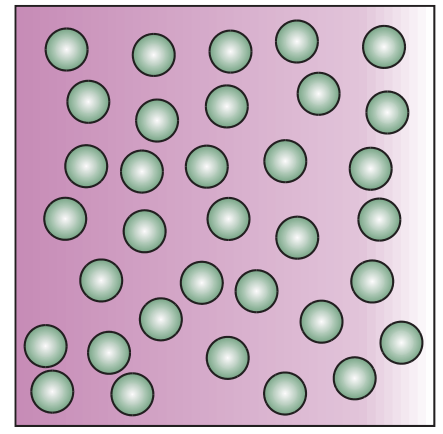

(a)

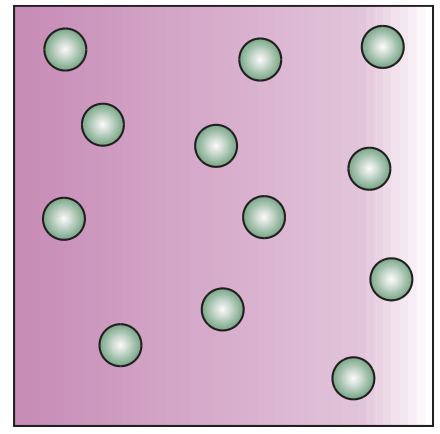

(b)

Figura 19. Esquema de uma amostra, os pontos quânticos são representados por círculos. Como pode ser observado, a densidade em (a) é maior que em (b).

A forma convencional de determinar as alturas dos pontos quânticos das imagens de AFM é explicada em seguida.

\subsection{1}

Processamento convencional das imagens de AFM

As imagens obtidas pelo AFM não podem ser tratadas diretamente, precisam ser ajustadas para corrigi-las, pois apresentam erros próprios dos fenômenos de histereses e drift dos piezoeléctricos (Ruiz, 2013) do AFM como se observa na figura 20 , na parte (a) a vista superior, na parte (b) uma visualização em 3 dimensões e na parte (c) uma vista transversal. 


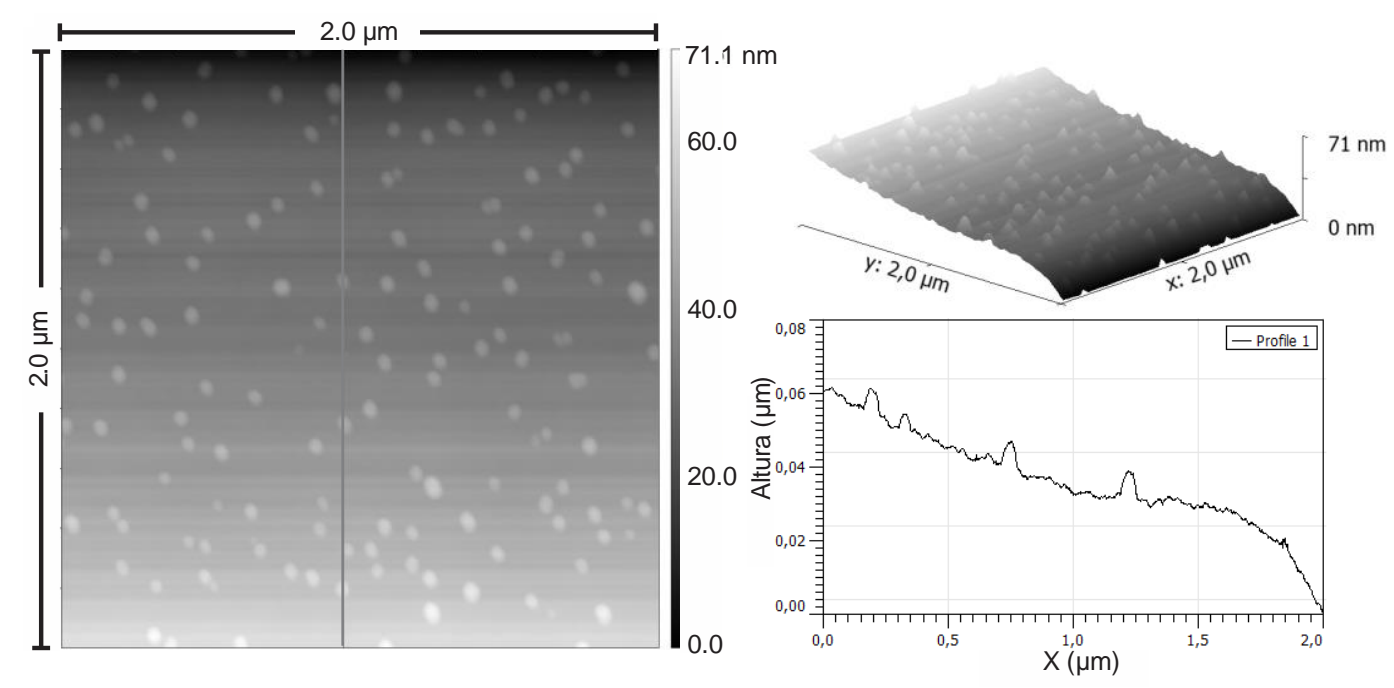

Figura 20. Imagem gerada por o AFM. (a) Vista superior. (b - parte superior) vista em 3D. (b - parte inferior) vista transversal.

Existem diversas ferramentas para fazer a correção da imagem. Geralmente o software do AFM tem opções para fazer melhorias na imagem. O software utilizado foi Gwyddion, um software livre. O nivelamento do plano é a primeira função aplicada. O plano é calculado a partir de todos os pontos da imagem e é subtraído de seus dados, gerando uma imagem como na figura 21, na parte (a) a vista superior, na parte (b) uma visualização em 3 dimensões e na parte (c) uma vista transversal. Independente da deformação da imagem gerada pelo AFM, é possível fazer o nivelamento do plano para melhorá-la, porém, é provável que se tenha que fazer mais processos para ter uma imagem pronta para ser analisada, pois a ferramenta subtrai precisamente um plano (uma rampa na vista transversal). Depois, são utilizadas outras opções para terminar de fazer a correção e obter uma imagem "plana" que se possa analisar. Pode-se encontrar no site do software uma explicação mais detalhada de cada ferramenta (http://gwyddion.net/). O software tem a possibilidade de transportar os valores das alturas, estabelecendo o ponto de menor intensidade da imagem como o zero e ajustando todos os valores das outras alturas. Por exemplo, uma imagem pode ter sua altura mínima igual a $32 \mathrm{~nm}$ e a máxima igual a 46nm. Com a ferramenta, as alturas da imagem são estabelecidas entre $0 \mathrm{nme} 14 \mathrm{~nm}$. Após fazer as correções da imagem, o resultado que se espera para poder trabalhar com a imagem é algo similar àfigura 22, na parte (a) a vista superior, na parte (b) uma visualização em 3 dimensões e na parte (c) uma vista transversal. 

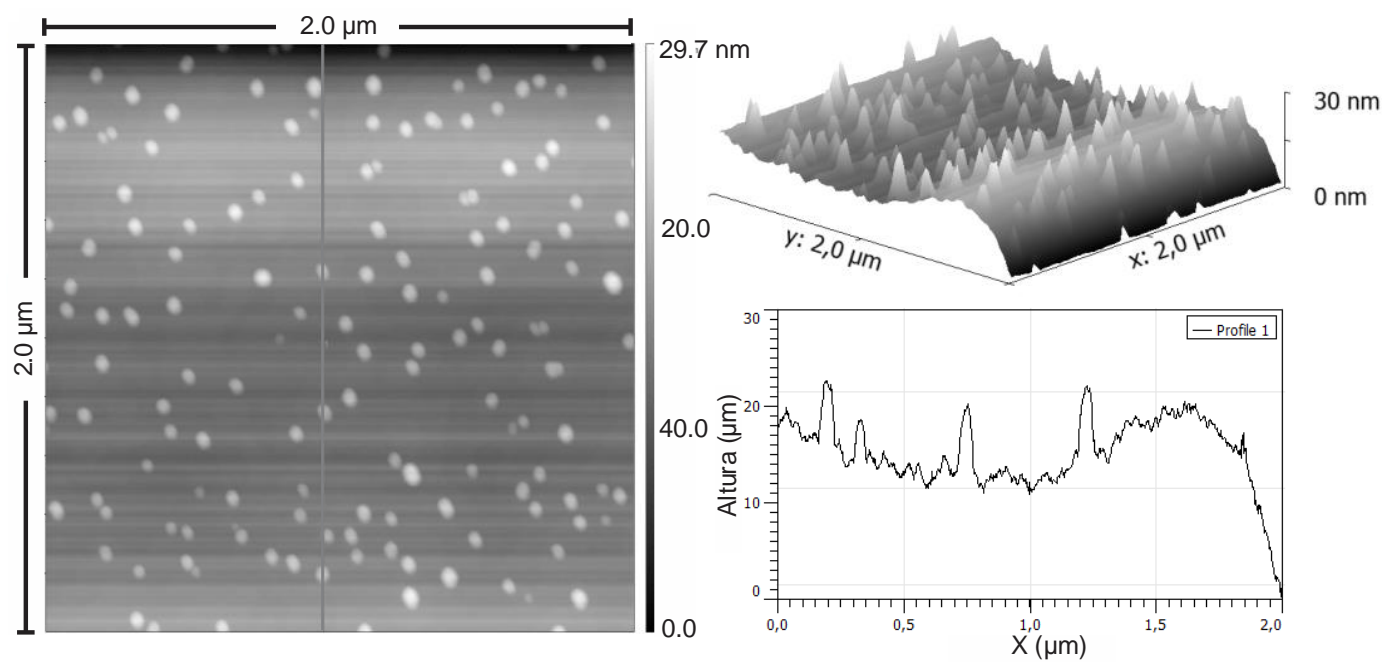

Figura 21. Imagem gerada por o AFM depois do processo de nivelamento do plano. (a) Vista superior. (b - parte superior) vista em 3D. (b - parte inferior) vista transversal.
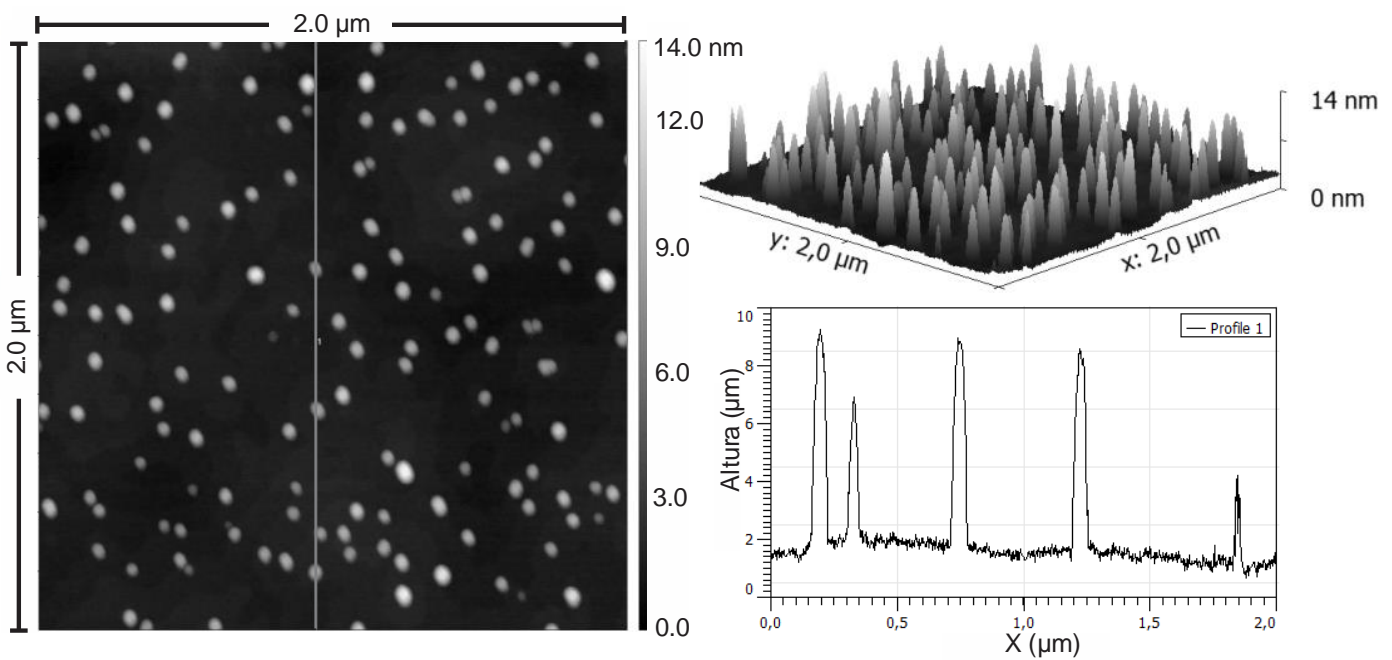

Figura 22. Imagem gerada por o AFM depois dos processos de nivelamento do plano e demais correções necessárias. (a) Vista superior. (b - parte superior) vista em 3D. (b - parte inferior) vista transversal.

A imagem é exportada para outro software (FIJI - ImageJ) para que os pontos sejam analisados. Existem diferentes ferramentas e softwares para fazer a análise da imagem, mas o software FIJI possui muitas ferramentas prontas para fazer diferentes análises além da possibilidade de criar novas ferramentas e programar sobre ele scripts para realizar processos que precisem ser repetidos, que sejam mais especializados ou particulares e complexos. A forma exportada para o FIJI é em formato bmp (mapa de bits) que não contém a informação real 
das dimensões e altura, é apenas um mapa com valores de cinza em cada pixel. Por isso é necessário fazer uma calibração da altura e das dimensões da imagem para obter os dados reais das amostras.

Da imagem no software do AFM se obtém a altura real dos pontos, tomando o valor máximo de toda imagem (14 nm, por exemplo). A imagem em cinza exportada ao FIJI é convertida em formato de 8 bits, tendo assim o ponto mais alto com um valor de 255 e o mais baixo com um valor de 0 , limitando a resolução da altura da imagem a o valor máximo da imagem dividido entre 255 (0.05 nm nesse caso). A calibração feita é uma função linear que para o pixel com valor de 0 corresponde a $0 \mathrm{~nm}$ e o pixel com valor de 255 corresponde o valor máximo da altura obtida (14nmnesse caso).

É necessário fazer a calibração das dimensões, existem diversos softwares para ler as imagens do AFM e conhecer suas dimensões, foi usado o software Gwyddion para obter as dimensões reais da imagem (exemplo $2000 \mathrm{~nm}$ x 2000 $\mathrm{nm}$ ), com esse valor estabelecemos a escala em ImageJ (se temos uma imagem de 1024 pixels x 1024 pixels se estabelecem no software que 1024 px $=2000 \mathrm{~nm}$ ). Feito isso, a imagem fica pronta para fazer a análise.

Para o processo de contagem dos pontos e suas alturas para uma amostra pronta para ser tratada como na figura 23 (a), são utilizados softwares especializados em processamento de imagens de AFM como o WSxM (Horcas, 2007), é estabelecido um limite de altura (Threshold) em toda a imagem, para detectar os pontos (partes que ficam acima do Threshold) como na figura 23 (b) as regiões da cor azul, isto é feito com o software WSxM com a ferramenta Flooding (WSxM, 2015), a altura do Threshold é definida pelo usuário e seu valor pode variar de experimento a experimento em função da altura da base da amostra. Tendo os pontos quânticos (regiões) selecionados, se faz uma leitura da parte mais alta de cada ponto quântico (pixel com a maior intensidade, ou mais claro) como se vê na figura 23 (c). Tendo os valores da altura máxima de cada ponto, se faz um histograma das alturas, com a quantidade de pontos e a área medida se faz o cálculo da densidade de pontos na amostra. Softwares como WSxM e outros como o Gwyddion oferecem ferramentas para fazer este processo, por isso estes softwares são amplamente usados para determinar as alturas dos pontos quânticos (Zhu, 2013; Zribi, 2013). 


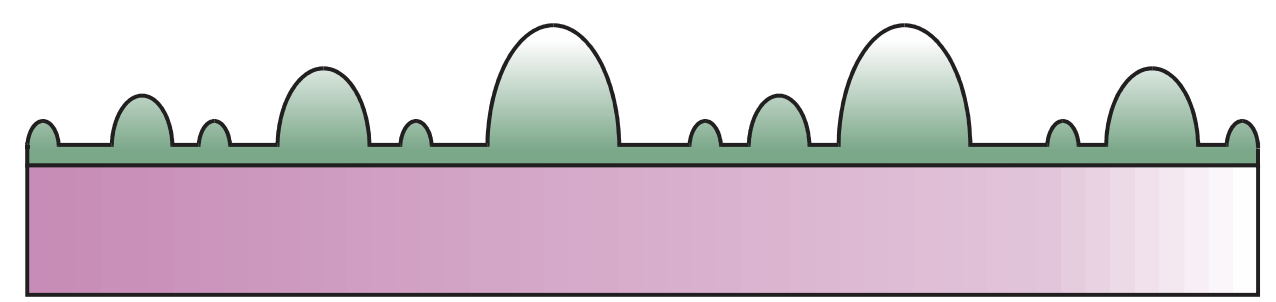

(a.)

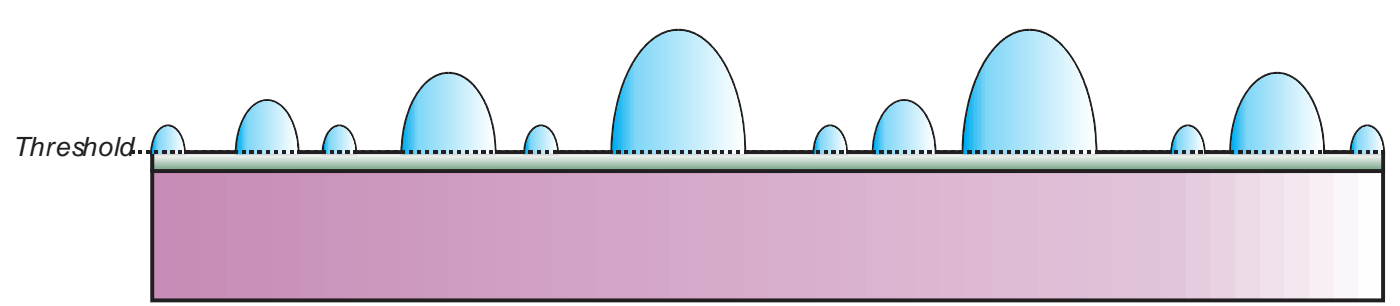

(b.)

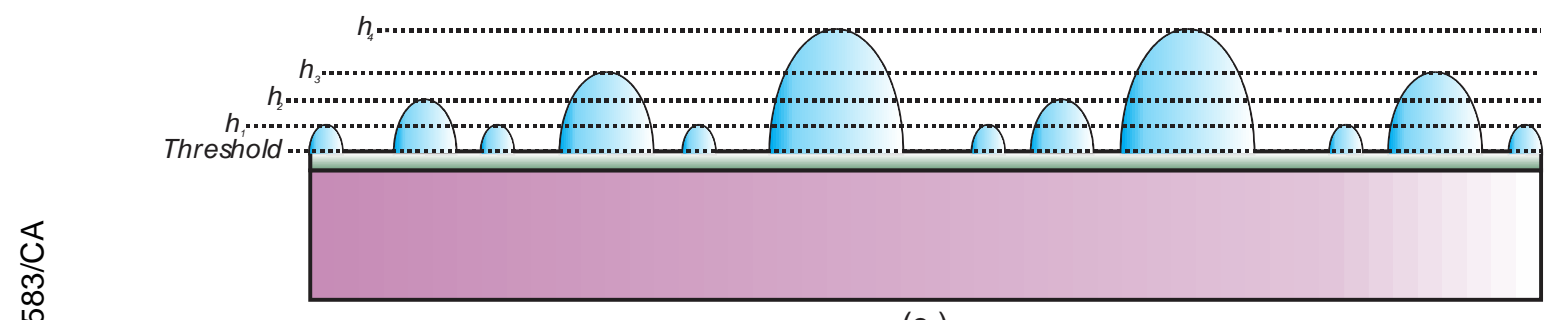

(c.)

Figura 23. Processo de contagem de pontos e alturas. (a) Vista transversal de uma imagem pronta para a análise. (b) Threshold estabelecido para encontrar pontos (regiões azuis). (c) Vista transversal das alturas máximas de cada ponto.

\subsection{2}

\section{Otimização no processamento das imagens de AFM}

A metodologia desenvolvida neste trabalho para determinar a altura de um ponto quântico não parte da base do material. Note que embaixo dos pontos existe uma fina camada (Wetting Layer). Na figura 24 se observa que a medida da altura do ponto deve ser feita da diferença entre a parte mais alta do ponto e o que definimos como a base do ponto. 


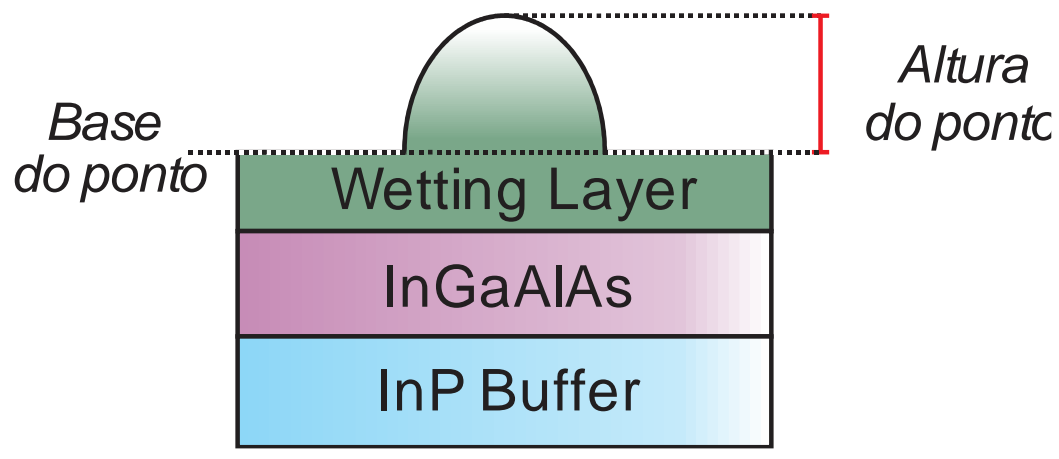

Figura 24. (a) Imagem da superfície de uma amostra. (b) Projeção da linha ressaltada na parte (a).

No final do crescimento de todas as camadas da amostra, a altura da base onde estão os pontos quânticos não é igual para toda a amostra. Se fossem retirados os pontos quânticos, a superfície da amostra teria forma irregular (Lee, 2009). Na figura 25 se evidencia uma representação do corte transversal da superfície da amostra.

Se for definida a mesma base (threshold) dos pontos para toda a amostra, as medidas das alturas dos pontos seriam erradas. Por exemplo, na figura 25 (a) é estabelecido um threshold adequado para as bases dos pontos um e dois, mas se são medidas com a mesma base as alturas dos outros pontos, elas estariam superestimadas.

Na figura 25 (b) se estabelece um threshold adequado para os pontos 4, 5, 6 e 10, mas se encontram erros em outros pontos, algumas medidas são mais altas como no ponto oito, outras subestimadas como nos pontos dois e três. Na figura 25 (c) é estabelecido um threshold adequado para os pontos com a base mais alta como o ponto oito. O problema na estimação da altura continua existindo e os pontos que ficam embaixo do threshold não são levados em consideração.

Desse modo, o ideal é ter uma altura de base para cada ponto a exemplo da figura $25(d)$.

O software FIJI possui uma ferramenta chamada Auto Local Threshold, que divide a imagem em regiões de tamanho determinado pelo usuário e calcula um threshold para cada divisão da imagem, podendo, desta forma, garantir uma medida mais próxima à realidade da imagem. 


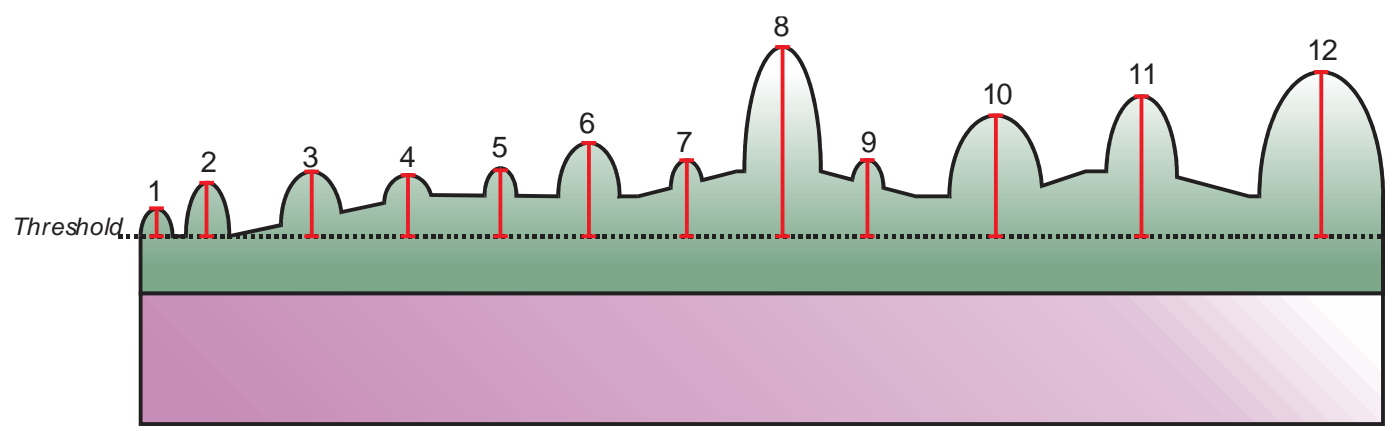

(a.)

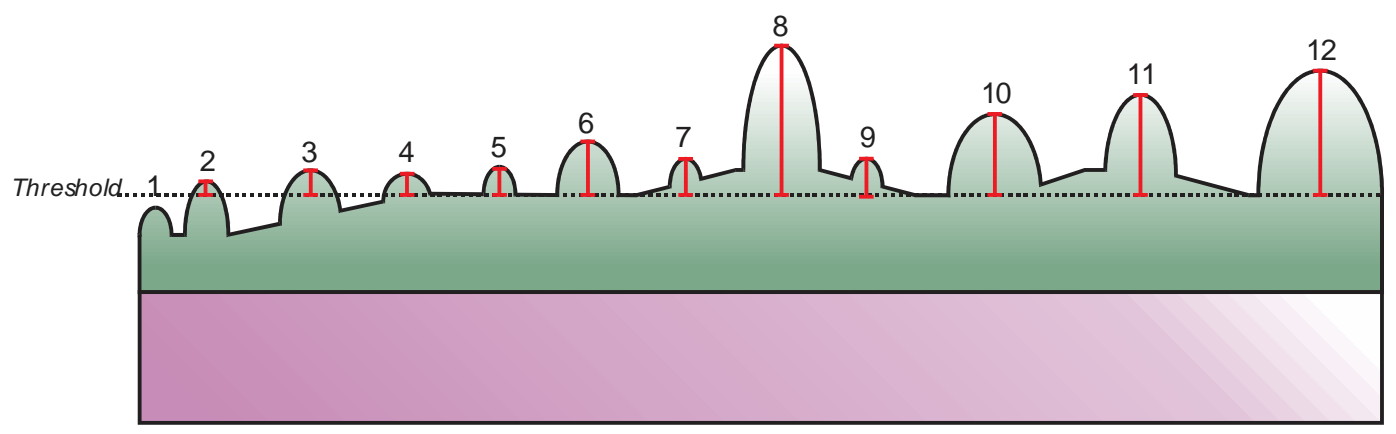

(b.)

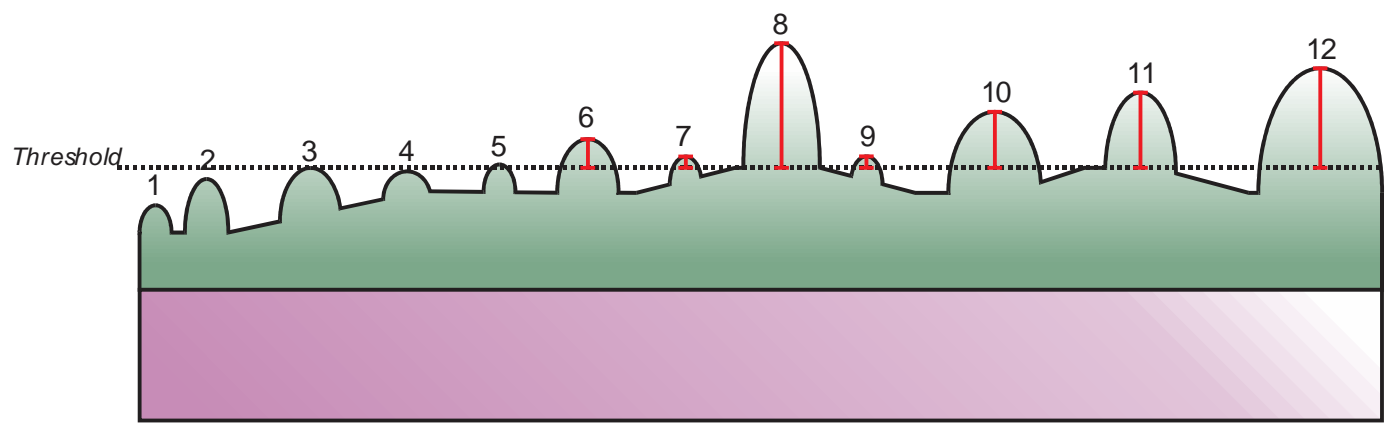

(c.)

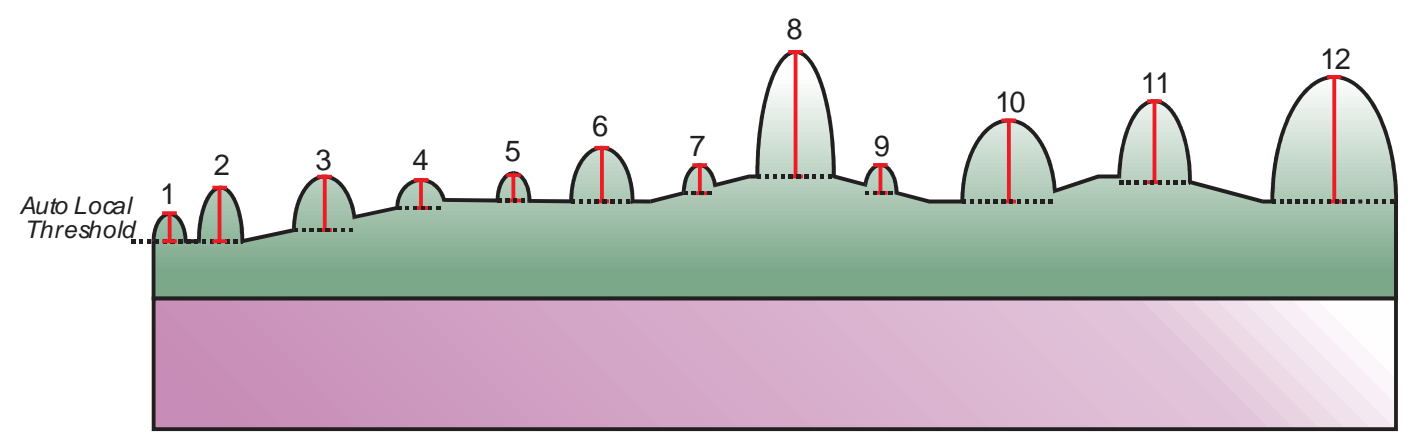

(d.)

Figura 25. Representação de uma amostra de pontos quânticos com diferentes alturas de threshold. (a) Altura de threshold baixa. (b) Altura de threshold média. (c) Altura de threshold alta. (d) Altura de threshold por regiões.

O software tem nove algoritmos para determinar o Auto Local Threshold. Cada um dos algoritmos é detalhado no site do software (http://fiji.sc/Fiji). Dependendo do método e seus parâmetros, o software identifica os pontos 
quânticos com diferentes sensibilidades. Na figura 26 é apresentada a imagem original e o resultado dos nove métodos, que podem variar dependendo dos parâmetros de configuração para cada um deles.

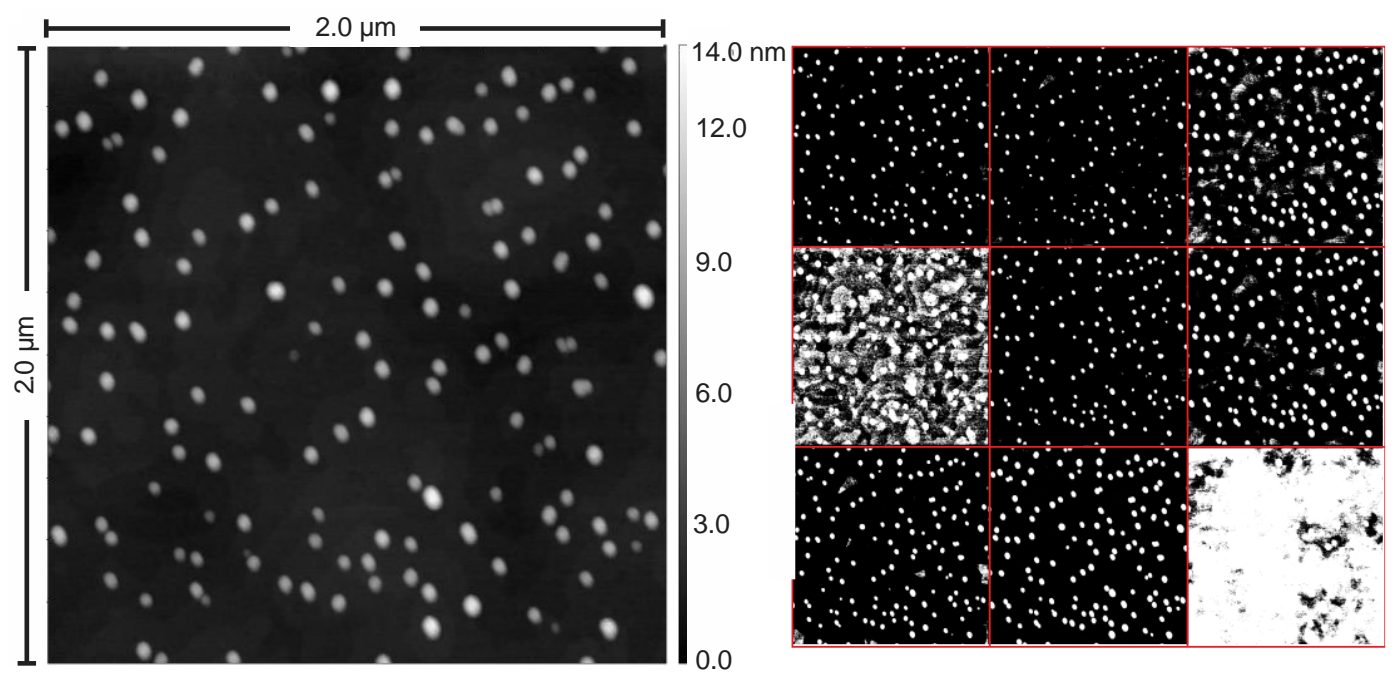

Figura 26. Imagem da superfície de uma amostra. (a) Imagem pronta para ser processada. (b) Resultados dos nove métodos de Auto Local Threshold com os parâmetros default.

Desde que se tenha a imagem pronta para ser processada, é possível fazer uma análise um a um de cada ponto quântico. Na figura 27 (a) é apresentada a amostra pronta para ser processada e na parte (b) está presente uma projeção de uma linha de superfície mostrada na parte (a), na qual se pode determinar com maior exatidão a altura real do ponto.

O software FIJI tem a possibilidade de gerar MACROS, que gravam uma série de comandos aplicados sobre uma imagem, que podem então ser repetidos para um conjunto de imagens.

Existe a possibilidade de que dois ou mais pontos coalesçam como se pode ver na figura 28 na parte (a) onde os pontos começam o crescimento e na parte (b) onde se observa dois pontos coalescidos. Para estes casos, existe uma função chamada Watershed que cria linhas de separação em pontos do contorno com mudanças de curvatura. Desta forma, pontos coalescidos são separados em 20 que se pode observar na parte (c). Este processo se observa na figura 29 nos círculos vermelhos. 

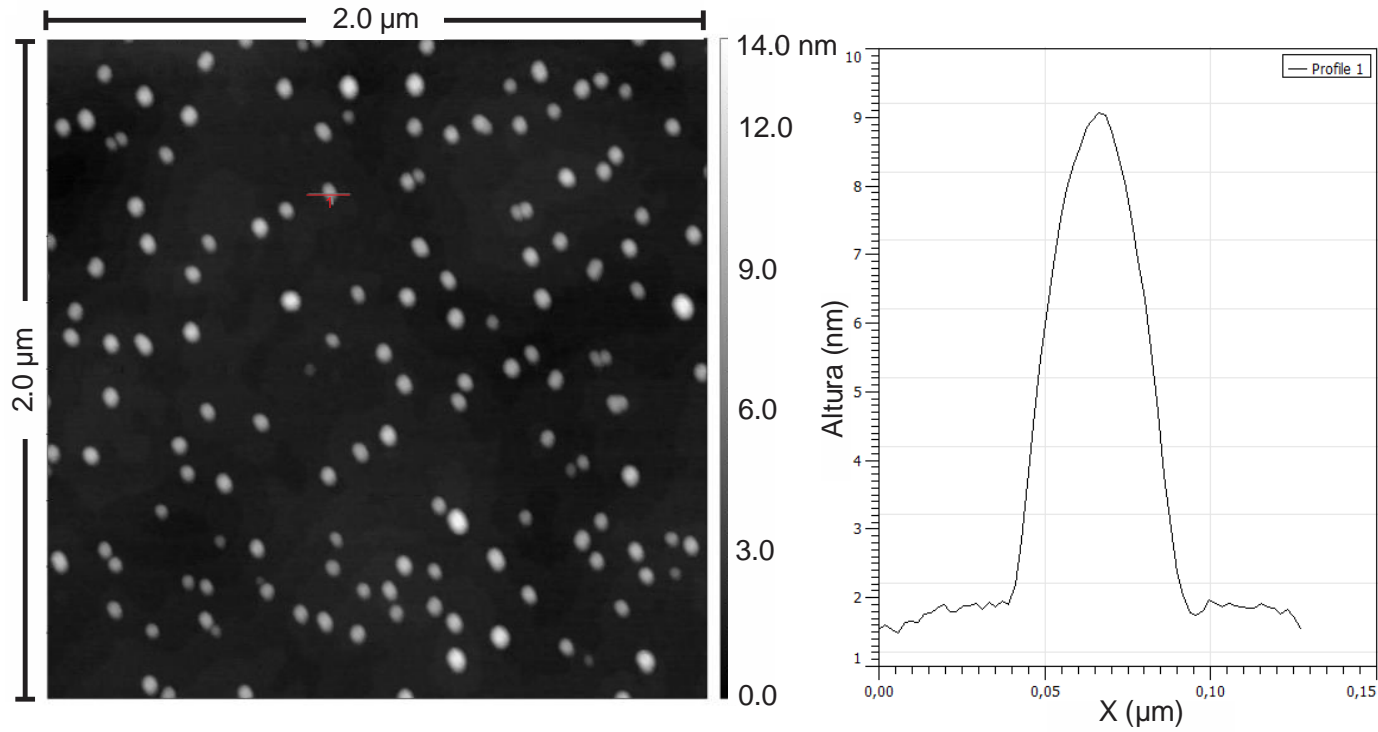

Figura 27. (a) Imagem da superfície de uma amostra. (b) Projeção da linha ressaltada na parte (a).

Em alguns casos, os métodos de Auto Local Threshold podem reconhecer alguns pixels ou pontos pequenos como os vistos na figura 29 nas ovais verdes. Estes pontos podem ser eliminados com um limiar de tamanho, preservando apenas os pontos que se deseja medir.

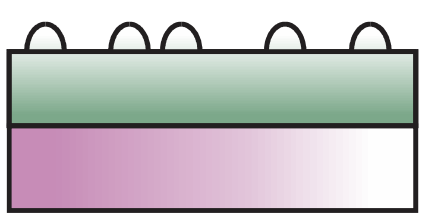

(a)

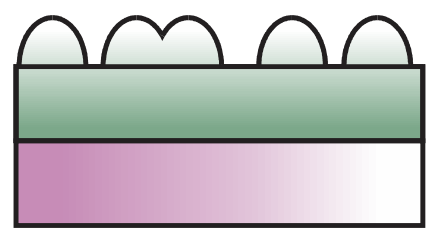

(b)

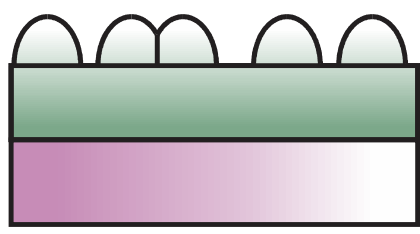

(c)

Figura 28. Representação do crescimento de pontos coalescendo. (a) Pontos crescendo. (b) Pontos coalescidos. (c) Pontos coalescidos divididos pelo método Watershed.

Com o conhecimento de todas estas ferramentas e opções, foi desenvolvido o método de otimização no processamento das imagens prontas para serem analisadas. Foi criado um Macros que transforma a imagem em 8 bits, faz a calibração das alturas e dimensões da imagem, seleciona diferentes pontos da imagem (três para nossas análises) mediante coordenadas dadas pelo usuário e salva os dados de cada um dos pontos. 
São executados os nove métodos para determinar o Auto Local Threshold, e cada um deles com diferentes valores de parâmetros e tamanho das regiões. Sendo executadas mais de 10.000 combinações de métodos para determinar o Auto Local Threshold. É gerado um arquivo com as informações de cada método e a configuração de cada um, os valores das alturas máximas e mínimas e a área dos três pontos estabelecidos no começo da Macro. Estes valores são comparados às alturas de referência que se obtiveram de cada ponto presente na figura 27 , e se calcula os erros das medições com a finalidade de determinar assim a melhor configuração para que essa imagem tenha uma medida mais confiável.

Com os valores dos parâmetros da configuração mais adequada, é executada outra Macro que faz a conversão da imagem para outra de 8 bits, com a calibração das alturas e das dimensões da imagem. Após o processo de reconhecimento das regiões de interesse pelo Auto Local Threshold, os pontos que coalesceram são separados e os pontos menores do que o tamanho mínimo estabelecido são descartados.

Na figura 29 (a) é possível observar uma seção de uma imagem pronta para ser processada. Na figura 29 (b) é realizado o Auto Local Threshold e são identificados os problemas de dois pontos coalescendo e alguns pixels reconhecidos como pontos quânticos (regiões de interesse). Na figura 29 (c) é feita a separação dos pontos coalescidos mediante a ferramenta Watershed. $\mathrm{Na}$ figura 29 (d) está presente a imagem original e os pontos escolhidos para serem analisados. Nela nota-se que os pontos coalescidos são considerados separadamente, e os pequenos pixels ou pontos pequenos não fazem parte dos pontos finais que são analisados. 


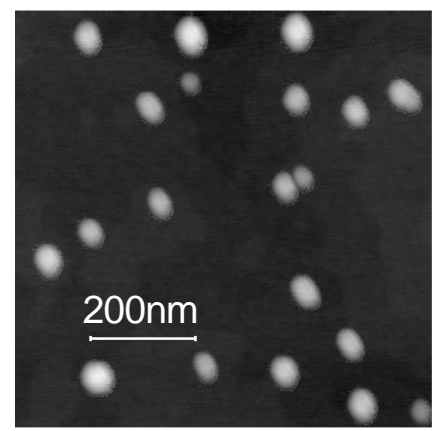

(a)

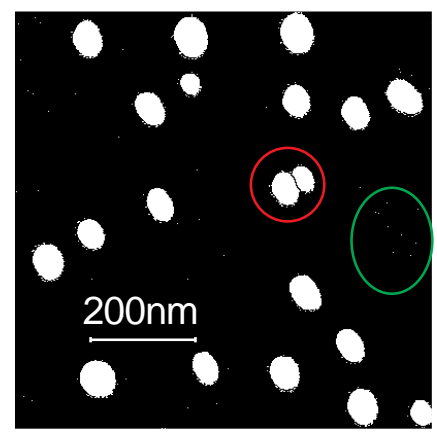

(c)

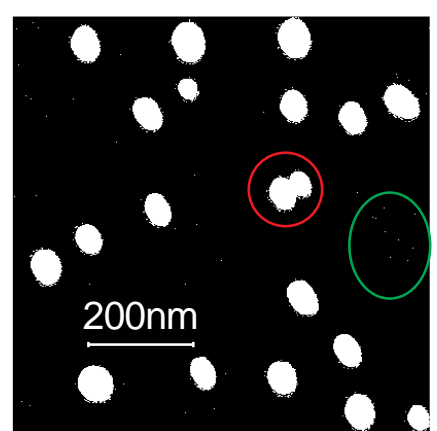

(b)

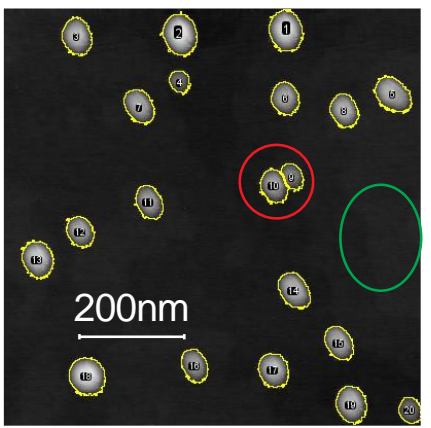

(d)

Figura 29. Exemplo do processamento de uma parte da superfície da amostra. (a) Imagem pronta para ser processada. (b) Zonas reconhecidas pelo Auto Local Threshold. (c) Separação de pontos coalescidos mediante Watershed. (d) Pontos escolhidos para a análise final.

São obtidos diferentes atributos de cada ponto escolhido para ser analisado, deles calculamos a diferença entre a maior e a menor altura de todo o ponto para obter a altura real. É verificada a eficiência da medição fazendo uma comparação da altura real de diversos pontos e a altura calculada com o método. Se a altura dos pontos está numa faixa de erro aceitável (até 5 angstroms para nós) se procede para fazer um histograma. Caso contrário, é escolhida a seguinte melhor configuração para determinar o Auto Local Threshold.

Na figura 30há o resultado do método convencional para fazer as medidas das alturas dos pontos quânticos e na figura 31 o resultado do método otimizado para fazer as medidas. Pode-se observar que o método proposto inclui os pontos de alturas menores e também mostra um ajuste melhor à curva de distribuição lognormal (Bergmann, 2008), o método convencional não reconhece os pontos de alturas menores, isso é um problema que se apresenta na análise de alturas de pontos quânticos (Zribi, 2013). Além disso, o método otimizado detecta uma maior quantidade de pontos, que anteriormente eram descartados por ter um 
threshold global inadequado, e pelo fato de não fazer a divisão dos pontos coalescidos. Na seção3.3.3 é explicitada uma comparação passo a passo de cada método, desde o momento em que a imagem da amostra está pronta para ser processada.

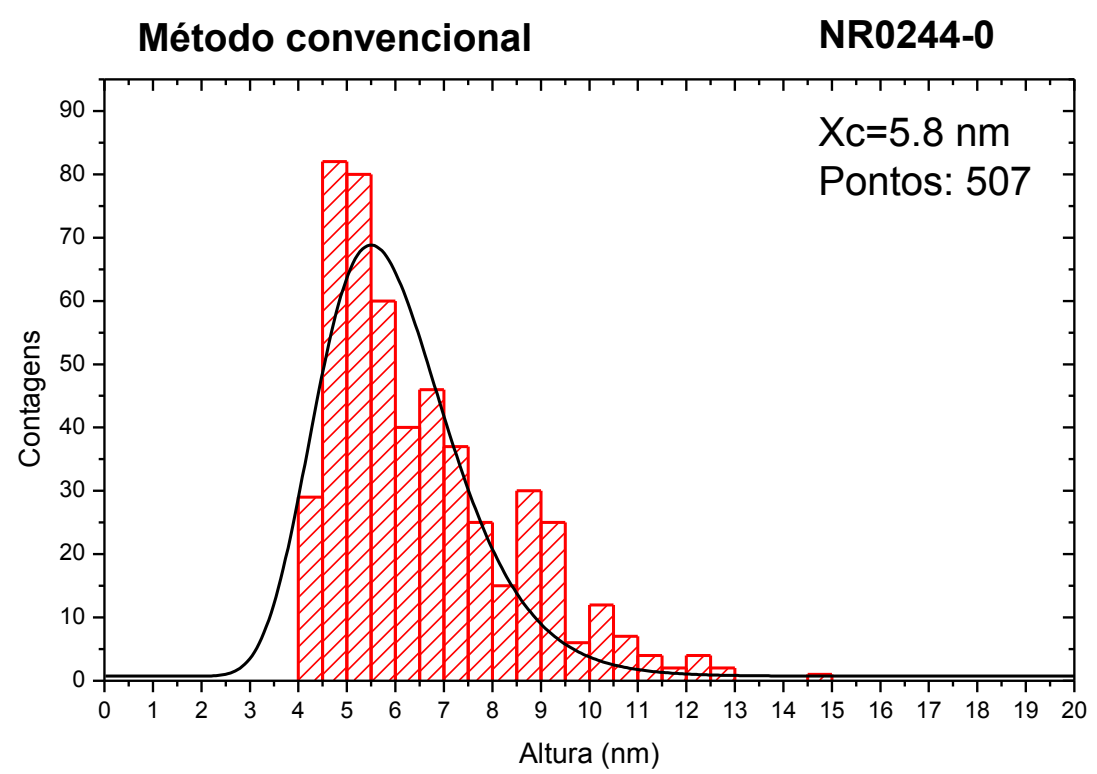

Figura 30. Histograma e ajuste por distribuição log-normal das alturas dos pontos quânticos da amostra NR0244 mediante o método comum.

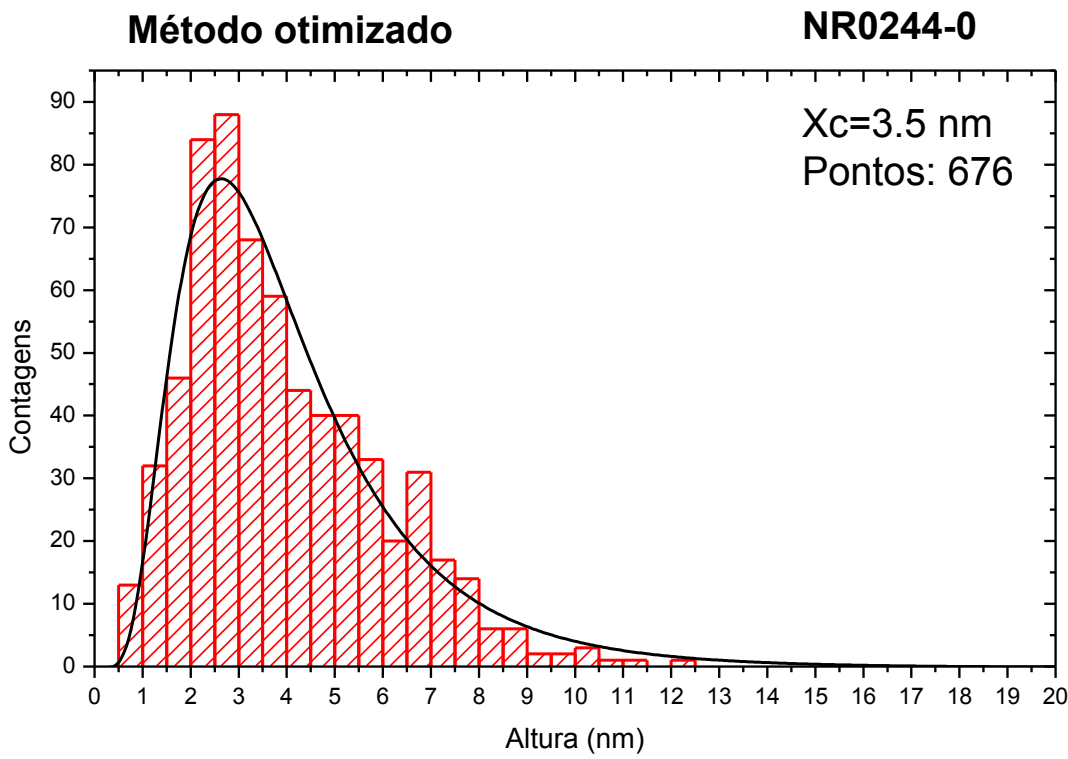

Figura 31. Histograma e ajuste por distribuição log-normal das alturas dos pontos quânticos da amostra NR0244 mediante o método otimizado. 


\subsection{3 \\ Comparação entre os métodos convencional e otimizado para o processamento das imagens do AFM}

Se mostra uma comparação entre o método convencional para fazer a medição das alturas dos pontos quânticos e o método otimizado proposto nesta dissertação. Para isso, é tomada uma das imagens da amostra NR0244, pois para cada amostra foram analisadas diferentes imagens correspondentes a diferentes regiões da amostra para ter dados mais confiáveis e garantir a homogeneidade dos resultados em diversas partes da amostra, como já foi explicado.

Na figura 32 (a) é exposta uma imagem pronta para ser analisada, na parte (b) o processo de Threshold para o método não otimizado, e na parte (c) o processo de Auto Local Threshold e a separação dos pontos coalescidos mediante o método de Watershed.

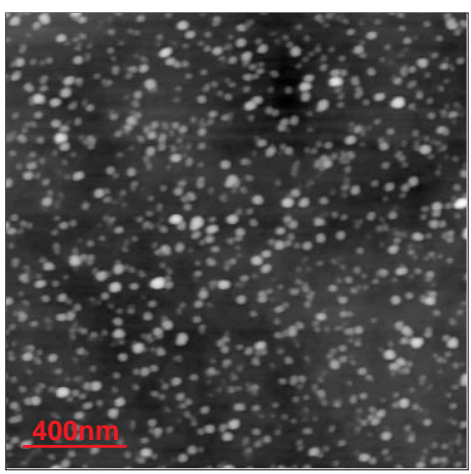

(a )

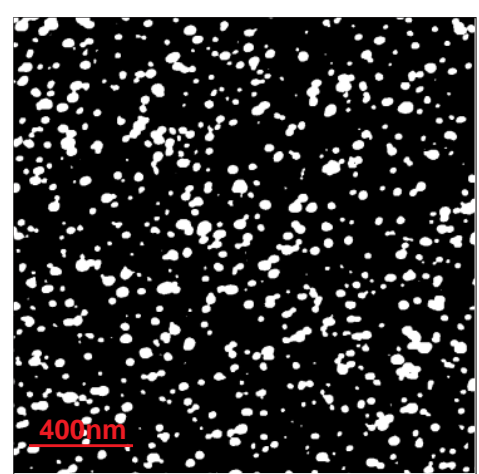

(b)

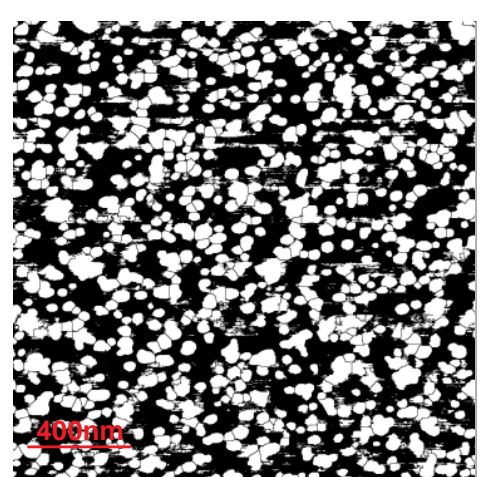

(c)

Figura 32. Resultados de Threshold para uma das imagens de pontos quânticos da superfície da amostra NR0244. (a) Imagem pronta para ser processada. (b) Resultado de Threshold global (método convencional). (c) Resultado de Auto Local Threshold (método otimizado) e separação dos pontos coalescidos. 
Na figura 33 (a) são vistos, com a borda amarela, os pontos selecionados para fazer a análise com o método sem otimização e na parte (b), são vistos os pontos selecionados com o método de Auto Local Threshold e a separação dos pontos coalescidos mediante o método de Watershed. Na figura 33 (c) pode-se observar as bordas dos pontos selecionados sobre a imagem original para o método sem otimização, e para o processo otimizado na figura 33 (d).

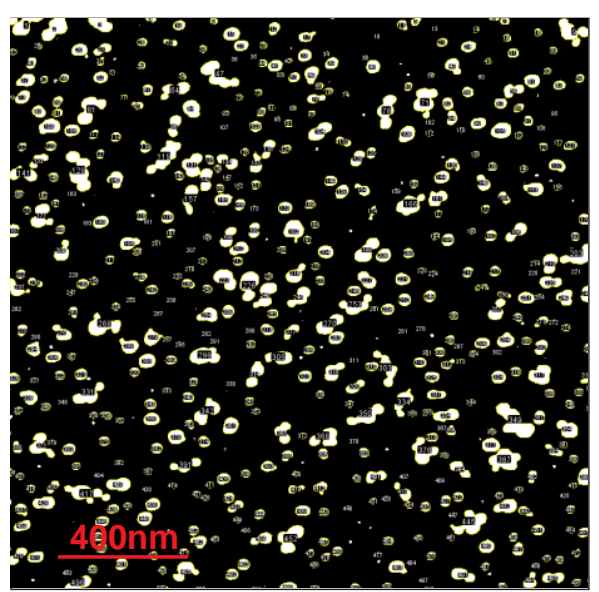

(a)

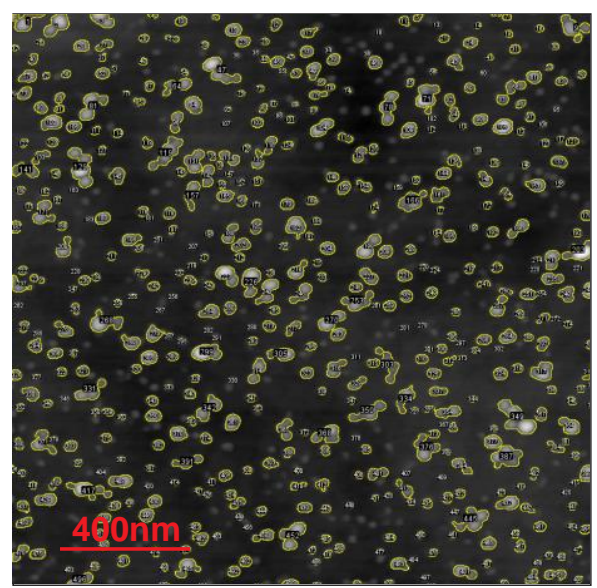

(c)

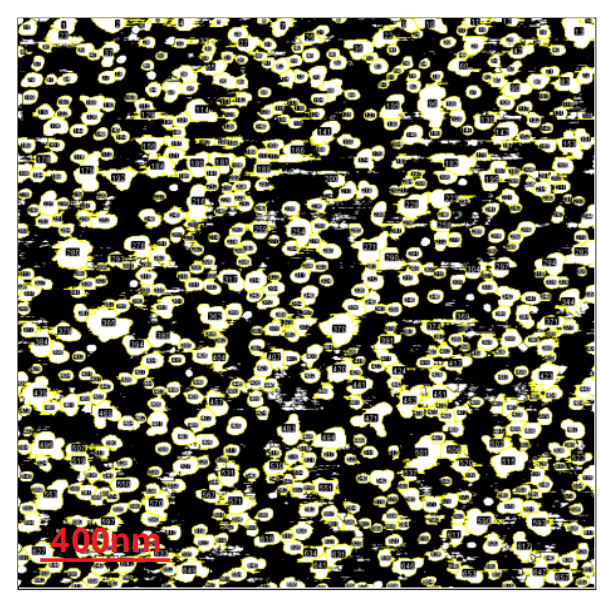

(b)

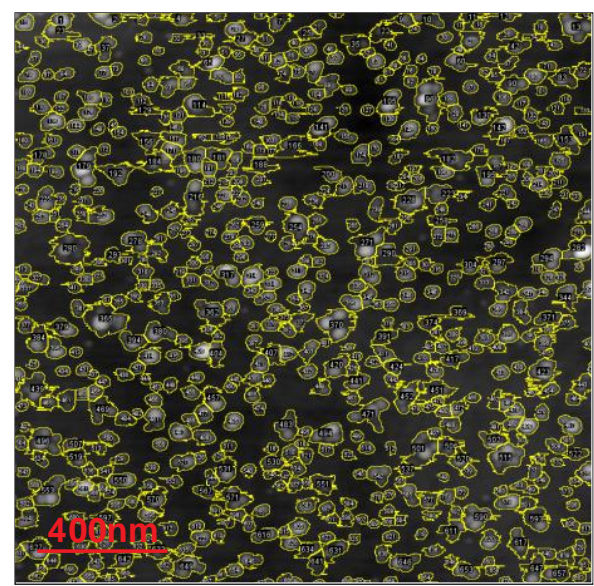

(d)

Figura 33. Resultados de Threshold e os pontos selecionados para a análise final de uma das imagens de pontos quânticos da superfície da amostra NR0244. (a) Pontos detectados com o método sem otimização. (b) Pontos detectados pelo método otimizado. (c) Pontos selecionados com o método sem otimização para a análise, vistos na imagem pronta para ser processada. (d) Pontos selecionados com o método otimizado para a análise, vistos na imagem pronta para ser processada. 
Se pode observar que a análise feita com o método otimizado é mais eficiente, pois ela considera diversos pontos que não são reconhecidos no outro processo. Outra vantagem é a região de interesse detectada para cada ponto. No método otimizado esse ponto é maior, o que garante ser detectada a base de cada ponto. Também é claro que nem todos os pontos coalescidos foram separados, mas em alguns casos o método conseguiu detectá-los e separá-los, o que melhora a análise final da imagem. 


\section{Discussão dos resultados}

As amostras estudadas nesta pesquisa foram crescidas em duas séries diferentes. Primeiro se criou a série de amostras NR02XX, e posteriormente foi crescida a série de amostras NR03XX. Apesar de, em princípio, poderem ser analisadas em conjunto, mostraremos mais adiante que as duas séries possuem propriedades distintas.

\section{1}

\section{Influência do tempo de crescimento sobre os pontos quânticos}

As amostras analisadas nesta seção foram crescidas com as mesmas condições de temperatura e fluxo de índio como se mostra na tabela 2. Nas figuras 34 e 35 se observa a altura e a densidade dos pontos quânticos em função do material depositado em monocamadas (ML), respectivamente. Os números nos gráficos se referem à identificação das amostras.

\begin{tabular}{|l|r|r|c|r|r|r|}
\hline \multirow{2}{*}{ Amostra } & TMIn & TC & QM & TemC & \multicolumn{1}{c|}{ A } & \multicolumn{1}{|c|}{ D } \\
\cline { 2 - 7 } & $(\mathbf{s c c m})$ & $(\mathbf{s e g})$ & $(\mathbf{M L})$ & $\left.{ }^{\mathbf{}} \mathbf{C}\right)$ & $(\mathbf{n m})$ & $\left.\mathbf{( x 1 0}^{\mathbf{1 0}} \mathbf{c m}^{\mathbf{2}}\right)$ \\
\hline NR0304 & 78 & 4,1 & 2,01 & 520 & 7,5 & 0,37 \\
\hline NR0221 & 78 & 4,8 & 2,36 & 520 & 1,5 & 2,33 \\
\hline NR0227 & 78 & 5,5 & 2,70 & 520 & 2,7 & 3,14 \\
\hline NR0228 & 78 & 6,2 & 3,05 & 520 & 3,0 & 3,69 \\
\hline NR0305 & 78 & 6,9 & 3,39 & 520 & 5,3 & 0,97 \\
\hline
\end{tabular}

Tabela 2.Condições de crescimento da camada de pontos quânticos e seus resultados das análises, variando o tempo de crescimento (quantidade de material) e mantendo fixos os outros parâmetros. TMIn: TMIn Q source; TC: Tempo de crescimento; QM: Quantidade de material; TemC: Temperatura de Crescimento; A: Altura dos pontos; D: Densidade

Na família de amostras NR02XX se pode observar que na medida em que a quantidade de material depositado sobre a amostra aumenta, parte deste material cresce sobre os pontos quânticos já existentes aumentando sua altura (Figura 35). 
Além disso, o material também cria novas regiões de nucleação, aumentando também a densidade de pontos sobre a amostra (Figura 34).

As amostras da família NR03XX apresentam um aumento na densidade com o aumento da quantidade de material depositado conforme mostra a figura 34, o erro na densidade é muito pequeno em comparação com os valores obtidos, por isso se descartou a barra de erro em todas as densidades, pois ela é mais pequena que o ponto que marca o valor da densidade na figura. Com o aumento na quantidade de material se pode esperar que a altura dos pontos quânticos fosse também maior (Chen, 2012). Porém, se observa uma redução na altura (Figura 35). Levando em conta que o aumento na quantidade de material ocorre porque se aumenta o tempo de deposição, no caso da amostra 305, a altura reduzida obtida pode ser explicada pelo fenômeno de coalescência que leva a uma altura média menor, além de dificultar a determinação da altura. Na figura 36 se pode observar uma representação deste fenômeno, na parte (a) quando os pontos começam seu crescimento, na parte (b) os pontos começando a coalescer, e finalmente na parte (c) os pontos crescendo e coalescendo de forma que na imagem do AFM não se poderia determinar a base dos pontos com exatidão.

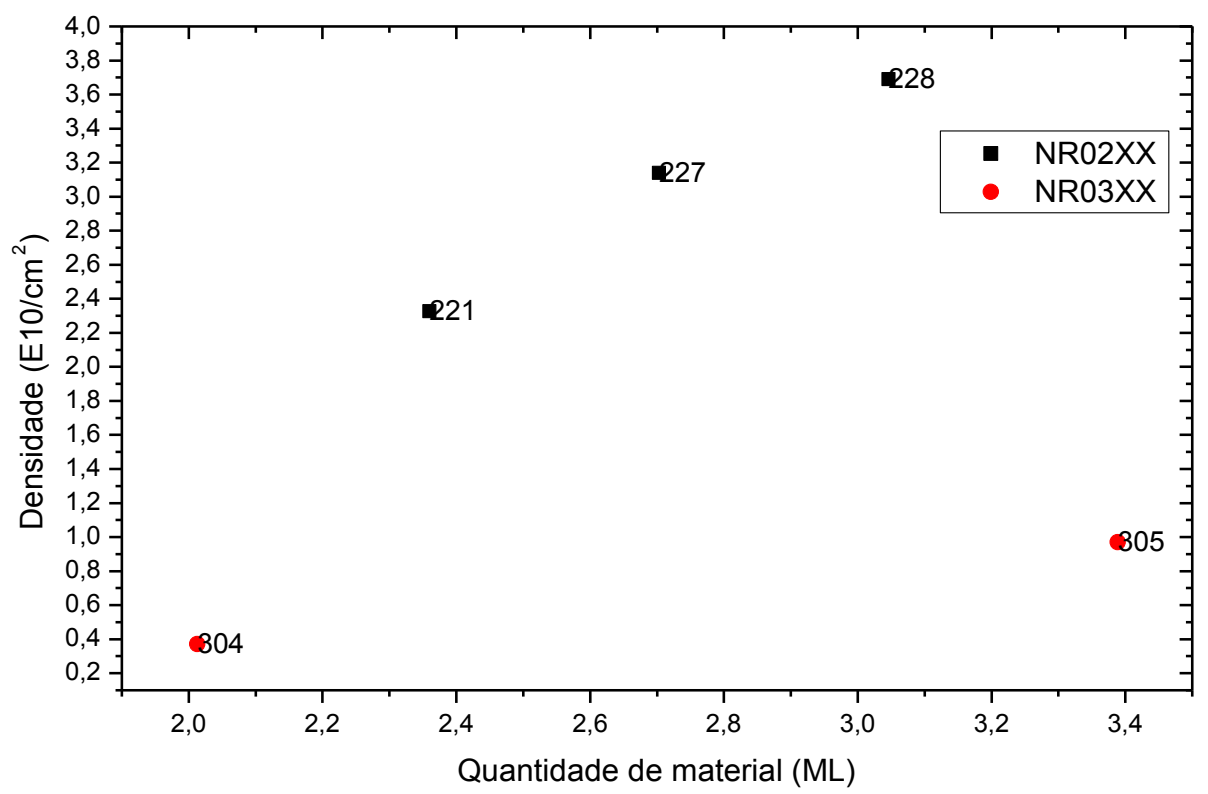

Figura 34. Relação entre a densidade de pontos quânticos e a quantidade de material crescido sobre a amostra (unidades em Mono Camadas "Mono Layers"), os números se referem à identificação das amostras. 


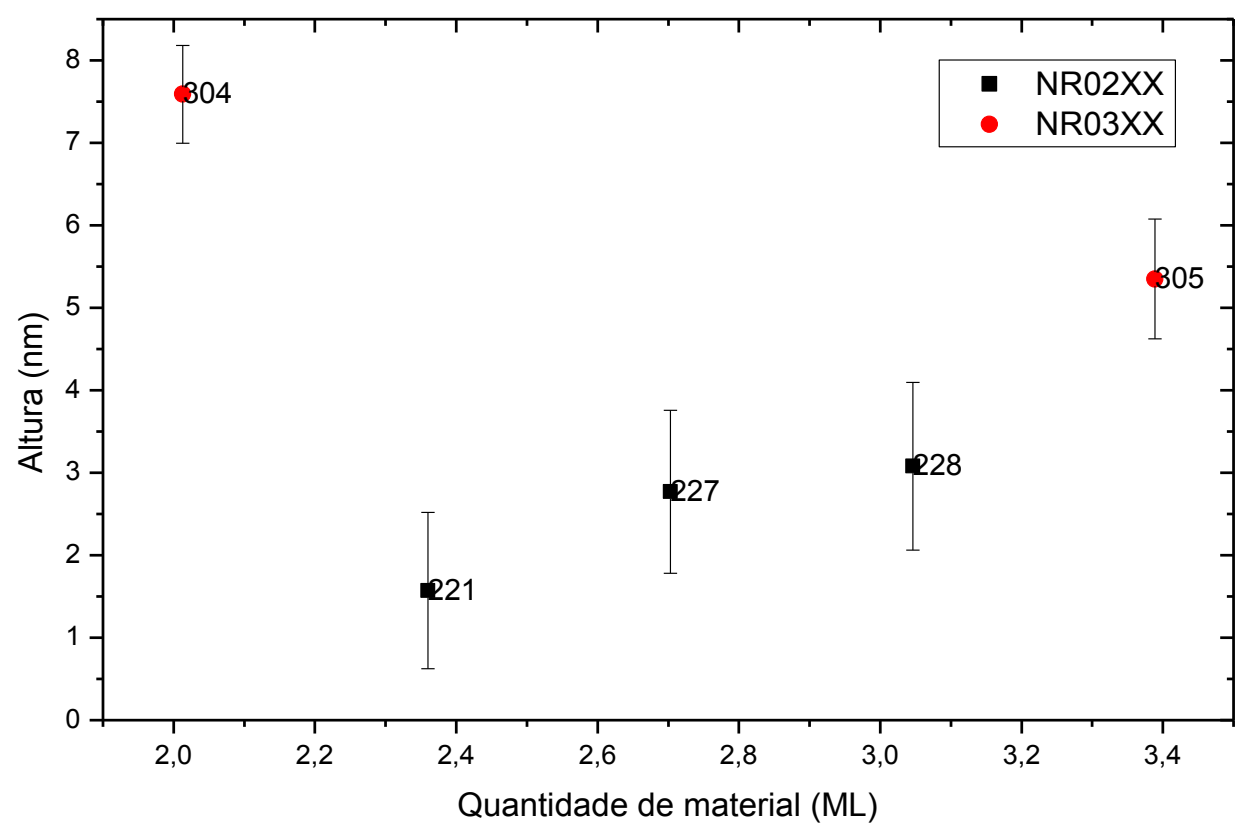

Figura 35. Relação entre a altura dos pontos quânticos e a quantidade de material crescido sobre a amostra (unidades em Mono Camadas "Mono Layers"), os números se referem à identificação das amostras. A barra de erro corresponde ao desvio padrão da distribuição Log-normal.

$\mathrm{Na}$ figura 34 se pode observar que o aumento do tempo de crescimento ou quantidade de material, repercute no incremento da densidade de pontos quânticos sobre a amostra independente do que acontece com as alturas dos pontos quânticos, isto pelo aumento de material total crescido (maior tempo de crescimento, maior quantidade de material total é depositado sobre a amostra). Isto acontece para as duas famílias de amostras mantendo para todas elas o mesmo comportamento de aumentar a densidade na medida em que é aumentada a quantidade de material depositado. No caso da amostra 305, as alturas dos pontos quânticos não podem ser determinadas com exatidão, mas o processo de contagem da quantidade dos pontos não é afetado. 


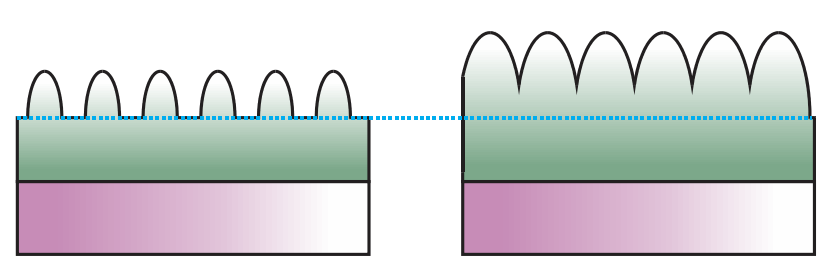

(a)

(b)

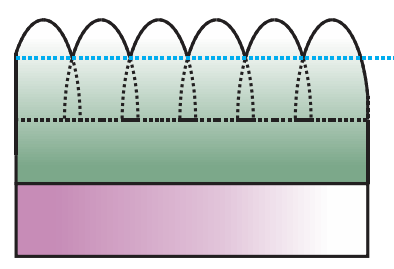

(c)

Figura 36. Representação do crescimento de pontos quânticos para altas quantidades de material depositado sobre a amostra, (a) pontos começam seu crescimento, (b) pontos começando a coalescer, (c) pontos crescendo e coalescendo sobre os outros.

\section{2}

\section{Influência do fluxo de TMIn sobre os pontos quânticos}

Nas figuras 37 e 38, se pode observar os resultados do efeito do fluxo de TMIn, mantendo fixas as demais condições de crescimento como se mostra na tabela 3 .

\begin{tabular}{|l|r|r|c|r|r|r|}
\hline \multirow{2}{*}{ Amostra } & TMIn & TC & QM & TemC & \multicolumn{1}{c|}{ A } & \multicolumn{1}{c|}{ D } \\
\cline { 2 - 7 } & $(\mathbf{s c c m})$ & $(\mathbf{s e g})$ & $(\mathbf{M L})$ & $\left.{ }^{\circ} \mathbf{C}\right)$ & $(\mathbf{n m})$ & $\left.\mathbf{( x 1 0}^{\mathbf{1 0}} / \mathbf{c m}^{\mathbf{2}}\right)$ \\
\hline NR0308 & 60 & 4,8 & 1,82 & 520 & 8,6 & 0,06 \\
\hline NR0306 & 100 & 4,8 & 3,02 & 520 & 6,1 & 1,16 \\
\hline NR0307 & 120 & 4,8 & 3,63 & 520 & 6,5 & 1,25 \\
\hline
\end{tabular}

Tabela 3.Condições de crescimento da camada de pontos quânticos e seus resultados das análises, variando o fluxo de índio e mantendo fixos os outros parâmetros. TMIn: TMIn

Q source sccm; TC: Tempo de crescimento; QM: Quantidade de material; TemC:

Temperatura de Crescimento; A: Altura dos pontos; D: Densidade

Na figura 37 se observa que a densidade de pontos quânticos diminui com o decaimento do fluxo de TMIn. Quando o fluxo de material é pequeno, os átomos que chegam nas diversas zonas da amostra geram regiões de nucleação e estas regiões relaxam. Os novos átomos que vão chegando sobre a amostra se deslocam pela superfície e são atraídos pelas regiões de nucleação (regiões relaxadas), gerando poucos pontos quânticos de alturas maiores o que representa uma amostra com baixa densidade. 
Quando o fluxo de índio aumenta, muito material é depositado rapidamente sobre a amostra. Os átomos que vão chegando sobre a amostra geram regiões de nucleação que atraem os novos átomos que são depositados posteriormente. Mas acontece que os novos átomos não conseguem chegar até as regiões de nucleação criadas; quando eles se estão deslocando sobre a superfície, se podem encontrar com os novos átomos na superfície (pois o material é depositado rapidamente pelo aumento de fluxo), gerando assim novas regiões de nucleação (Jakomin, 2014). Assim amostras com maior densidade de pontos quânticos são obtidas, com pontos quânticos de alturas menores, como se observa na figura 38 .

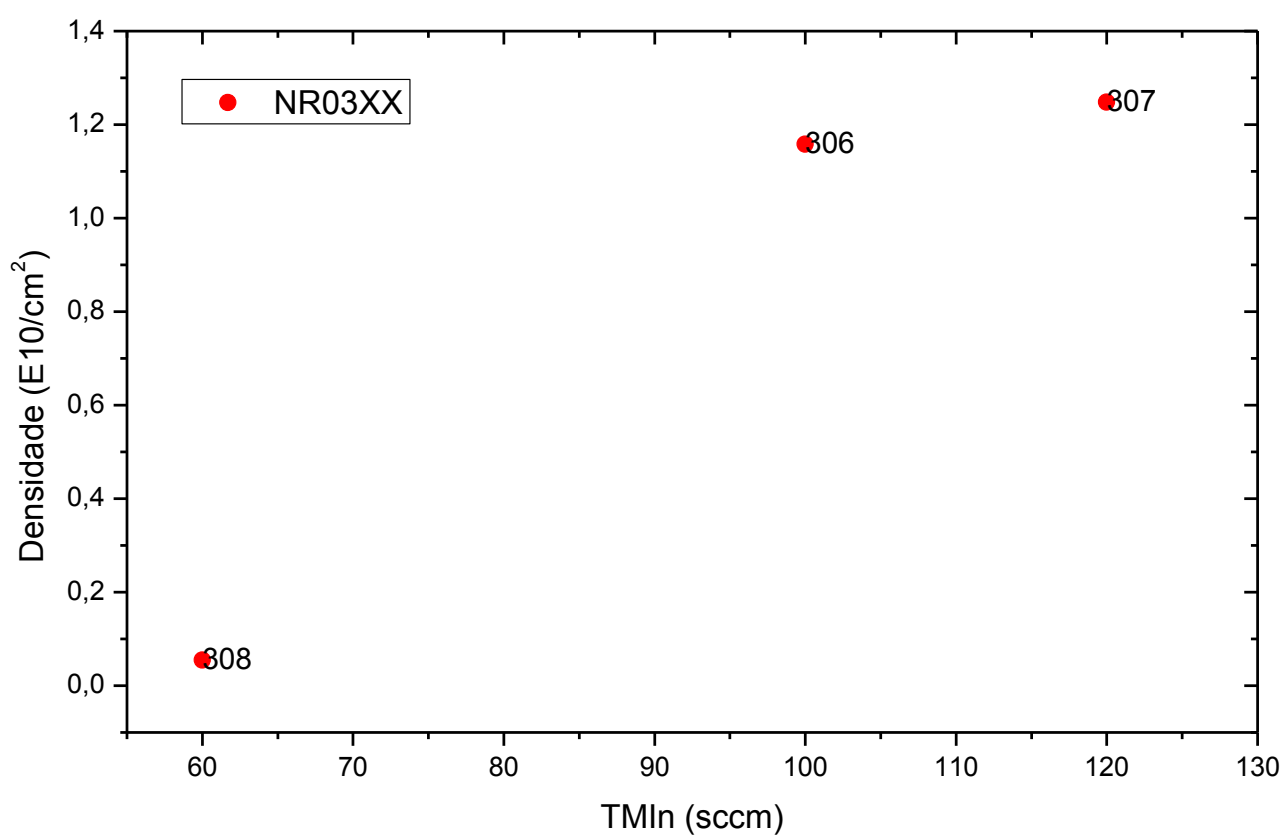

Figura 37. Relação entre a densidade dos pontos quânticos e o fluxo de TMIn. 


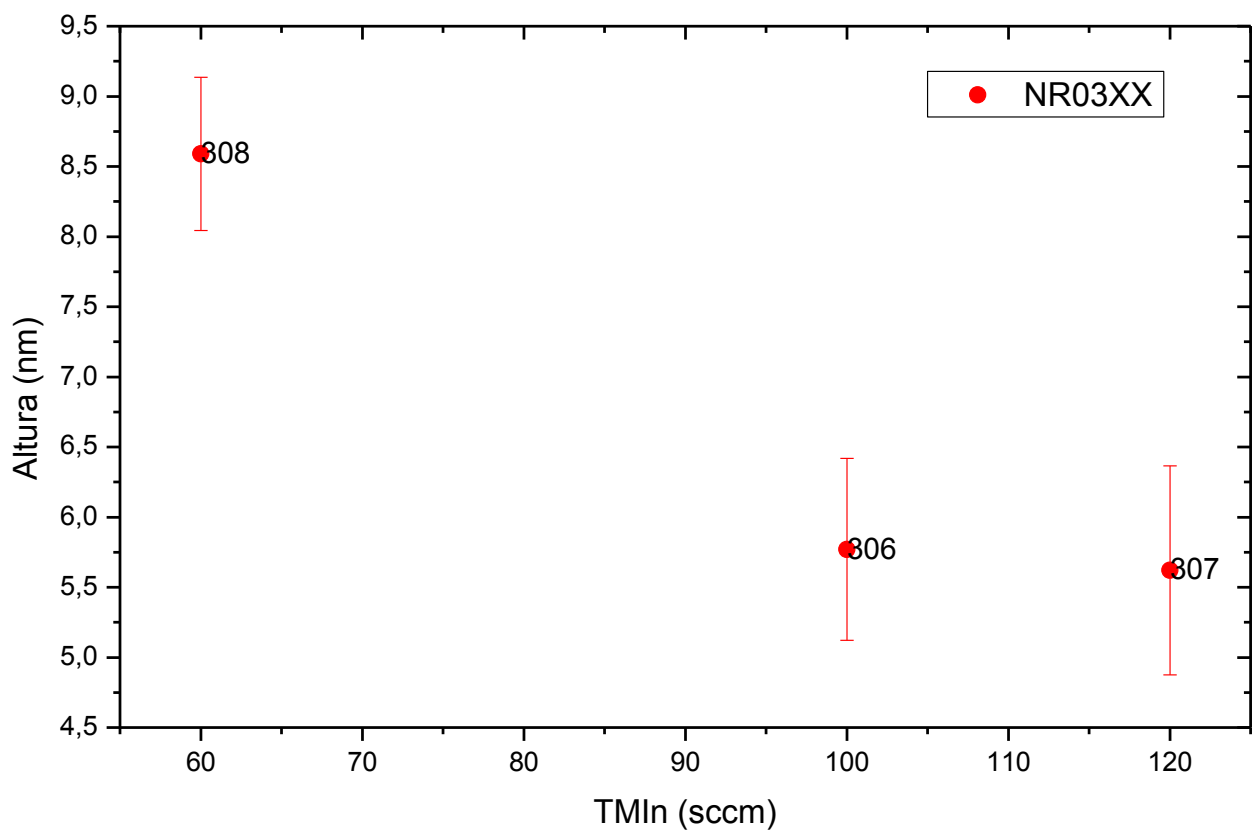

Figura 38. Relação entre a altura dos pontos quânticos e o fluxo de TMIn. A barra de erro corresponde ao desvio padrão da distribuição Log-normal.

\section{3}

\section{Influência da temperatura de crescimento sobre os pontos quânticos}

Nas figuras 39 e 40, se mostram os resultados do efeito da temperatura de crescimento dos pontos quânticos como se mostra na tabela 4 .

Com o aumento da temperatura espera-se que a altura dos pontos quânticos aumente. Isto acontece porque com o aumento da temperatura, os átomos que chegam sobre a amostra têm uma mobilidade maior, o que permite a eles se deslocar até as regiões onde estão acontecendo nucleações e crescer pontos quânticos de maiores alturas. Esse aumento na altura dos pontos quânticos deve representar um decaimento na densidade de pontos crescidos sobre a amostra (Jakomin, 2014).

Observa-se na figura 39 que a densidade de pontos para a série NR03XX diminui ligeiramente, conforme o esperado. Em relação à altura dos pontos quânticos, observa-se nas figuras que eles sofrem um ligeiro aumento. Porém, levando em consideração as barras de erro, podemos afirmar que a temperatura pouco influencia a altura. Já para a série NR02XX nota-se um comportamento inesperado tanto para a densidade quanto para a altura. A densidade aumenta com 
a temperatura e a altura oscila. Com os modelos existentes (Jakomin, 2014; Baskaran, 2012) não podemos explicar tais resultados. Podemos levantar a hipótese que para pontos quânticos tão pequenos $(\sim 2 \mathrm{~nm})$ o regime de nucleação seja diferenciado.

\begin{tabular}{|l|r|r|c|r|r|r|}
\hline \multirow{2}{*}{ Amostra } & TMIn & TC & QM & TemC & \multicolumn{1}{c|}{ A } & \multicolumn{1}{c|}{ D } \\
\cline { 2 - 7 } & (sccm) & (seg) & $(\mathbf{M L})$ & $\left.{ }^{\mathbf{}} \mathbf{C}\right)$ & $(\mathbf{n m})$ & $\left.\mathbf{( x 1 0}^{\mathbf{1 0}} / \mathbf{c m}^{\mathbf{2}}\right)$ \\
\hline NR0302 & 78 & 4,8 & 1,98 & 510 & 6,7 & 0,84 \\
\hline NR0244 & 78 & 4,8 & 2,18 & 515 & 3,5 & 2,11 \\
\hline NR0221 & 78 & 4,8 & 2,36 & 520 & 1,5 & 2,33 \\
\hline NR0243 & 78 & 4,8 & 2,52 & 525 & 3,0 & 2,41 \\
\hline NR0303 & 78 & 4,8 & 2,79 & 535 & 7,7 & 0,64 \\
\hline
\end{tabular}

Tabela 4.Condições de crescimento da camada de pontos quânticos e seus resultados das análises, variando a temperatura de crescimento e mantendo fixos os outros parâmetros.

TMIn: TMIn Q source; TC: Tempo de crescimento; QM: Quantidade de material; TemC:

Temperatura de Crescimento; A: Altura dos pontos; D: Densidade

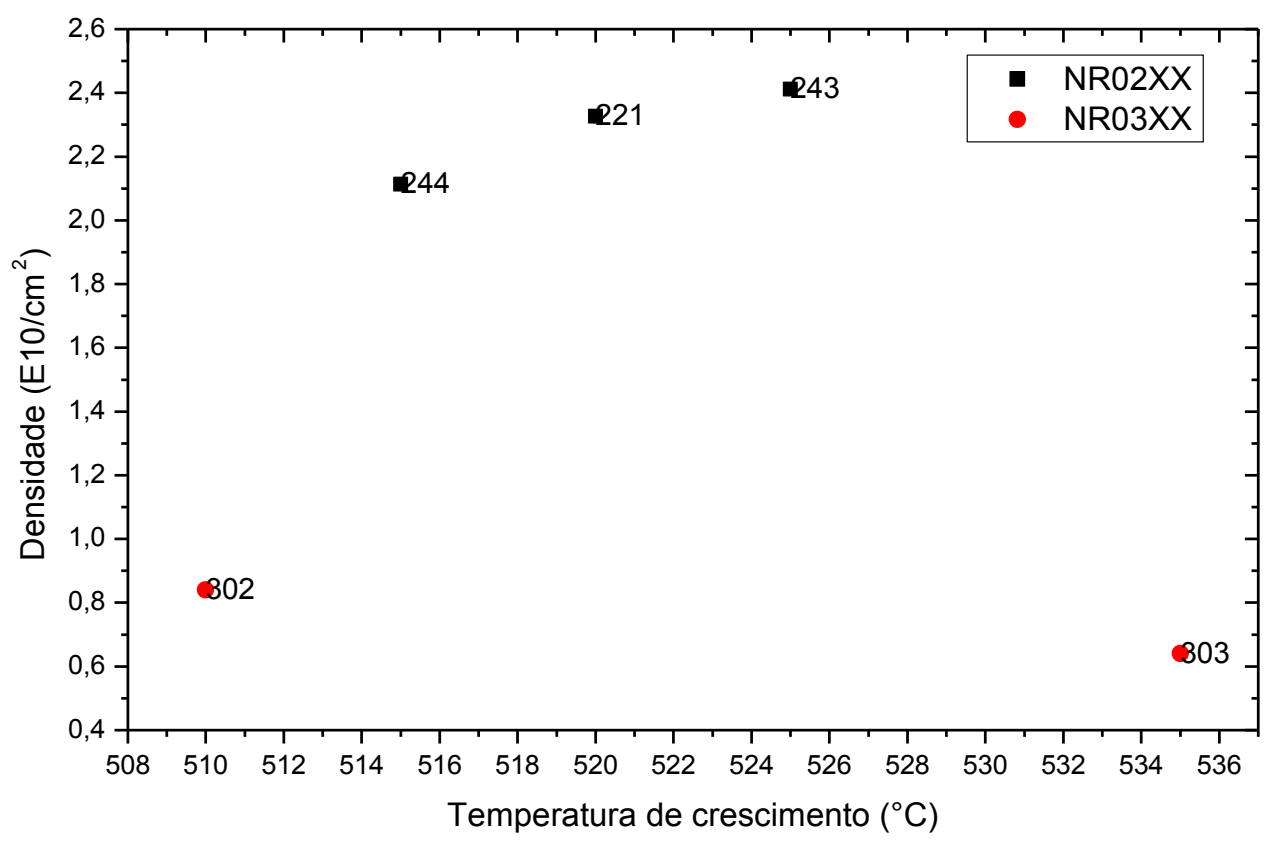

Figura 39. Relação entre densidade de QD e a temperatura de crescimento. 


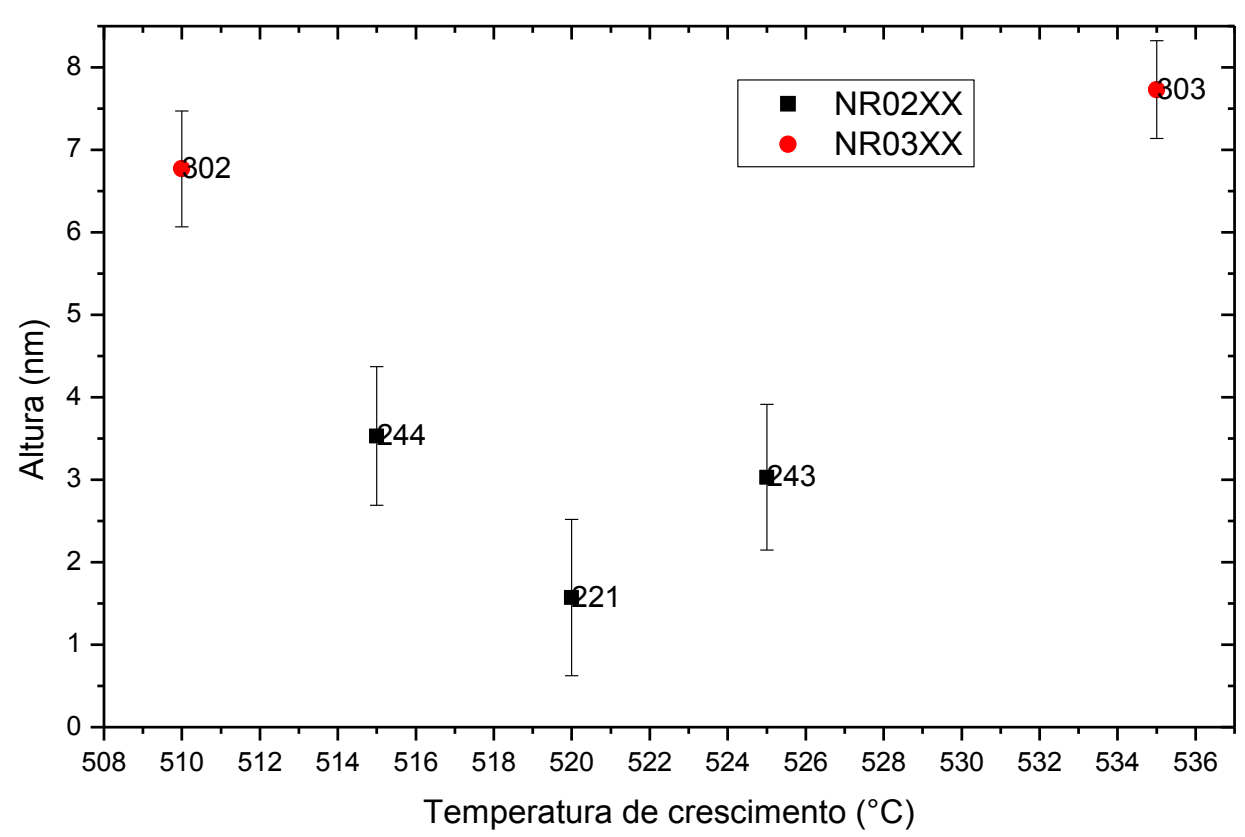

Figura 40. Relação entre a altura dos QD e a temperatura de crescimento. A barra de erro corresponde ao desvio padrão da distribuição Log-normal.

\section{4 \\ Correlação dos resultados de altura e densidade}

Na figura 41 são mostrados os resultados da altura em função da densidade para amostras com tempo de crescimento de 4,8 segundos. Observa-se que nas amostras com altas densidades o material está distribuído em diversas partes da amostra formando uma grande quantidade de pontos quânticos de alturas menores; mas nas amostras que têm baixas densidades o material é concentrado em poucas regiões formando pontos quânticos mais altos, tendo assim uma densidade muito menor. Se observa que na medida em que a altura dos pontos quânticos diminui, sua densidade aumenta, conforme esperado por conservação de quantidade de material. 


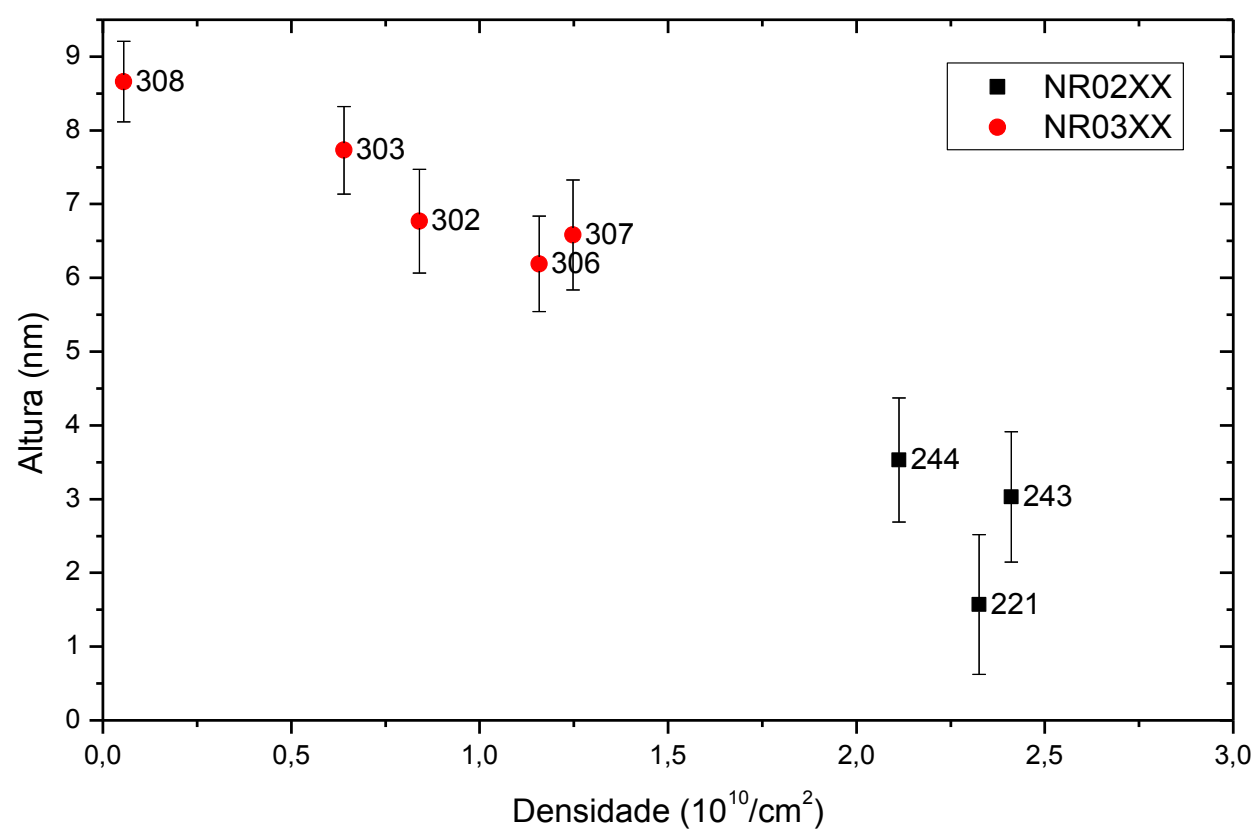

Figura 41. Relação entre a altura dos pontos quânticos e a densidade da amostra para a família de amostras com tempo de crescimento de 4,8 segundos. A barra de erro corresponde ao desvio padrão da distribuição Log-normal.

\section{5}

\section{Análise da fotoluminescência}

Nessa seção será feita a correlação entre os resultados dos espectros de fotoluminescência e as características morfológicas das amostras conforme mostrado na seção 3.2 .

Na figura 42 se apresenta a relação entre a altura dos pontos quânticos e sua respectiva energia do pico da fotoluminescência do nível fundamental. Podemos fazer a comparação para todas as amostras investigadas nesta dissertação independente das condições de crescimento, pois a fotoluminescência é uma propriedade diretamente relacionada com a altura dos pontos quânticos, independente de como foram nucleados. Observa-se que os pontos de maior altura apresentam uma fotoluminescência de menor energia e na medida em que a altura vai diminuindo, a energia da fotoluminescência vai aumentando. Isto é que os pontos quânticos de maior altura geram radiação da fotoluminescência de comprimentos de onda maiores, e os pontos quânticos de menor altura geram 
radiação da fotoluminescência de menor comprimento de onda, conforme esperado. Isto é observado na figura 42.

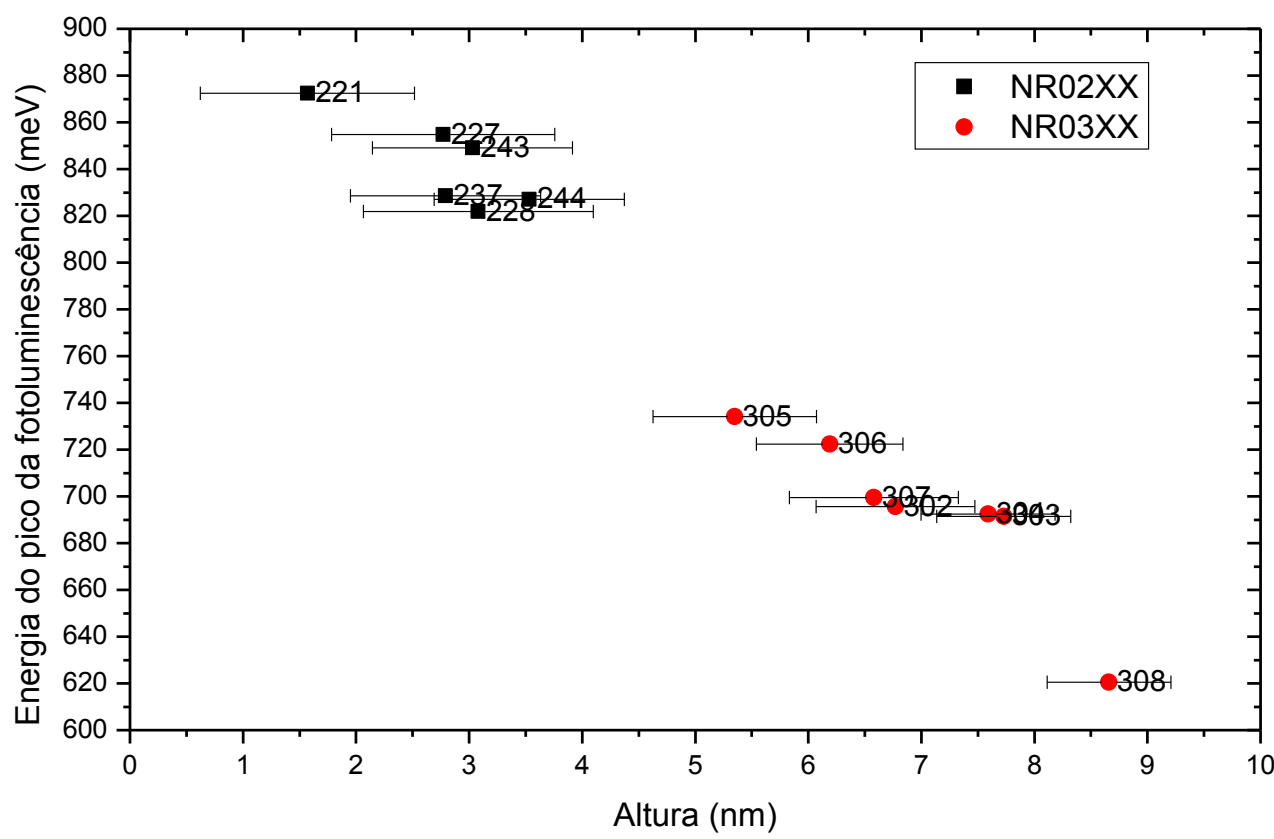

Figura 42. Relação entre o pico de estado fundamental de fotoluminescência e a altura dos pontos quânticos de todas as amostras crescidas. A barra de erro corresponde ao desvio padrão da distribuição Log-normal.

Deve-se lembrar que a fotoluminescência medida procede dos pontos quânticos que estão enterrados. Os pontos quânticos da superfície não emitem fótons porque os elétrons e buracos são armadilhados em estados de superfície. Assim, a altura dos pontos quânticos determinada na superfície por AFM traduz uma estimativa do volume dos pontos quânticos enterrados. Os pontos quânticos enterrados, em função do processo de recobrimento seguido de recozimento, terão uma altura reduzida em relação aos da superfície, exceto para os menores que são totalmente cobertos antes do recozimento. Porém, a área da base dos pontos quânticos permanece inalterada. Em outras palavras, mesmo que a altura dos pontos quânticos das diferentes amostras seja a mesma, a área deles será tanto maior quanto maior for a altura dos pontos quânticos na superfície. 


\section{6 Simulação de níveis de energia de pontos quânticos}

Sabendo que as propriedades eletrônicas dos pontos quânticos variam em função de sua altura e sua composição (Narvaez, 2005), (Ngo, 2006), se realizaram simulações dos níveis energéticos para pontos quânticos de InAs sobre o material quaternário InGaAlAs em função desses parâmetros. Um programa em linguagem Fortran no software Geany aplica uma série de cálculos para resolver a equação de Schrödinger em uma dimensão usando o método conhecido como Split-Operator (Degani, 2010). Com esta ferramenta se pode calcular os níveis de energia para diferentes geometrias de pontos quânticos (discos ou lentes), alturas e diâmetros. No programa se definem as energias do gap do material quaternário, do gap do InAs, a altura e o diâmetro do ponto quântico que se quer simular. As alturas simuladas foram de 2 a $13 \mathrm{~nm}$ com passos de um $\mathrm{nm}$. Nas imagens de AFM se pode observar que os pontos quânticos têm forma de lentes e foi escolhido um diâmetro médio de $70 \mathrm{~nm}$, observado nas imagens de AFM.

É definido o gap do material quaternário, que para todas as simulações será o valor da fotoluminescência da amostra de referência NR0319. Deste valor se subtrai o gap do InAs tensionado que depende do nível de tensão do material dos pontos quânticos, os quais estarão mais tensionados para os pontos pequenos e estarão mais relaxados para pontos de tamanhos maiores. Os offsets de energia das bandas de condução e de valência entre o quaternário e o InAs utilizados foram de $70 \%$ e $30 \%$ respetivamente. (Shu-Shen, 1996). Em seguida são mostradas as formulas.

$$
\begin{gathered}
E_{\text {gap }} \text { InGaAlAs }=E_{\text {gap }} \text { InAs }+E_{\text {elétrons }}+E_{\text {buracos }} \\
E_{\text {elétrons }}=0.7 *\left(E_{\text {gap }} \operatorname{InGaAlAs}-E_{\text {gap }} \operatorname{InAs}\right) \\
E_{\text {buracos }}=0.3 *\left(E_{\text {gap }} \operatorname{InGaAlAs}-E_{\text {gap }} \operatorname{InAs}\right) \\
E_{\text {gap }} \operatorname{InGaAlAs}=1020 \mathrm{meV}
\end{gathered}
$$


$\mathrm{Na}$ figura 43 se mostra um esquema das energias calculadas para o gap de InGaAlAs de $1020 \mathrm{meV}$, e o gap de InAs de $471 \mathrm{meV}$ que corresponde ao material parcialmente tensionado.

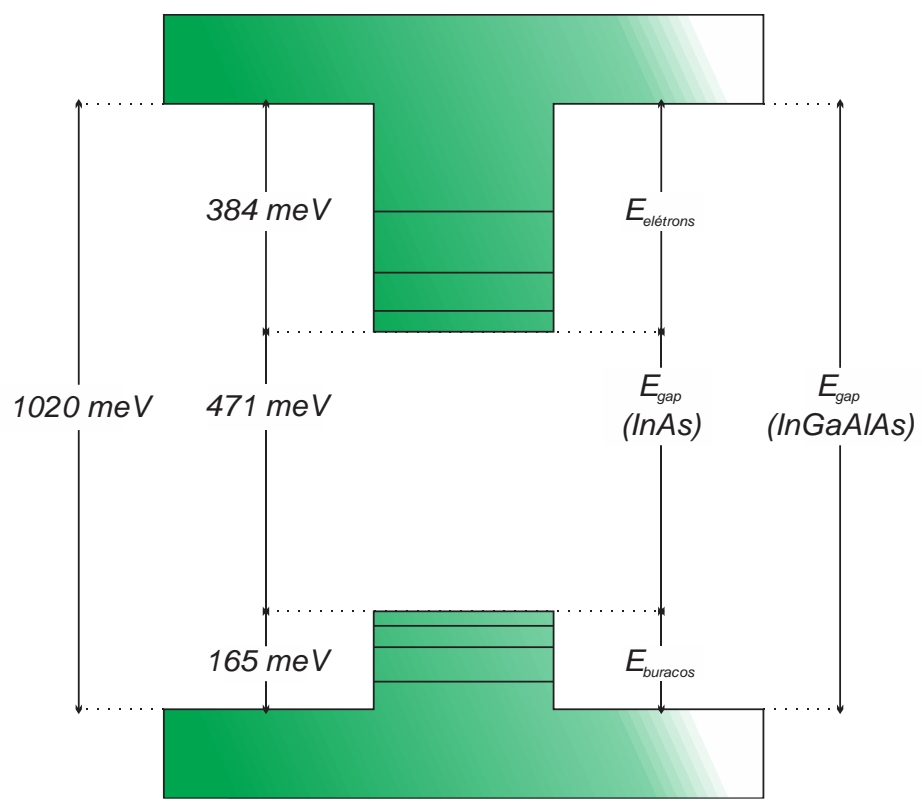

Figura 43. Esquema da estrutura de pontos quânticos de InAs com gap parcialmente tensionado de $471 \mathrm{meV}$, sobre material quaternário de InGaAlAs com gap de $1020 \mathrm{meV}$.

Se fizeram três simulações dos níveis de energia de pontos quânticos em função da altura para diferentes valores de gap para o InAs tensionado, $784 \mathrm{meV}$ (Figura 49) para o material totalmente tensionado (fully strained) modelo proposto por (Shu-Shen Li, 1996), $471 \mathrm{meV}$ (Figura 50) para o material parcialmente tensionado (Linares, 2011), e 565meV (Figura 51) como um valor intermediário entre os dois modelos.

$\mathrm{Na}$ tabela 5 se pode observar que as simulações feitas têm um comportamento similar com as simulações de outro autor (Narvaez, 2005) figura 44, porém elas têm uns valores um pouco maiores, da ordem de $70-110 \mathrm{meV}$, isto pode ser consequência do valor do gap que é usado para as simulações. Neste trabalho se usaram três valores diferentes dependendo do nível de tensão do material, mas o importante é observar que as duas simulações têm um comportamento similar como se observa na figura 45. 


\begin{tabular}{|r|r|r|}
\hline \multicolumn{1}{|c|}{$\mathbf{A}$} & \multicolumn{1}{c|}{$\mathbf{N}$} & \multicolumn{1}{c|}{$\mathbf{T}$} \\
\hline$(\mathbf{n m})$ & $\mathbf{( m e V})$ & $(\mathbf{m e V})$ \\
\hline 2,0 & 1085 & 970 \\
\hline 3,5 & 1015 & 940 \\
\hline 5,0 & 980 & 920 \\
\hline 6,5 & 960 & 900 \\
\hline 7,5 & 955 & 880 \\
\hline
\end{tabular}

Tabela 5. Comparação dos valores simulados em outro trabalho (Narvaez, 2005) e os obtidos neste trabalho (Energias de transição de pontos quânticos, com gap de InAs tensionado $=784 \mathrm{meV}$ ). A: Altura dos pontos quânticos; $\mathrm{N}$ : Valores do trabalho (Narvaez, 2005) para pontos quânticos de InAs; T: Valores obtidos nas simulações neste trabalho

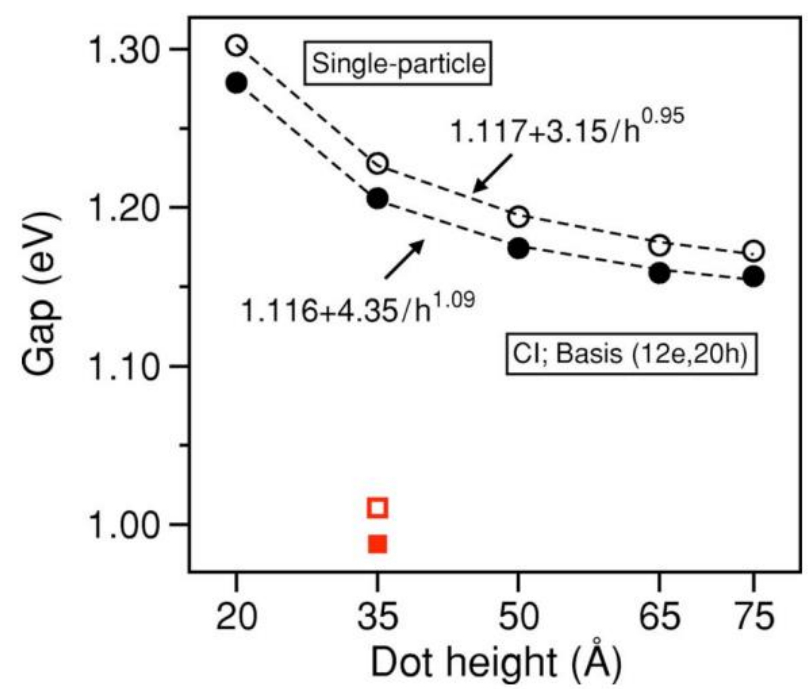

Figura 44. Gap em função da altura de pontos quânticos; Círculos: InGaAs/GaAs; Quadrados: InAs/GaAs a partir da referência (Narvaez, 2005) 


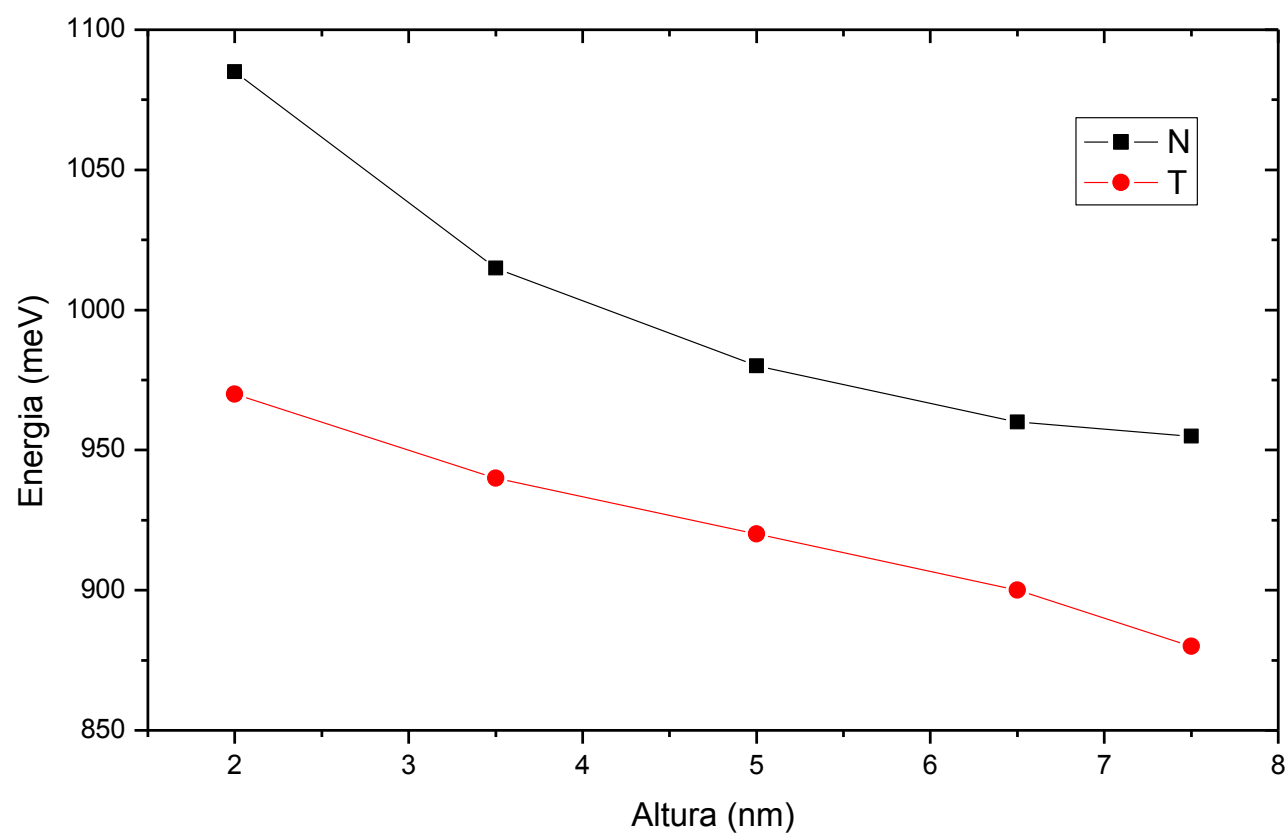

Figura 45. Comparação dos valores simulados em outros trabalhos (Narvaez, 2005) e os obtidos neste trabalho (Energias de transição de pontos quânticos, com gap de InAs = $784 \mathrm{meV}$ ). N: Valores do trabalho (Narvaez, 2005); T: Valores obtidos neste trabalho

As simulações feitas neste trabalho apresentam também um comportamento similar em comparação com outro trabalho (Ngo, 2006) (Figura 48), onde são efetuados os cálculos das energias dos elétrons (Figura 46) e dos buracos (Figura 47) em função do volume do ponto quântico. Lembrando que as simulações feitas neste trabalho são para pontos quânticos com forma de lente e com um diâmetro de $70 \mathrm{~nm}$, podemos estimar o volume de nossos pontos quânticos e comparar os resultados com as simulações feitas no trabalho (Ngo, 2006). Para comparar os resultados, se somam os valores das energias dos buracos e elétrons do trabalho (Ngo, 2006) e se adiciona o valor de $784 \mathrm{meV}$ para comparar com as nossas simulações, figura 49. Na tabela 6 se mostram os valores das alturas dos pontos quânticos, o volume dos pontos quânticos deste trabalho com diâmetro da base de $70 \mathrm{~nm}$, a energia dos elétrons (Ngo, 2006), a energia dos buracos (Ngo, 2006), a energia de transição para pontos quânticos supondo um gap de $784 \mathrm{meV}$, as energias de transição para pontos quânticos com gap de $784 \mathrm{meV}$ obtidas nas simulações deste trabalho e o valor absoluto da diferença entre as energias do trabalho (Ngo, 2006) e nossas simulações. Se pode observar sua similaridade no 
comportamento e nos valores das energias (diferenças menores a $70 \mathrm{meV}$ ), ainda sendo as duas simulações de tipo diferente, já que em nossas simulações se aplica uma série de cálculos para resolver a equação de Schrödinger em uma dimensão usando o método conhecido como Split-Operator e no trabalho (Ngo, 2006) são usados modelos atomísticos que são mais complexos de efetuar e demoram mais tempo que os nossos, podemos inferir que nossas simulações são confiáveis para fazer as posteriores análises embora elas sejam mais simples de efetuar.

\begin{tabular}{|r|r|r|r|c|c|r|}
\hline \multicolumn{1}{|c|}{$\mathbf{A}$} & \multicolumn{1}{|c|}{$\mathbf{V T}$} & \multicolumn{1}{c|}{$\mathbf{E e}$} & \multicolumn{1}{c|}{$\mathbf{E b}$} & $\mathbf{E n}$ & $\mathbf{E t}$ & \multicolumn{1}{c|}{$\mathbf{D}$} \\
\hline $\mathbf{( n m})$ & $\left.\mathbf{( x 1 0}^{\mathbf{3}} \mathbf{n m}^{\mathbf{3}}\right)$ & $\mathbf{( m e V})$ & $(\mathbf{m e V})$ & $(\mathbf{m e V})$ & $(\mathbf{m e V})$ & $\mathbf{m e V})$ \\
\hline 2 & 2,89 & 82,1 & 38,6 & 904,7 & 970,0 & 65,3 \\
\hline 3 & 4,33 & 75,1 & 37,8 & 896,9 & 949,0 & 52,1 \\
\hline 4 & 5,77 & 68,0 & 37,0 & 889,0 & 930,0 & 41,0 \\
\hline 5 & 7,22 & 60,9 & 36,2 & 881,1 & 916,0 & 34,9 \\
\hline 6 & 8,66 & 60,7 & 36,1 & 880,8 & 905,0 & 24,2 \\
\hline 7 & 10,10 & 59,5 & 35,9 & 879,4 & 895,0 & 15,6 \\
\hline 8 & 11,55 & 58,4 & 35,7 & 878,1 & 885,0 & 6,9 \\
\hline 9 & 12,99 & 57,2 & 35,5 & 876,7 & 878,0 & 1,3 \\
\hline 10 & 14,43 & 56,1 & 35,3 & 875,4 & 872,0 & 3,4 \\
\hline 11 & 15,87 & 54,9 & 35,1 & 874,0 & 865,0 & 9,0 \\
\hline 12 & 17,32 & 53,7 & 35,0 & 872,7 & 861,0 & 11,7 \\
\hline 13 & 18,76 & 52,6 & 34,8 & 871,4 & 857,0 & 14,4 \\
\hline
\end{tabular}

Tabela 6. Comparação de valores deste trabalho com as simulações de outro trabalho (Ngo, 2006); A: Altura dos pontos quânticos; VT: Volume dos pontos quânticos deste trabalho com diâmetro da base de $70 \mathrm{~nm}$; Ee: Energia dos elétrons (Ngo, 2006); Eb: Energia dos buracos (Ngo, 2006); En: Energia de transição para pontos quânticos com gap de 784 meV (Ngo, 2006); Et: Energia de transição para pontos quânticos com gap de

784 meV obtidas nas simulações deste trabalho; D: Diferença entre Et e Em

$\mathrm{Na}$ comparação das duas simulações (Figura 48) se observa que o comportamento é similar, na medida em que aumenta a altura dos pontos, e portanto o volume, a energia de transição diminui. Para pontos quânticos maiores, a energia não varia de forma significativa. 


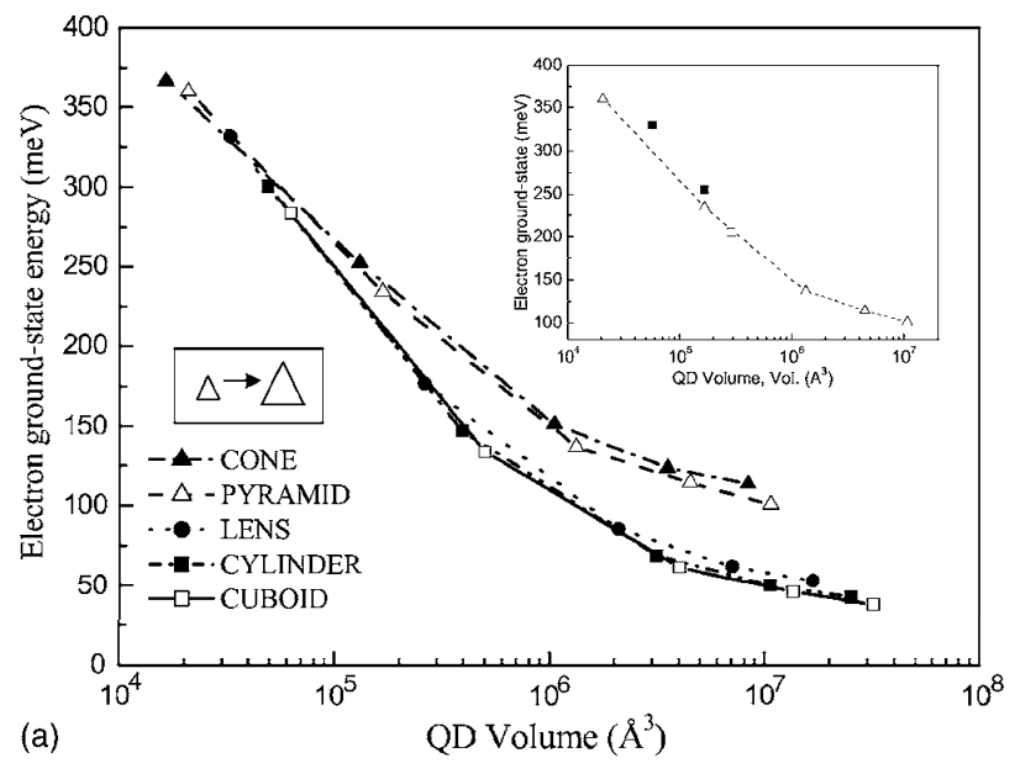

Figura 46. Energia dos elétrons em função do volume do ponto quântico a partir da referência $(\mathrm{Ngo}, 2006)$

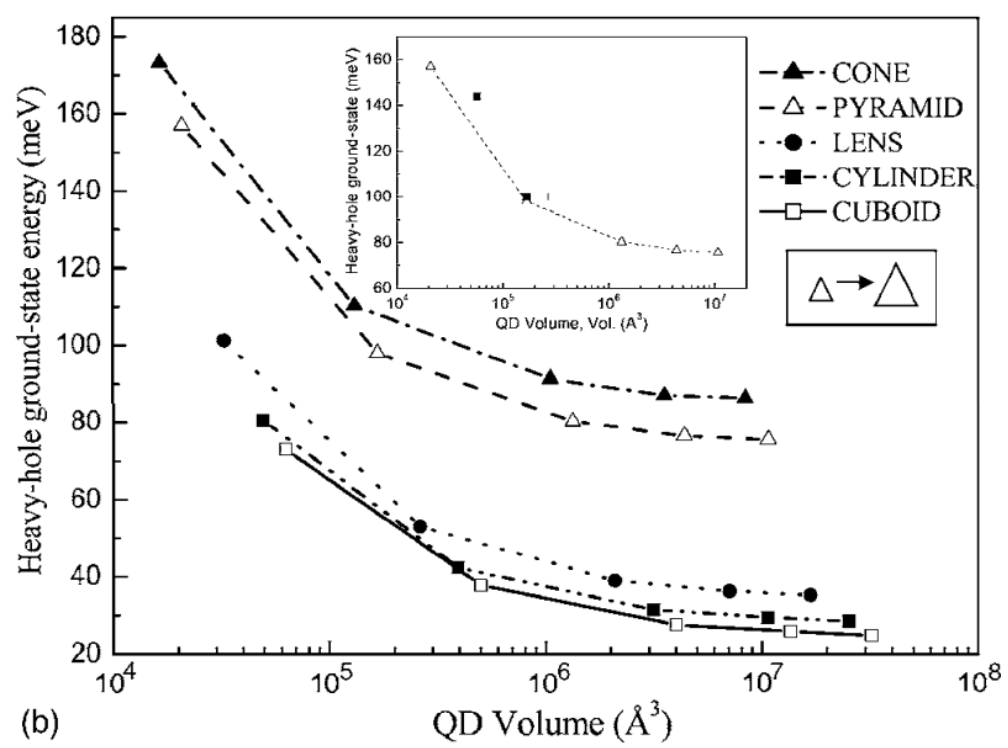

Figura 47. Energia dos buracos em função do volume do ponto quântico a partir da referência (Ngo, 2006) 


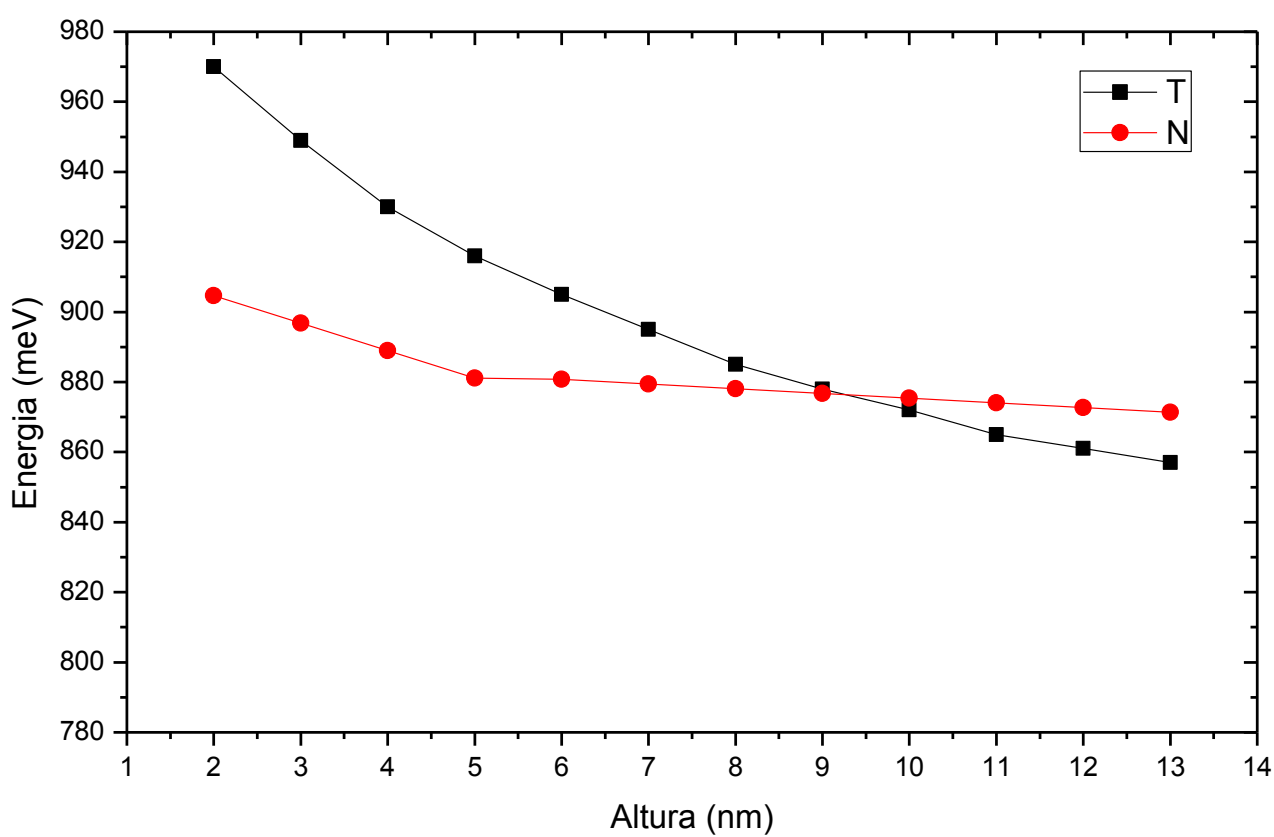

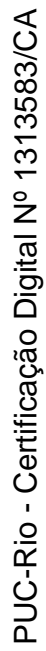

Figura 48. Comparação do gap de pontos quânticos em função da altura entre as simulações feitas neste trabalho e as simulações obtidas no trabalho (Ngo, 2006)

Energias de transição de pontos quânticos - $\left(\mathrm{E}_{\text {gap }} \ln \mathrm{As}=784 \mathrm{meV}\right)$

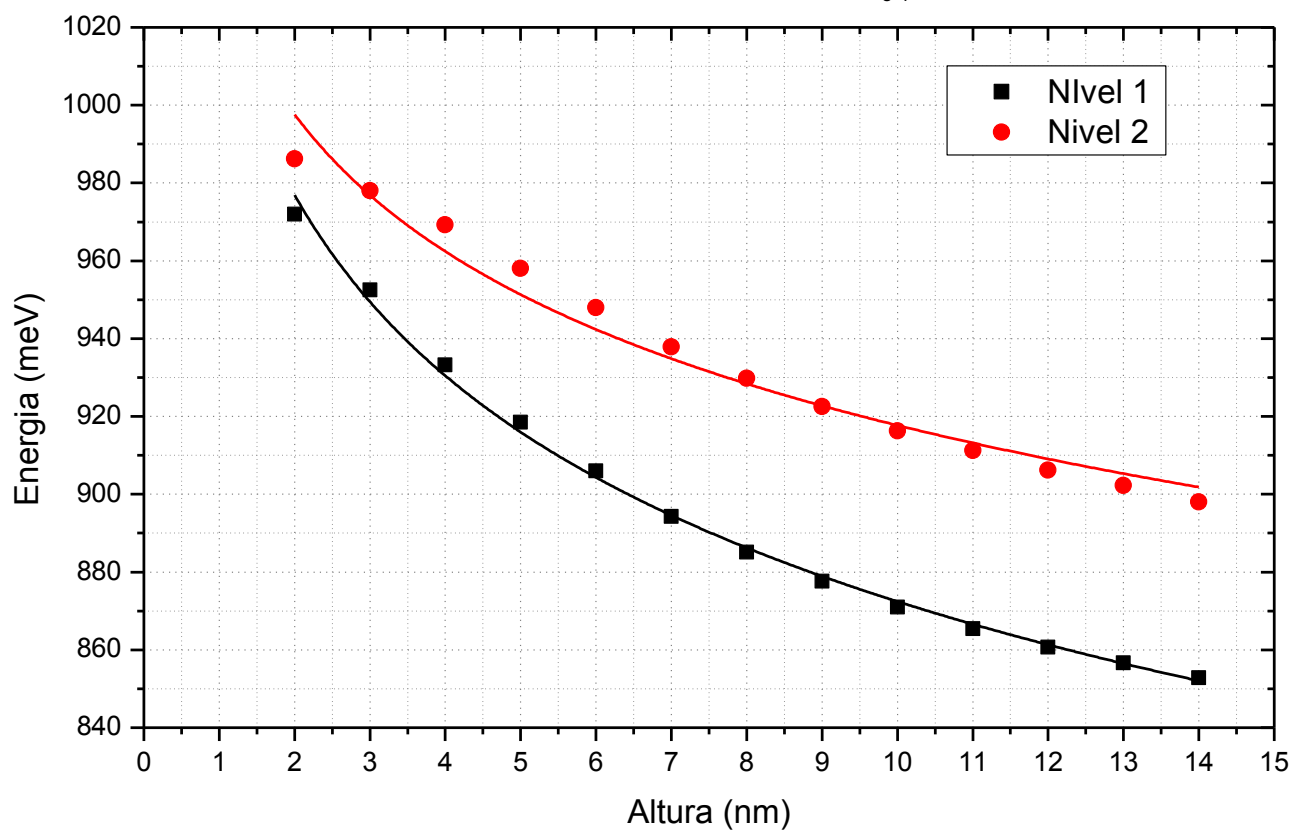

Figura 49. Energias de transição de pontos quânticos em função da altura, com gap de InAs $=784 \mathrm{meV}$. 


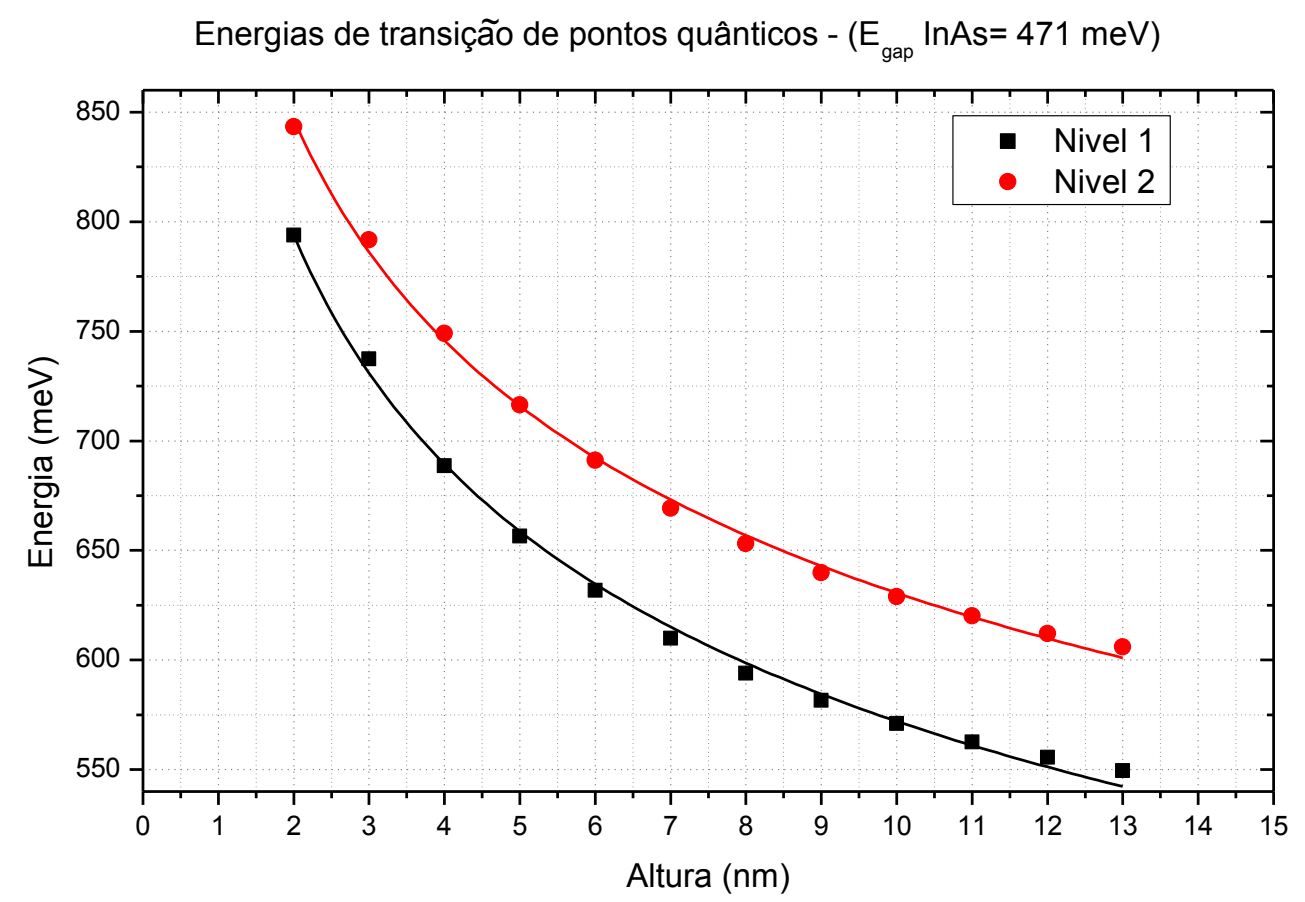

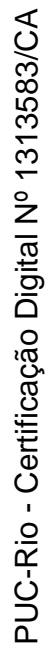

Figura 50. Energias de transição de pontos quânticos em função da altura, com gap de InAs $=471 \mathrm{meV}$.

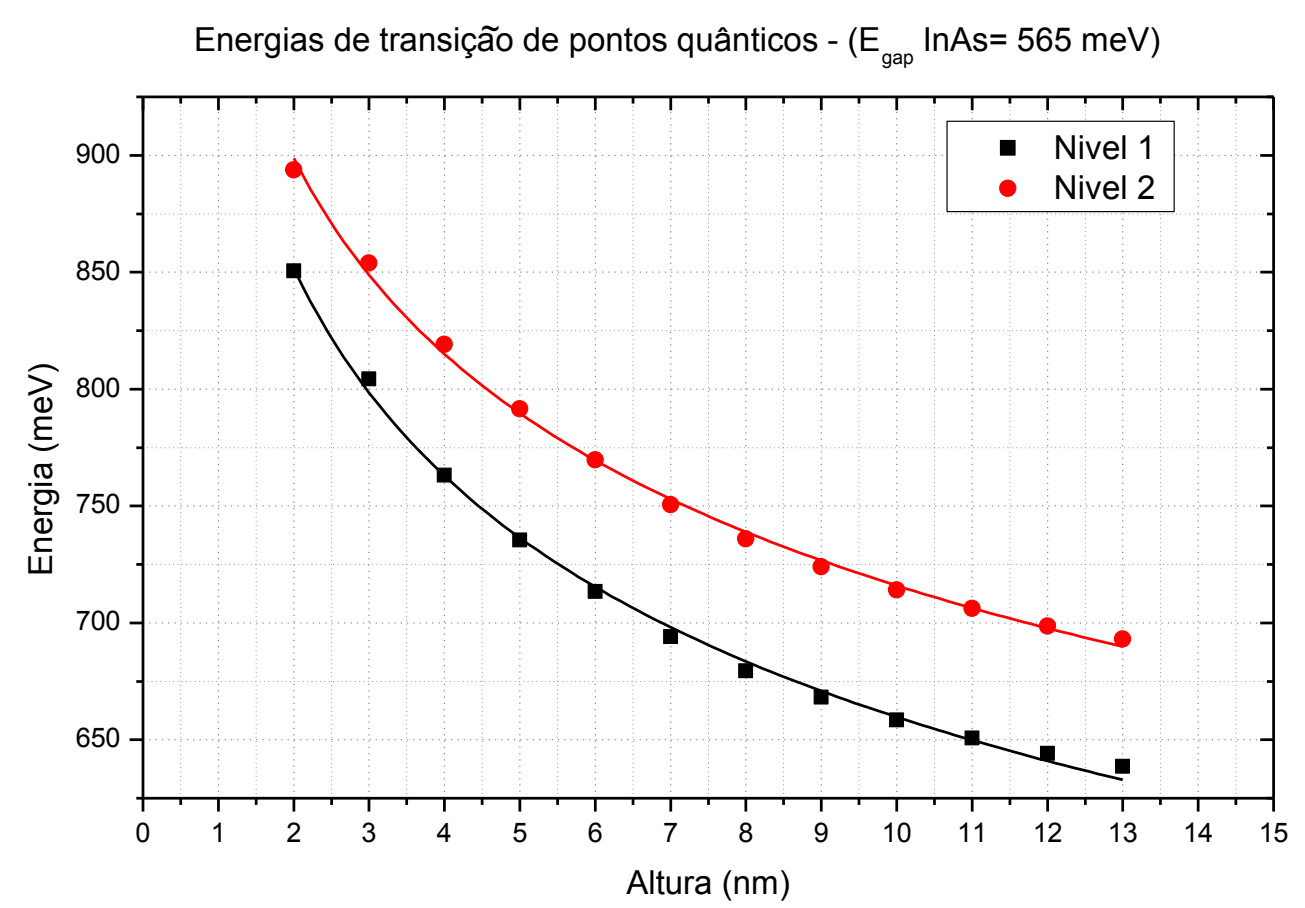

Figura 51. Energias de transição de pontos quânticos em função da altura, com gap de InAs $=565 \mathrm{meV}$. 
Destas simulações podemos obter os valores de energia de transição do nível fundamental e do excitado para qualquer altura de ponto quântico, assumindo três tensões diferentes do InAs.

Para calcular o nível de tensão do InAs e os níveis de energia para cada altura de pontos quânticos das amostras analisadas se realizou uma série de estimativas, as quais são mostradas em seguida, tomando como exemplo a amostra NR0305.

O histograma das alturas dos pontos quânticos da amostra NR0305 é mostrado na figura 52, a altura média dos pontos é $5.3 \mathrm{~nm}$. Para esta altura se determinam os valores das transições dos dois primeiros níveis de energia para os três valores de tensão do InAs simulados, mediante os gráficos das simulações, como se mostra na figura 53. Neste gráfico são mostrados os valores das transições de energia para pontos quânticos de InAs de $5.3 \mathrm{~nm}$ de altura em função da tensão do material InAs.

$\mathrm{Na}$ figura 54 é realizado o ajuste com curvas gaussianas para a sinal de fotoluminescência da mesma amostra NR0305, podendo observar nele, a fotoluminescência do material quaternário (energias entre 975 e $1075 \mathrm{meV}$ ) e a fotoluminescência dos pontos quânticos (energias entre 600 e $975 \mathrm{meV}$ ), sendo duas gaussianas com centros em 734.2 e $801.4 \mathrm{meV}$.

É estabelecida a energia mais baixa $(734.2 \mathrm{meV})$ como a energia de transição do primeiro nível; com esse valor se determina na figura 53 o valor da tensão do InAs para pontos quânticos de $5.3 \mathrm{~nm}$, que têm como energia de transição do nível fundamental um valor de $734.2 \mathrm{meV}$; se observa que o valor do gap de InAs tensionado que cumpre estas condições é $571 \mathrm{meV}$, marcando a interseção com uma estrela azul no desenho. 


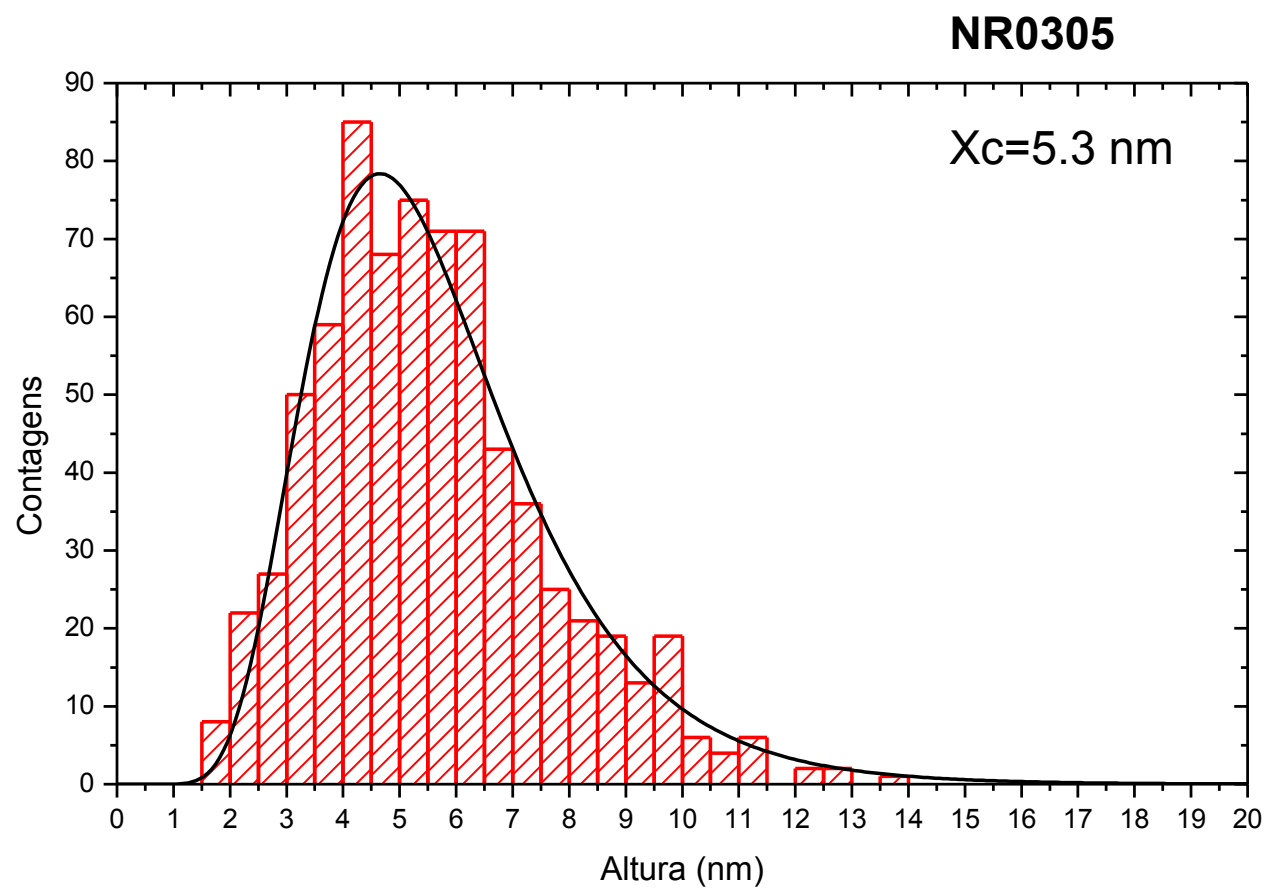

Figura 52. Histograma e ajuste por distribuição log-normal das alturas dos pontos quânticos da amostra NR0305.Xc representa o valor da média da distribuição.

É determinada a energia de transição para o segundo nível para o InAs tensionado com gap de $571 \mathrm{meV}$ que corresponde a um valor de $787.3 \mathrm{meV}$ como se mostra na figura 53. Este valor é muito próximo ao outro centro da gaussiana (801.4 meV) da fotoluminescência, considerando essa pequena diferença como um erro que pode ser dado pela soma dos pequenos erros de aproximação durante os processos, e as curvas que foram ajustadas na simulação dos pontos quânticos e que as diferenças em torno de $30 \mathrm{meV}$ não representam uma diferença de alguns angstrons na altura dos pontos quânticos.

Com esta análise, se determina que a energia do pico de fotoluminescência referente ao estado fundamental da amostra NR0305 que tem pontos quânticos de $5.3 \mathrm{~nm}$, é de $734,2 \mathrm{meV}$ e a resposta da fotoluminescência de $801.4 \mathrm{meV}$ corresponde ao segundo nível de energia para essa altura de pontos quânticos; além que a tensão do material para pontos quânticos de altura $5.3 \mathrm{~nm}$ fornece um valor para o gap do InAs tensionado é de $571 \mathrm{meV}$. 
Transições de energia para pontos de $5.3 \mathrm{~nm}$

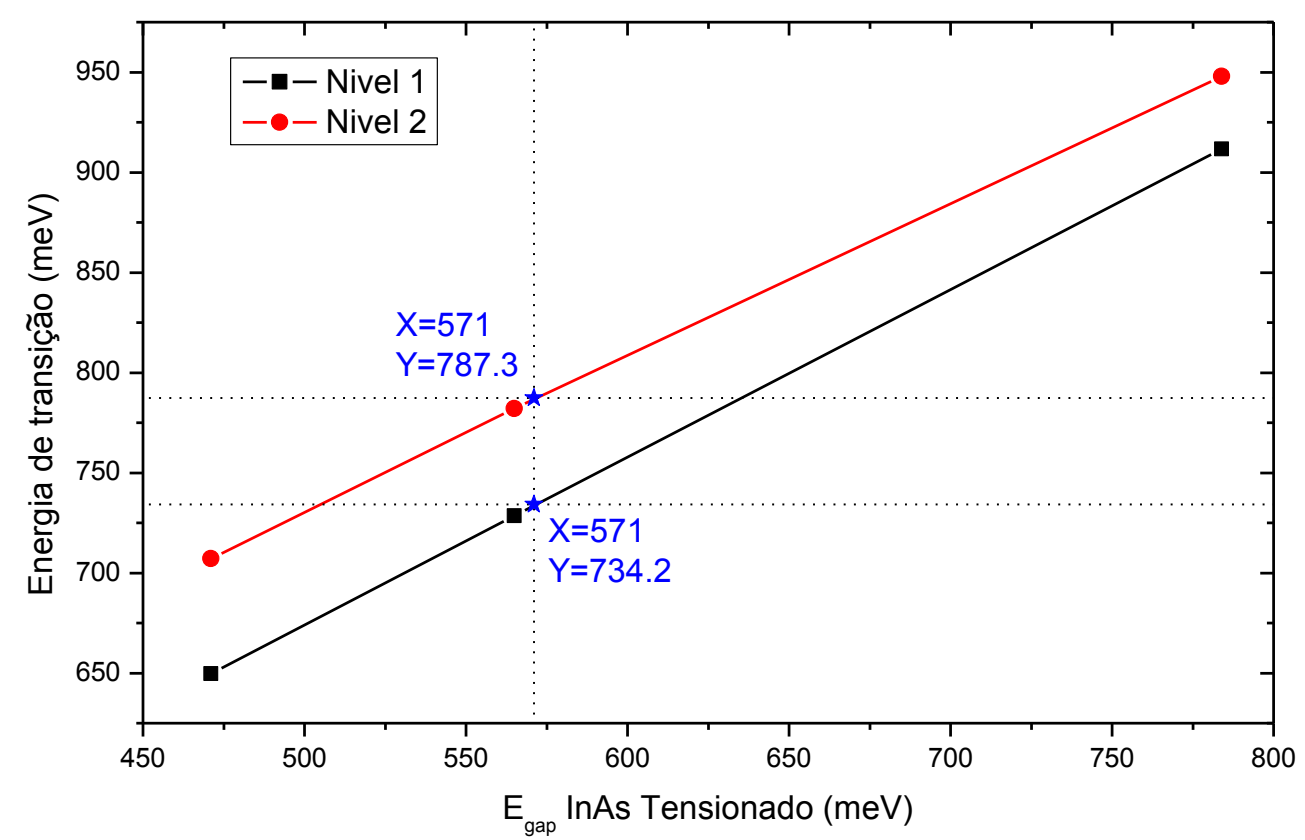

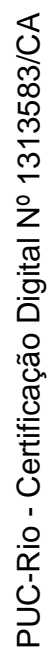

Figura 53. Transições dos dois primeiros níveis de energia para pontos quânticos de $5.3 \mathrm{~nm}$ em função da tensão do material. São marcadas em azul, os pontos correspondentes para uma energia de gap de InAs tensionado de $571 \mathrm{meV}$

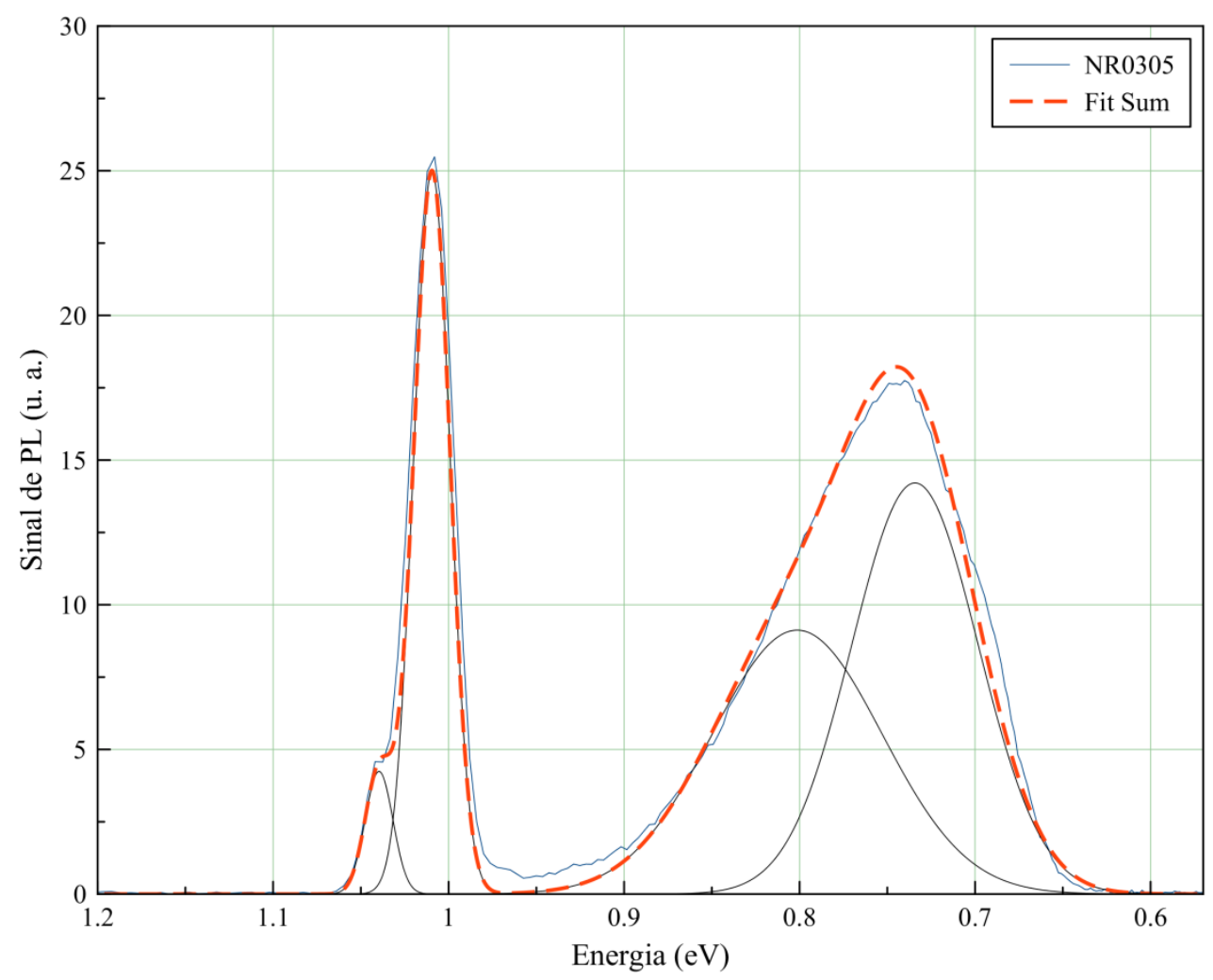

Figura 54. Ajuste da medida de fotoluminescência (300 mW) da amostra NR0305. 
O processo é repetido para cada uma das amostras, e os resultados finais são apresentados na tabela 7. Estes resultados correspondem a valores com as correções e otimização no processamento das medidas do AFM, e o valor da fotoluminescência com o ajuste.

\begin{tabular}{|c|c|c|c|c|c|c|c|c|c|c|c|}
\hline \multirow{2}{*}{ Amostra } & TMIn & TC & $\mathbf{Q M}$ & TemC & $\mathbf{A}$ & D & PL1 & PL2 & E2 & Gap & \multirow{2}{*}{\begin{tabular}{|c|} 
PT \\
$(\%)$ \\
\end{tabular}} \\
\hline & $(\mathrm{sccm})$ & (seg) & (ML) & $\left({ }^{\circ} \mathrm{C}\right)$ & $(\mathbf{n m})$ & $\left(\mathrm{x10} 0^{10} / \mathrm{cm}^{2}\right)$ & \multicolumn{4}{|c|}{$(\mathrm{meV})$} & \\
\hline NR0221 & 78 & 4,8 & 2,36 & 520 & 1,5 & 2,33 & 872,4 & 921,0 & 917,9 & 571,4 & 43,8 \\
\hline NR0227 & 78 & 5,5 & 2,70 & 520 & 2,7 & 3,14 & 854,8 & 927,8 & 897,1 & 634,1 & 65,5 \\
\hline NR0228 & 78 & 6,2 & 3,05 & 520 & 3,0 & 3,69 & 821,8 & 927,8 & 868,3 & 603,2 & 58,3 \\
\hline NR0237 & 78 & 5,5 & 3,05 & 530 & 2,7 & 1,92 & 828,6 & 933,6 & 875,0 & 596,1 & 56,7 \\
\hline NR0243 & 78 & 4,8 & 2,52 & 525 & 3,0 & 2,41 & 849,0 & 925,9 & 891,6 & 639,8 & 66,8 \\
\hline NR0244 & 78 & 4,8 & 2,18 & 515 & 3,5 & 2,11 & 827,1 & 944,2 & 871,9 & 631,8 & 64,9 \\
\hline NR0302 & 78 & 4,8 & 1,98 & 510 & 6,7 & 0,84 & 695,6 & 784,4 & 750,5 & 557,9 & 47,9 \\
\hline NR0303 & 78 & 4,8 & 2,79 & 535 & 7,7 & 0,64 & 691,4 & 732,3 & 746,4 & 569,5 & 50,6 \\
\hline NR0304 & 78 & 4,1 & 2,01 & 520 & 7,5 & 0,37 & 692,4 & 767,3 & 747,4 & 568,5 & 50,3 \\
\hline NR0305 & 78 & 6,9 & 3,39 & 520 & 5,3 & 0,97 & 734,2 & 801,4 & 787,3 & 571,8 & 51,1 \\
\hline NR0306 & 100 & 4,8 & 3,02 & 520 & 6,1 & 1,16 & 722,4 & 764,8 & 775,8 & 577,1 & 52,3 \\
\hline NR0307 & 120 & 4,8 & 3,63 & 520 & 6,5 & 1,25 & 699,5 & 744,6 & 754,3 & 558,7 & 48,1 \\
\hline NR0308 & 60 & 4,8 & 1,82 & 520 & 8,6 & 0,06 & 620,5 & & 677,9 & 505,4 & 35,8 \\
\hline
\end{tabular}

Tabela 7.Condições de crescimento da camada de pontos quânticos e os resultados da análise de suas propriedades ópticas e morfológicas. TMIn: TMIn Q source; TC: Tempo de crescimento; QM: Quantidade de material; TemC: Temperatura de Crescimento; A:

Altura dos pontos; D: Densidade; PL1: Fotoluminescência do primer nível; PL2: Fotoluminescência do segundo nível; E2: Energia do segundo nível (simulada); Gap: Gap do InAs tensionado; PT: Percentual de tensão do material InAs

\section{7}

\section{Análise das tensões do InAs}

A tensão dos pontos quânticos varia dependendo das condições de crescimento (Madhukar, 1994) e lembrando que na fabricação de amostras, quando o crescimento epitaxial começa, com cada camada que é crescida, o material vai se tencionando mais, até chegar à espessura crítica, nesse momento não ocorre o crescimento de mais outra camada. No lugar disso, quando um átomo chega sobre uma região que está muito tensionada, essa região começa a relaxar. Na medida em que vão chegando mais átomos, a região continua relaxando cada 
vez mais. Por isto se espera que para os pontos quânticos maiores, o material esteja mais relaxado em comparação com os pontos quânticos menores.

$\mathrm{Na}$ figura 55 se pode observar que a energia do gap do material InAs tensionado previsto pelas simulações conduzidas aumenta na medida em que diminuem as alturas dos pontos quânticos. Na medida em que os pontos aumentam de altura, o material InAs vai relaxando o que se pode observar na figura. Só há a exceção para os pontos menores que $2 \mathrm{~nm}$. Talvez sua dimensão tão reduzida esteja abaixo da espessura crítica e se trata de pontos quânticos ainda em formação. Finalmente se estima o nível de tensão dos pontos quânticos nas diferentes amostras fazendo uma interpolação linear, o resultado está mostrado na figura 55 na direita.

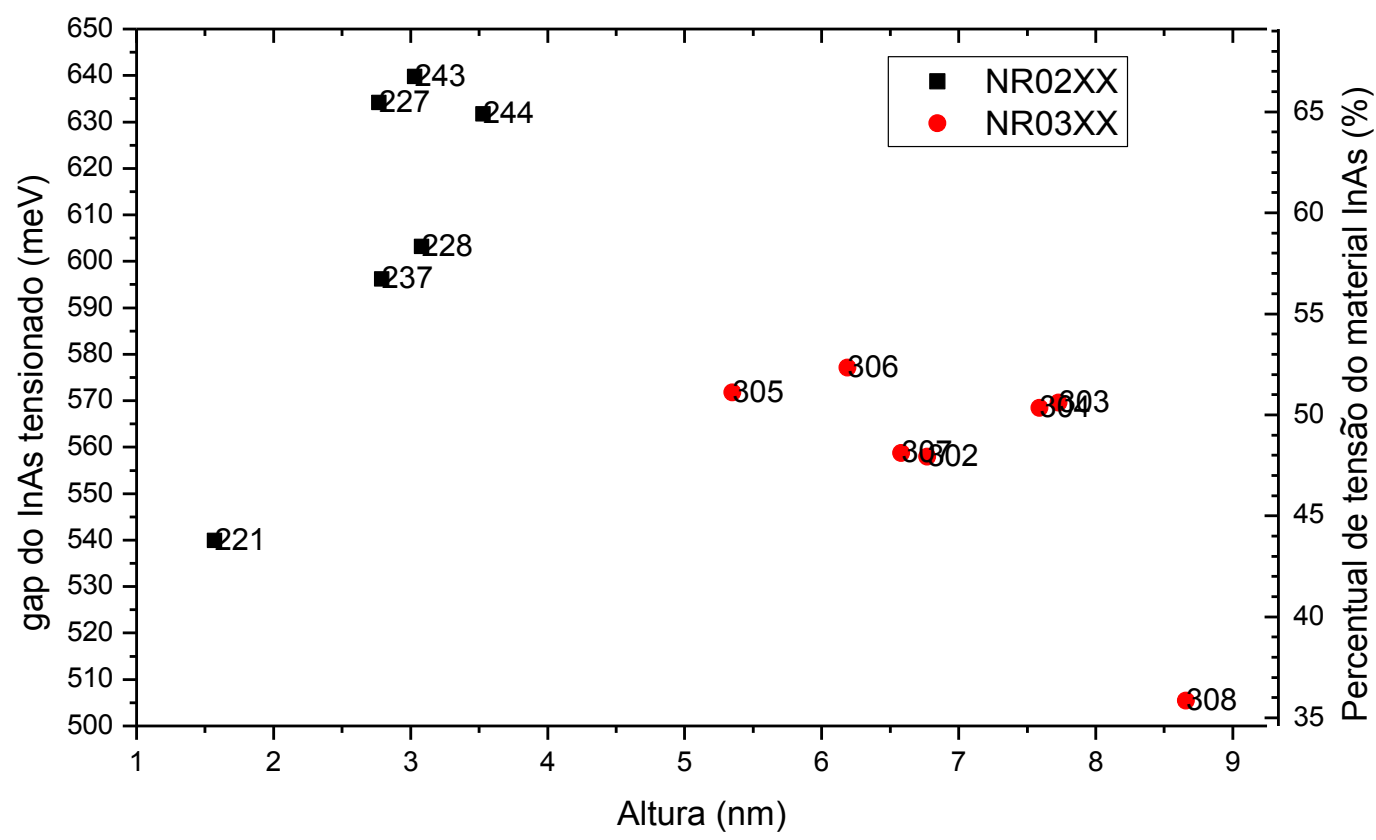

Figura 55. Relação entre a altura dos pontos quânticos e a energia do gap do InAs. 


\section{5 \\ Conclusões e Trabalhos Futuros}

\section{1}

\section{Conclusões}

Esta dissertação teve como objetivo principal realizar uma caracterização das propriedades ópticas e morfológicas das amostras com pontos quânticos de InAs crescidos sobre InGaAlAs e suas condições de crescimento. Realizando um estudo detalhado destas condições de crescimento e das características de cada uma das amostras, se conseguiu compreender as propriedades dos pontos quânticos em função de seus parâmetros de produção. Ainda que se apresentaram dificuldades nos processos de caracterização e inconvenientes nos resultados de algumas amostras como foi visto nos capítulos anteriores desta dissertação, se pode compreender como os parâmetros de crescimento influenciam no resultado final das amostras. As imagens obtidas por AFM foram avaliadas para ter as medições das alturas e densidades dos pontos quânticos. Uma metodologia para otimizar o processamento das imagens foi desenvolvida tendo resultados mais precisos na determinação das densidades e das alturas dos pontos quânticos. Se realizou um ajuste para os sinais de fotoluminescência das amostras, e foram reconhecidos, para cada uma delas, os picos de emissão do material quaternário, assim como os picos de fotoluminescência referentes aos estados fundamental e primeiro estado excitado de energia.

Se observou que o aumento da quantidade de material depositado resulta no aumento da densidade de pontos quânticos sobre a amostra, ao mesmo tempo as alturas dos pontos quânticos podem permanecer constantes ou ter um pequeno aumento.

Com o aumento do fluxo de TMIn a densidade de pontos quânticos sobre a amostra aumenta, mas a altura dos pontos quânticos diminui. Assim amostras com menor densidade de pontos quânticos têm pontos quânticos de maiores alturas.

Se observou que a densidade de pontos para a série NR03XX diminui ligeiramente, conforme o esperado, mas a alturas dos pontos quânticos sofrem um 
ligeiro aumento. Se afirma que a temperatura pouco influencia a altura dos pontos para esta série. Para a série NR02XX a densidade aumenta com a temperatura e a altura dos pontos oscila. Este fenômeno não pode ser explicado com os modelos existentes e se pode levantar a hipótese que para pontos quânticos tão pequenos $(\sim 2 \mathrm{~nm})$ o regime de nucleação seja diferenciado.

Os dados das densidades e das alturas das amostras com tempo de crescimento de 4,8 segundos se correlacionam, sendo que as amostras com altas densidades têm uma grande quantidade de pontos quânticos de alturas menores; mas nas amostras que têm baixas densidades o material é concentrado em poucas regiões formando pontos quânticos mais altos, tendo assim uma densidade muito menor. Trata-se de uma verificação da conservação de material.

Correlacionando os dados das simulações dos níveis de energia dos pontos quânticos com os valores dos picos das gaussianas ajustadas nos sinais de fotoluminescência e com as alturas dos pontos quânticos, se determinou que a energia do gap do material InAs tensionado aumenta na medida em que diminuem as alturas dos pontos quânticos. Em outras palavras, verifica-se que a medida que os pontos quânticos aumentam de altura, sua estrutura cristalina tende a relaxar mais. O gap de InAs apropriado para cada amostra dependendo do grau de tensão foi então determinado.

Conclui-se que as condições reais de crescimento podem variar, apesar do controle acurado que se tem dos parâmetros de crescimento. Amostras crescidas em épocas diferentes podem apresentar alterações difíceis de serem identificadas. Portanto, é sempre fundamental que amostras de calibração sejam feitas imediatamente antes de amostras finais para dispositivos.

\section{2 \\ Trabalhos Futuros}

As seguintes oportunidades de trabalhos futuros podem ser destacadas a partir deste trabalho:

- Criar um software que possibilite a automatização do processamento dos dados obtidos na fotoluminescência e AFM, aplicando algoritmos genéticos para reduzir o tempo de análise das imagens de AFM, além de 
facilitar a criação de gráficos com os dados finais e uma forma fácil de fazer o ajuste nos sinais de fotoluminescência.

- Crescer amostras com maior número de camadas de pontos quânticos, no lugar de ter apenas uma camada de pontos quânticos enterrada, se pode crescer amostras com mais camadas para analisar a influência da quantidade de camadas enterradas sobre os resultados finais.

- Aumentar o número de amostras para criar uma base de dados maior para otimizar o processo de obtenção de pontos quânticos utilizando técnicas de Inteligência Computacional como Algoritmos Genéticos e Redes Neurais.

- Avaliar o resultado de variar outros parâmetros nas amostras, tais como a temperatura de recozimento que é feito depois do crescimento dos pontos quânticos, variar as concentrações de alumínio no material quaternário, usar materiais ternários no lugar de materiais quaternários, mudar o material dos pontos quânticos (Borgstrom, 2003). Por exemplo, crescer pontos quânticos de InGaAs. 


\section{Referências Bibliográficas}

BASKARAN1, Arvind; SMEREKA, Peter. Mechanisms of Stranski-Krastanov growth. JOURNAL OF APPLIED PHYSICS 111, 044321, 2012.

BERGMANN, R.B., F.G. Shi, H.J. Queisser, J. Krinke, Formation of polycrystalline silicon with log-normal grain size distribution. Appl. Surf. Sci. 123/124,376, 1998.

BERGMANN, R.B., J. Krinke, H.P. Strunk, J.H. Werner. Deposition and characterization of polycrystalline silicon films on glass for thin film solar cells. Mater. Res. Soc. Symp. Proc.467, 325-330, 1997.

BERGMANN, Ralf B.; BILL, Andreas. On the origin of logarithmic-normal distributions: An analytical derivation, and its application to nucleation and growth processes. Journal of Crystal Growth 310, 3135- 3138, 2008.

BIMBERG, D; GRUNDMANN, M.; LEDENTSOV, N. N. Quantum Dot Heterostructures. ed. Wiley, 338, 1999.

BINnIG, G.; QUATE, C. F.; GERBER, Ch. Atomic Force Microscope, Phys. Rev. Lett. 56, 930, 1986.

BORGSTROM, M.; PIRES, M.P; BRYLLERT T.; LANDI, S.; SEIFERT, W.;SOUZA, P.L. InAs quantum dots grown on InAlGaAs lattice matched to InP. Journal of Crystal Growth 252, 481-485, 2003.

CAPASSO, F.; GMACHL, C.; PAIELLA, R.; TREDICUCCI, A.; HUNTCHINSON, A. L.; SIVCO,D. L.; BAILLAARGEON, J. N.; CHO, A. Y.; LIU, H. C. New Frontiers in Quantum Cascade Lasers and Applications. IEEE Journal of Selected Topics in Quantum Electronics 6, 931-947, 2000.

CAPPER, P.; M. Mauk. Liquid Phase Epitaxy of Electronic, Optical and Optoelectronic Materials. John Wiley \& Sons Ltd., England, 2007.

CHEN, J. F.; LIN, Y. C.; CHIANG, C. H.; CHEN, Ross C. C.; CHEN, Y. F.; WU, Y. H.; CHANG, L. How do InAs quantum dots relax when the InAs growth thickness exceeds the dislocation-induced critical thickness?. J. Appl. Phys, $111,013709,2012$.

CHO. A. Y; ARTHUR, J. R. Molecular beam epitaxy. Bell Laboratories, Murray Hill, New Jersey 07974, 1975.

DAWSON, L. R. Liquid phase epitaxy. Bell Telephone Laboratories, Incorporated, Murray Hill, New Jersey. Progress in Solid State Chemistry, 7, 117 139, 1972.

DEGANI, M. H.; MAIALLE, M. Z., Numerical Calculations of the Quantum States in Semiconductor Nanostructures. J. Comput. Theor. Nanosci. 7, 454, 2010 . 
DEGANI, Marcos H.; MAIALLE, Marcelo Z. Numerical Calculations of the Quantum States in Semiconductor Nanostructures. Journal of computational and theoretical nanoscience, 7, 454-473, 2010.

DOWLING, A. The Royal Society \& The Royal Academy of Engineering. Nanoscience and nanotechnologies: opportunities and uncertainties. Nanoscience and nanotechnologies, 2004

DREXLER, K. Eric. Nanosystems - molecular machinery, manufacturing, and computation. New York: John Wiley \& Sons. 362, 123, 1992.

DREXLER, K. Eric. Eric. Engines of Creation: The Coming Era of Nanotechnology. Doubleday, 1986.

Fiji Is Just ImageJ. http://fiji.sc/Fiji

GRUNDMANN, M., The Physics of Semiconductors: An Introduction Including Nanophysics and Applications.2nd Ed. Berlin: Springer, 689p, 2010.

HERMAN M.A.; H. SITTER. Molecular Beam Epitaxy, Fundamentals and Current Status. Springer Series in Materials Science 7, 2nd edition. SpringerVerlag, Berlin, 1996.

HORCAS, I.; FERNÁNDEZ, R.; GÓMEZ-RODRÍGUEZ, J. M.; COLCHERO, J.; GÓMEZ-HERRERO, J.; BARO, A. M. WSXM: A Software for Scanning Probe Microscopy and a Tool for Nanotechnology. Rev. Sci. Instrum. 78, 013705, 2007.

JAKOMIN, R.; KAWABATA, R.M.S.; MOURAO, R.T.; MICHA, D.N.; PIRES, M.P.; XIE, H.; FISCHER, A.M.; PONCE, F.A.; SOUZA, P.L. InAs quantum dot growth on Al $x$ Ga1 - $x$ As by metalorganic vapor phase epitaxy for intermediate band solar cells. J. Appl. Phys., 116, 093511, 2014

LEE, J. H.; WANG, Z. M.; KIM, N. Y.; SAlAMO, G. J. Size and Density Control of In Droplets at Near Room Temperatures. Nanotechnology, 20, 285602, 2009.

LINARES P. G.; MARTÍ, A; ANTOLÍN, E.; LUQUE, A. III-V compound semiconductor screening for implementing quantum dot intermediate band solar cells. Journal of Applied Physics 109, 014313, 2011.

MADHUKAR, A.; XIE, Q.; CHEN, P.; KONKAR, A. Nature of strained InAs three-dimensional island formation and distribution on GaAs(100). Appl. Phys. Lett. 64, 2727, 1994.

MANASEVIT, H. M. Single-crystal gallium arsenide on insulating substrates. Appl. Phys. Lett., 12, 4, 156, 1968.

MANASEVIT, H. M.; SIMPSON, W. I. The use of metal-organics in the preparation of semiconductor materials, J. Electrochem. Soc., 116, 12, 1725, 1969. 
MICHA, Daniel Neves. Estudo de alternativas para minimização de perdas em dispositivos fotovoltaicos de GaAs.2015. Teses (Doutorado em física) Instituto de Física, UFRJ, Rio de Janeiro, 2015.

MOORE, Gordon E. Cramming more components on to integrated circuits. Electronics magazine, 38, 8, 1965.

MOURÃO, Renato Teixeira. Crescimento e caracterização de materiais e nanoestruturas semicondutores para aplicação em células solares.2013. Dissertação (Mestrado em física) - Instituto de Física, UFRJ, Rio de Janeiro, 2013.

Nanotecnologia na PUC-Rio http://nanotech.ica.ele.puc-rio.br/

NARVAEZ, G.; BESTER, G.; ZUNGER, A. Dependence of the electronic structure of self-assembled (In, Ga) As/GaAs quantum dots on height and composition. J. Appl. Phys. 98, 043708, 2005.

NGO, C.Y.; YOON, S.F.; FAN, W.J.; CHUA, S.J. Effects of size and shape on electronic states of quantum dots. Phys. Rev. B, 74, 245331, 2006.

PANKOVE, J. I. Optical Processes in Semiconductors. Dover Publications Inc., New York. 422p, 1971.

RUIZ, J. E. Caracterización del desplazamiento de un disco piezoeléctrico em función del voltaje com corrección de histéresis y arrastre mediante um control em lazo cerrado, utilizando interferometría. 2013. $153 \mathrm{f}$. Trabalho de grado (Graduação) -Facultad de ingeniería - Programa de electrónica, Universidad de Nariño, San Juan de Pasto, Colombia, 2013.

SÁNCHEZ, J.T.; COPPOLA, H.R.; REIG, G.A. Nanoestructuras semiconductoras: fundamentos $\mathbf{y}$ aplicaciones. ed. CYTED, Ciencia y Tecnología Para el Desarrollo, 422p, 2003.

SEIFERT, W.; CARLSSON, N.; JOHANSSON, J.PISTOL; M.E.; SAMUELSON, L. In situ growth of nano-structures by metal-organic vapour phase epitaxy. Journal of Crystal Growth, 70, 39, 1997.

SHU-SHEN, Li; XIA, Jian-Bai; YUAN, Z. L.;XU, Z. Y. Effective-mass theory for InAs/GaAs strained coupled quantum dots. Physical review b, 54, 16, 1996.

SILVA. Artur Jorge. Crescimento de Pontos Quânticos das Famílias InAs/InP, InAs/InGaAs e InAs/InGaAlAs para Fotodetectores de Radiação Infravermelha. 2008. Teses (Doutorado) - Departamento de Engenharia elétrica, PUC-Rio, Rio de Janeiro, 2008

SOUZA, P. L.; LOPES A. J.; GEBHARD, T.; UNTERRAINER, K.; PIRES, M. P.; VILLAS-BOAS, J. M.; VIEIRA, G. S.; GUIMARÃES, P. S. S.; STUDART, Nelson. Quantum dot structures grown on Al containing quaternary material for infrared photodetection beyond $10 \boldsymbol{\mu m}$. Applied Physics Letters 90, 173510, 2007. 
STRINGFELLOW, G. B. Organometallic vapor phase epitaxy: theory and practice. Academic Press, Inc., San Diego. 572p, 1989.

TOWE, E.; PAN, D. Semiconductor quantum-dot nanostructures: their application in a new class of infrared photodetectors. IEEE J. Selec Top. Quantum Electr. 6, 408, 2000.

WOLFGANG, L.; Bottom-up Methods for Making Nanotechnology Products. Industrial Application of Nanomaterials - Chances and Risks: Technology Analysis. $2004 . \quad$ Disponível $<$ http://www.azonano.com/article.aspx?ArticleID=1079\#_SelfAssembly_of_Nanoparticles> Acesso em: 20 fev. 2015.

WSxM, version 4.0. Windows Scanning X (Force, Tunneling, Near Optical, ...) Microscope. SPM Image Process - Flooding. Free software at www.nanotec.es. 2015 .

ZANETTE, Suzana I. Introdução a Microscopia de Força Atómica, Livraria da Física, 1a edição.112p, 2010.

ZHANG, Xiang; SUN, Cheng; FANG, Nicholas. Manufacturing at nanoscale: Top-down, bottom-up and system engineering. Journal of Nanoparticle Research. 6, 125, 2003.

ZHU, T.; EL-ELLA, H. A. R.; REID, B.; HOLMES, M. J.; TAYLOR, R. A.;KAPPERS, M. J.; OLIVER, R. A. Growth and Optical Characterisation of Multilayers of InGaN Quantum Dots. J. Cryst. Growth, 338, 262, 2012.

ZRIBI, J.; ILAHI, B.; MORRIS, D.; AIMEZ, V.; ARÈS, B. Chemical beam epitaxy growth and optimization of InAs/GaAs quantum dot multilayers. J. Cryst. Growth, 384, 21, 2013 


\section{Apêndice A - Resultados de caracterização morfológica}

O processo de caracterização das propriedades morfológicas das amostras foi realizado com ajuda de um microscópio de força atômica. A medida foi feita em diferentes regiões da amostra para garantir uma homogeneidade nos resultados. Seguem os histogramas obtidos, bem como o ajuste com uma distribuição log-normal.

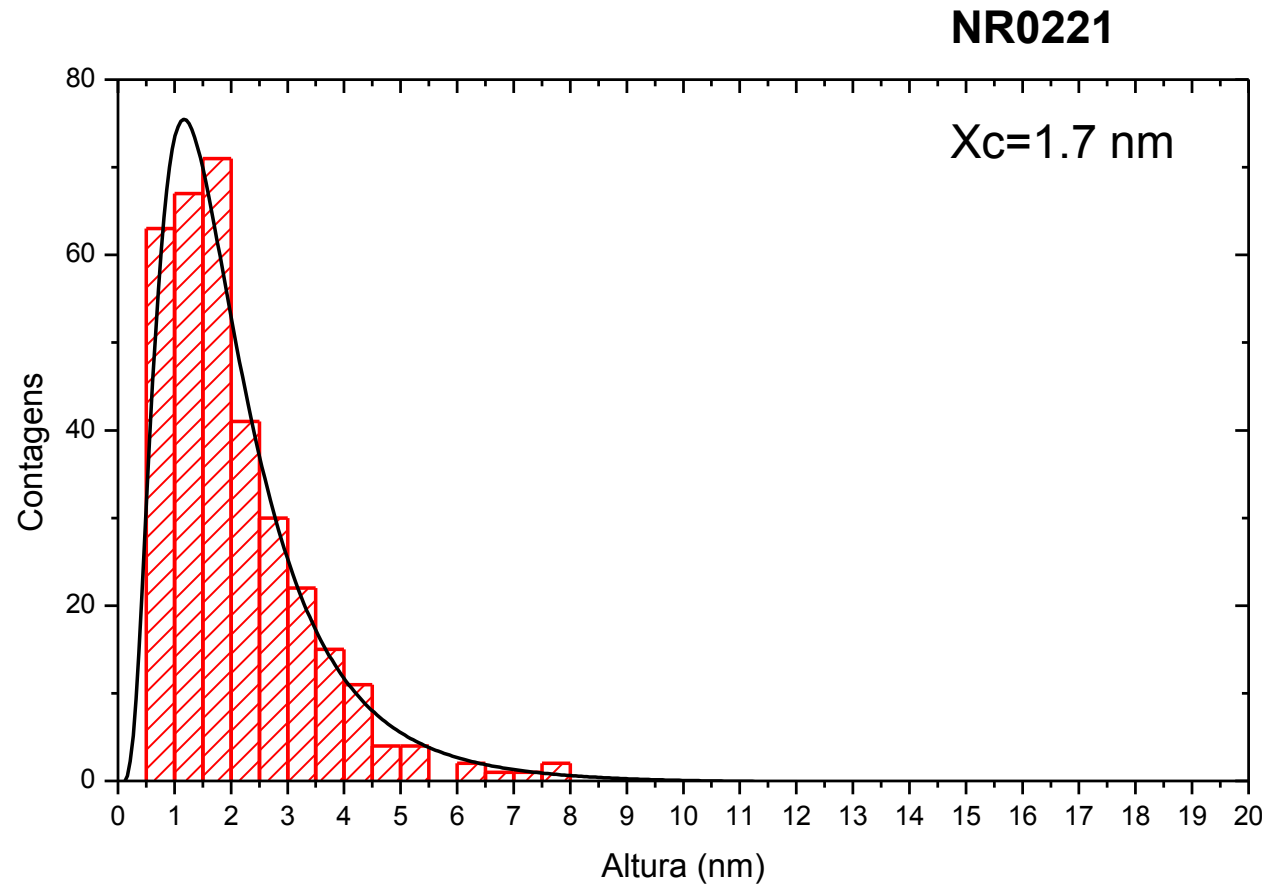

Figura 56. Histograma e ajuste por distribuição log-normal das alturas dos pontos quânticos da amostra NR0221.Xc representa o valor da média da distribuição. 
NR0227

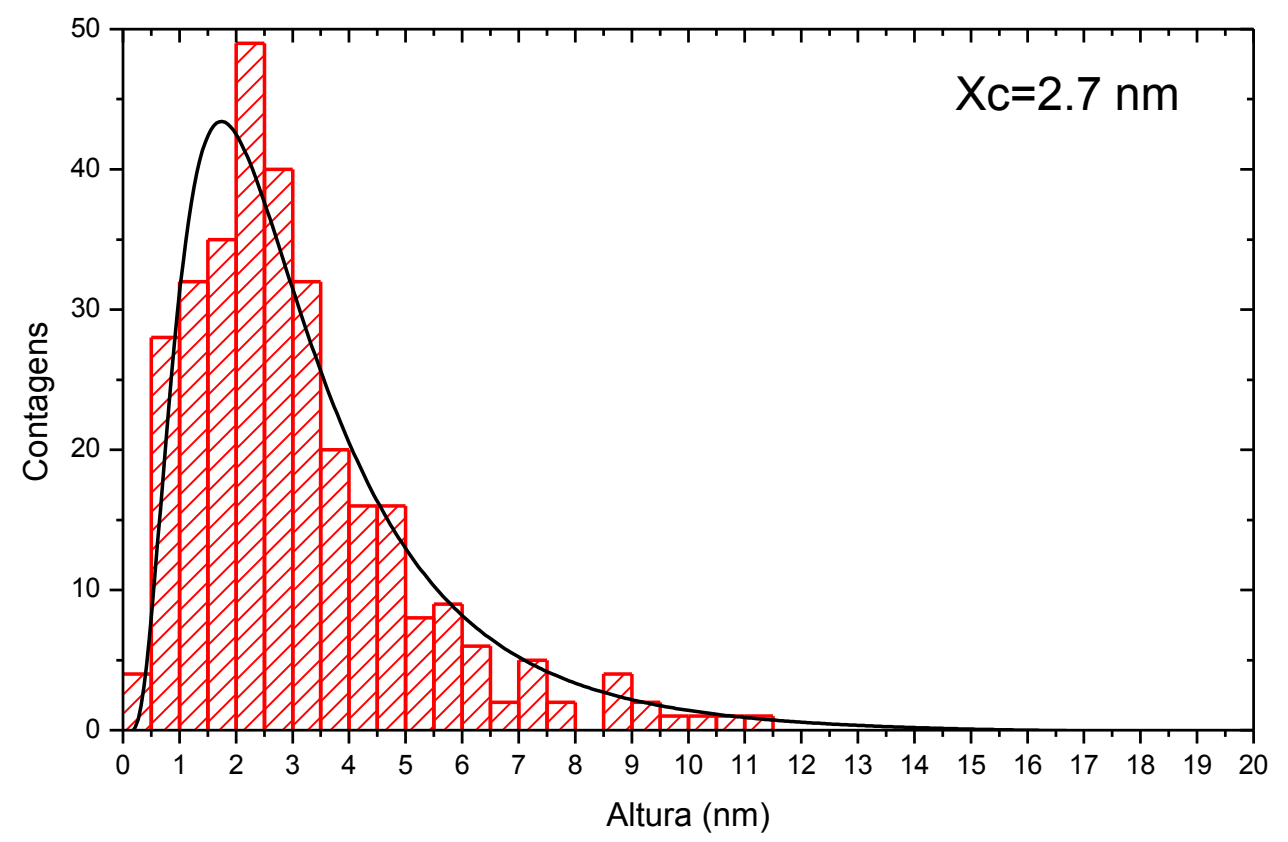

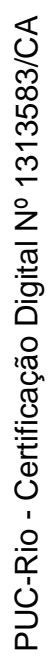

Figura 57. Histograma e ajuste por distribuição log-normal das alturas dos pontos quânticos da amostra NR0227.Xc representa o valor da média da distribuição.

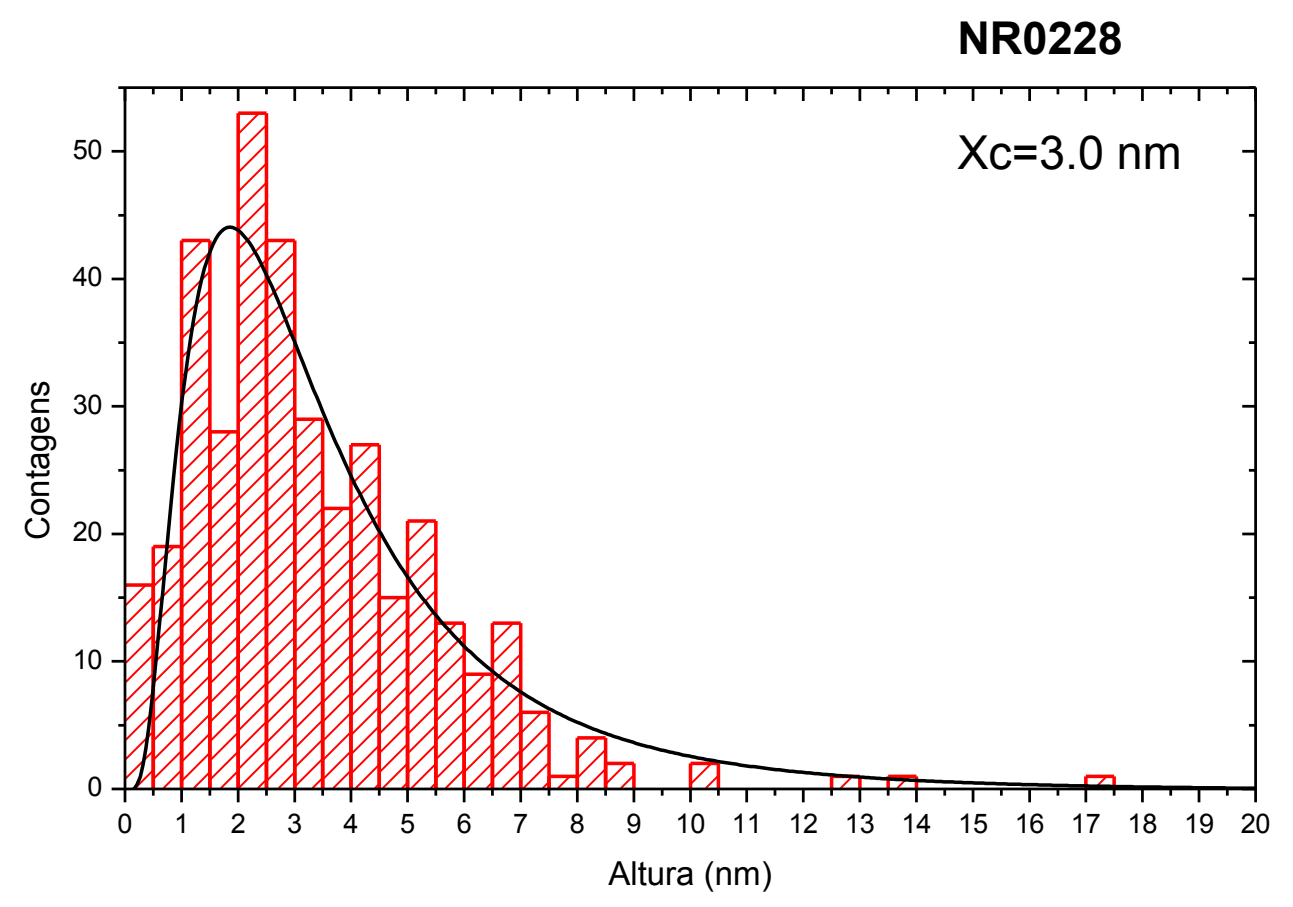

Figura 58. Histograma e ajuste por distribuição log-normal das alturas dos pontos quânticos da amostra NR0228.Xc representa o valor da média da distribuição. 
NR0237

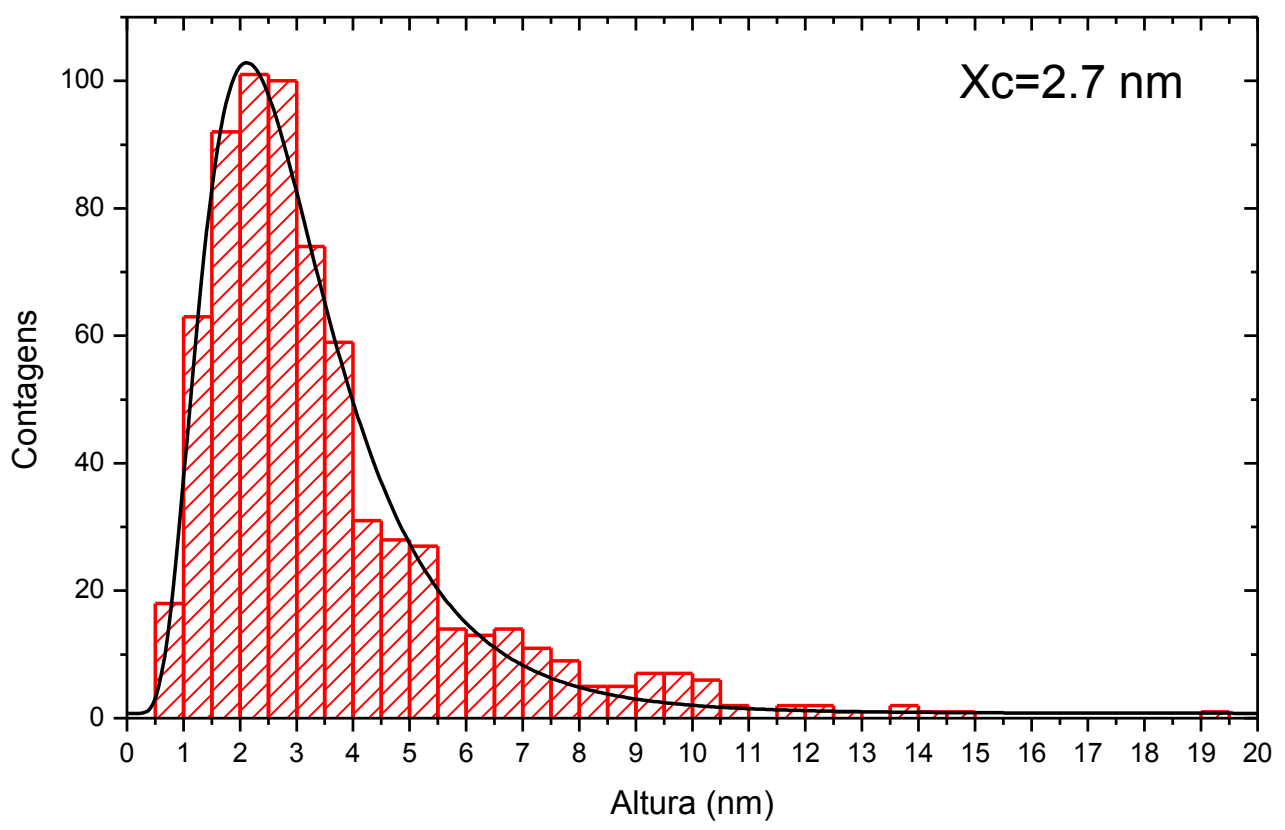

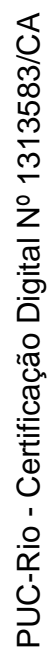

Figura 59. Histograma e ajuste por distribuição log-normal das alturas dos pontos quânticos da amostra NR0237.Xc representa o valor da média da distribuição.

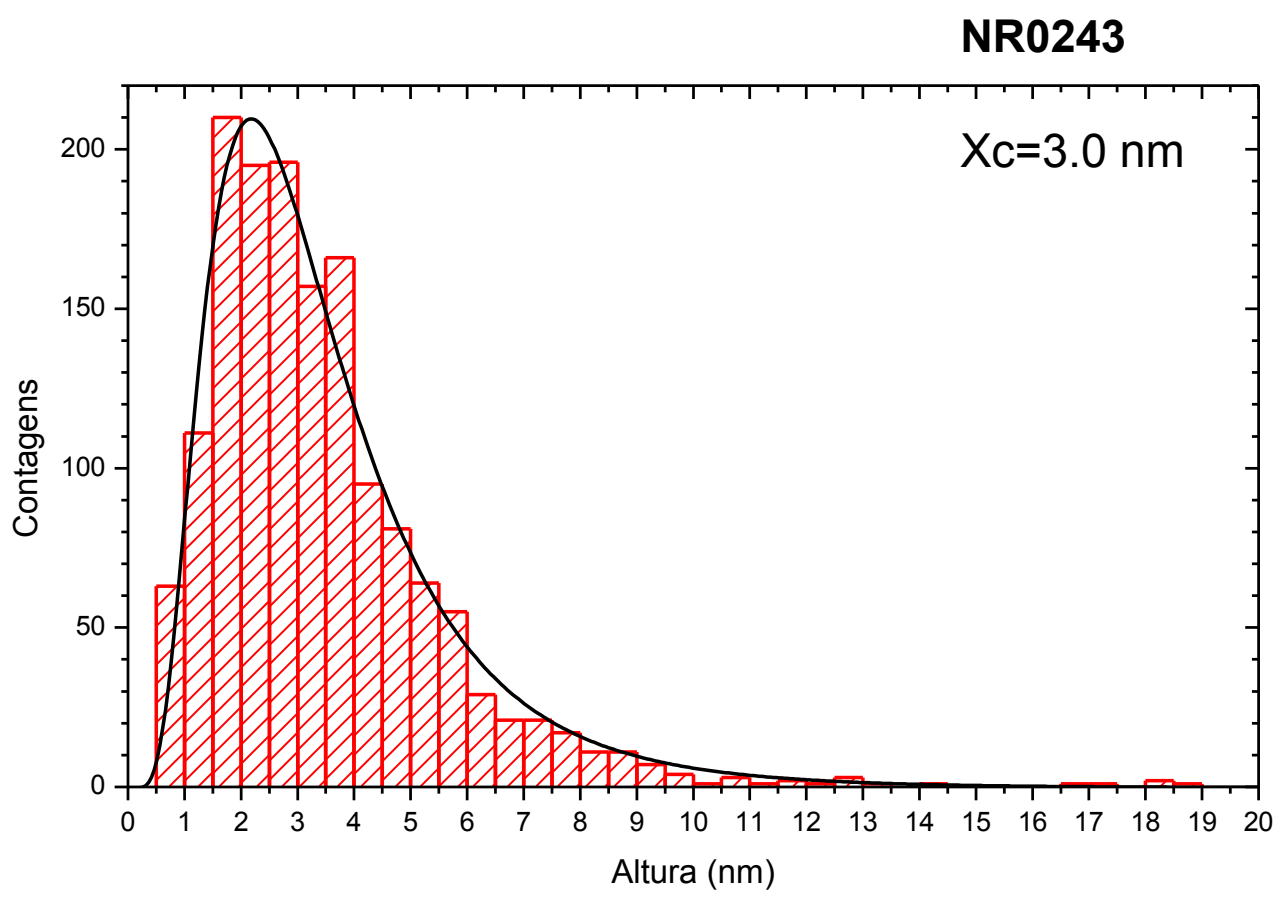

Figura 60. Histograma e ajuste por distribuição log-normal das alturas dos pontos quânticos da amostra NR0243.Xc representa o valor da média da distribuição. 


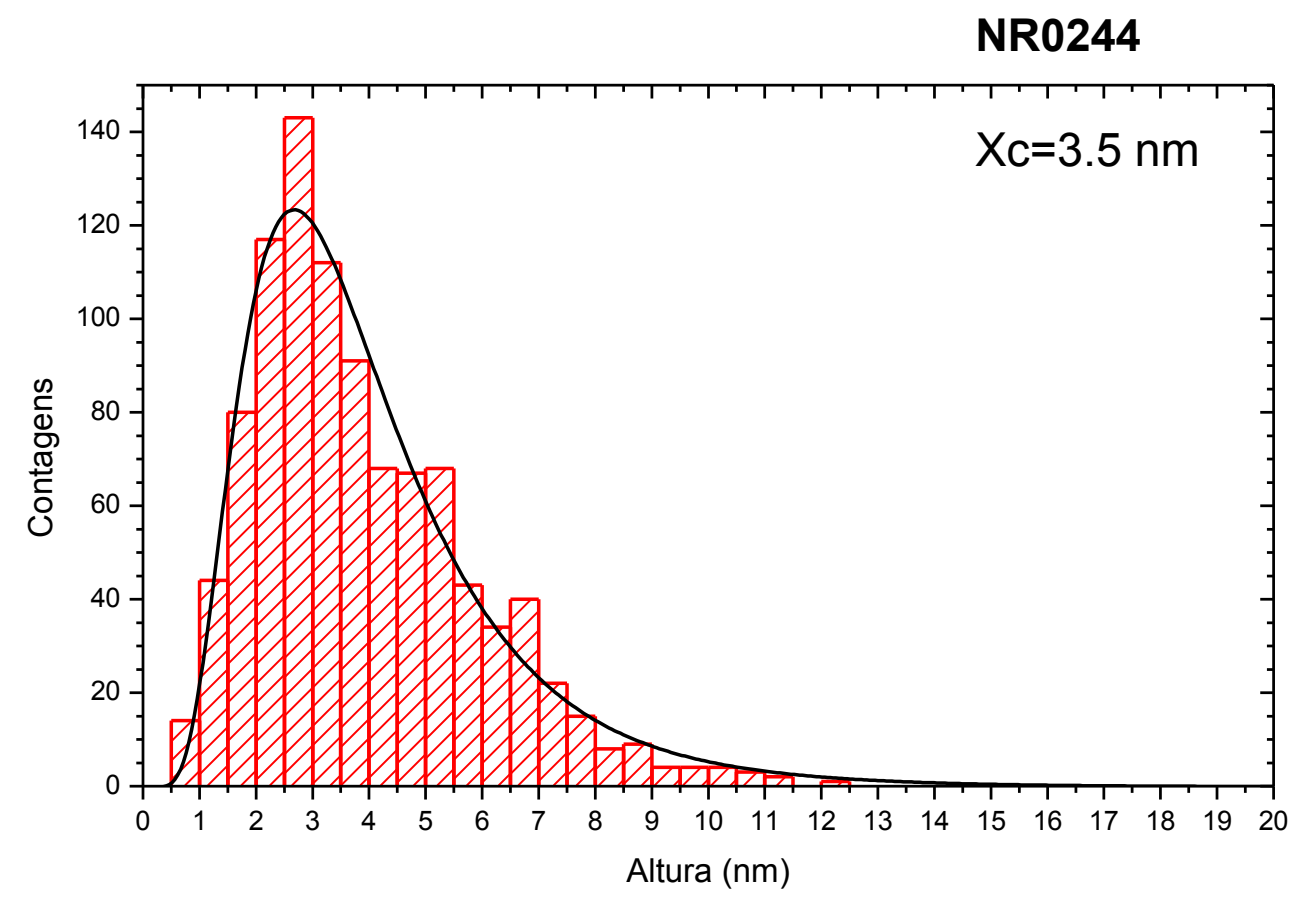

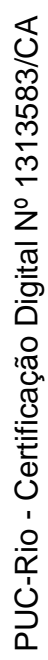

Figura 61. Histograma e ajuste por distribuição log-normal das alturas dos pontos quânticos da amostra NR0244.Xc representa o valor da média da distribuição.

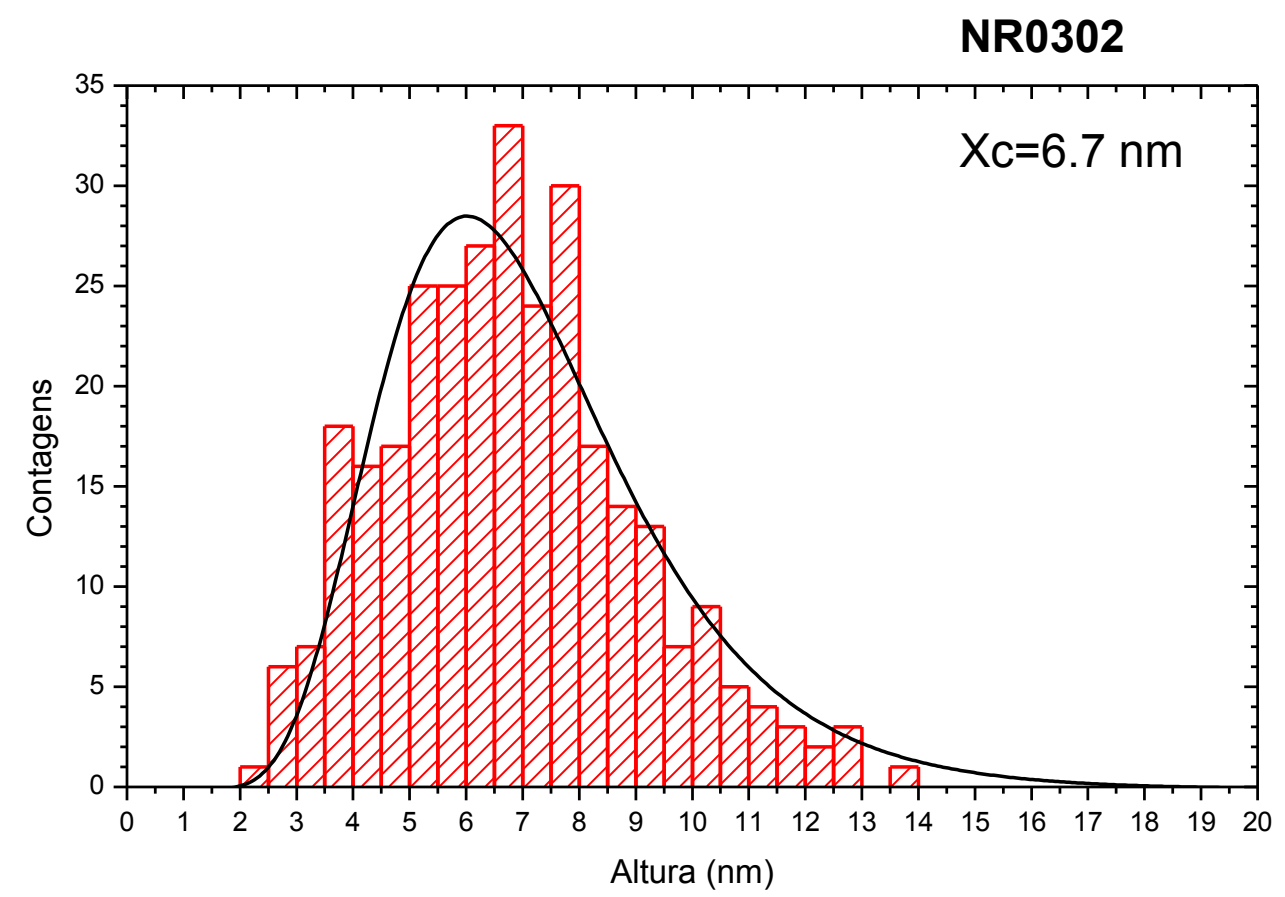

Figura 62. Histograma e ajuste por distribuição log-normal das alturas dos pontos quânticos da amostra NR0302.Xc representa o valor da média da distribuição. 
NR0303

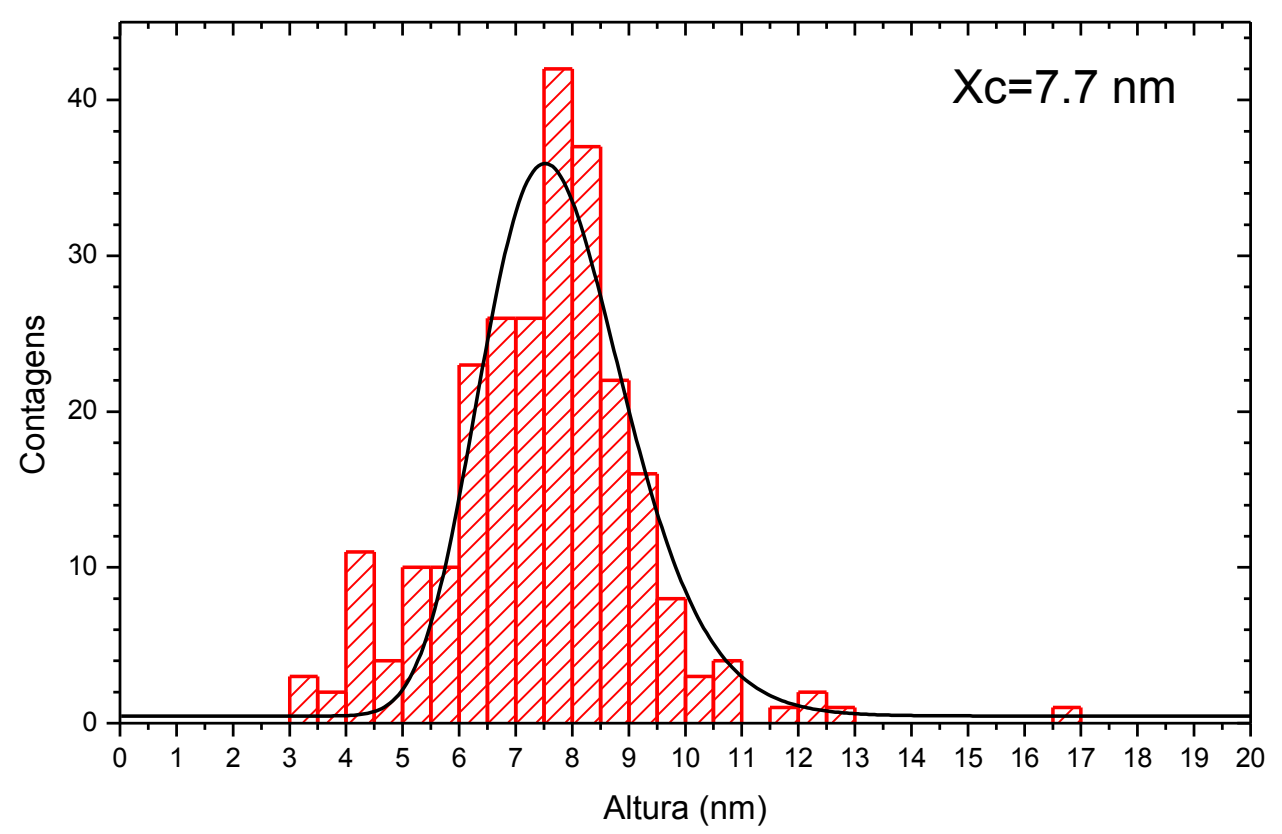

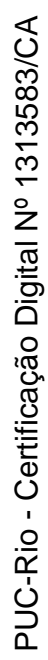

Figura 63. Histograma e ajuste por distribuição log-normal das alturas dos pontos quânticos da amostra NR0303.Xc representa o valor da média da distribuição.

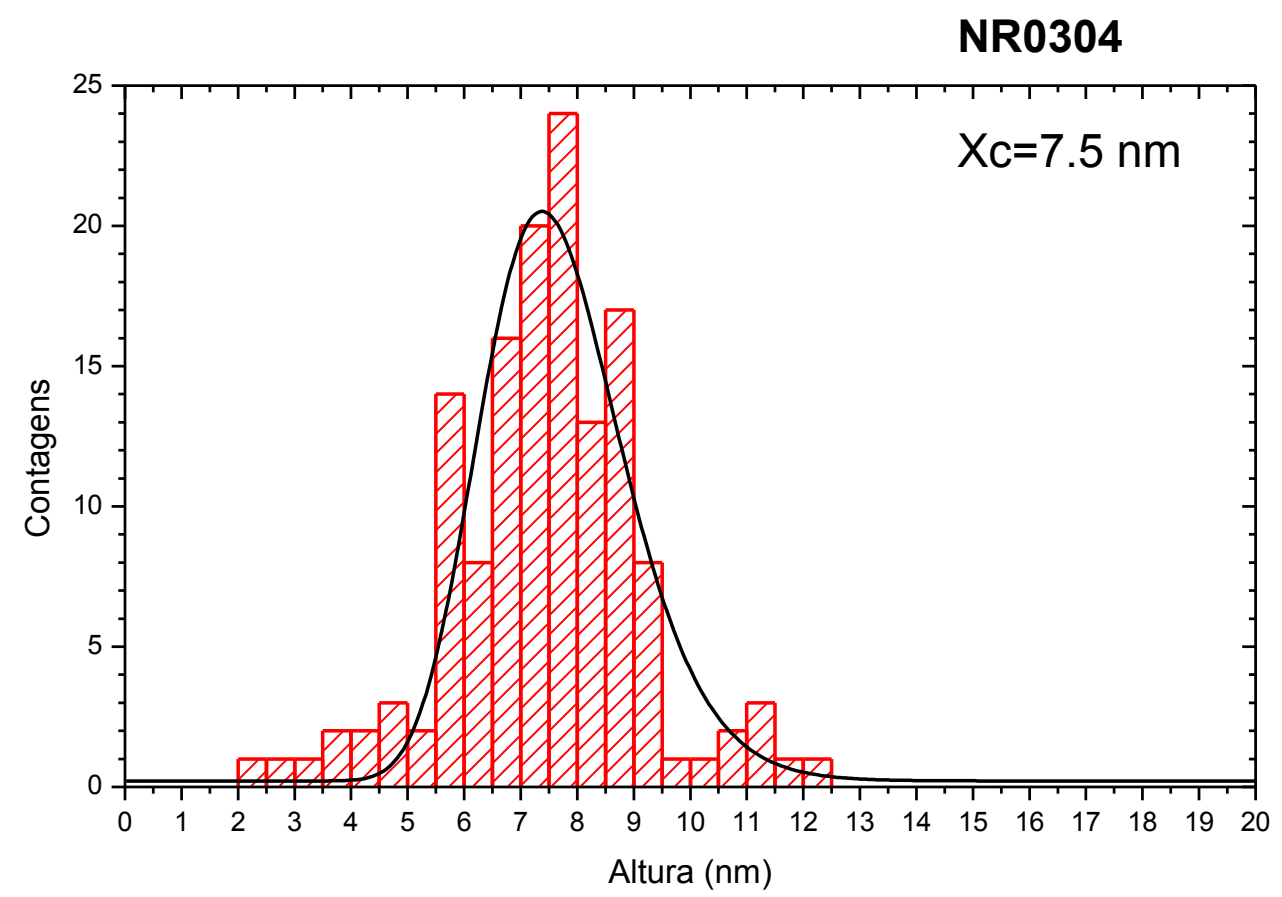

Figura 64. Histograma e ajuste por distribuição log-normal das alturas dos pontos quânticos da amostra NR0304.Xc representa o valor da média da distribuição. 
NR0305

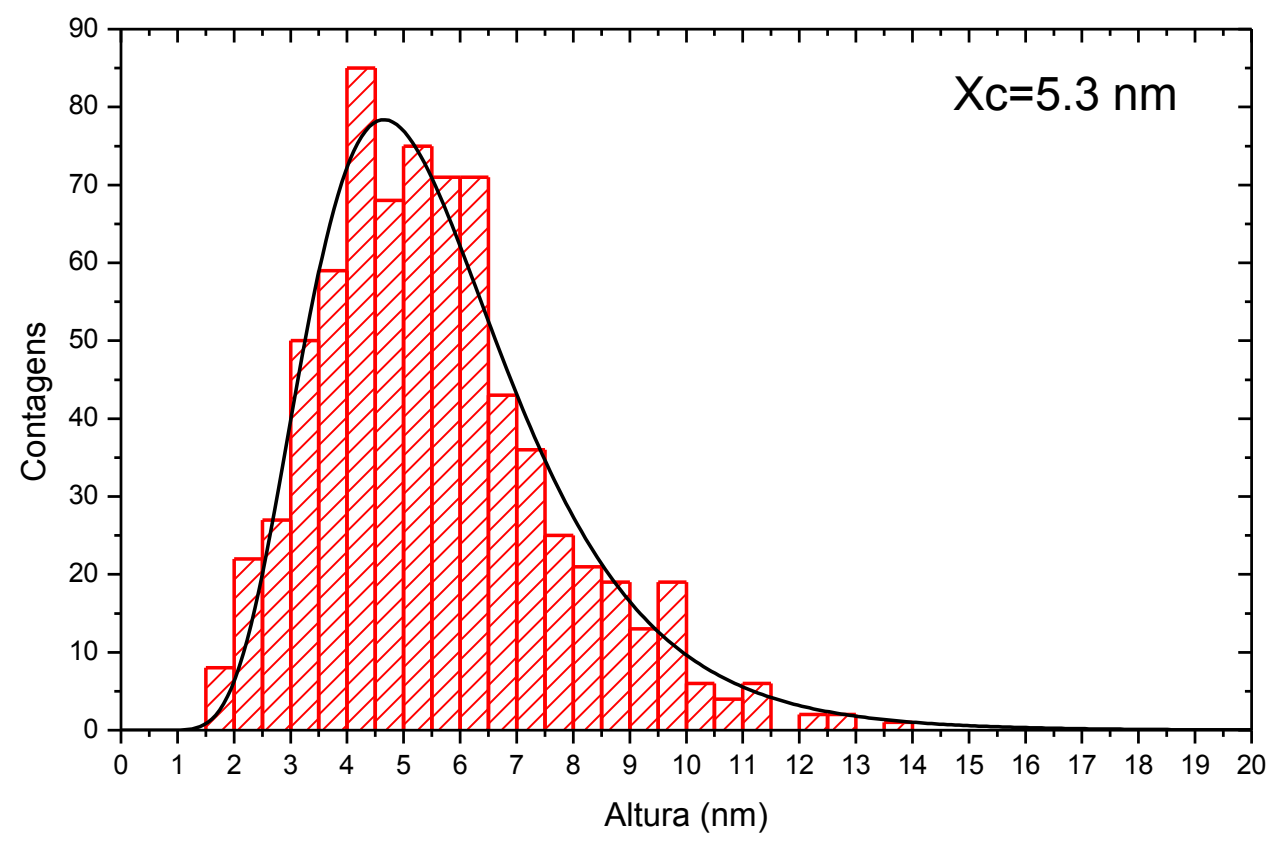

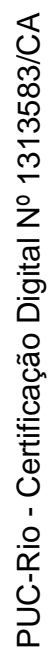

Figura 65. Histograma e ajuste por distribuição log-normal das alturas dos pontos quânticos da amostra NR0305.Xc representa o valor da média da distribuição.

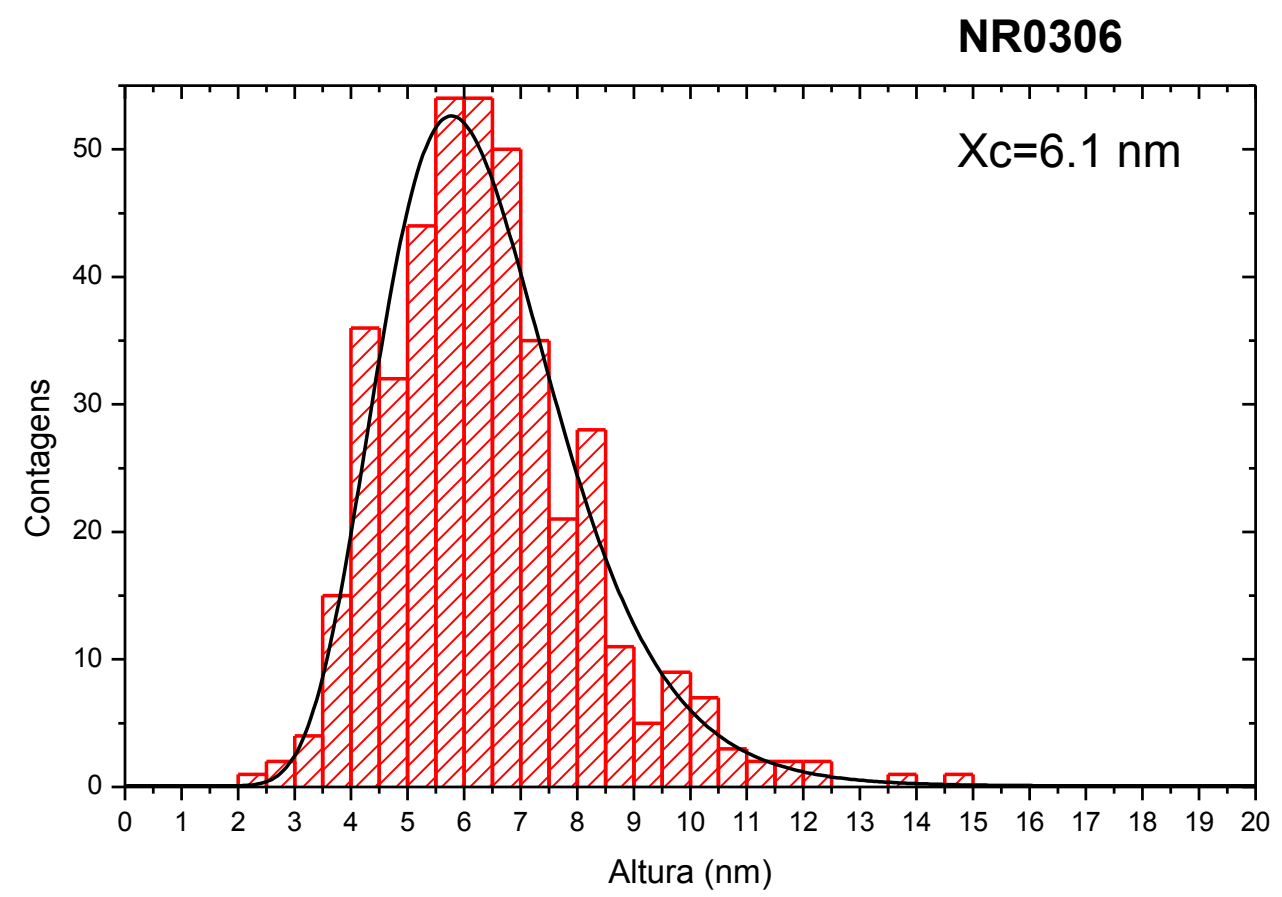

Figura 66. Histograma e ajuste por distribuição log-normal das alturas dos pontos quânticos da amostra NR0306.Xc representa o valor da média da distribuição. 
NR0307

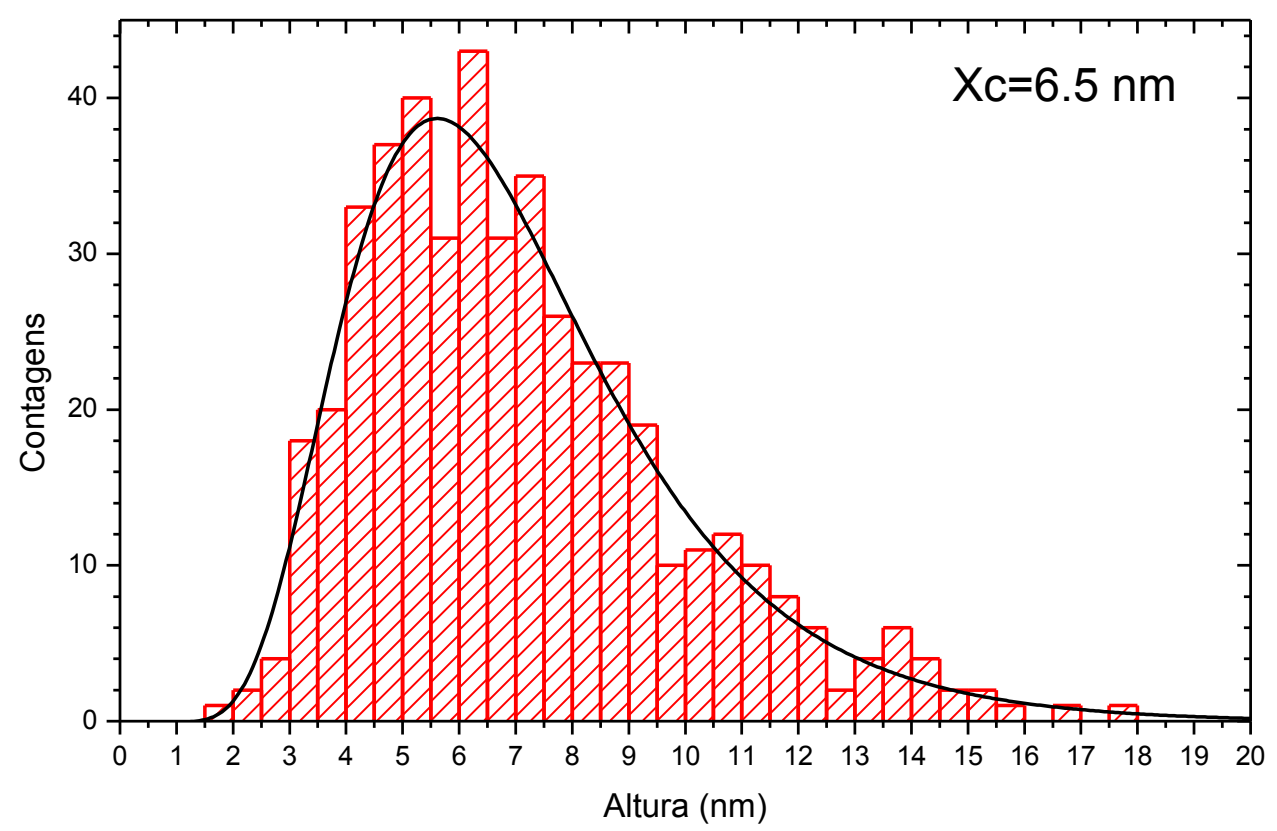

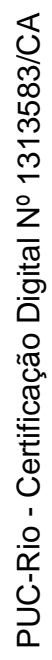

Figura 67. Histograma e ajuste por distribuição log-normal das alturas dos pontos quânticos da amostra NR0307.Xc representa o valor da média da distribuição.

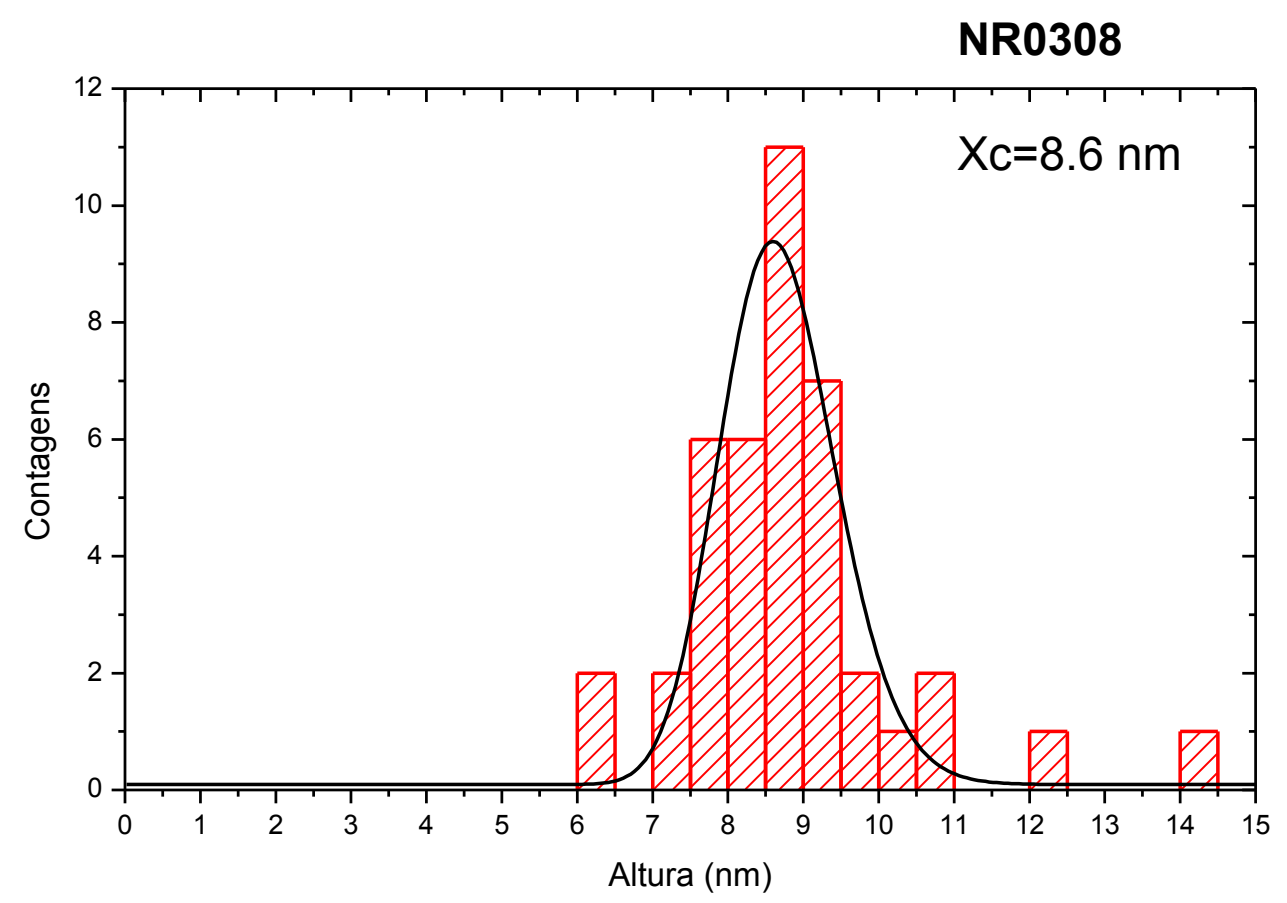

Figura 68. Histograma e ajuste por distribuição log-normal das alturas dos pontos quânticos da amostra NR0308.Xc representa o valor da média da distribuição. 


\section{Apêndice B- Resultados de fotoluminescência}

O processo de caracterização das propriedades óticas das amostras, foi realizado com as mesmas condições, mudando a potência do feixe de laser incidente sobre a amostra $(50 \mathrm{~mW}, 150 \mathrm{~mW}, 300 \mathrm{~mW}$ e $500 \mathrm{~mW})$, entre uma faixa de $1.23 \mathrm{eV}$ até $0.56 \mathrm{eV}$ (comprimento de onda de 1000 até $2200 \mathrm{~nm}$ ), a temperatura do criostato foi sempre $15 \mathrm{~K}$. Os espectros medidos para as diferentes amostras estão a seguir.

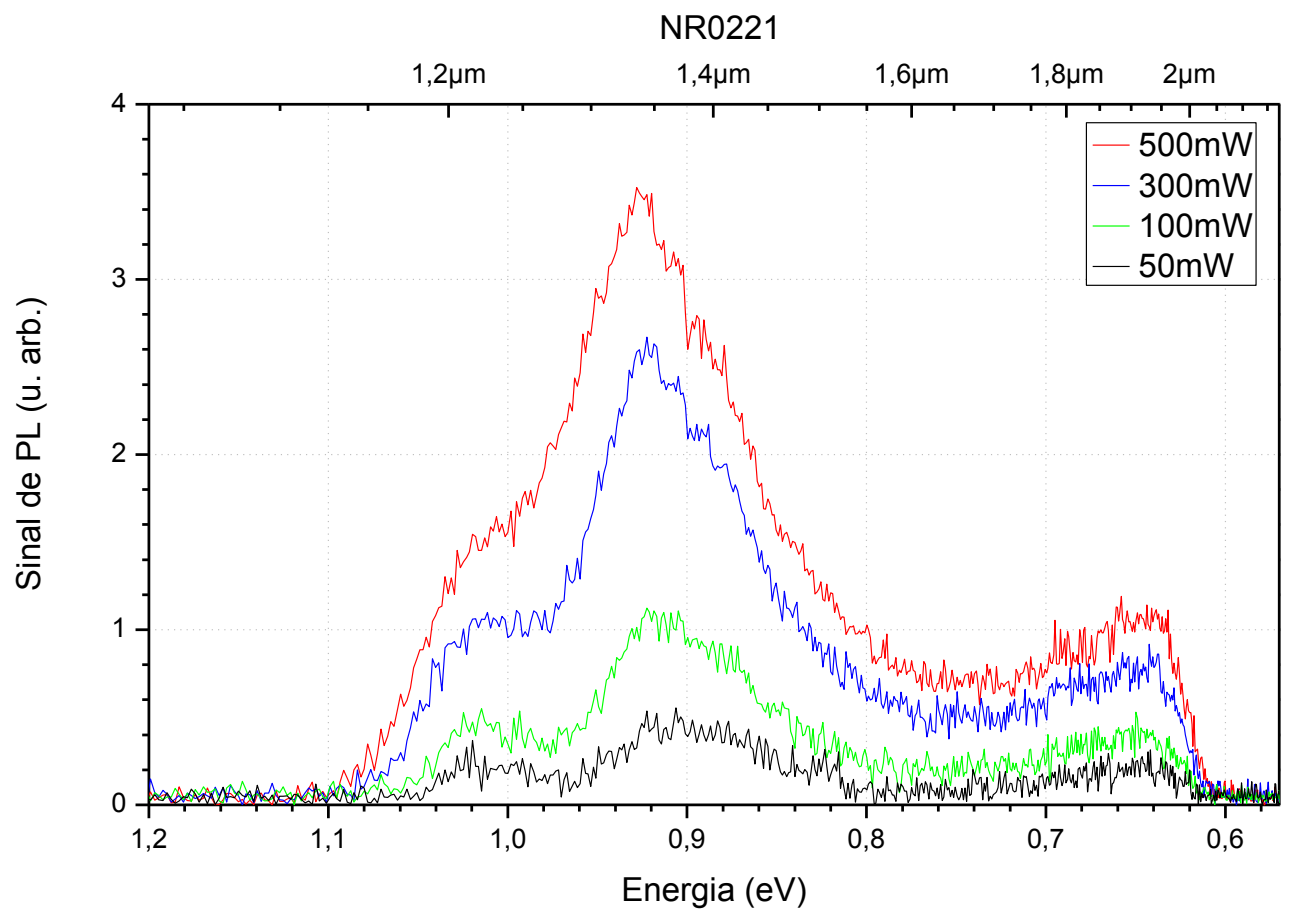

Figura 69. Medida de fotoluminescência com diferentes potências do feixe de laser incidente sobre a amostra NR0221. 


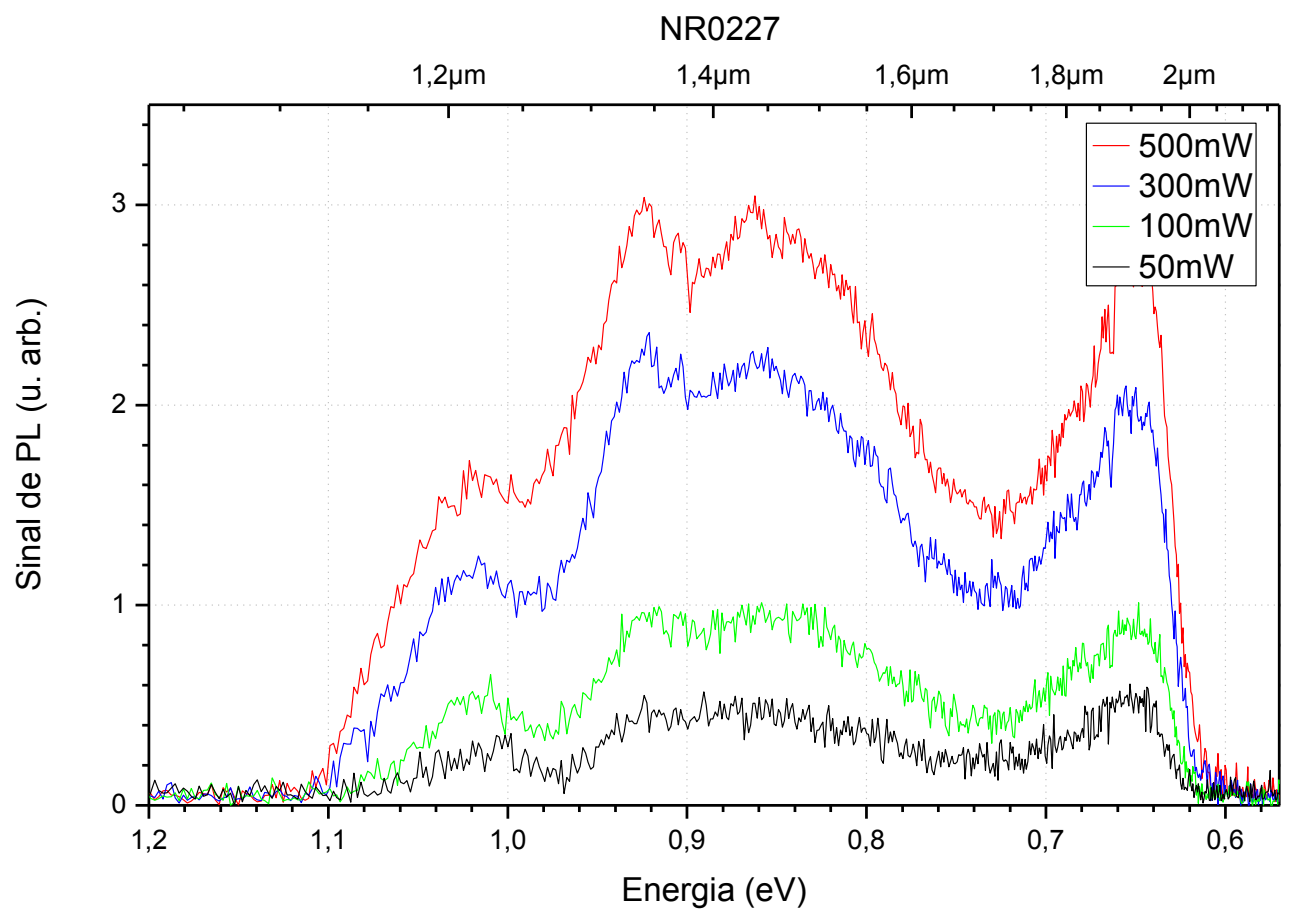

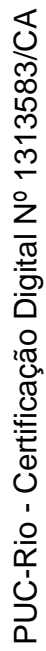

Figura 70. Medida de fotoluminescência com diferentes potências do feixe de laser incidente sobre a amostra NR0227.

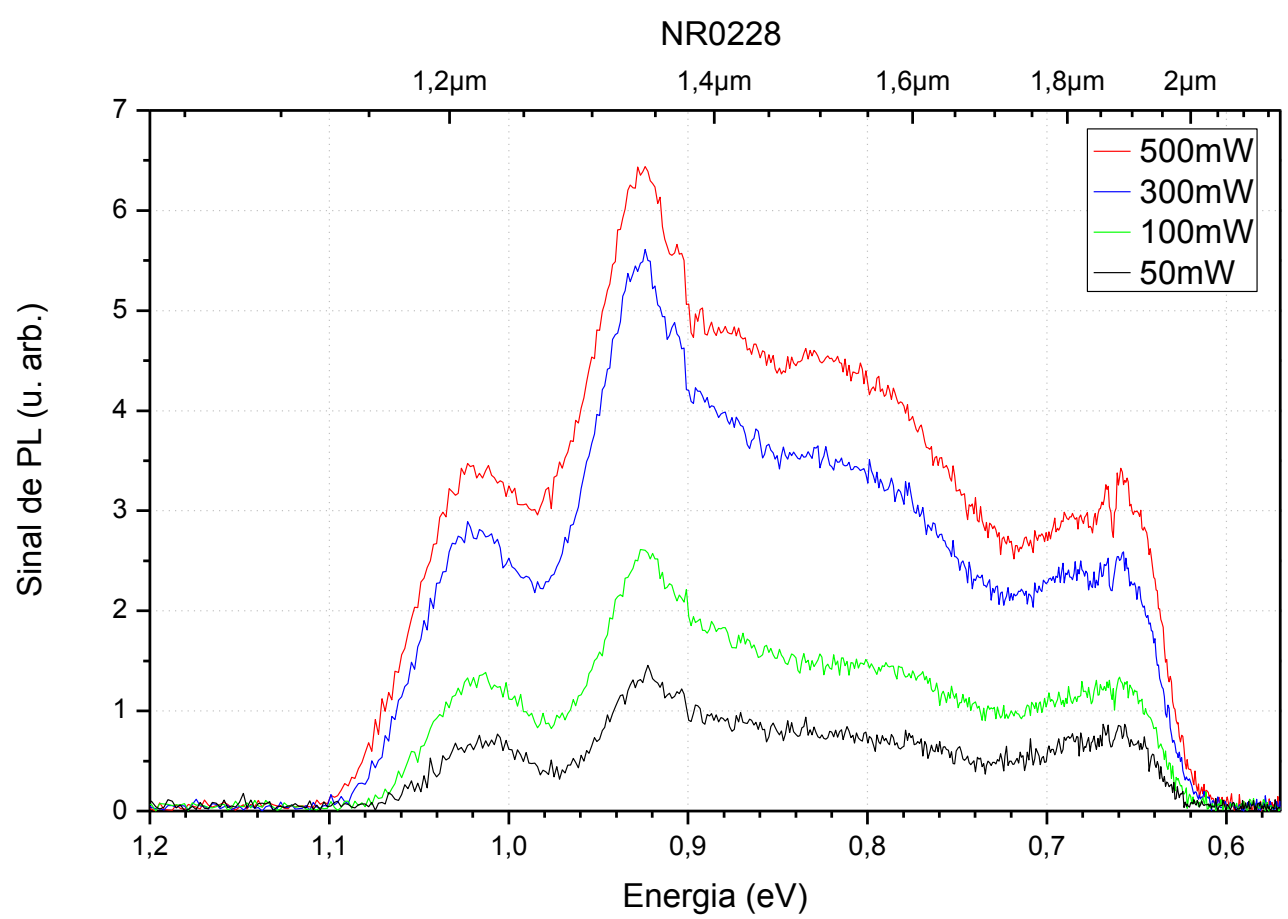

Figura 71. Medida de fotoluminescência com diferentes potências do feixe de laser incidente sobre a amostra NR0228. 


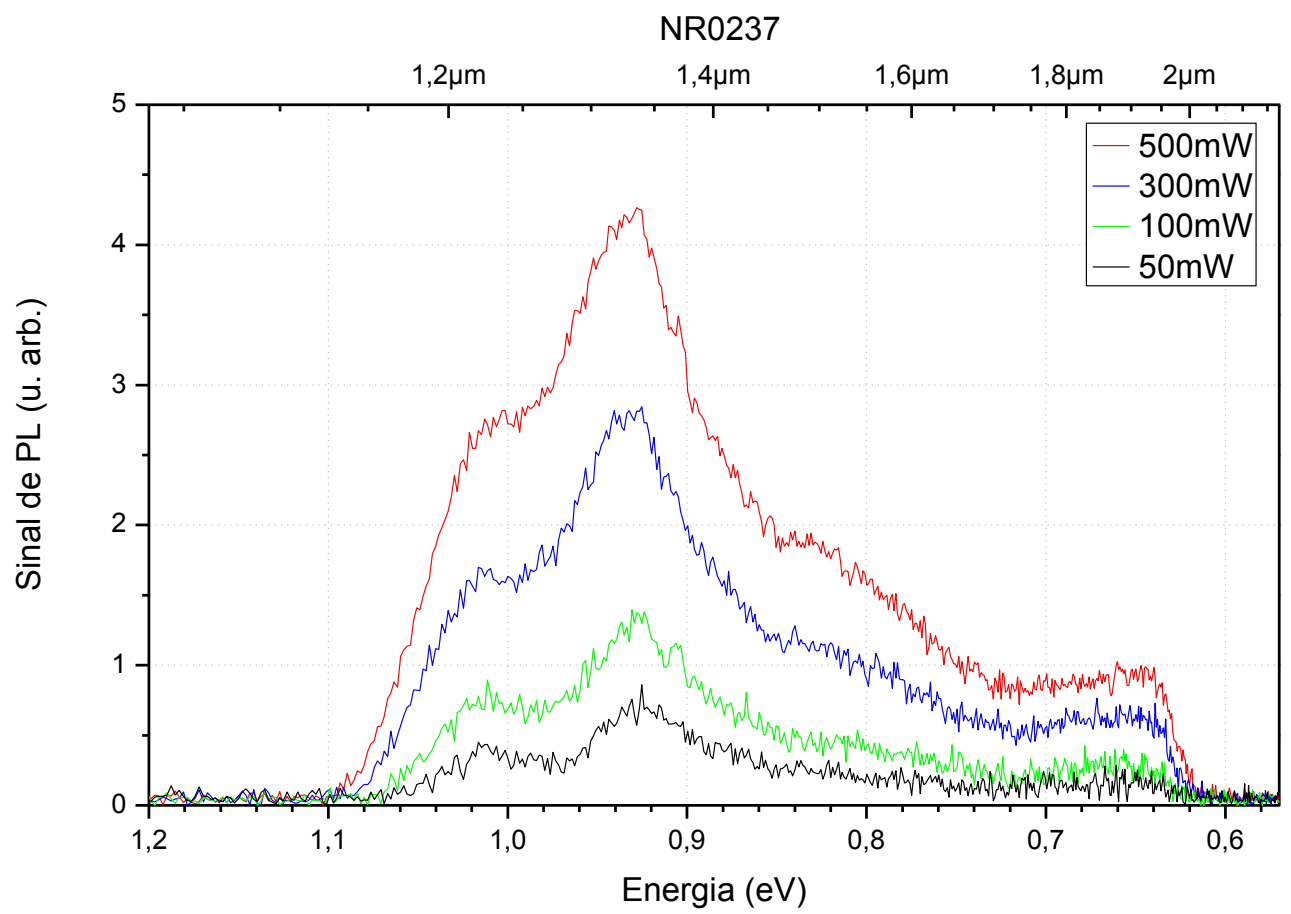

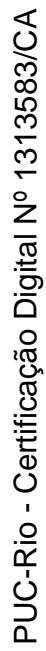

Figura 72. Medida de fotoluminescência com diferentes potências do feixe de laser incidente sobre a amostra NR0237.

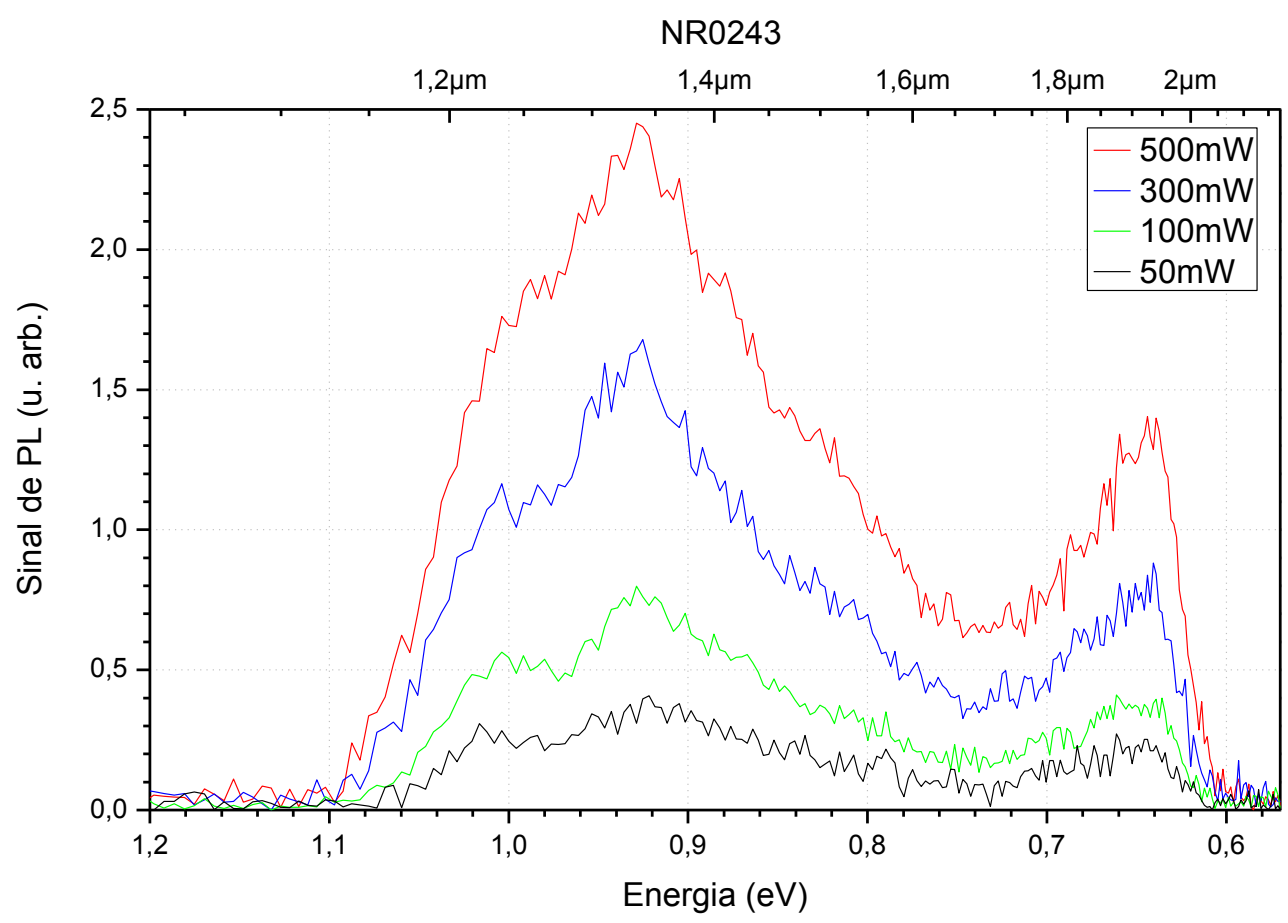

Figura 73. Medida de fotoluminescência com diferentes potências do feixe de laser incidente sobre a amostra NR0243. 


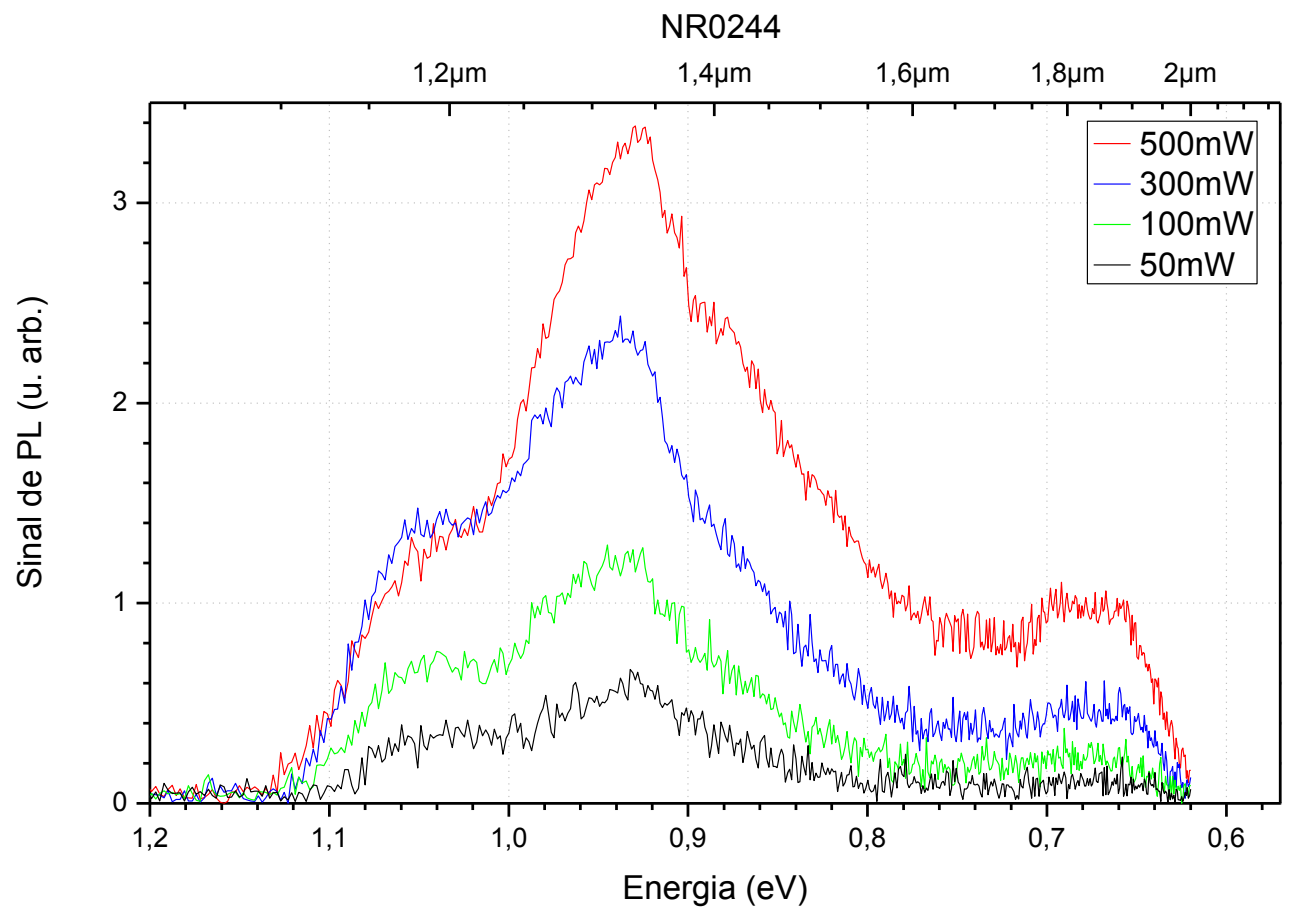

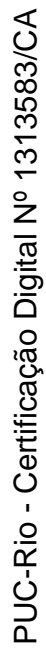

Figura 74. Medida de fotoluminescência com diferentes potências do feixe de laser incidente sobre a amostra NR0244.

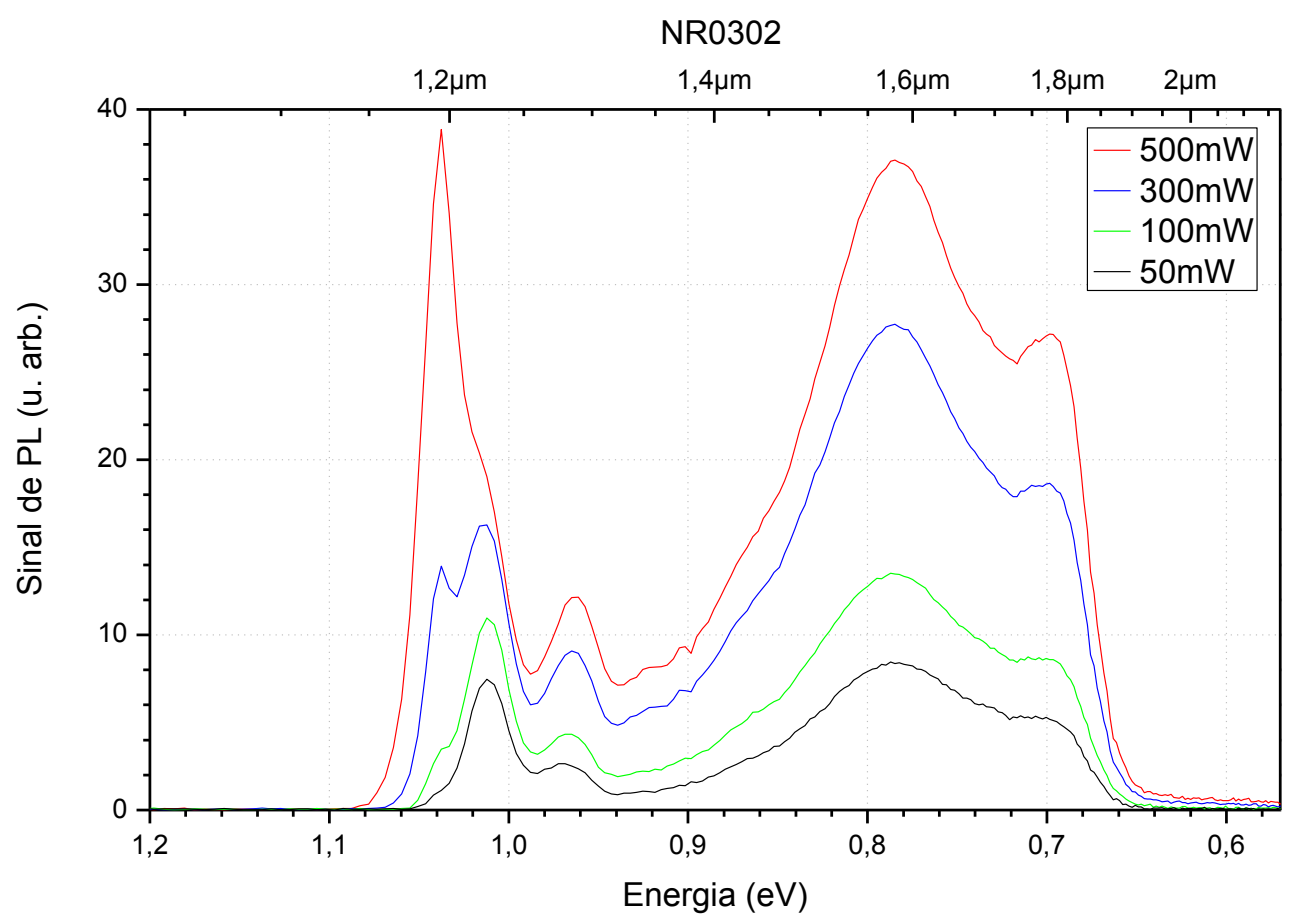

Figura 75. Medida de fotoluminescência com diferentes potências do feixe de laser incidente sobre a amostra NR0302. 


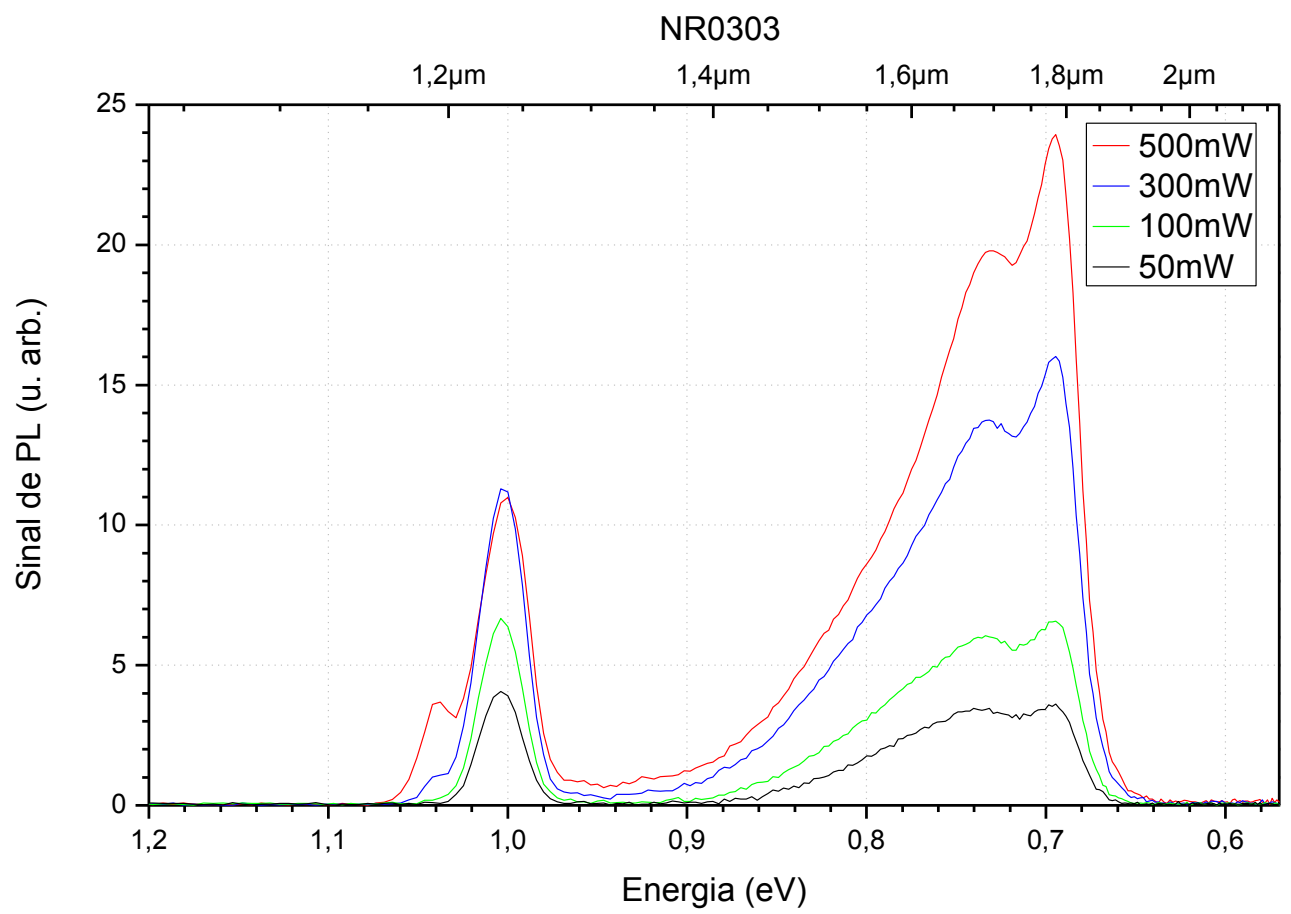

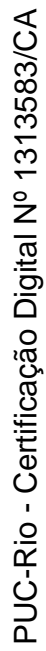

Figura 76. Medida de fotoluminescência com diferentes potências do feixe de laser incidente sobre a amostra NR0303.

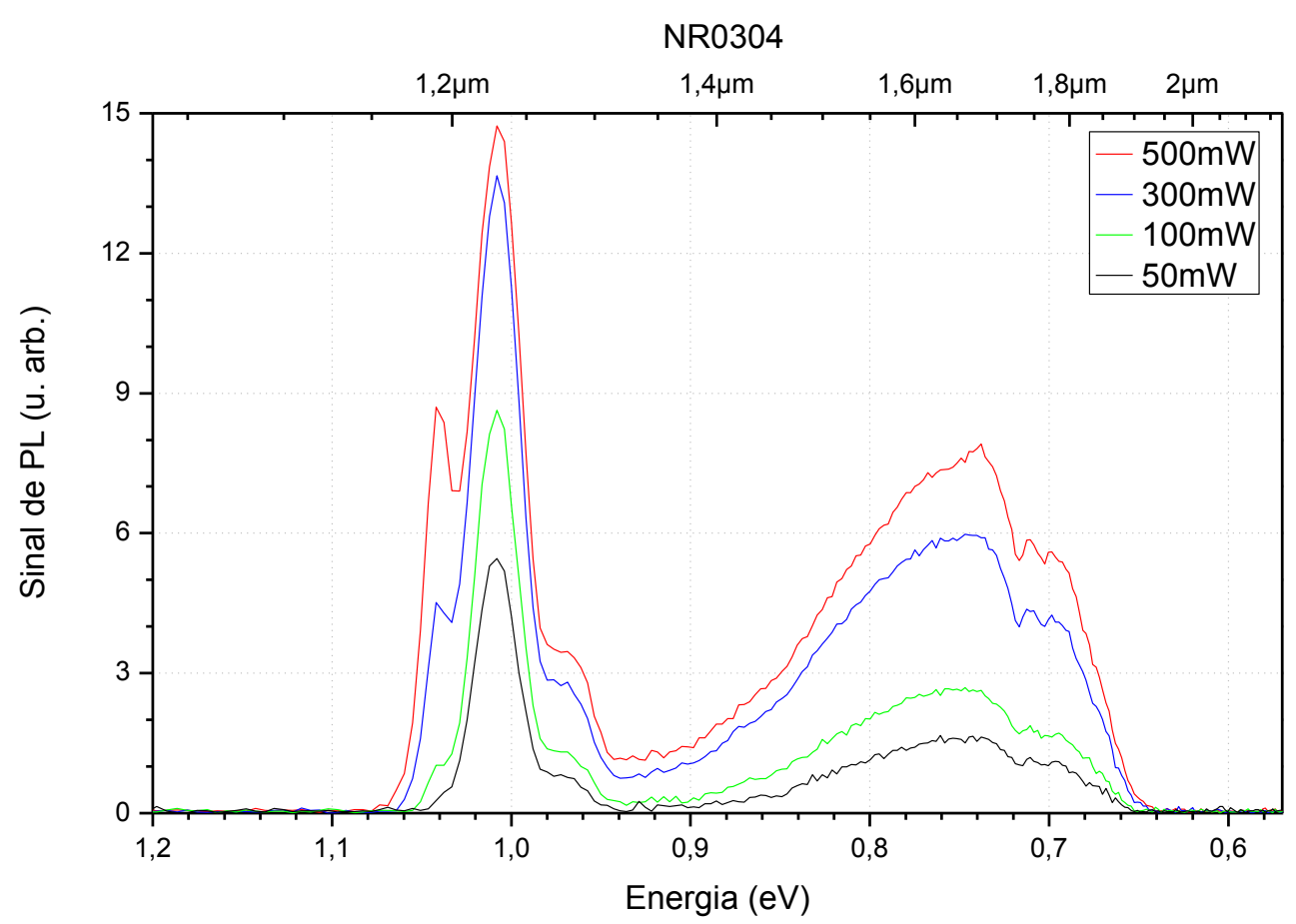

Figura 77. Medida de fotoluminescência com diferentes potências do feixe de laser incidente sobre a amostra NR0304. 


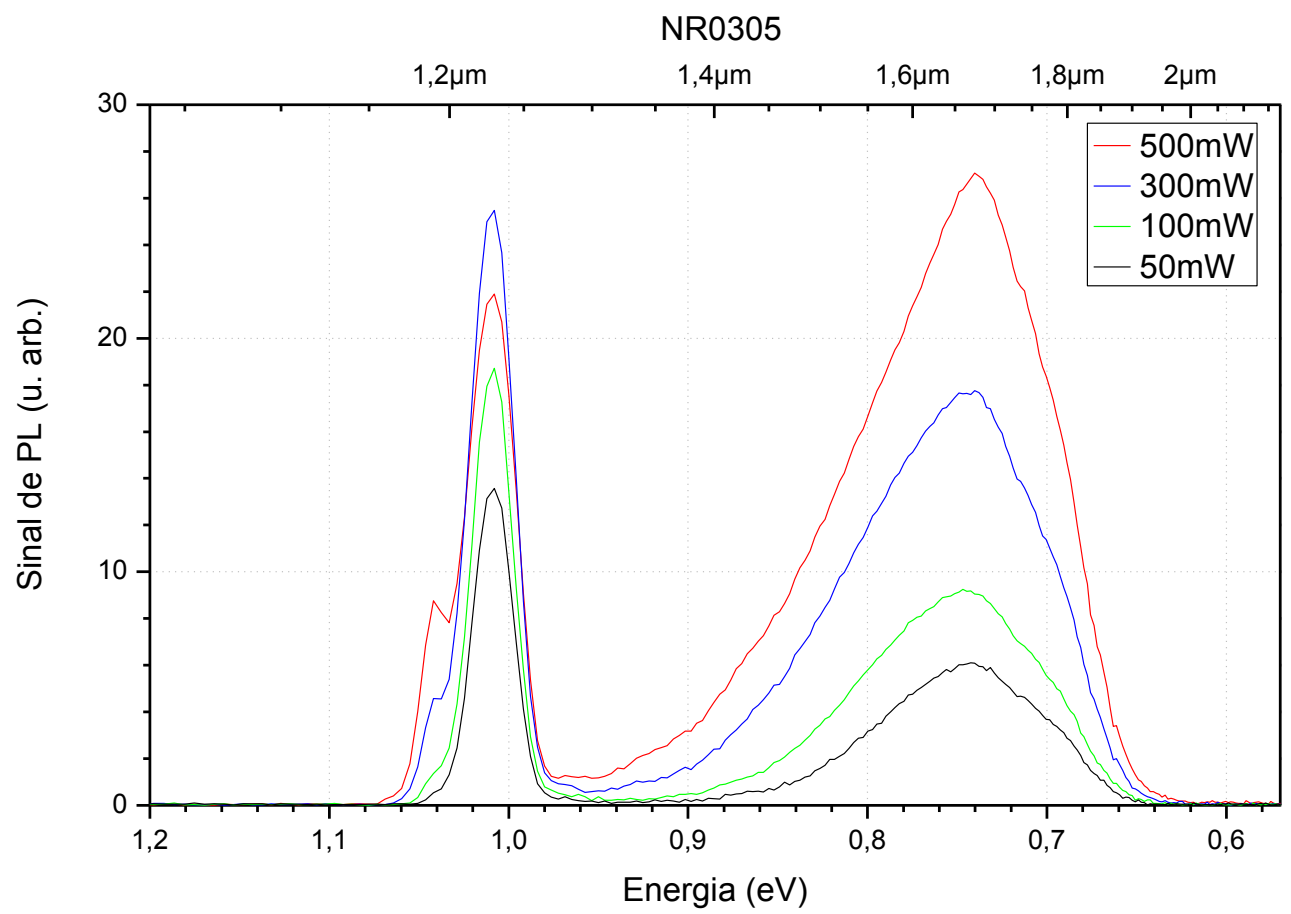

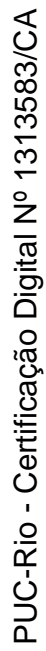

Figura 78. Medida de fotoluminescência com diferentes potências do feixe de laser incidente sobre a amostra NR0305.

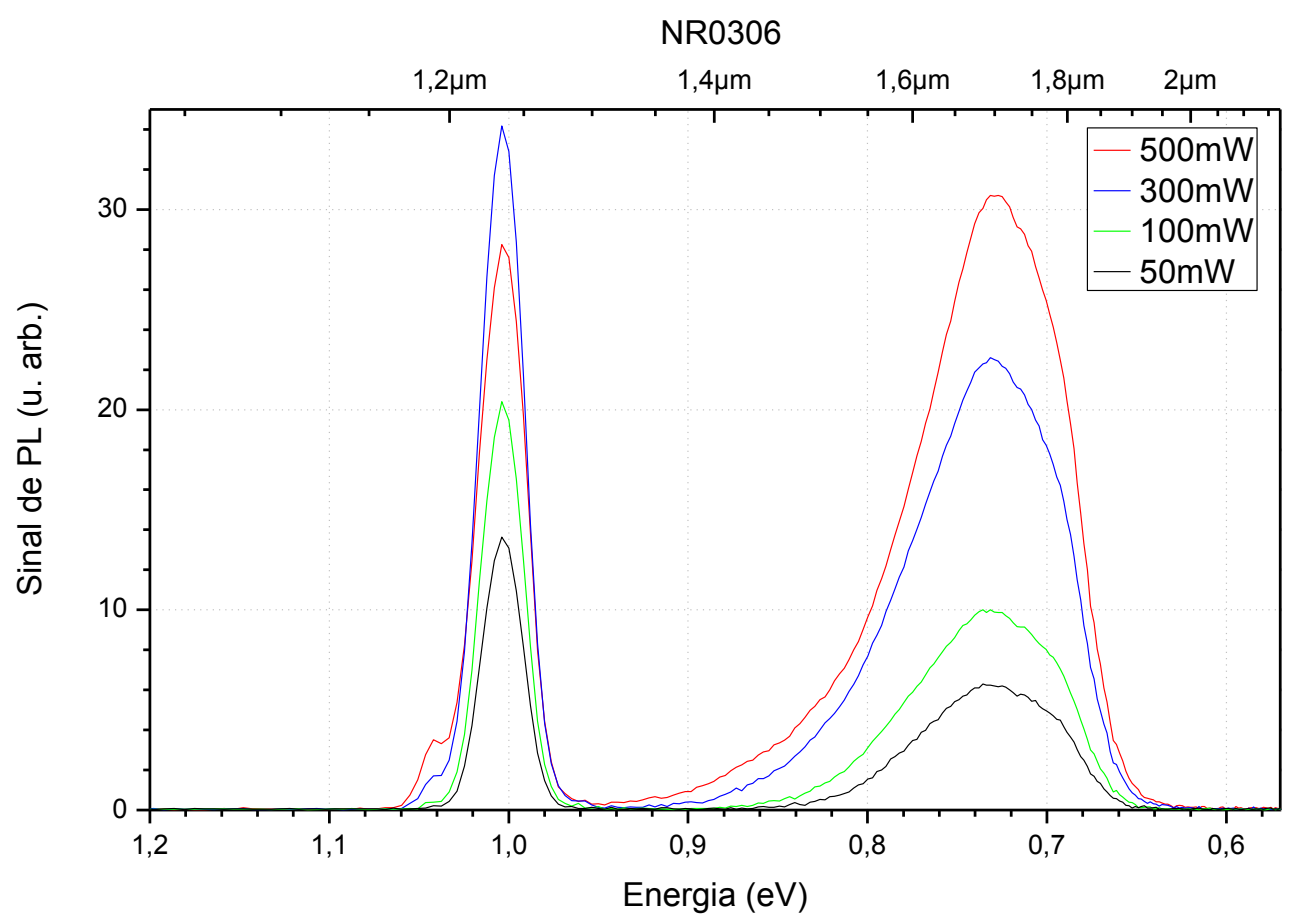

Figura 79. Medida de fotoluminescência com diferentes potências do feixe de laser incidente sobre a amostra NR0306. 


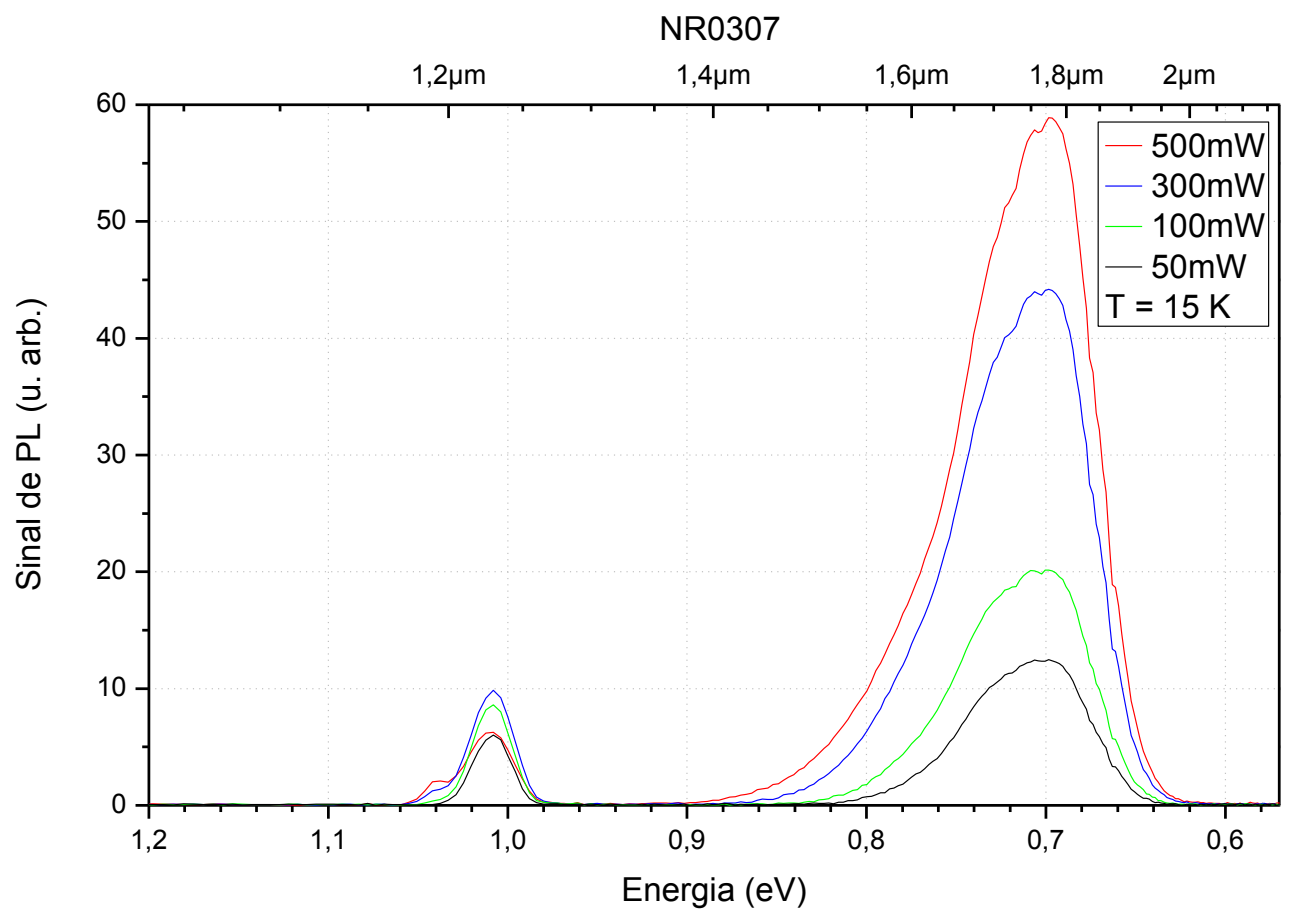

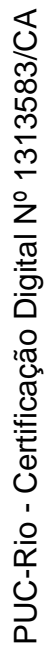

Figura 80. Medida de fotoluminescência com diferentes potências do feixe de laser incidente sobre a amostra NR0307.

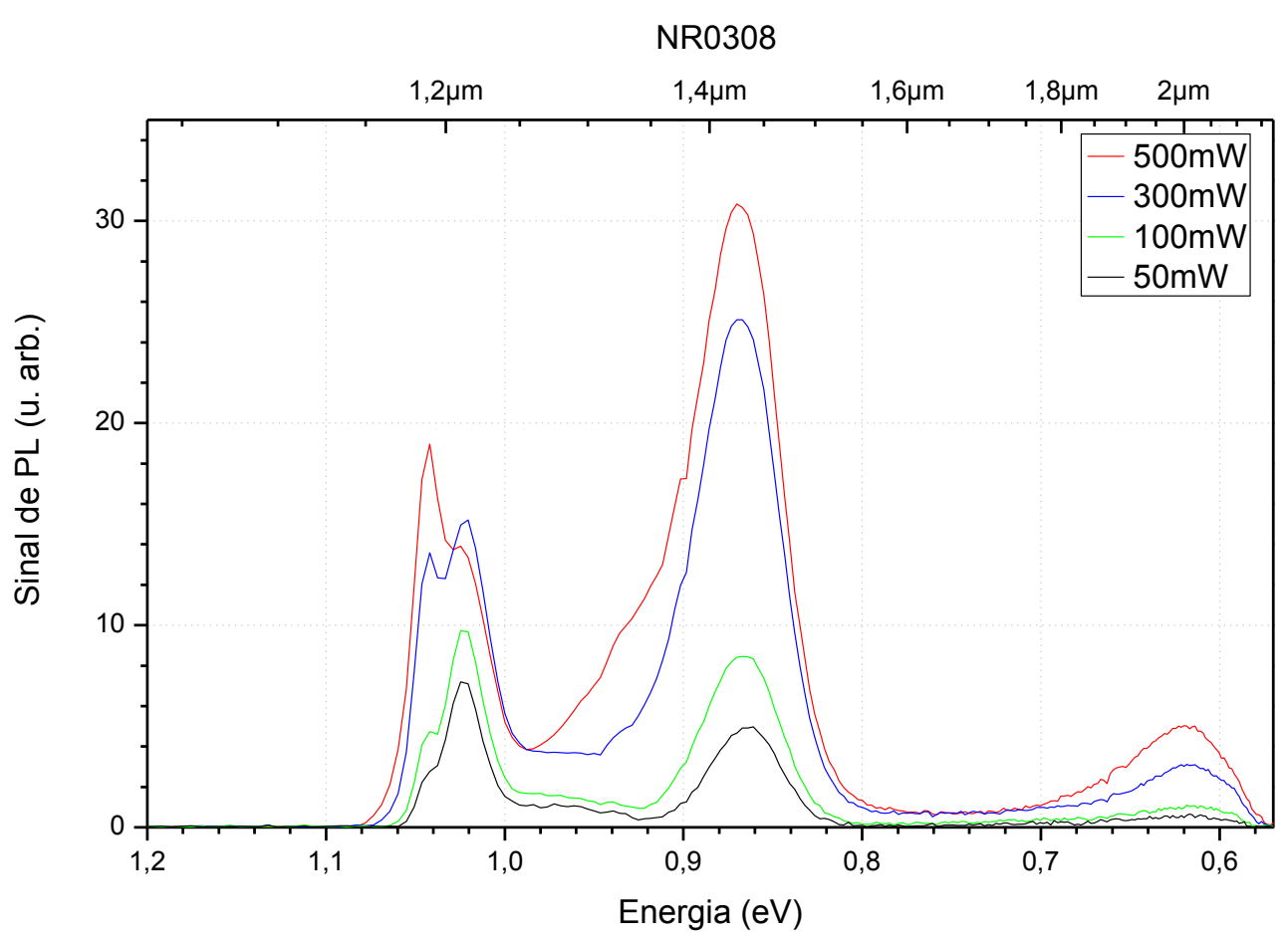

Figura 81. Medida de fotoluminescência com diferentes potências do feixe de laser incidente sobre a amostra NR0308. 


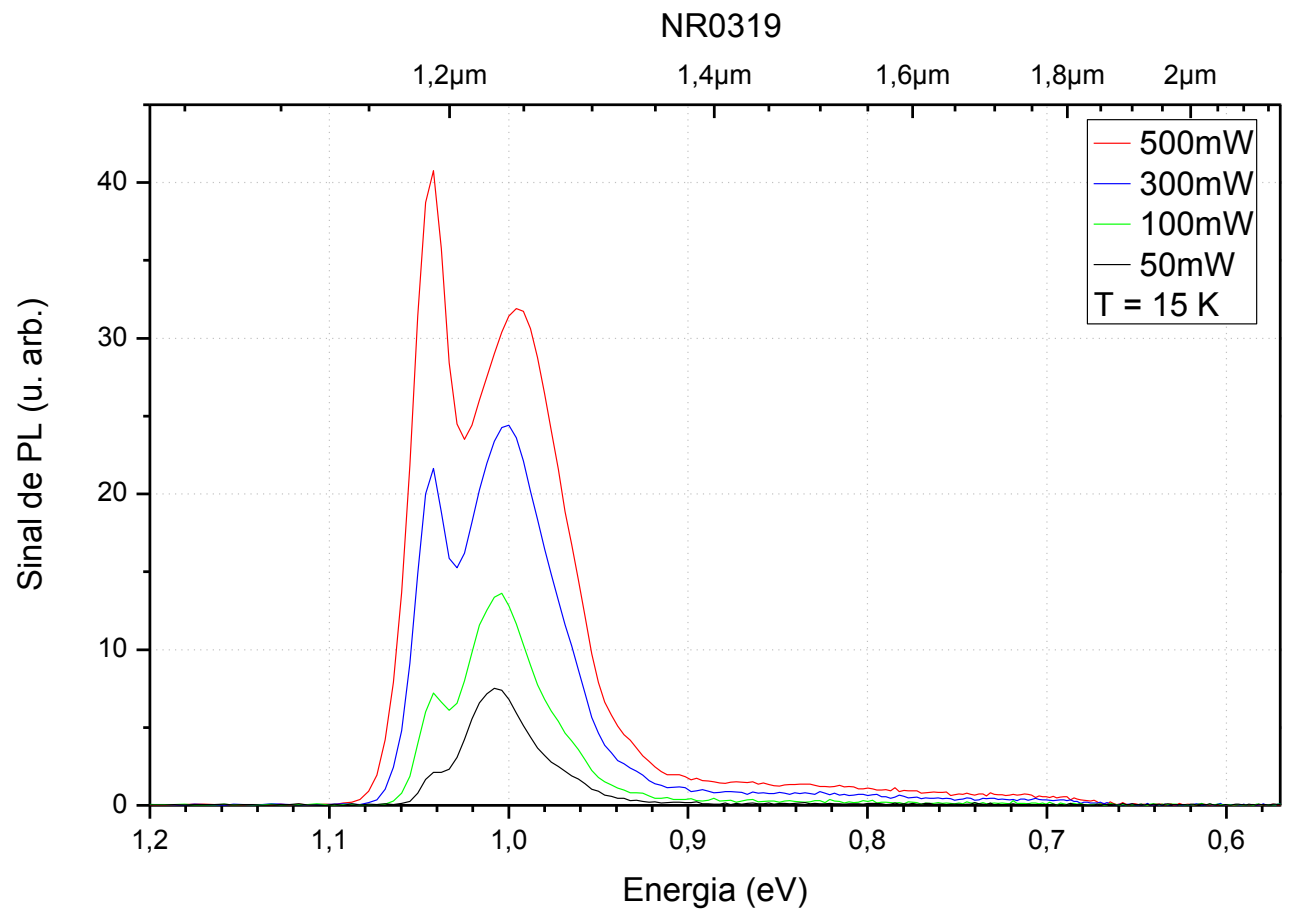

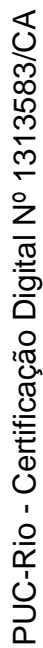

Figura 82. Medida de fotoluminescência com diferentes potências do feixe de laser incidente sobre a amostra NR0319. 


\section{Apêndice C - Ajustes aos sinais de fotoluminescência}

São mostrados a seguiros ajustes realizados com gaussianas para os sinais de PL de $300 \mathrm{~mW}$ para todas as amostras entre uma faixa de $1.23 \mathrm{eV}$ até $0.56 \mathrm{eV}$ (comprimento de onda de 1000 até $2200 \mathrm{~nm}$ ), a temperatura do criostato foi sempre $15 \mathrm{~K}$.

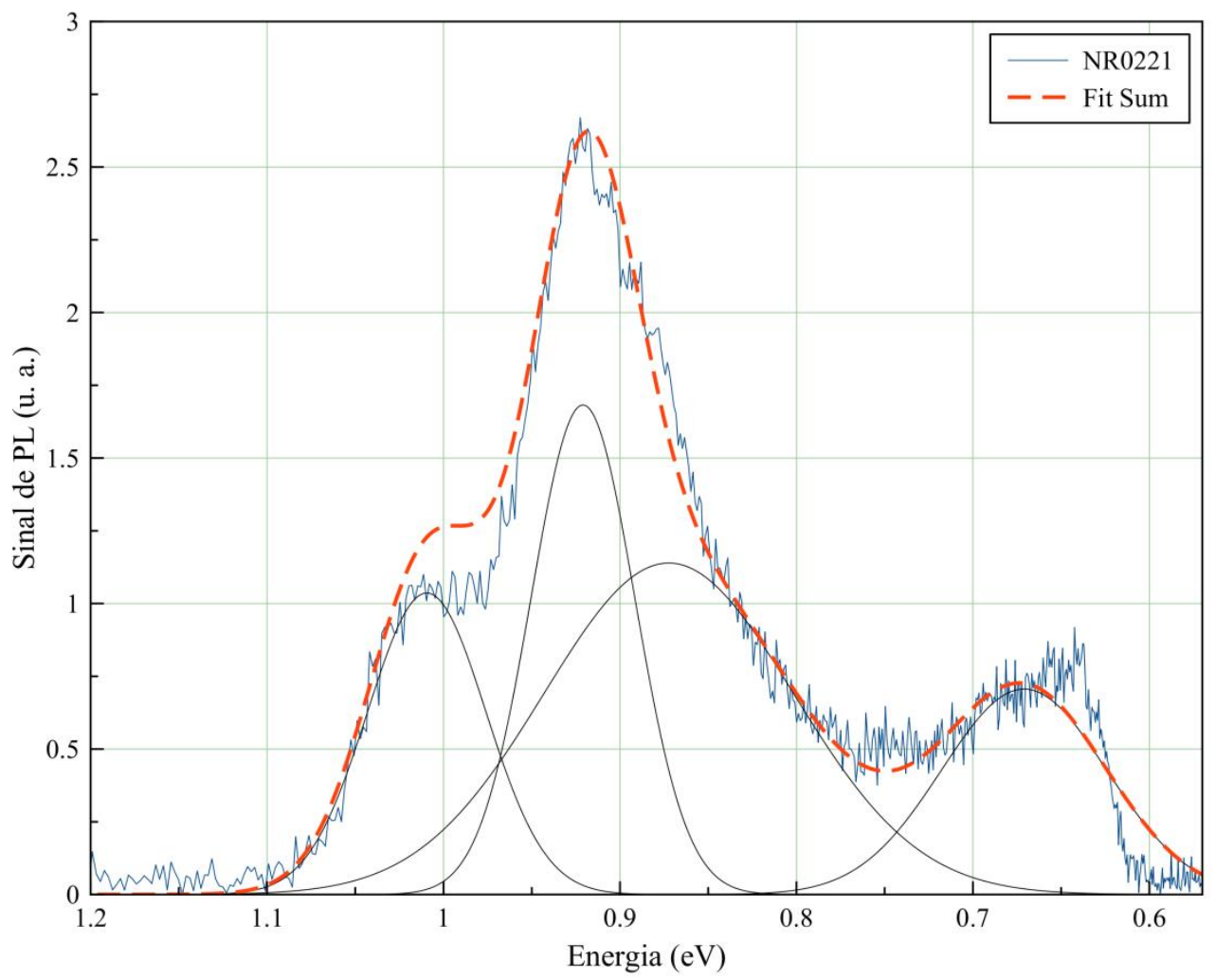

Figura 83. Ajuste da medida de fotoluminescência $(300 \mathrm{mw})$ da amostra NR0221 realizada a $15 \mathrm{~K}$. 


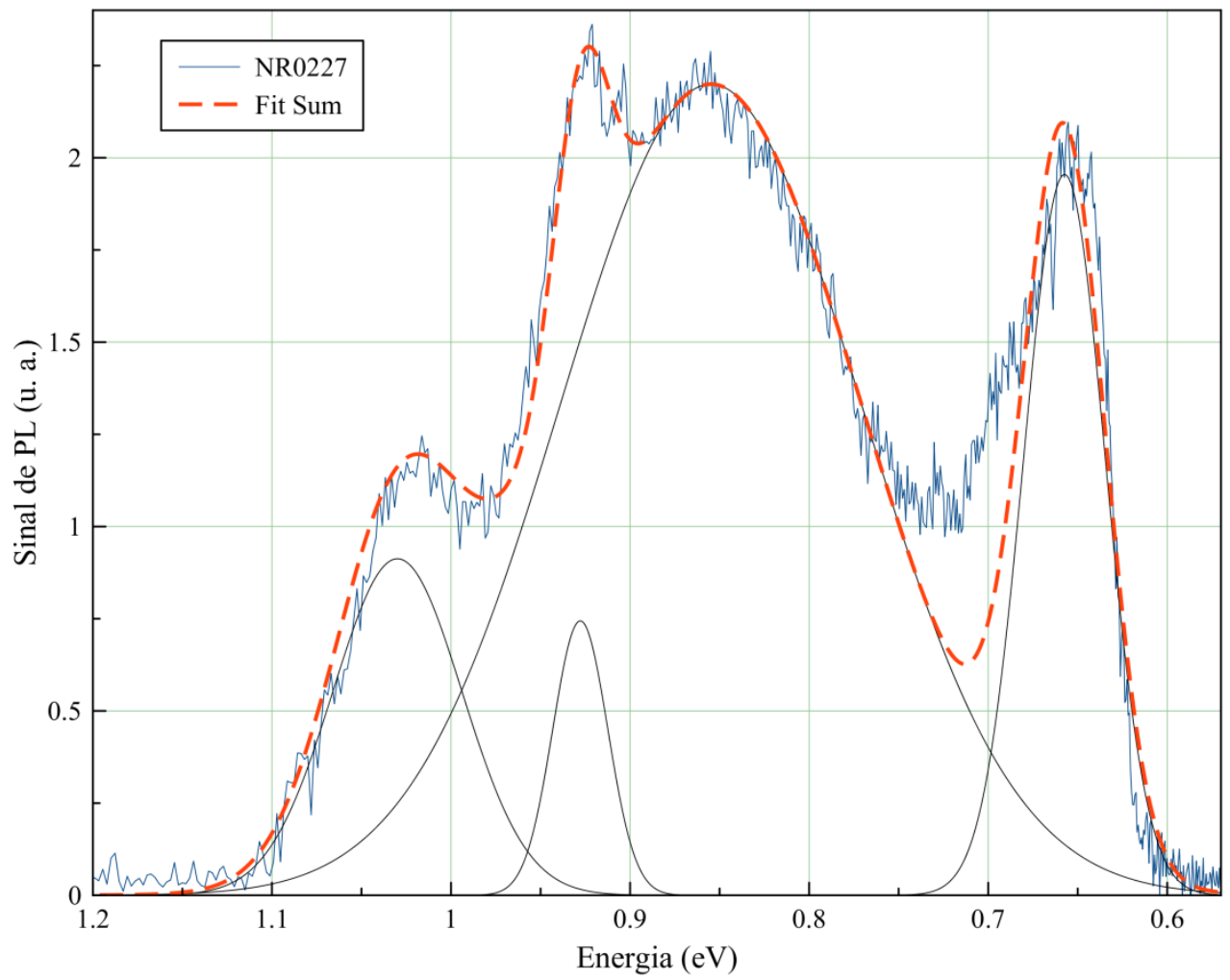

Figura 84. Ajuste da medida de fotoluminescência $(300 \mathrm{mw})$ da amostra NR0227 realizada a $15 \mathrm{~K}$.

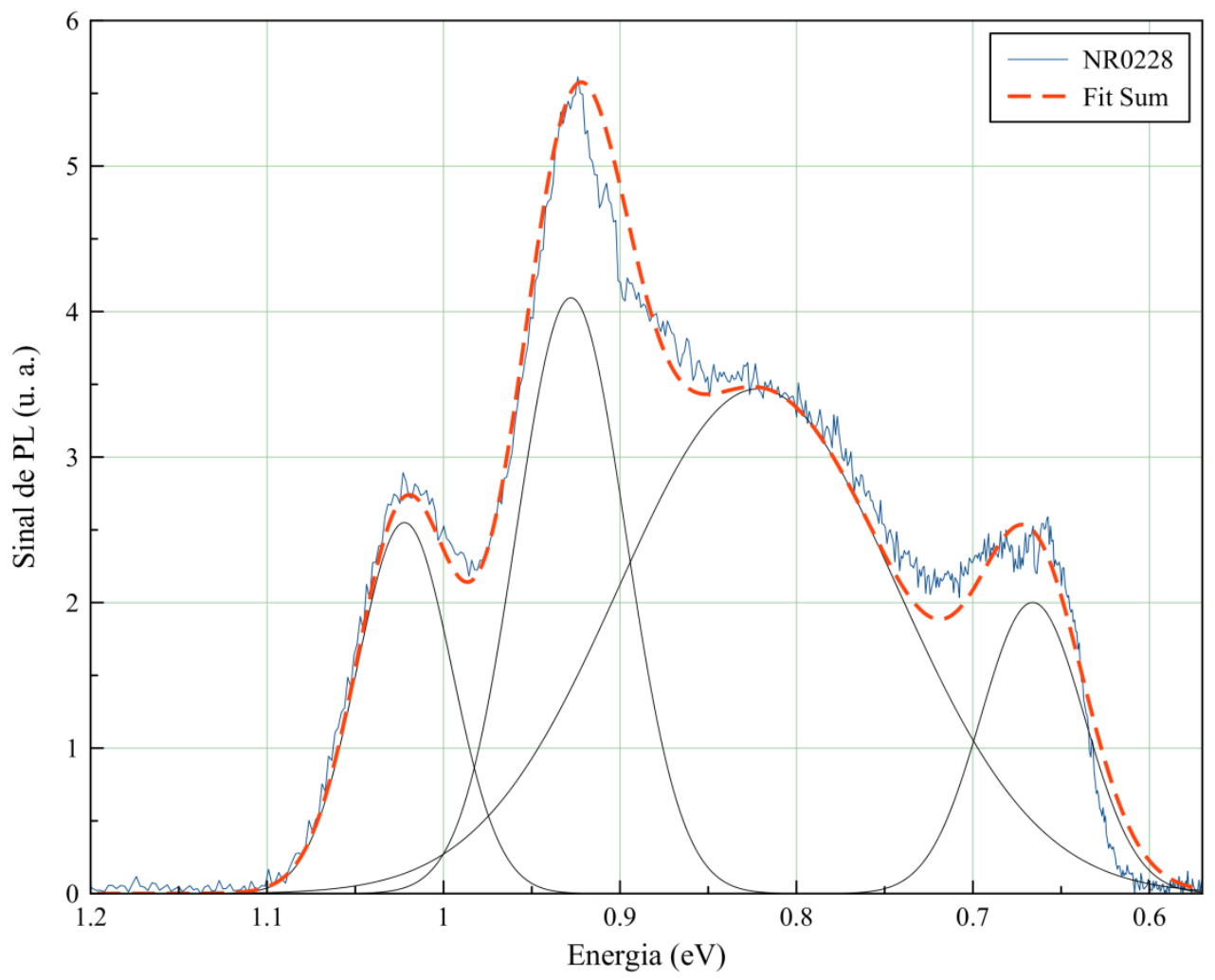

Figura 85. Ajuste da medida de fotoluminescência $(300 \mathrm{mw})$ da amostra NR0228 realizada a $15 \mathrm{~K}$. 


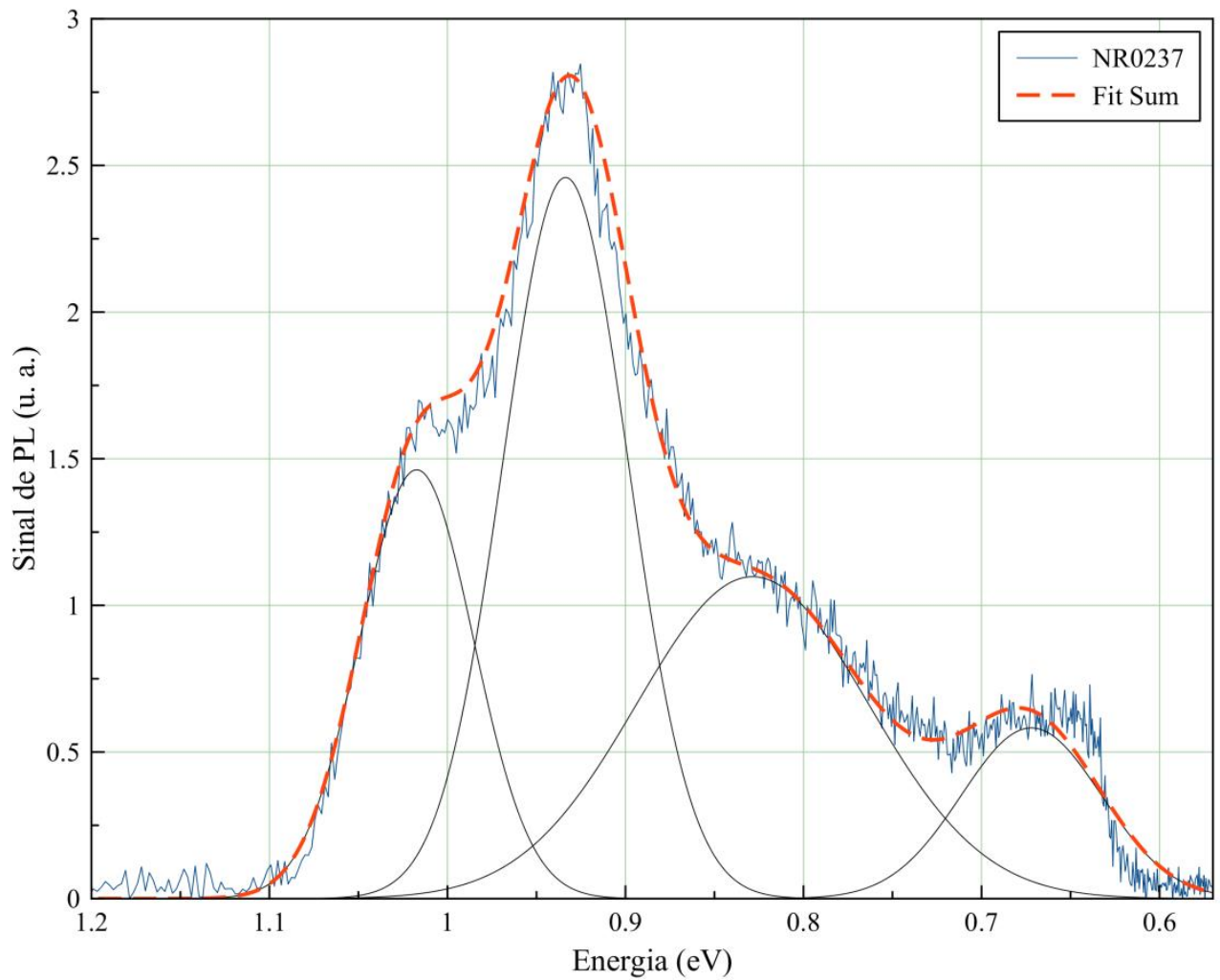

Figura 86. Ajuste da medida de fotoluminescência $(300 \mathrm{mw})$ da amostra NR0237 realizada a $15 \mathrm{~K}$.

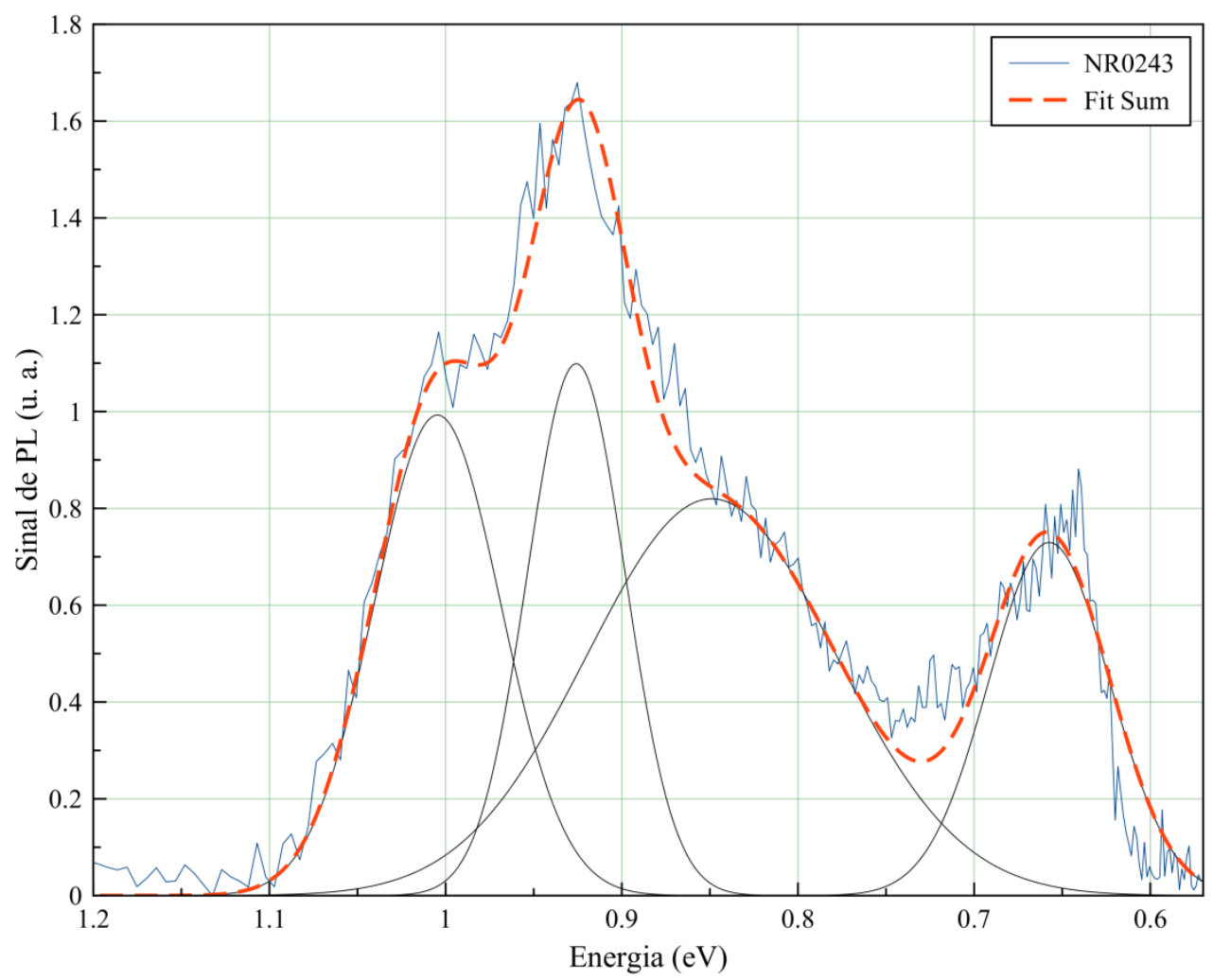

Figura 87. Ajuste da medida de fotoluminescência $(300 \mathrm{mw})$ da amostra NR0243 realizada a $15 \mathrm{~K}$. 


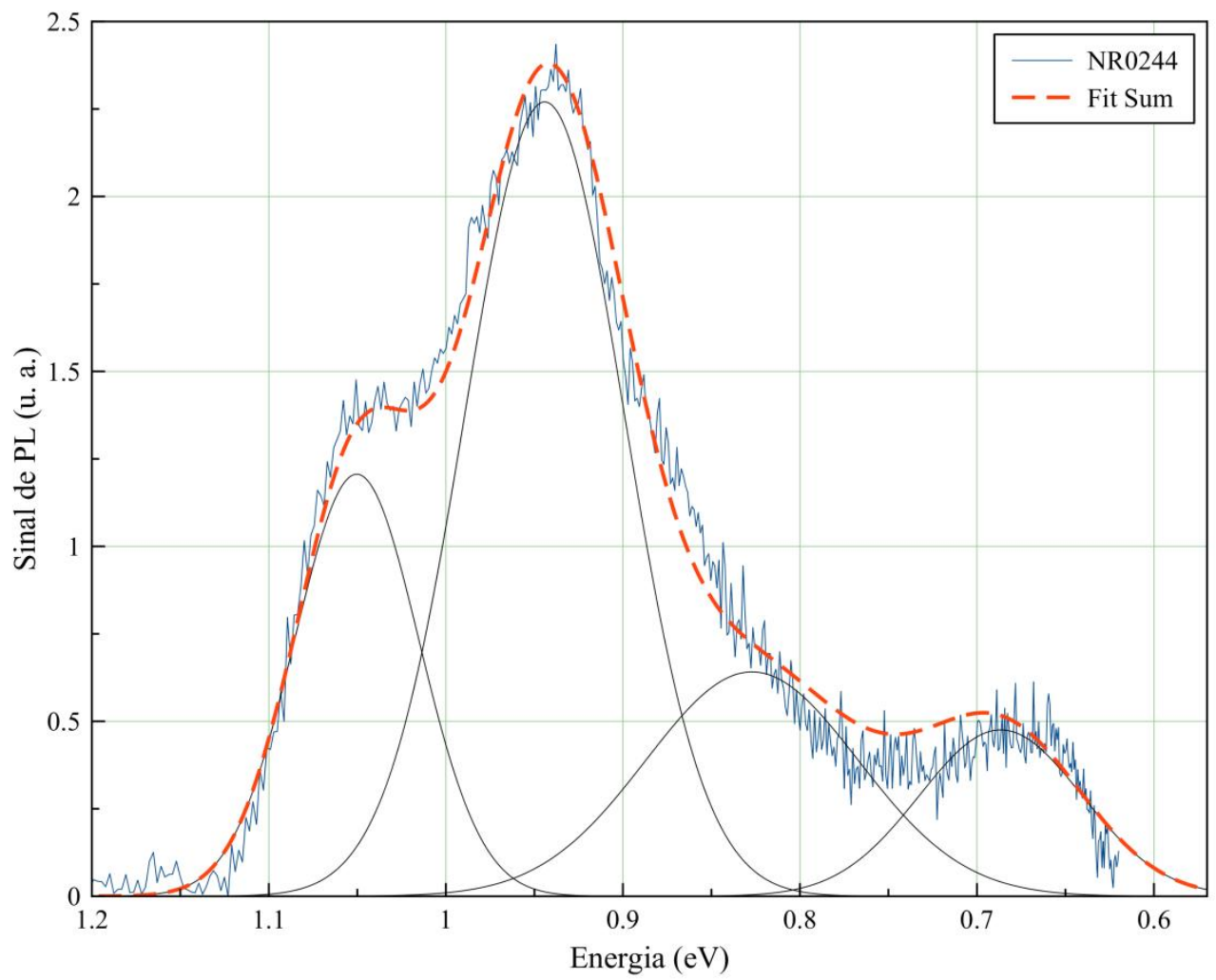

Figura 88. Ajuste da medida de fotoluminescência (300mw) da amostra NR0244 realizada a $15 \mathrm{~K}$.

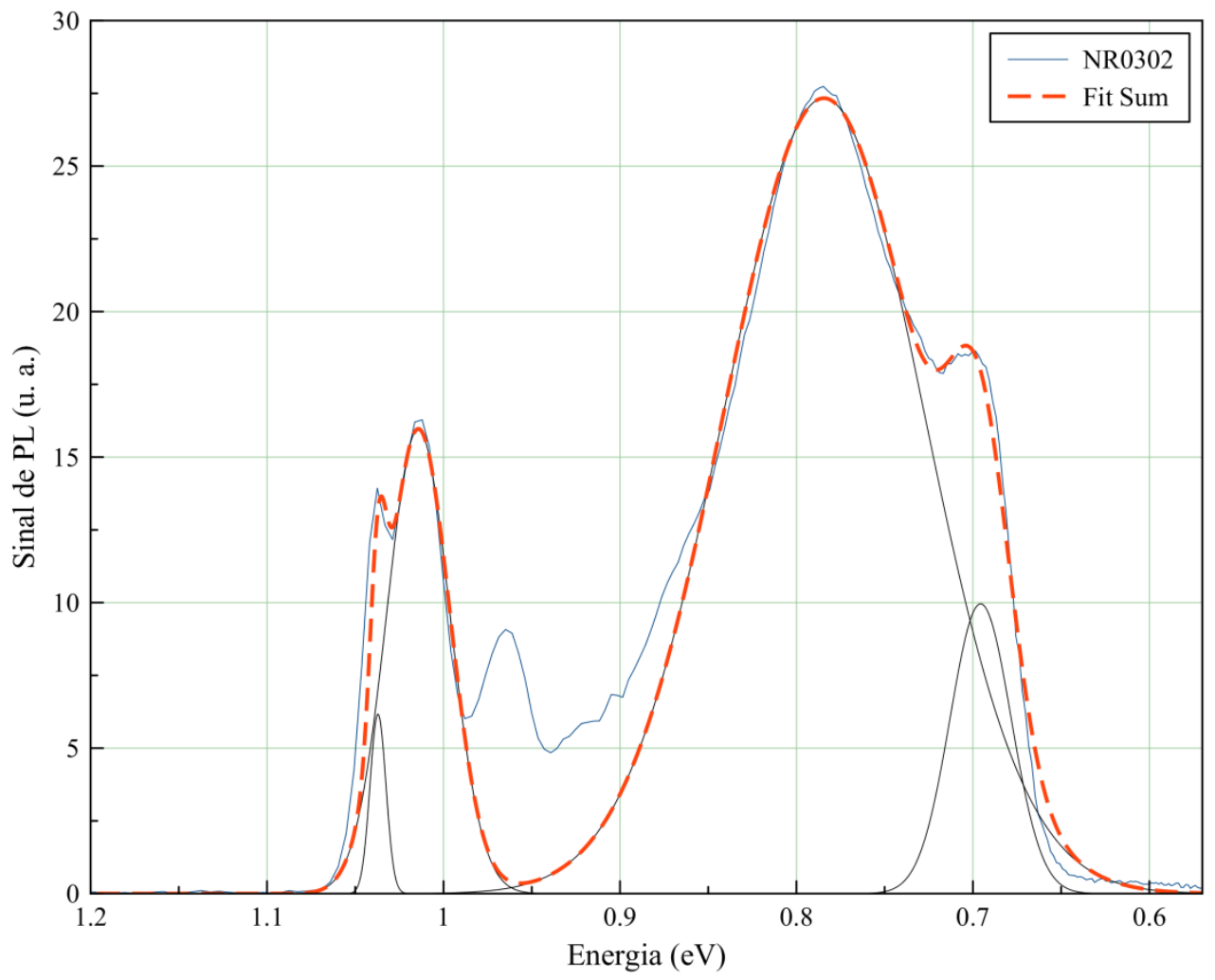

Figura 89. Ajuste da medida de fotoluminescência $(300 \mathrm{mw})$ da amostra NR0302 realizada a $15 \mathrm{~K}$. 


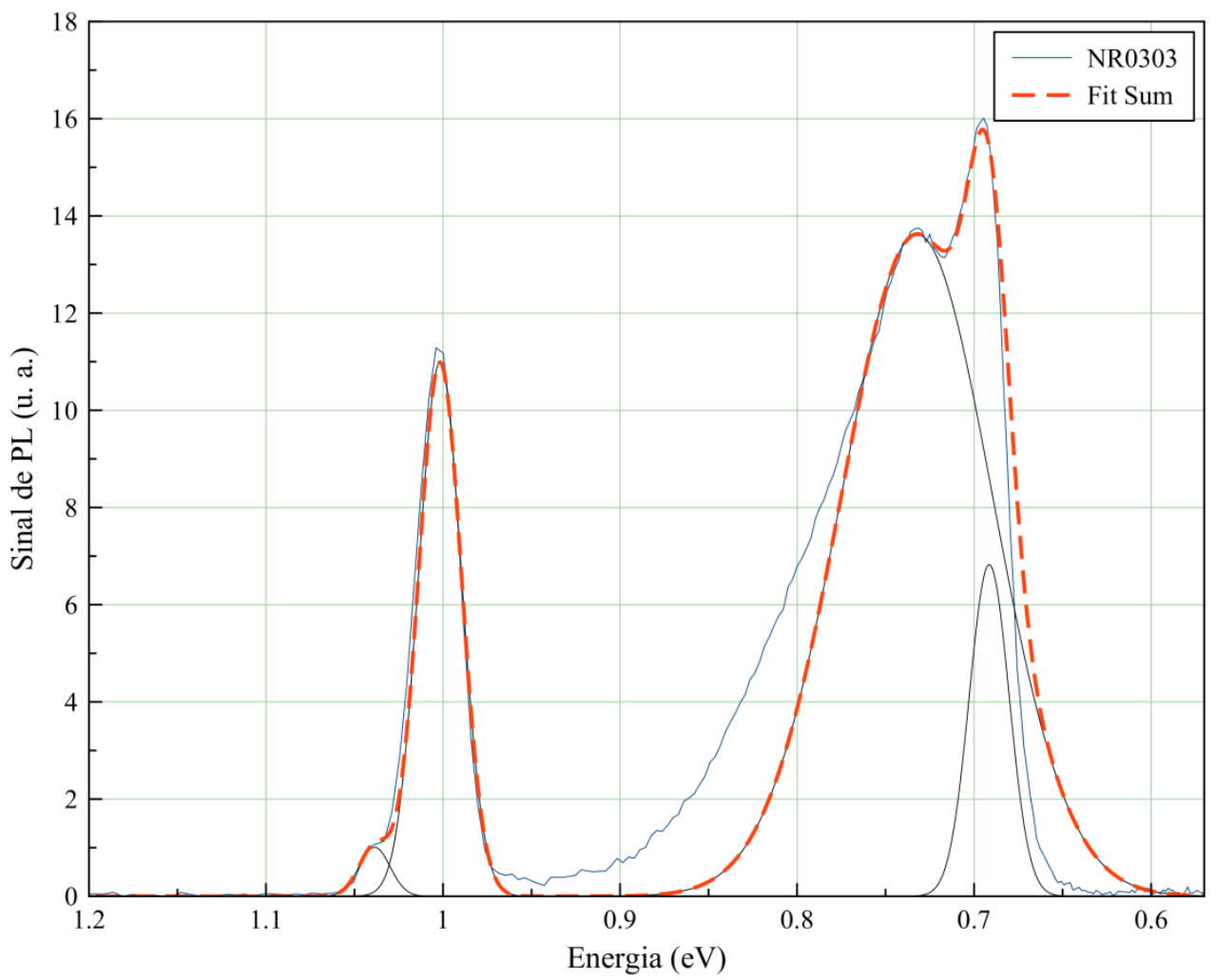

Figura 90. Ajuste da medida de fotoluminescência (300mw) da amostra NR0303 realizada a $15 \mathrm{~K}$.

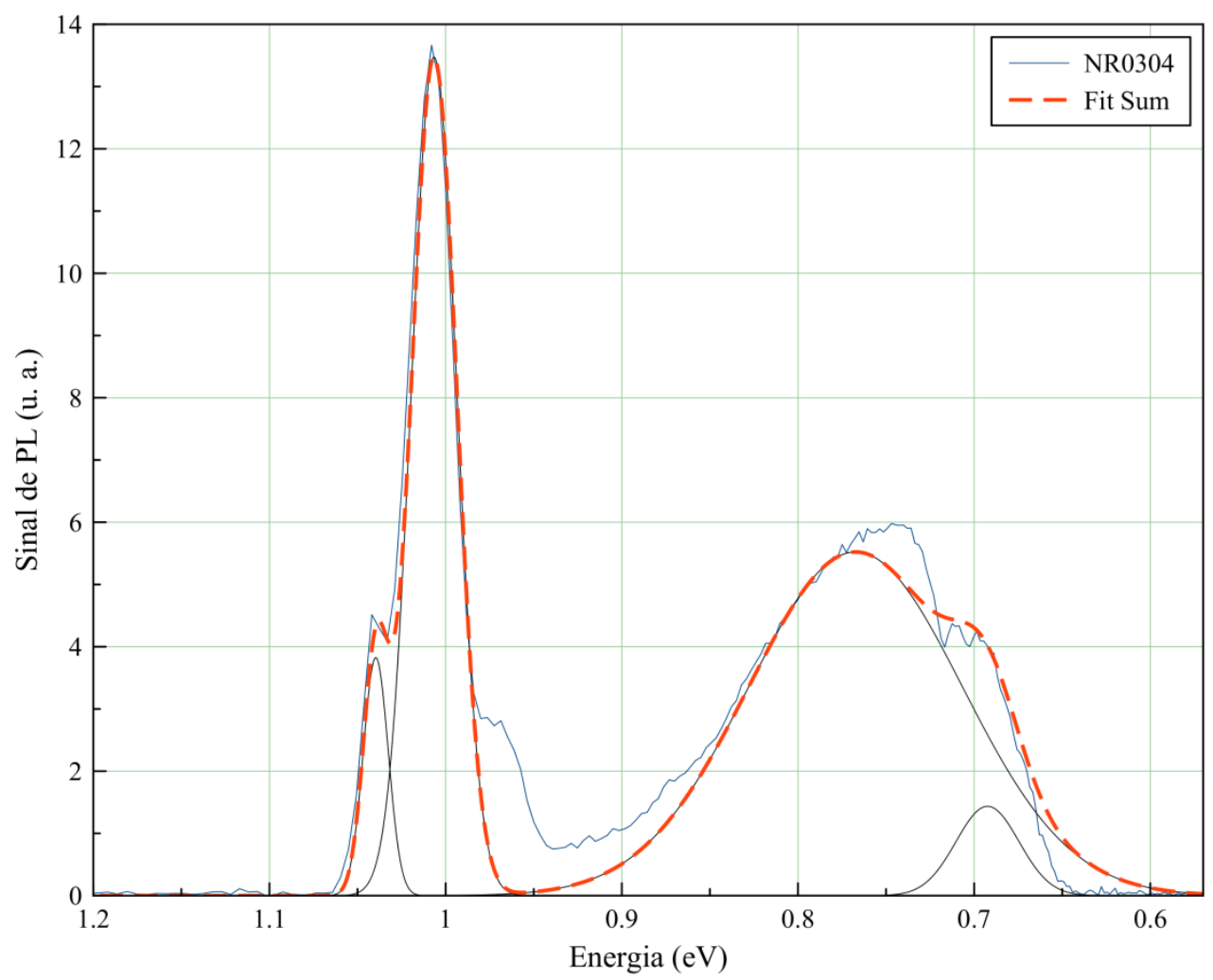

Figura 91. Ajuste da medida de fotoluminescência $(300 \mathrm{mw})$ da amostra NR0304 realizada a $15 \mathrm{~K}$. 


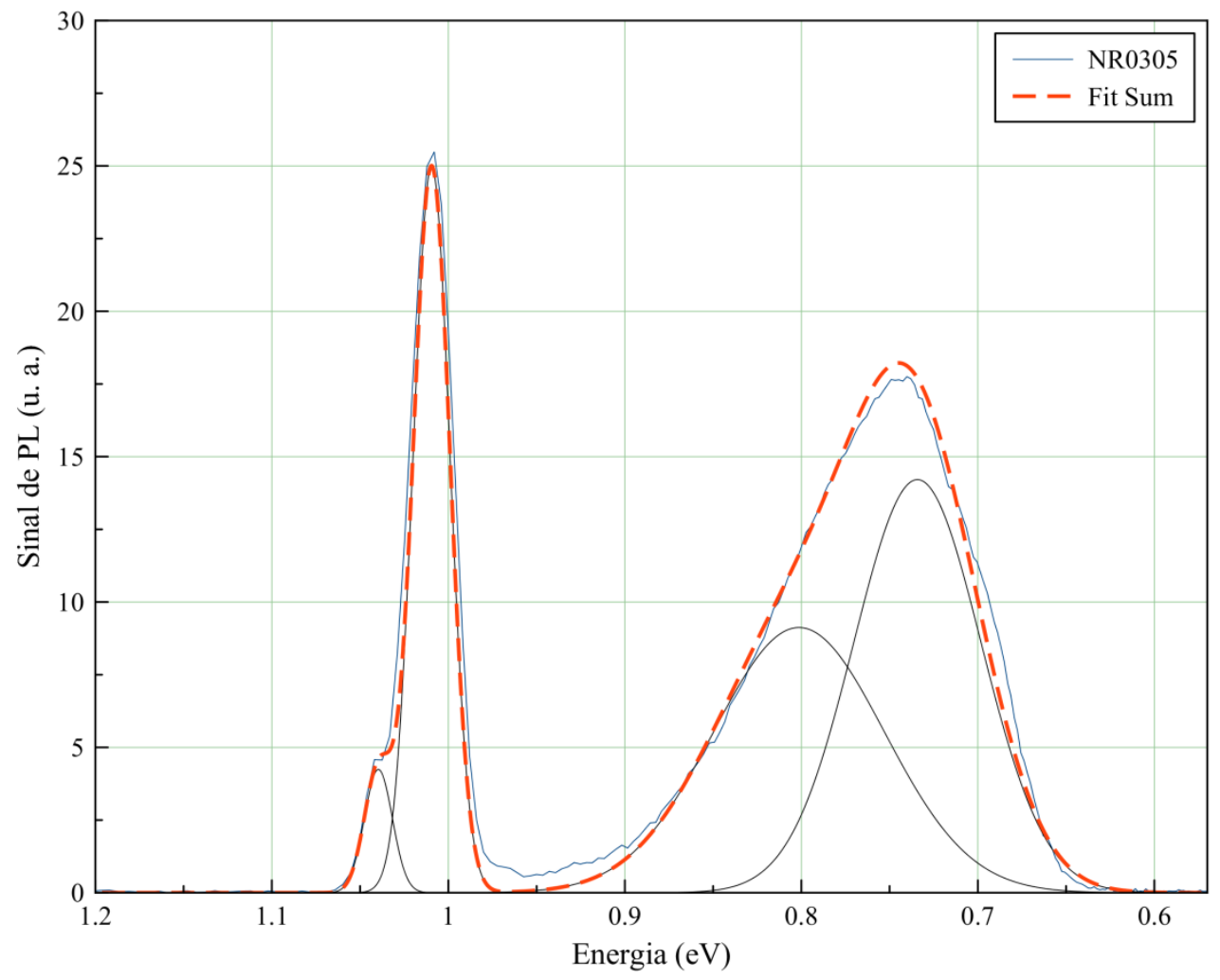

Figura 92. Ajuste da medida de fotoluminescência $(300 \mathrm{mw})$ da amostra NR0305 realizada a $15 \mathrm{~K}$.

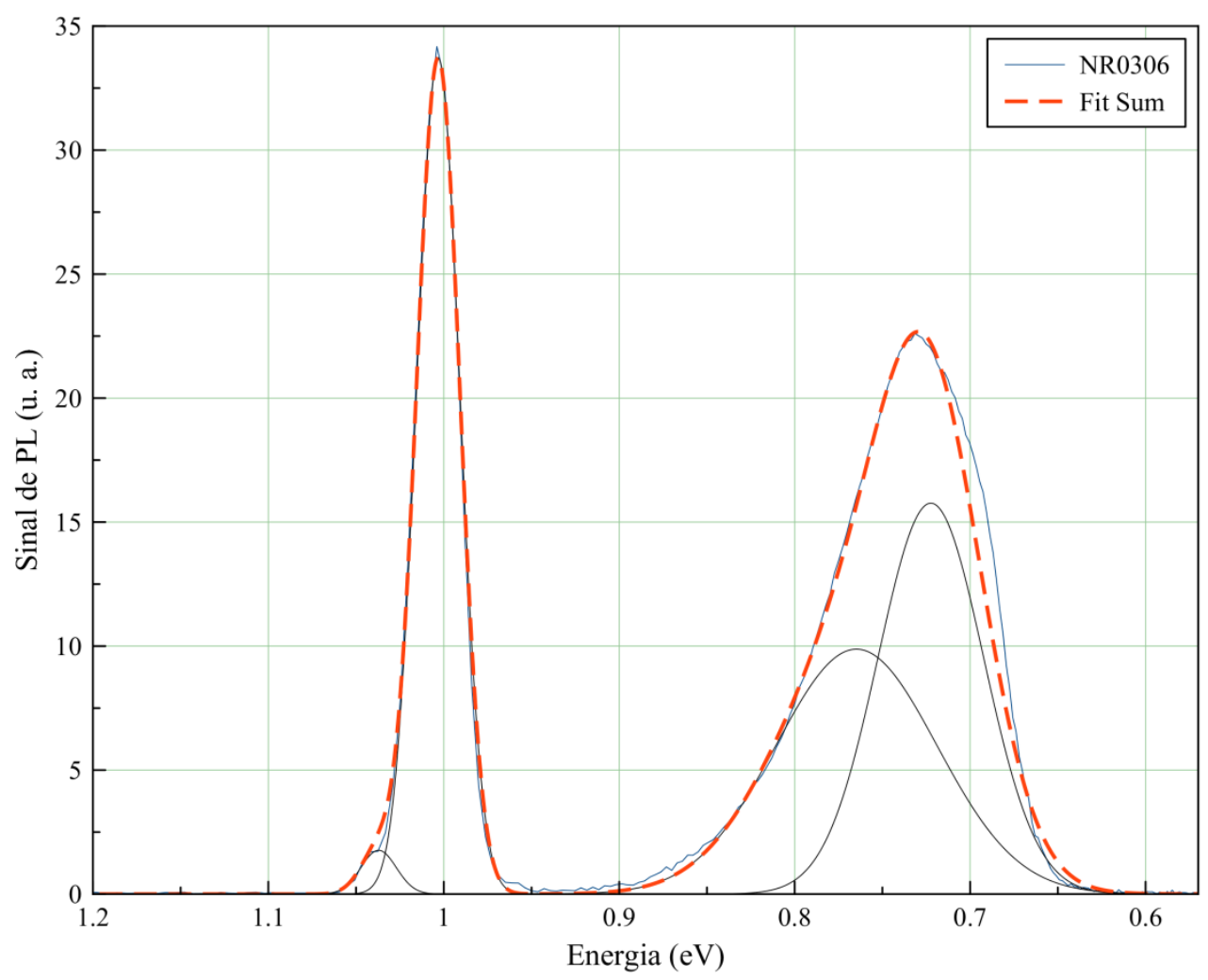

Figura 93. Ajuste da medida de fotoluminescência $(300 \mathrm{mw})$ da amostra NR0306 realizada a $15 \mathrm{~K}$. 


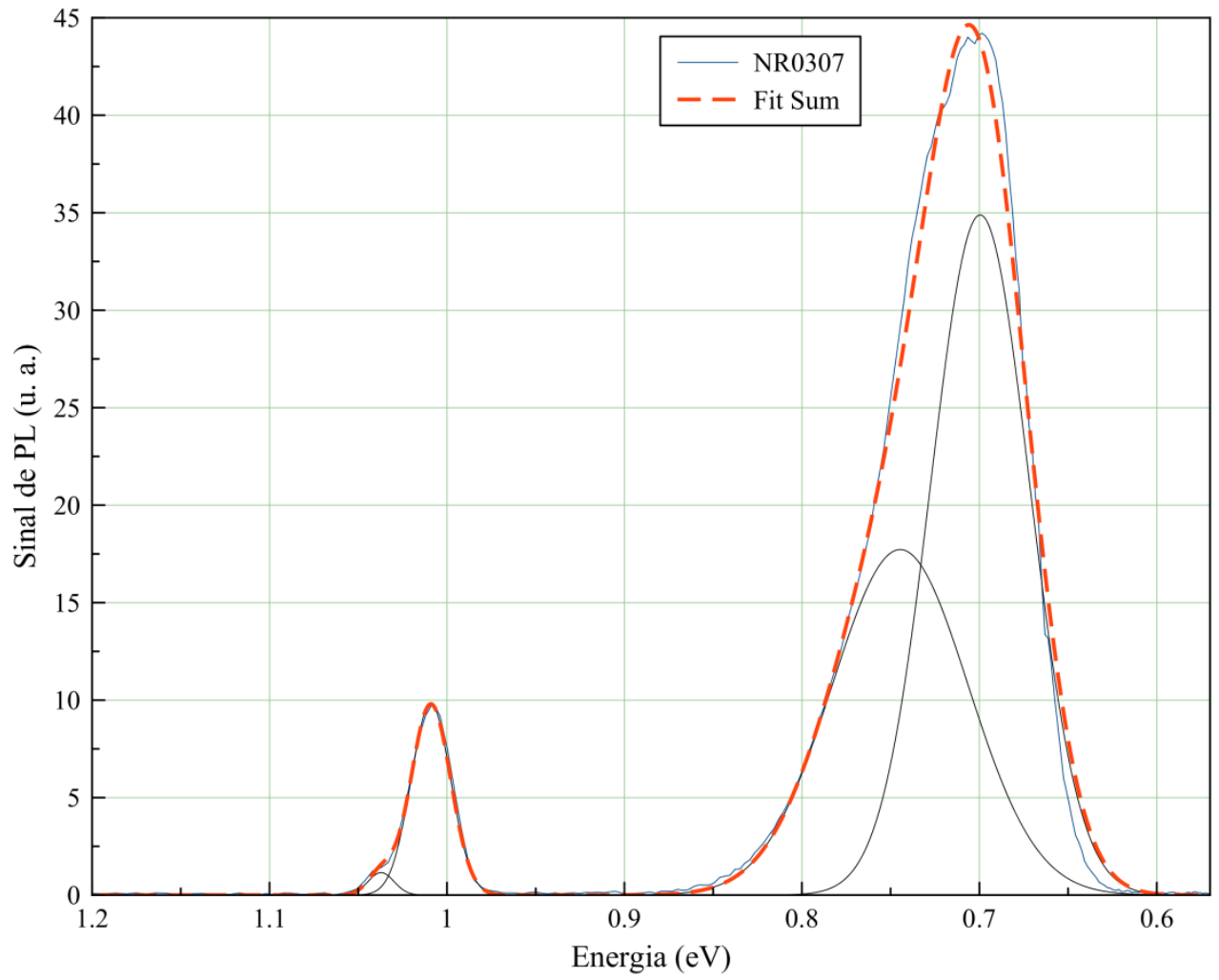

Figura 94. Ajuste da medida de fotoluminescência $(300 \mathrm{mw})$ da amostra NR0307 realizada a $15 \mathrm{~K}$.

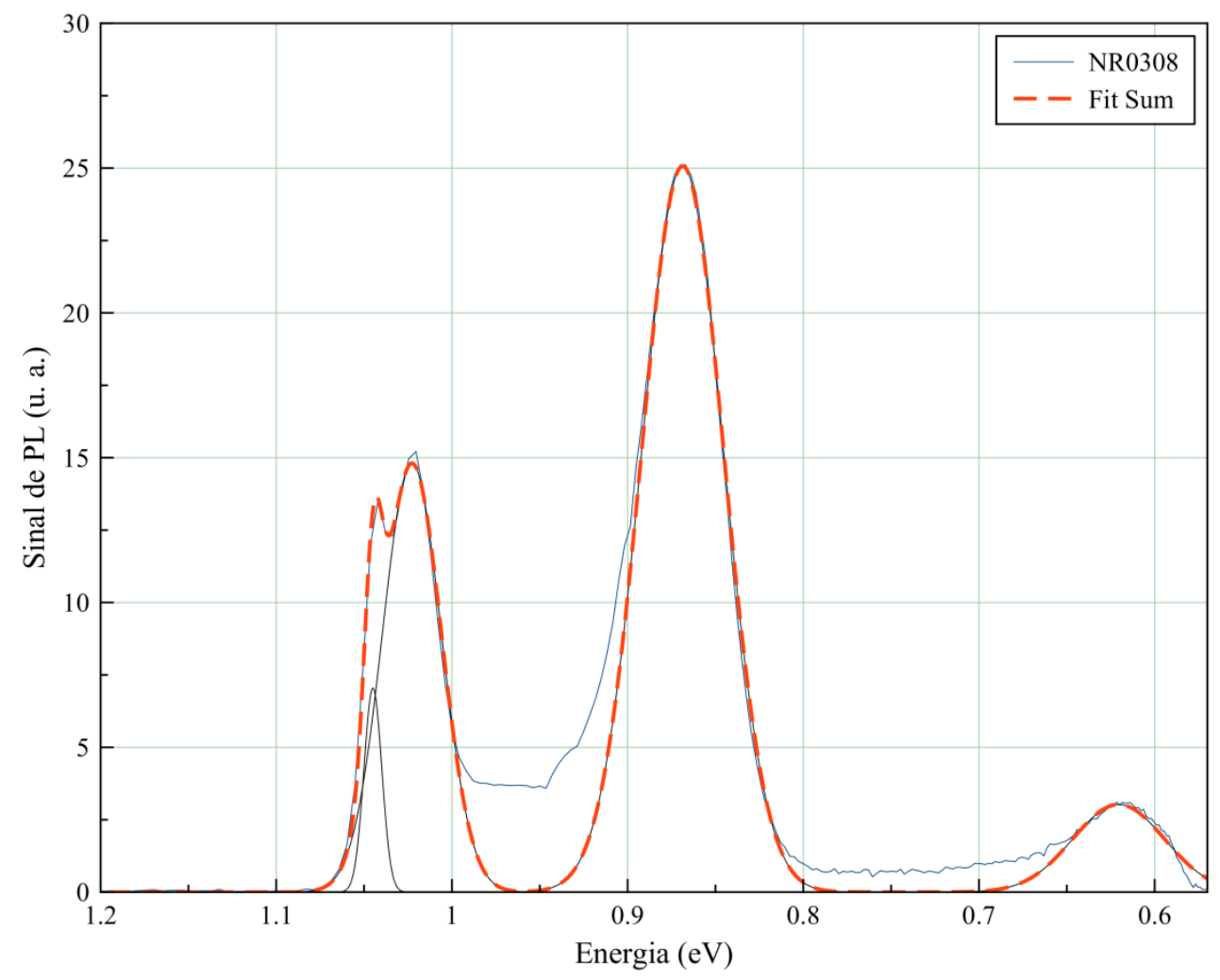

Figura 95. Ajuste da medida de fotoluminescência $(300 \mathrm{mw})$ da amostra NR0308 realizada a $15 \mathrm{~K}$. 


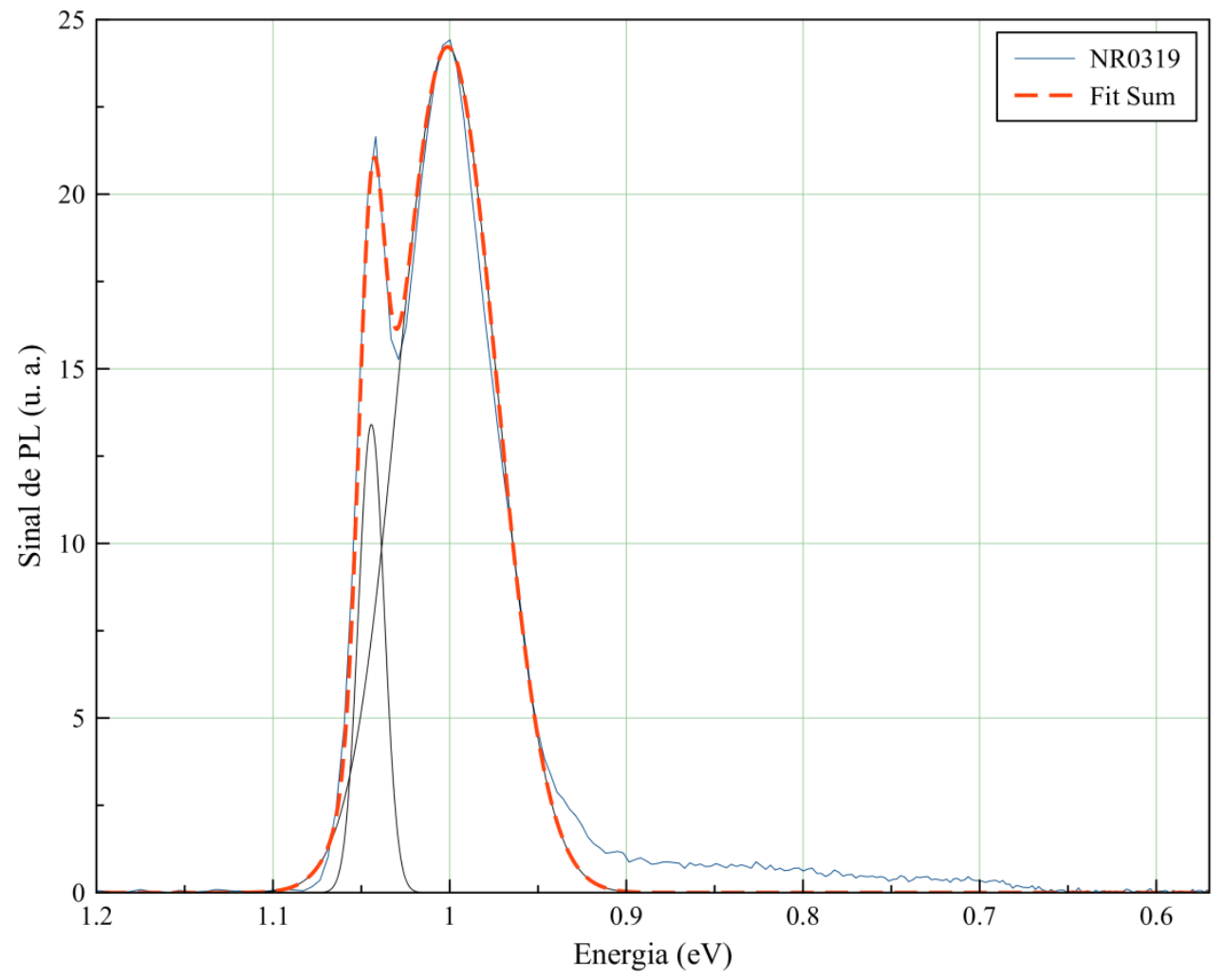

Figura 96. Ajuste da medida de fotoluminescência $(300 \mathrm{mw})$ da amostra NR0319 realizada a $15 \mathrm{~K}$. 